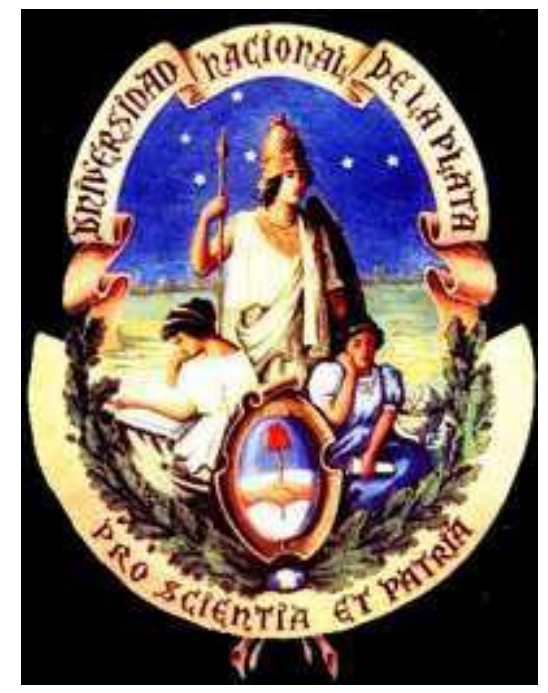

UNIVERSIDAD NACIONAL DE LA PLATA

FACULTAD DE CIENCIAS EXACTAS

DEPARTAMENTO DE CIENCIAS BIOLOGICAS

Trabajo de Tesis Doctoral

\title{
ESTUDIOS DE CO-INMOVILIZACIÓN DE ENZIMAS Y ANTIBIÓTICOS EN MATRICES BIOPOLIMÉRICAS PARA EL TRATAMIENTO DE INFECCIONES RESPIRATORIAS
}

\author{
Lic. Germán Abel Islan \\ Director de Tesis: Dr. Guillermo R. Castro \\ 2014 \\ Centro de Investigación y Desarrollo en Fermentaciones \\ Industriales y Biotecnología Aplicada (CINDEFI) \\ Universidad Nacional de La Plata (UNLP) \\ La Plata- Argentina
}




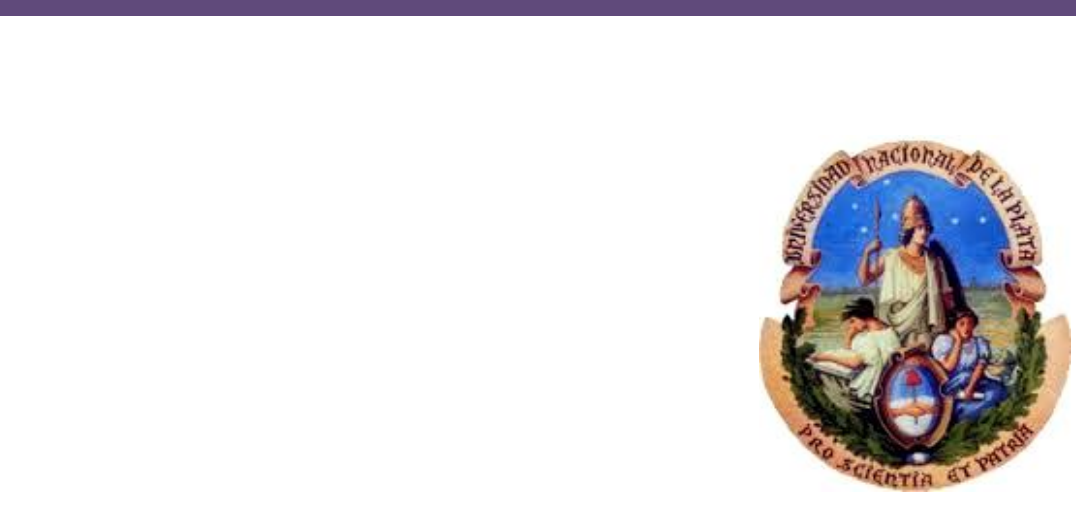

Universidad Nacional de La Plata

Facultad de Ciencias Exactas

Departamento de Ciencias Biológicas

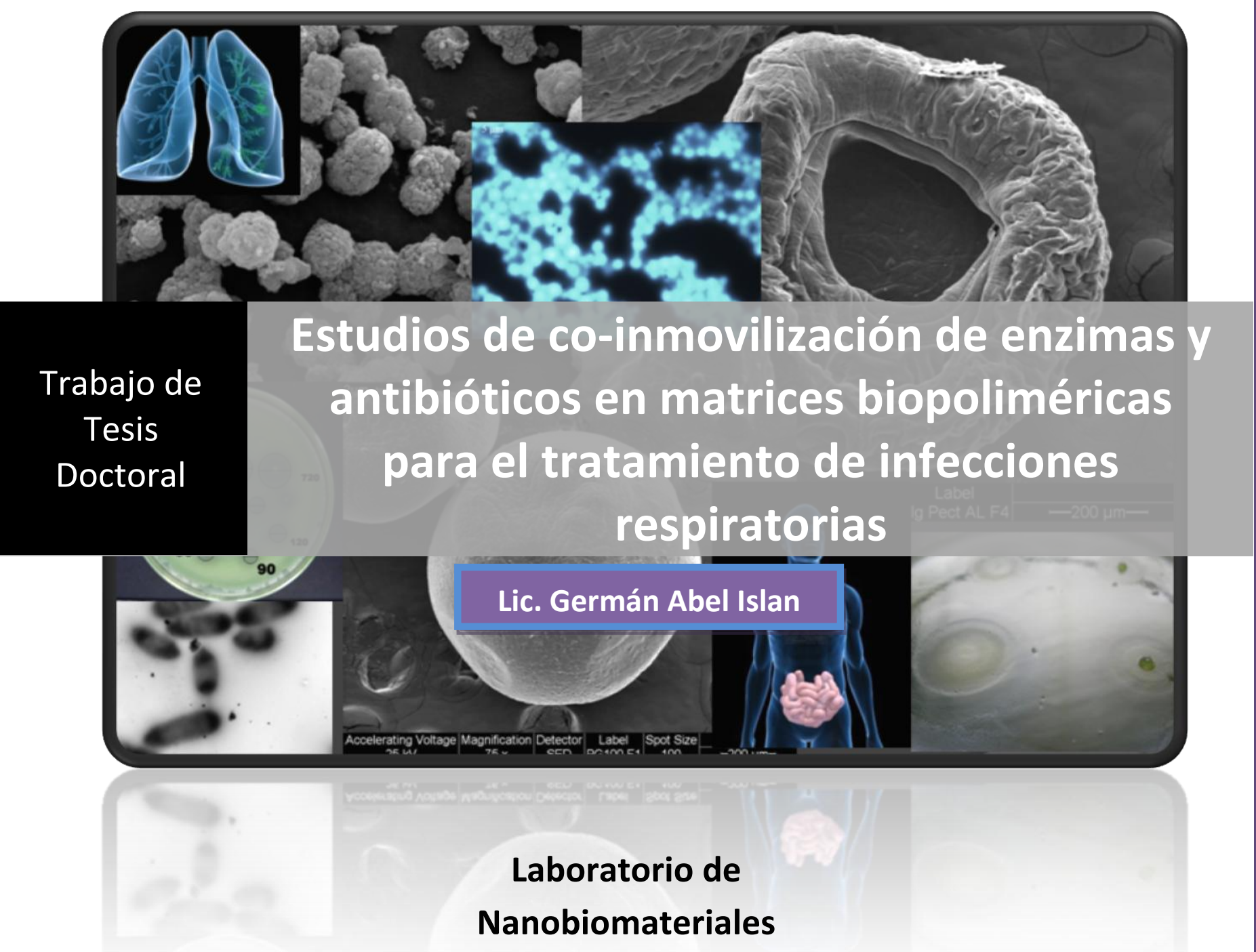

Centro de Investigación en

Fermentaciones Industriales y Biotecnología Aplicada (CINDEFI) UNLP - CONICET (CCT La Plata)

Argentina 
El presente trabajo de Tesis, para optar al título de Doctor de la Facultad de Ciencias Exactas, fue realizado en el Centro de Investigaciones $y$ Desarrollo en Fermentaciones Industriales y Biotecnología Aplicada (CINDEFI), Facultad de Ciencias Exactas, Universidad Nacional de la Plata, con el financiamiento de la Universidad Nacional de La Plata, la Agencia Nacional de Promoción Científica y Tecnológica (ANPCYT), el CONICET y la Fundación Argentina de Nanotecnología (FAN) bajo la dirección del Dr. Guillermo R. Castro. 


\section{ERPDECWIFNTOS}

Guiye, por permitirme ser parte de su proyecto, por su confianza, por su apoyo emocional en momentos difíciles de mi vida, y por darme las herramientas para ir creciendo en este mundo de la investigación así como la libertad para ir tomando mis propias decisiones.

A mis amigos del lab de nanobiomateriales, a cuatro personas que me acompañaron en este camino, cada uno me aportó su semilla para crecer en este proyecto de tesis y como persona: Vale (mi mentora y mi hermana), Maxi (mi brother, persona en quien más confío y padrino de Sofi), Yani (mi fuente de rizas y compañera de aventuras) y Berni (mi amiguito en esta última etapa).

Otros chicos del lab: Seba (gracias por su esfuerzo para realizar su tesina conmigo), a Florciña (por sus pilas para llevar a cabo las emulsiones), a Fiona (eh vooo...), Flor Drach y Caro (eh amiga).

CINDEFI y su gente, instituto que me abrió sus puertas desde el momento de mi tesina de grado hasta mi tesis doctoral, a travéz de su director Edgardo Donati.

Cecilia Dini, por su ejemplo de trabajo, genialidad y esfuerzo para concretar el trabajo conjunto de Fagos, así como resultados de mi tesis.

Ignacio Perez de Verti y Gustavo Marchetti, por el trabajo conjunto y en especial su ayuda con los espectros de FTIR.

Laura Bartel, por los aportes de cultivo celular para evaluar la citotoxidad de las matrices desarrolladas.

Ana Cahuerhff, por las correcciones de mi plan de trabajo y por dejarnos ser oyentes de su "radio" aquellas tardes en el CINDEFI.

Nelson Duran y Priscila Marcato, por abirme las puertas de sus hogares y sus familias (algo que nunca olvidaré) y por compartir el conocimiento de sus laboratorios para un crecimiento profesional que será parte de mi plan pos-doctoral.

Leandro Sasiambarrena, por su ayuda orgánica con la molécula de Ciprofloxacina.

Tato Cavalitto, el cumplidor de sueños, por considerarme para el curso "Technical Support for SMEs Promotion toward the Construction of a Sustainable Society (Biotechnology)" realizado en Japón, donde viví una experiencia increíble.

Ivana Cavello, por su valentía al manipular el sulfúrico concentrado a $100^{\circ} \mathrm{C}$ para la realización del método de Antrona.

Mariela Theiller, por su gran manejo del microscopio SEM, su gran capacidad de observación y sobre todo su "buena onda". 
Susana Jurado, por su aporte para la microscopía TEM.

Daniel y Javier, técnicos del CIDCA por su ayuda para la determinación de los ensayos con el DSC.

Emiliano Cortez y Maria Elena Vela (INIFTA), por su generosidad para la toma de imágenes con el microscopio de fuerza atómica.

Arup Mukherjee, por su conocimiento en el desarrollo de nanocompositivos y sistemas antimicrobianos.

Andrés Illanes, por su enseñanza para el desarrollo de los agregados enzimáticos entrecruzados (CLEAs).

Paul Dumas, por abrirnos las instalaciones del Sincrotron SOLEI, en Francia.

Jimena González y Dra. Vera Alvarez, por facilitarlos el uso de los equipos del INTEMA (Mar del Plata) para la medición de los espectros de rayos X, DSC y FTIR.

Catedra de microbiología, por bancarme en los años de docencia paralelos al desarrollo de esta tesis y por proveerme microorganismos ATCC para los ensayos antimicrobianos.

A mis amigos de toda la vida, los "viejitos" compañeros de esta aventura.

A mi familia de siempre, mi hermano y mi mamá por estar conmigo a la distancia y ser pilares para juntos salir adelante después de la temprana partida de Papi y Nain (abu).

A mi nueva familia, Ro (junto con Lili, Luis y Sabri) y Sofi por ser los seres que mas amo y que siempre me acompañan en este camino.

A Sofi, mi bebe, en particular por ser ese solcito que apareció en el momento justo $e$ iluminó nuestras vidas. 


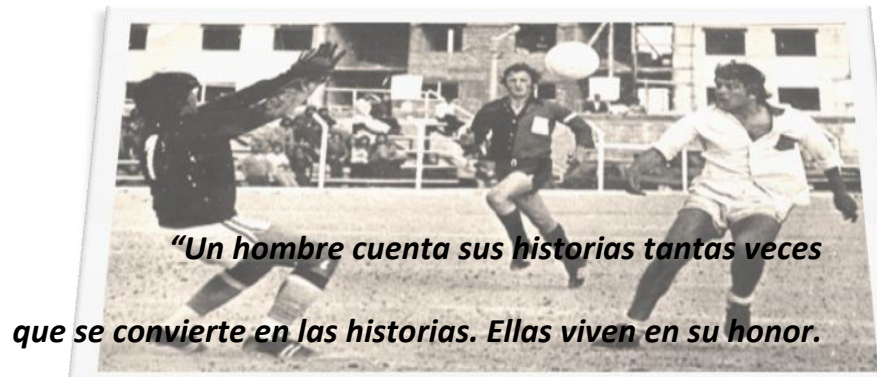

$Y$ de esa manera se convierte en inmortal" de "El Gran Pez" (Tim Burton, 2003)

Dedicado a Tatano...mi papá. 


\begin{tabular}{|c|c|c|}
\hline \multicolumn{2}{|c|}{ INTRODUCCION GENERAL } & 7 \\
\hline & 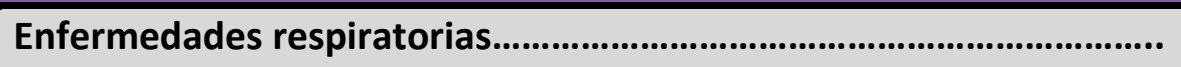 & 7 \\
\hline & 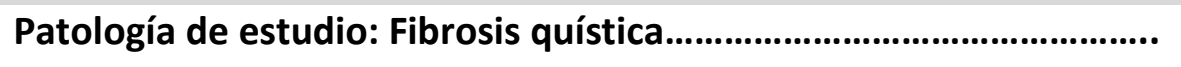 & 8 \\
\hline & 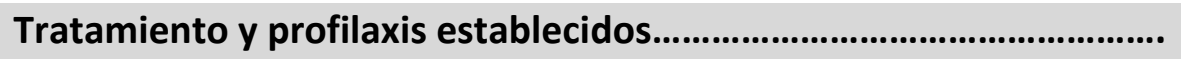 & 10 \\
\hline & 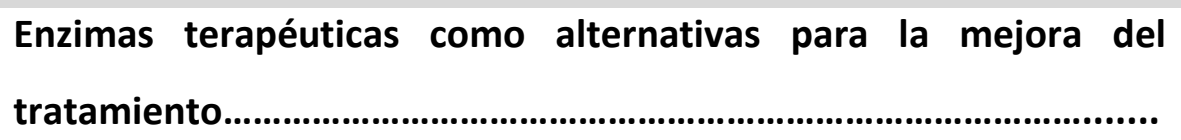 & 12 \\
\hline & Biopolímeros como herramientas en aplicaciones terapéuticas....... & 13 \\
\hline & Diseño de una matriz para la administración de fármacos.................. & 15 \\
\hline & 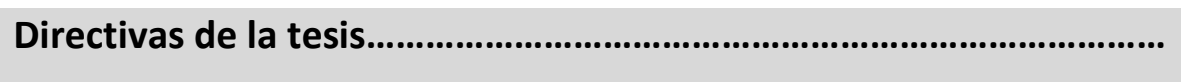 & 20 \\
\hline & 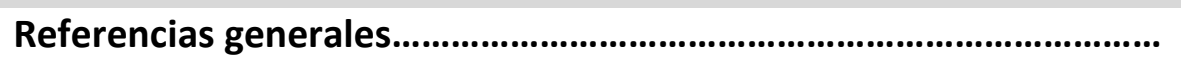 & 21 \\
\hline \multicolumn{2}{|c|}{ OBJETIVOS GENERALES } & 23 \\
\hline \multirow[t]{7}{*}{ CAPITULO 1} & $\begin{array}{l}\text { Selección de un fármaco modelo y matriz para administración oral. } \\
\text { Estudios de encapsulación y liberación }\end{array}$ & 24 \\
\hline & 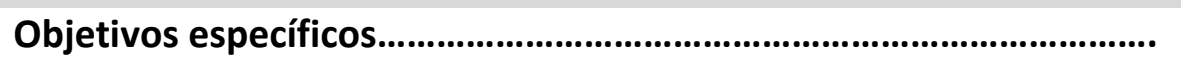 & 25 \\
\hline & 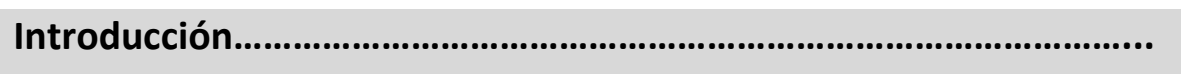 & 26 \\
\hline & 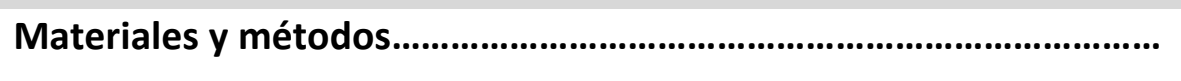 & 35 \\
\hline & 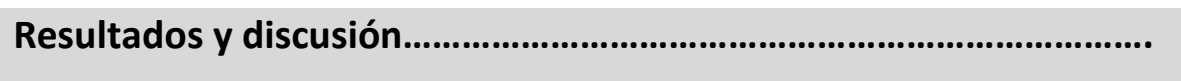 & 42 \\
\hline & 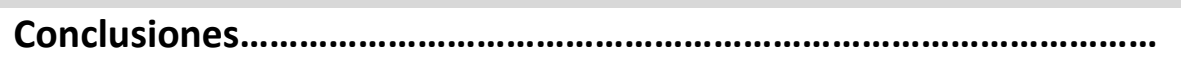 & 79 \\
\hline & 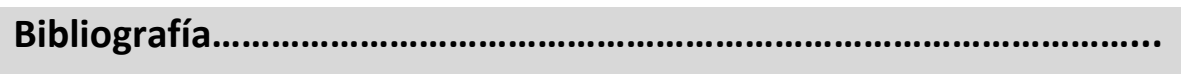 & 81 \\
\hline \multirow[t]{7}{*}{ CAPITULO 2} & $\begin{array}{l}\text { Incorporación de una enzima hidrolítica a la matriz: } \\
\text { Efectos de la co-inmovilización }\end{array}$ & 85 \\
\hline & 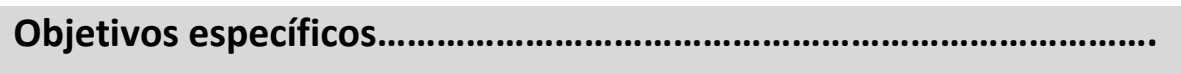 & 86 \\
\hline & 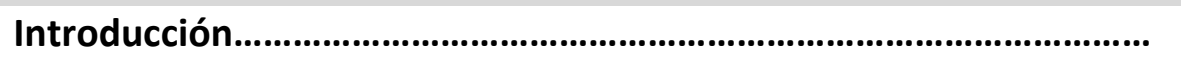 & 87 \\
\hline & 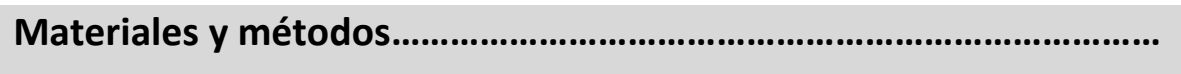 & 89 \\
\hline & 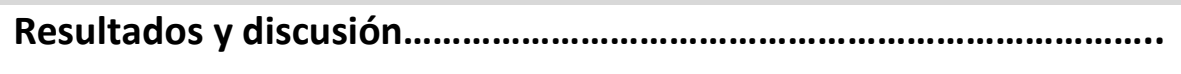 & 96 \\
\hline & 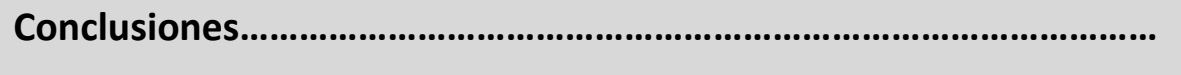 & 115 \\
\hline & 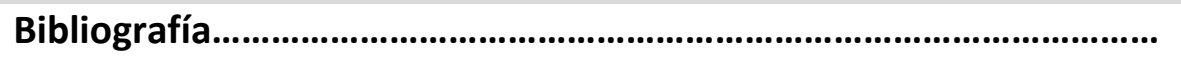 & 116 \\
\hline
\end{tabular}




\begin{tabular}{|c|c|c|}
\hline \multirow[t]{7}{*}{ CAPITULO 3} & $\begin{array}{c}\text { Estabilización de la Alginato Liasa: desarrollo de agregados } \\
\qquad \text { enzimáticos entrecruzados }\end{array}$ & 118 \\
\hline & 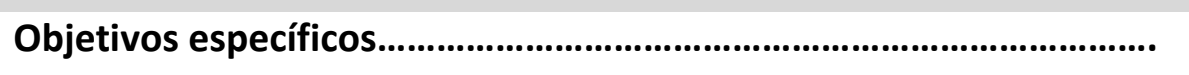 & 119 \\
\hline & 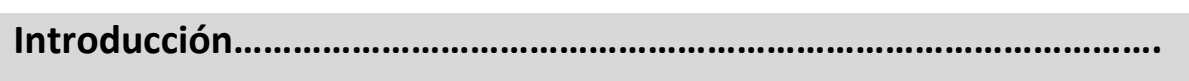 & 120 \\
\hline & 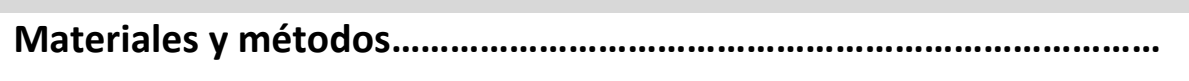 & 123 \\
\hline & 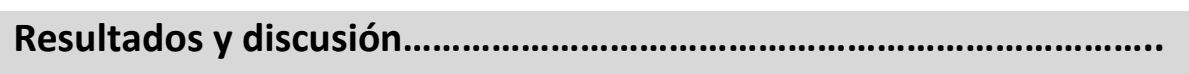 & 127 \\
\hline & 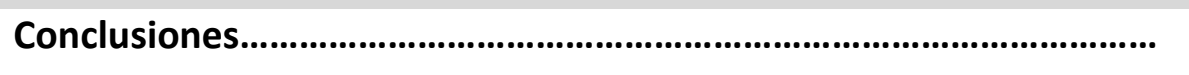 & 141 \\
\hline & 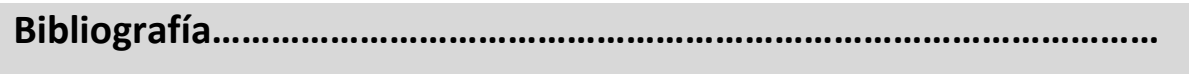 & 142 \\
\hline \multirow[t]{7}{*}{ CAPITULO 4} & Desarrollo de matriz inhalable con propiedades bactericidas & 144 \\
\hline & 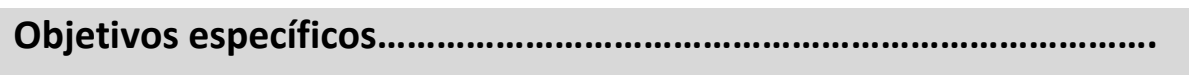 & 145 \\
\hline & 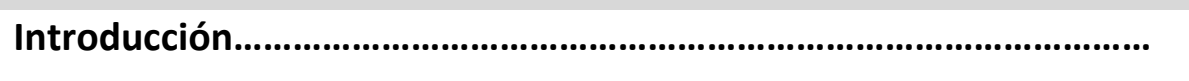 & 146 \\
\hline & 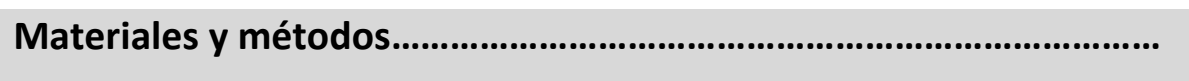 & 149 \\
\hline & 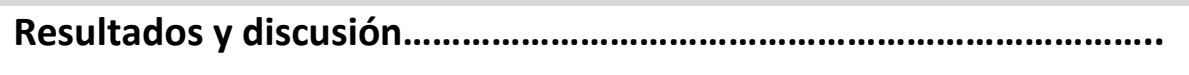 & 156 \\
\hline & 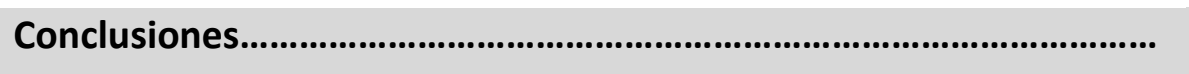 & 187 \\
\hline & 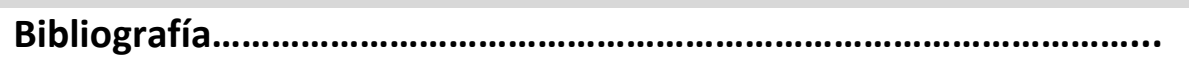 & 188 \\
\hline \multicolumn{2}{|c|}{ CONCLUSIONES GENERALES, LOGROS y PERSPECTIVAS } & 191 \\
\hline
\end{tabular}




\section{INTRODUCCIÓN GENEREL}

\section{Enfermedades respiratorias}

Las infecciones respiratorias son patologías recurrentes en pacientes hospitalizados y una seria causa de muerte si la infección no es erradicada tempranamente. En la mayoría de los casos, los causantes son microorganismos oportunistas, que toman ventaja del sistema inmune debilitado del hospedador, dentro de los cuales se destacan Streptococcus pneumoniae (neumonía), Haemophilus influenzae, Bordetella pertussis (toz convulsa), Staphylococcus aureus y Pseudomonas aeruginosa (fibrosis quística y otras). Tal es el caso de pacientes con VIH (virus de la inmunodeficiencia humana) que presentan deficiencias en la respuesta inmune a agentes patógenos, lo que aumenta el riesgo de infecciones entre las cuales las respiratorias juegan un papel relevante (Dockrell y col., 2011). A su vez, pacientes con cáncer de pulmón son susceptibles a desarrollar infecciones pulmonares, causadas principalmente por dos factores asociados con la enfermedad: cuando el tumor obstruye la vía aérea bronquial y la enfermedad pulmonar obstructiva crónica (Ruckdeschel y col., 2003). Este tipo de patologías también se encuentra asociada a pacientes con fibrosis quística (FQ) que sufren infecciones recurrentes y crónicas a nivel del tracto respiratorio inferior. Entre los patógenos, Pseudomonas aeruginosa está particularmente asociada con la morbilidad y la mortalidad de los pacientes con $F Q$, y ha sido catalogada como la responsable de la disminución de la función pulmonar a través de la formación de biopelículas (Høiby y col., 2010). En particular, la fibrosis quística es una patología compleja que requiere múltiples abordajes, y su tratamiento implica la utilización de estrategias adicionales a las convencionales para infecciones respiratorias. La FQ será utilizada como patología modelo de estudio a los largo del presente trabajo. 
Patología de estudio: Fibrosis quística

La fibrosis quística (FQ) es una enfermedad genética hereditaria de carácter autosómica producida por una mutación en el gen que codifica la proteína reguladora de la conductancia transmembrana de la fibrosis quística (CFTR), cuya función es el transporte de iones cloruro a través de la membrana celular. Su deficiencia genera un trastorno

Luz del conducto pulmonar

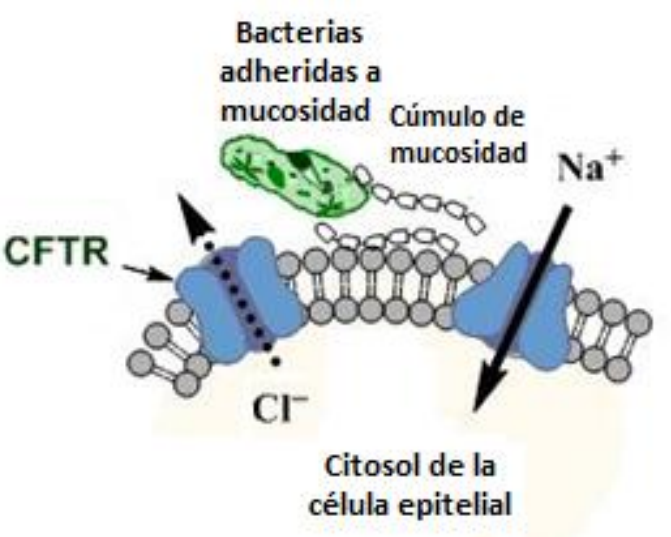
en la producción de sudor, jugos gástricos y moco en distintas regiones del organismo. Por este motivo se habla de que es una enfermedad multisistémica que afecta desde la función respiratoria y digestiva hasta la reproductora. Es la enfermedad genética letal más común entre los caucásicos, con una incidencia en un rango comprendido entre uno en 1700 a uno en 7.700. Las infecciones pulmonares crónicas causadas por patógenos oportunistas afecta a más del 90\% de pacientes con FQ (Cystic Fibrosis Foundation, 2009). Entre ellos, Pseudomonas aeruginosa, la principal bacteria colonizante, es capaz de producir cantidades considerables del exopolisacárido alginato (Pedersen y col., 1992; Growcott y col., 2011). El alginato no es capaz de ser degradado por las células de mamífero, por lo que se acumula en las distintas mucosidades, aumentando así las propiedades viscoelásticas de las secreciones pulmonares e intestinales. Cuando las cepas de Pseudomonas aeruginosa mutan a la variante mucoide (la cual se refiere a la capacidad de producir alginato de forma exacerbada) son capaces de sobrevivir a las terapias agresivas con antibióticos y, una vez establecidas, se vuelven extremadamente difíciles de erradicar lo que conduce a una sobrevida del paciente drásticamente reducida (Hodges y col., 1991). El avance en el conocimiento de la patología ha sugerido que el alginato juega un papel relevante en la patogenicidad:

- al facilitar la formación de biopelículas.

- mejorar la supervivencia bacteriana y la adhesión a la capa epitelial del pulmón y otras mucosas. 
- al disminuir la acción de los radical libres y reduciendo el proceso de fagocitosis por parte de los macrófagos.

- el retardo de la difusión de antibióticos hacia el sitio de la infección (May y col., 1991).

Por otra parte, se ha establecido que la infección generada por los microorganismos encontrados en el esputo de los pulmones infectados actúa como reservorio para la propagación de la bacteria hacia el resto del organismo: colonizando el tracto intestinal y generando la obstrucción de las vías pancreáticas, con lo cual se ve interferida la correcta digestión y absorción de nutrientes, que conlleva a la desnutrición del paciente (Sarles, 2012).

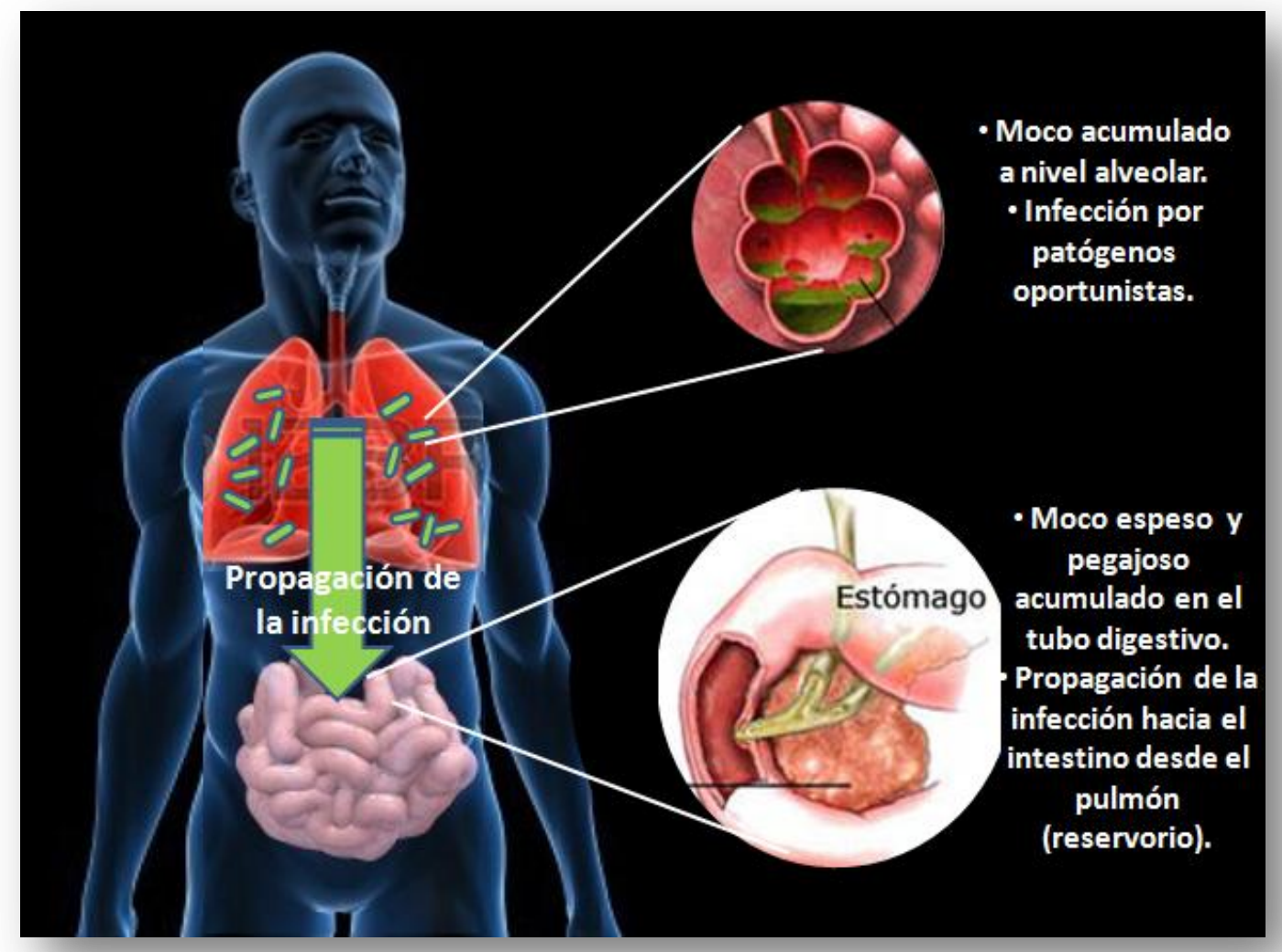

A su vez, la infección endo-bronquial induce un proceso inflamatorio persistente y no controlado, que desemboca en la denominada tríada característica de la enfermedad: obstrucción bronquial-inflamación-infección. Este proceso, se produce durante sucesivos ciclos y conduce a un daño pulmonar irreversible, con bronquiectasias, insuficiencia respiratoria y muerte (Consenso Nacional de Fibrosis Quística, 2008). 


\section{Tratamiento y profilaxis establecidos}

La primera aclaración que resulta primordial mencionar, es que la FQ no posee hasta el momento una cura establecida. Si bien en los últimos años se ha observado un notable aumento en la edad de sobrevida, el principal tratamiento apunta a mejorar la calidad de vida del paciente, mediante el control y atenuación de los daños ocasionados por la excesiva mucosidad y las infecciones recurrentes (tanto a nivel pulmonar como intestinal).

La administración de antibióticos por las vías intravenosa, inhalatoria y oral es la base del tratamiento para contrarrestar las infecciones crónicas. En el caso de infecciones agudas, el tratamiento es extremadamente agresivo: la frecuencia y dosis utilizadas alcanzan niveles que rozan dosis tóxicas para el propio organismo, con la consecuente aparición de severos efectos secundarios. Los antimicrobianos comúnmente utilizados son mencionados en la siguiente tabla.

\section{Tabla 1}

\begin{tabular}{|c|c|c|c|}
\hline Fármaco & $\begin{array}{l}\text { Vía de administración } \\
\text { y dosis-frecuencia }\end{array}$ & $\begin{array}{l}\text { Patógeno } \\
\text { erradicado }\end{array}$ & Efectos secundarios \\
\hline Eritromicina & $\begin{array}{l}\text { Oral } \\
\mathrm{c} / 6-8 \mathrm{~h}\end{array}$ & $\begin{array}{l}\text { Staphylococcus } \\
\text { aureus }\end{array}$ & $\begin{array}{l}\text { Náuseas, vómitos, diarrea y alergias. } \\
\text { Hipoacusia reversible. Hepatitis } \\
\text { colestática transitoria. }\end{array}$ \\
\hline $\begin{array}{l}\text { Amoxicilina } \\
\text { con } \\
\text { clavulanato }\end{array}$ & Oral, EV c/8 h & $\begin{array}{l}\text { Haemophilus } \\
\text { influenzae }\end{array}$ & $\begin{array}{lr}\text { Candidiasis oral. } & \text { Exantemas } \\
\text { morbiliformes, pápulas. } & \text { Trastornos } \\
\text { gastrointestinales. } & \text { Colitis } \\
\text { seudomembranosar } & \end{array}$ \\
\hline TMP-SMX & Oral c/12 h & $\begin{array}{l}\text { Haemophilus } \\
\text { influenzae1 } \\
\text { Staphylococcus } \\
\text { aureus }\end{array}$ & $\begin{array}{llr}\text { Exantema alérgico y fiebre. } & \text { y } \\
\text { Síndrome de } & \text { Stevens-Johnson. } \\
\text { Neutropenia } & \text { y } & \text { anemia. } \\
\text { Trombocitopenia. } & & \text { Trastornos } \\
\text { gastrointestinales } & & \end{array}$ \\
\hline Clindamicina & $\begin{array}{l}\text { Oral o EV } \\
\mathrm{c} / 6-8 \mathrm{~h}\end{array}$ & $\begin{array}{l}\text { Staphylococcus } \\
\text { aureus }\end{array}$ & $\begin{array}{l}\text { Náuseas, vómitos, diarrea, colitis } \\
\text { pseudomembranosa por supresión } \\
\text { de la flora normal. Anafilaxia. }\end{array}$ \\
\hline Ciprofloxacina & $\begin{array}{l}\text { Oral }(500 \mathrm{mg}) \mathrm{y} \mathrm{EV} \\
(400 \mathrm{mg}) \mathrm{c} / 12 \mathrm{~h}\end{array}$ & $\begin{array}{l}\text { Pseudomonas } \\
\text { aeruginosa, } B . \\
\text { cepacia }\end{array}$ & $\begin{array}{l}\text { Intolerancia gastrointestinal. } \\
\text { Cefalea. Artralgia. Exantema. }\end{array}$ \\
\hline Levofloxacina & $\begin{array}{l}\text { Oral e inhalatoria, } \\
120 \mathrm{mg} \text { cada 6-8 h. }\end{array}$ & $\begin{array}{l}\text { Staphylococcus } \\
\text { aureus, } \\
\text { Pseudomonas } \\
\text { aeruginosa }\end{array}$ & $\begin{array}{l}\text { Tendinitis. Desgarro de tendón. } \\
\text { Colitis pseudomembranosa. } \\
\text { Convulsiones y psicosis tóxica. } \\
\text { Náuseas y vómitos. }\end{array}$ \\
\hline $\begin{array}{l}\text { Ceftazidime } \\
\text { mas Amikacina }\end{array}$ & $\begin{array}{l}\text { EV } 100 \mathrm{mg} c / 6-8 \mathrm{~h} \\
\text { EV } 15 \mathrm{mg} / \mathrm{c} / \mathrm{-12} \mathrm{h}\end{array}$ & $\begin{array}{l}\text { Pseudomonas } \\
\text { aeruginosa }\end{array}$ & $\begin{array}{lr}\text { Eritemas cutáneos } & \text { fugaces. Colitis } \\
\text { seudomembranosa. } & \text { Trastornos } \\
\text { gastrointestinales. } & \text { Otoxicidad y } \\
\text { nefrotoxicidad. } & \text { Bloqueo }\end{array}$ \\
\hline
\end{tabular}




\begin{tabular}{|l|l|l|l|}
\hline Colistín & $\begin{array}{l}\text { Nebulizado } \\
\text { 50-100 mg/día, } \\
\text { dos veces por día, } \\
\text { durante } 3 \text { meses }\end{array}$ & $\begin{array}{l}\text { Pseudomonas } \\
\text { aeruginosa }\end{array}$ & $\begin{array}{l}\text { Obstrucción bronquial, faringitis y } \\
\text { tos. }\end{array}$ \\
\hline Tobramicina & $\begin{array}{l}\text { Inhalatorio y oral } \\
\text { Dosis: } 300 \mathrm{mg}, \text { dos } \\
\text { veces por día, por } \\
\text { períodos } \\
\text { alternos de } 28 \text { días }\end{array}$ & $\begin{array}{l}\text { Pseudomonas } \\
\text { aeruginosa }\end{array}$ & Tinnitus, disfonía, faringitis y tos. \\
\hline EV: endovenosa & & & \\
\hline
\end{tabular}

Se administran antibióticos individuales o combinados (según solubilidad, disponibilidad, tolerancia, sensibilidad y costo) por vía intravenosa cada 3-4 meses, por vía oral (como por ejemplo ciprofloxacina, eritromicina) y antibióticos aerosolizados en meses alternos (como por ejemplo tobramicina, levofloxacina) o en forma continua (colistina) (Consenso Nacional de Fibrosis Quística, 2008). El propio tratamiento con varios antibióticos es posiblemente la causa de un factor adicional de estrés para el propio organismo, el cual favorece la selección y al aumento de cepas resistentes a los antimicrobianos, que en subsiguientes generaciones podría dar lugar a variedades de cepas microbianas mutantes multi-resistentes a antibióticos (Cantón y col., 2011).

El procedimiento general estandarizado para la terapia inhalatoria es realizado en diversas etapas que incluyen la administración de un broncodilatador, una ADNasa y/o solución salina hipertónica para aflojar o reducir la viscoelasticidad de la mucosidad acumulada en el pulmón, seguido de kinesioterapia respiratoria para expectorar el moco y finalmente un antibiótico en aerosol, asi como corticoides para reducir la inflamación producida por la respuesta inmune a la infección y al tratamiento. Esta secuencia debe, en los casos más severos, realizarse hasta dos veces por día, lo cual refleja la tolerancia que debe soportar el paciente frente al tratamiento y como se ve afectada su calidad de vida frente a una rutina estricta.

En los casos más severos, y luego de un deterioro irreversible de la capacidad pulmonar, la única alternativa para la supervivencia del paciente radica en la intervención quirúrgica y realizar un trasplante de pulmón. Finalmente, nuevas alternativas basadas en terapia génica, a fin de reemplazar los transportadores de cloruro con función defectuosa en las células de órganos específicos, resulta una prometedora área a explorar. 
El tratamiento descripto implica gastos económicos que no están al alcance de todos los estratos sociales. El tratamiento de la enfermedad, como la mayoría de las enfermedades denominadas "olvidadas", posee un costo elevado. En un estudio publicado por el Departamento de Farmacia y Tecnología Farmacéutica de la Universidad de Granada en 2008, se reveló que el costo medio sólo del tratamiento farmacológico (sin contar pruebas diagnósticas, fisioterapia respiratoria, hospitalizaciones, ayuda psicológica) por paciente rondaría en el orden de los $6.000 €$

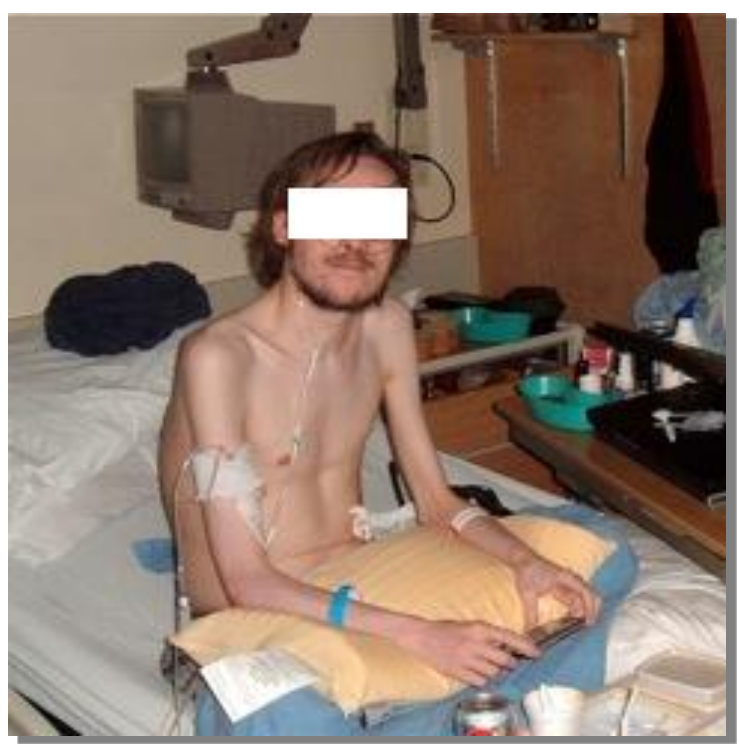

Jamie, un paciente con FQ en espera de un trasplante de pulmón. Fuente: http://lungsforjamie.wordpress.com/cystic-fibrosis2/ al año, una cifra excesivamente alta considerando un ingreso medio. Si bien este tratamiento se encuentra cubierto por el sistema nacional de salud en algunos países (sobre todo países desarrollados), en otros, el acceso a un tratamiento óptimo se ve limitado, no solo porque las obras sociales no reconocen los costos completos, sino porque en el sistema público el déficit de abastecimiento de fármacos muchas veces conlleva a la interrupción de los tratamientos (Montes Casas, 2008).

\section{Enzimas terapéuticas como alternativas para la mejora del tratamiento}

En más del $90 \%$ de los casos de FQ, resulta necesaria la administración de enzimas pancreáticas (amilasas, lipasas y proteasas) por vía oral dado que, como fuera previamente mencionado, la capa de moco que recubre el intestino y el páncreas no permite el acceso de las enzimas al sitio de acción así como la absorción de nutrientes se ve reducida. La suplementación inadecuada lleva a casos graves de desnutrición, y sumado al desgaste de otros órganos, puede llevar a un estado del paciente comprometido e incluso la muerte (Sarles, 2012).

Una interesante alternativa para mejorar la sobrevida, consiste en la administración por vía inhalatoria de una enzima capaz de hidrolizar el ácido desoxirribonucleico (ADN) extracelular que se encuentra en mayores cantidades en el 
fluido pulmonar. El mismo, es uno de los responsables del aumento de la viscoelasticidad del esputo, promoviendo un ciclo de infección pulmonar crónico y procesos inflamatorios que en última instancia conducen a la insuficiencia respiratoria (Ratjen y col., 2005). Estos restos de ADN provienen en su mayor parte de la degeneración de leucocitos, bacteria y tejido producto de los sucesivos ciclos de infección que sufren los pacientes. La administración de la ADNasa, permite la reducción de la viscosidad del fluido pulmonar, favoreciendo así el mecanismo de depuración mucociliar del pulmón. De esta forma, las bacterias tienen un menor tiempo de residencia, la acción de los antibióticos inhalados se ve favorecida y el aire fluye de forma más eficiente (Robinson, 2002). Actualmente, se pueden encontrar en el mercado productos conteniendo la ADNasa en la forma de Dornasa alfa, una forma recombinante humana de la enzima de alta pureza.

Se ha reportado la utilización de enzimas capaces de hidrolizar el alginato (las llamadas "alginato liasas") como alternativa para el tratamiento de los pacientes (Mrsny y col., 1994; Alkawash y col., 2006). Considerando que la cepa mucoide de Pseudomonas aeruginosa es capaz de producir grandes cantidades de este biopolímero, que constituye una biopelícula y representa una barrera difusional para el tratamiento con antibióticos, la utilización de esta enzima podría ser de gran utilidad para la reducción de la viscoelasticidad del esputo y la erradicación de la infección (Hatch y col. 1998).

\section{Biopolímeros como herramientas en aplicaciones terapéuticas}

En las últimas décadas, el uso de matrices biopoliméricas ha constituido un campo de gran interés para las industrias cosméticas y farmacéuticas. La utilización de micro- y nano-tecnologías ha revolucionado el mercado debido a las nuevas propiedades que ofrecen los agentes encapsulados, y son una gran promesa para el tratamiento de enfermedades de alta complejidad como el cáncer o infecciones agudas. En este sentido, es de vital importancia considerar que la matriz seleccionada no genere respuesta inmune, presente biocompatibilidad y que la misma y sus productos de degradación no sean tóxicos para el organismo (Castro y cols., 2006; Bosio y cols, 2011). 
Los biopolímeros son macromoléculas producidos por los organismos vivos y son la resultante de la condensación de monómeros simples mediante técnicas enzimáticas. Algunos de ellos presentan características deseadas para el diseño de matrices con aplicaciones biomédicas y numerosas ventajas en comparación con los polímeros sintéticos, tal como se describe en la siguiente tabla:

\section{Tabla 2}

\section{Propiedades}

Medio de síntesis

Catálisis

Síntesis

Parámetros ambientales de

sintesis

Producto estéreo especifico

Peso molecular promedio

Actividad biológica

Escalado

Purificación

Productos de

biodegradación

\begin{tabular}{|l|l|}
\hline \multicolumn{1}{|c|}{ Polímeros de síntesis química } & \multicolumn{1}{c|}{ Biopolímeros } \\
\hline acuoso & orgánico \\
\hline Inorgánica (tóxica) & biocatálisis (no tóxica) \\
\hline inespecíficas & especificas (centro quiral) \\
\hline extremos & suaves \\
\hline bajo & alto \\
\hline variable & Rango restringido \\
\hline inespecífica & Altamente específica \\
\hline Extremadamente costoso & costoso \\
\hline Muy costoso & costoso \\
\hline Pueden ser tóxicos & biocompatibles \\
\hline
\end{tabular}

El atractivo de los biopolímeros radica principalmente en su amplia disponibilidad en la naturaleza, su bajo costo, su diversidad para realizarle numerosas modificaciones químicas, su potencial degradabilidad, biocompatibilidad y carencia de toxicidad en la mayoría de los casos.

Los biopolímeros, y en particular los polisacáridos, pueden provenir de diferentes fuentes naturales a saber: algas y microorganismos (en el caso de alginatos), plantas (pectinas y goma guar), microorganismos (dextrano, goma xantano, emulsano) o animal (quitosano o condritin-sulfato) entre otros. Poseen un gran número de grupos funcionales reactivos, regiones hidrofílicas y/o hidrofóbicas, amplio rango de pesos moleculares, y composiciones químicas diferentes, lo cual amplía su biodiversidad para diferentes potenciales aplicaciones. Los biopolímeros en general pueden ser clasificados por su carga neta en neutros y polielectroliticos. Estos últimos, a su vez, pueden clasificarse en catiónicos (como por ejemplo, los quitosanos) o aniónicos (como los alginatos, el ácido hialurónico o las pectinas). 
Algunos biopolímeros naturales, han sido utilizados para el diseño de diferentes tipos de vehículos para transportar moléculas de interés biológico (Castro y cols., 2005; Costas y cols., 2008; Islan y cols., 2012), algunos de los más relevantes se mencionan en la siguiente tabla.

\begin{tabular}{|c|c|c|c|}
\hline \multicolumn{4}{|l|}{ Tabla 3} \\
\hline Biopolímero & Tipo & Monómeros & Usos \\
\hline Alginato & Polisacárido aniónico. & $\begin{array}{l}\text { ácidos D-manúrico y } \\
\text { L-gulurónico }\end{array}$ & $\begin{array}{l}\text { Liberación controlada de } \\
\text { fármacos, encapsulamiento } \\
\text { de células }\end{array}$ \\
\hline Almidón & Polisacárido hidrofílico & glucosa & $\begin{array}{l}\text { Ingeniería de tejidos, } \\
\text { Liberación controlada de } \\
\text { fármacos }\end{array}$ \\
\hline Carragenina & Polisacárido aniónico. & $\begin{array}{l}\text { galactosa y/o de } \\
\text { anhidrogalactosa, } \\
\text { sulfatadas o no }\end{array}$ & $\begin{array}{l}\text { Ingeniería de tejidos, } \\
\text { Liberación controlada de } \\
\text { fármacos }\end{array}$ \\
\hline $\begin{array}{l}\text { Colágeno y } \\
\text { gelatina }\end{array}$ & Proteínas complejas & $\begin{array}{l}\text { Aminoácidos de } \\
\text { distinto tipo }\end{array}$ & $\begin{array}{l}\text { Liberación controlada de } \\
\text { fármacos, recubrimiento } \\
\text { de heridas, ingeniera de } \\
\text { tejidos }\end{array}$ \\
\hline $\begin{array}{l}\text { Celulosa y } \\
\text { derivados }\end{array}$ & Polisacárido hidrofílico & $\beta$-glucosa & $\begin{array}{l}\text { ingeniera de tejidos, } \\
\text { Liberación controlada de } \\
\text { fármacos }\end{array}$ \\
\hline Dextranos & $\begin{array}{l}\text { Polisacárido } \\
\text { ramificado hidrofílico }\end{array}$ & $\alpha$-D-glucosa & $\begin{array}{l}\text { Liberación controlada de } \\
\text { fármacos, recubrimiento } \\
\text { de heridas, ingeniería de } \\
\text { tejidos, encapsulamiento } \\
\text { de células. }\end{array}$ \\
\hline Pectinas & $\begin{array}{l}\text { Heteropolisacarido } \\
\text { hidrofílico con } \\
\text { regiones hidrofóbicas } \\
\text { dadas por zonas } \\
\text { metoxiladas }\end{array}$ & $\begin{array}{l}\text { Residuos de ácido } \\
\text { D-galacturónico que } \\
\text { pueden estar } \\
\text { metoxilados o no. }\end{array}$ & $\begin{array}{l}\text { Liberación controlada de } \\
\text { fármacos, recubrimiento } \\
\text { de heridas, ingeniería de } \\
\text { tejidos, espesante de } \\
\text { alimentos }\end{array}$ \\
\hline Quitosano & Polisacárido catiónico & $\begin{array}{l}\text { D-glucosamina y } \mathrm{N}- \\
\text { acetil-D- } \\
\text { glucosamina. }\end{array}$ & $\begin{array}{l}\text { Liberación controlada de } \\
\text { fármacos, recubrimiento } \\
\text { de heridas, ingeniera de } \\
\text { tejidos }\end{array}$ \\
\hline
\end{tabular}

\section{Diseño de una matriz para la administración de fármacos}

Actualmente, la administración de fármacos no poseen parámetros fármacocinéticos ajustados a los requerimientos de la patología y las altas dosis administradas terminan alcanzando concentraciones tóxicas en un gran número de terapias (anticancerígenas, antimicrobianas, etc). Por otra parte, varias dosis diarias son 
necesarias para mantener la efectividad terapéutica a lo largo del tratamiento, lo cual resulta inconveniente para el paciente, en especial para niños y ancianos. A su vez, los fármacos administradas pueden generar efectos secundarios adversos sobre otros órganos del cuerpo fuera del órgano blanco, lo cual repercute negativamente en la calidad de vida del paciente (Thanki, 2013).

Frente a las observaciones mencionadas, una matriz biopolimérica debe ser diseñada considerando tanto aspectos fármaco-cinéticos como aspectos fisiológicos. Dentro de los cuales cabe destacar:

- la obtención de un perfil de liberación controlada de principios activos para reducir los efectos tóxicos de altas dosis administradas.

- la localización a dianas farmacológicas.

- el sobrepaso de barreras fisiológicas (procesos de vaciado gástrico, de recambio de mucosas).

- protección de principios activos frente a condiciones fisiológicas (como el pH ácido del estómago o la presencia de proteasas u otras enzimas hidrolíticas).

- el direccionamiento especifico a cierto tipo de células o tejidos (como tumores o zonas infectadas).

- aumentar el tiempo de circulación de la matriz al ser administrada (como la PEGilación de proteínas que mejora su estabilidad, aumenta la solubilidad, disminuye la proteólisis y excreción renal).

- Mejorar la biodisponibilidad del fármaco, favoreciendo la absorción por parte de las células por contacto directo con la matriz.

Algunos polímeros son considerados "inteligentes" debido a su rápida respuesta frente a modificaciones de las condiciones fisicoquímicas ambientales, como la temperatura, la fuerza iónica, los solventes, campos eléctricos, estrés mecánico, presión, el $\mathrm{pH}$, iones específicos u otros agentes químicos, siendo capaces de cambiar sus propiedades drásticamente. En éste sentido, la encapsulación de fármacos en matrices de biopolímeros a micro- y nano- escala ha permitido controlar su liberación espacial y temporal en el cuerpo humano y además protegerlos contra procesos de inactivación. De esta forma, el principio activo es liberado en el sitio blanco deseado y 
se logra mantener la concentración del fármaco dentro de una ventana terapéutica en un período de tiempo establecido.

A su vez, las propiedades de las matrices diseñadas pueden ser manejadas fácilmente de acuerdo a la aplicación y condiciones fisiológicas. Por ejemplo, mediante la modificación de las propiedades de hidrofobicidad de la matriz, que al ser incrementadas, impiden la difusión de protones hacia el interior, con lo cual el fármaco encapsulado es protegido de la inactivación por pHs ácidos. Un ejemplo de ellos es la aplicación de dichos sistemas realizada mediante el uso de microesferas encapsulando fagos (o moléculas sensibles para su administración por vía oral, que de otra forma, sufrirían una rápida inactivación frente al pH estomacal y la presencia de proteasas). Sin embargo, mediante la utilización de vehículos biopoliméricos, son protegidos contra condiciones ambientales extremas (ácidas por ejemplo, en donde además la matriz es insoluble), para luego ser liberados en el tracto intestinal debido a la presencia de iones fosfato y de un pH levemente alcalino que permite la disolución de la matriz, ejerciendo de esta forma, su efecto terapéutico en el sitio especifico (Dini y col., 2012).

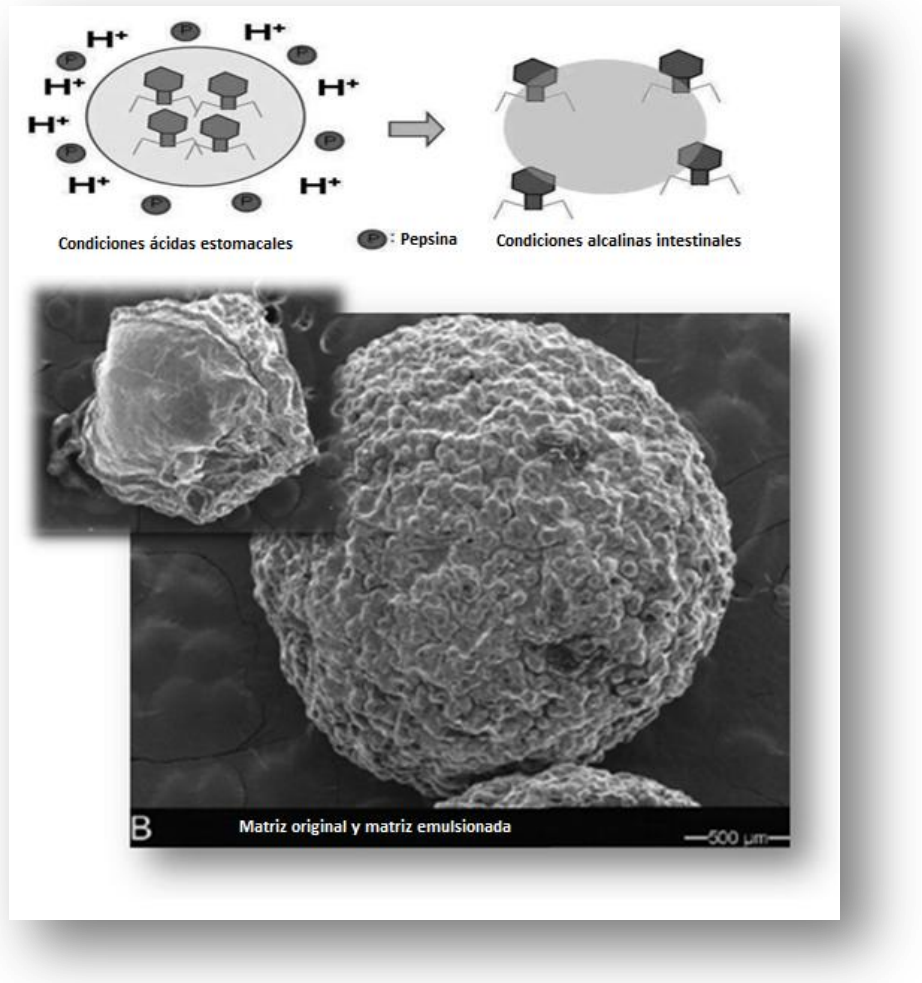

Matriz de base biopolimérica emulsionada que muestra propiedades de hidrofobicidad superficial, que favorece la estabilidad de una estructura lábil (partícula viral) al pH ácido (Dini y col., 2012) 
EL desarrollo de sistemas de liberación controlada de moléculas posibilita la administración de fármacos en pequeñas dosis terapéuticas de forma tal que ejercen su función sin alcanzar concentraciones tóxicas para las células, tejidos y órganos, razón por la cual es indispensable establecer las posibles interacciones entre la/s molécula/s transportada/s, la matriz de transporte, y el ambiente fisiológico en donde se efectuaría la liberación (órgano blanco), así como definir la vía de administración del sistema. El tamaño necesario para atravesar barreras fisiológicas así como las características de superficie de la partícula son otras características relevantes a considerar. Una vez definidos dichos parámetros, es posible desarrollar modificaciones y rediseños de nuevas formulaciones para optimizar la administración de los fármacos (Luckachan y col., 2011).

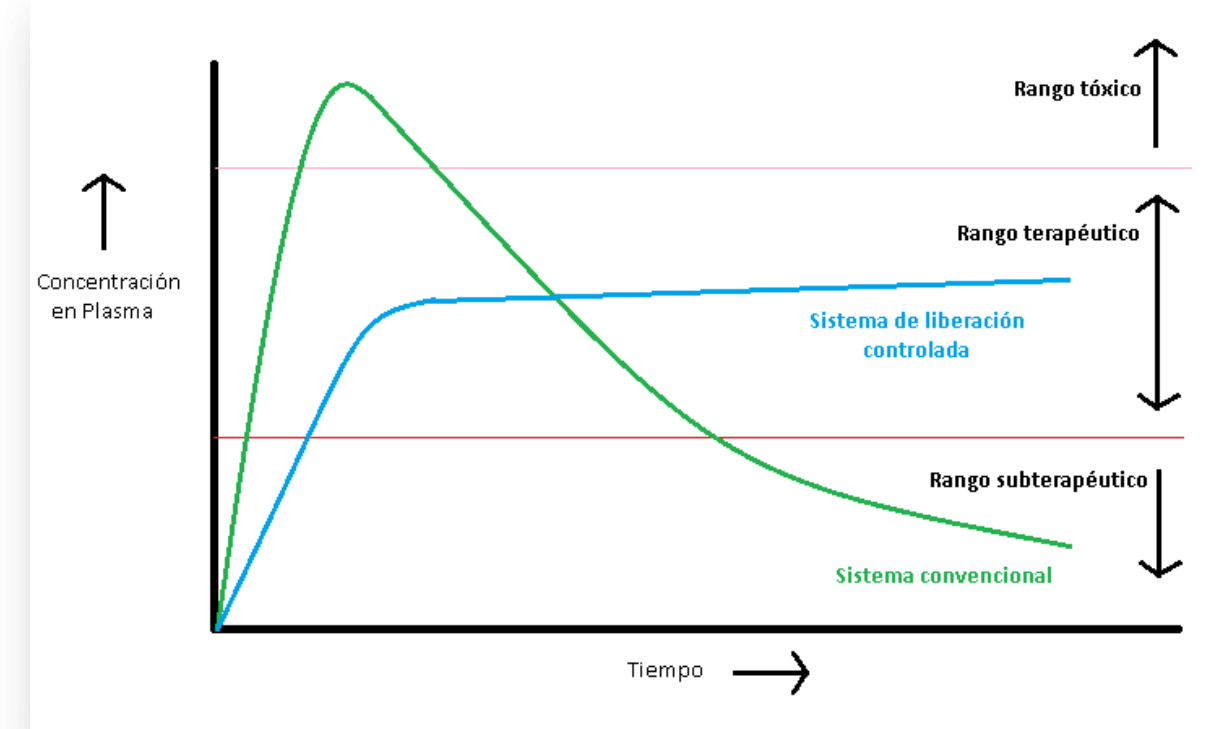

En particular, las formulaciones orales representan la plataforma más sencilla y deseada para la administración de fármacos. En formulaciones farmacéuticas convencionales, como pastillas y cápsulas, el transporte de moléculas se produce por vía gastrointestinal, y la absorción del principio activo se realiza mediante un gradiente de concentraciones en un proceso de absorción pasiva sobre la superficie del epitelio intestinal, proceso gobernado por tres factores primarios: grado de ionización, peso molecular, e hidrofobicidad. Otra ventaja de la administración oral, es que el paciente puede dosificarse de una forma sencilla en cualquier ámbito. Formulaciones para administración de otro tipo, como pulmonar o intravenosa, requiere la utilización de 
instrumentación específica (como nebulizadores o jeringas) y debe intervenir personal capacitado e instalaciones apropiadas. Por otro lado, los transportadores deben ser modificados, teniendo en cuenta consideraciones fisiológicas, como lo es la PEGilación (adición de moléculas de polietilenglicol), necesaria para disminuir la eliminación de las partículas por parte de los macrófagos del propio organismo.

El proceso mediante el cual el fármaco es liberado de la matriz, también es otro factor relevante que debe tenerse en cuenta en el diseño del sistema. La liberación del fármaco de la matriz puede clasificarse principalmente en dos mecanismos: difusional pasivo o difusional por erosión. En el primer caso, el mecanismo difusional a través de la matriz se produce de forma pasiva, generado por un gradiente de concentración del

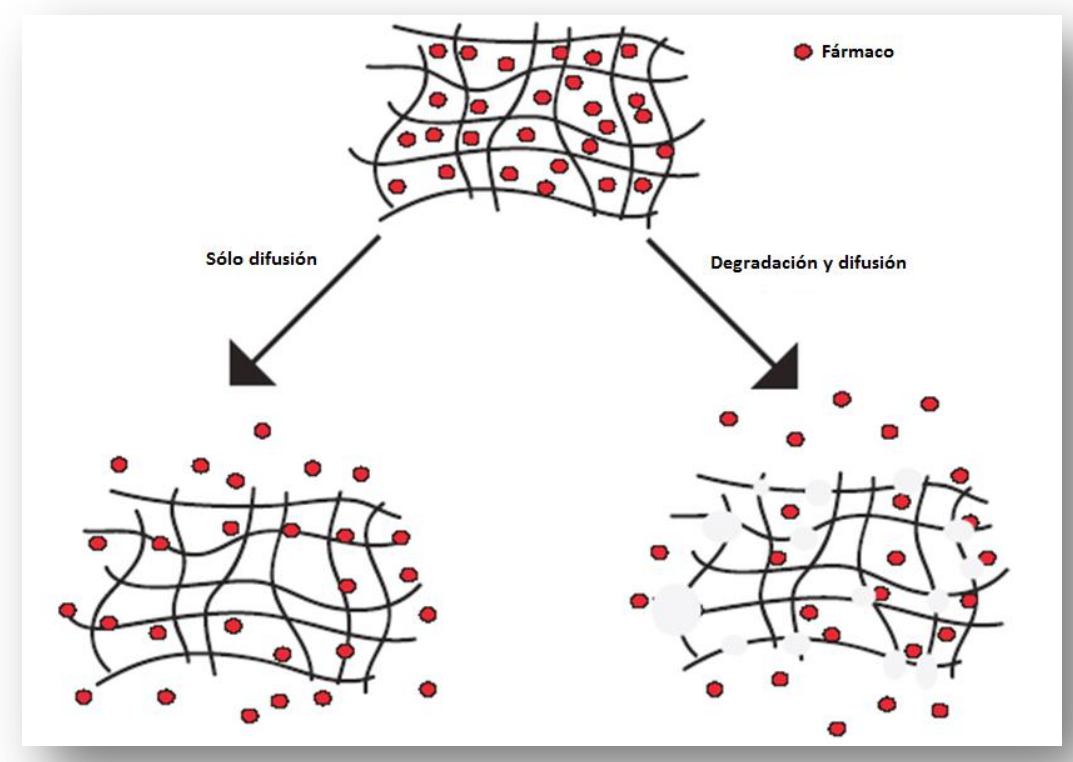

fármaco, desde la matriz donde se halla en mayor concentración hacia el medio circundante, $\sin$ que se altere la estructura del transportador, mecanismo establecido por las leyes de Fick. En el segundo caso, la liberación del fármaco se produce por un mecanismo de degradación de la red polimérica debido a la presencia de enzimas, agua, concentraciones de ácido/base, sales o fuerza iónica.

La degradación por erosión puede producirse como proceso masivo o superficial. En la degradación superficial, la matriz del polímero queda cada vez más expuesta a la superficie, pero la fracción de volumen de polímero permanece esencialmente inalterada. En la degradación masiva no ocurren cambios significativos en el tamaño del polímero hasta que finalmente la matriz es completamente degradada o erodada, sin embargo durante todo el proceso la fracción remanente de polímero en la matriz va disminuyendo gradualmente. Por este motivo, los productos 
de degradación de los polímeros utilizados deben ser, como fuera previamente señalado, biocompatibles y atóxicos para las células humanas.

\section{Directivas de la tesis}

El presente trabajo de tesis posee como objetivo de desarrollar sistemas de liberación de fármacos con potencial aplicación para el tratamiento de Fibrosis Quística. La FQ puede ser catalogada como una enfermedad pulmonar debido a que es el principal órgano afectado y su disfunción progresiva es la principal causa de mortalidad. La afección sistémica hace que tenga un carácter más agudo y sea considerada como una enfermedad de mayor complejidad, que posee varios sitios diana de ataque para establecer un tratamiento eficaz y mejorar la calidad de vida del paciente. En el primer y segundo capítulo se buscará desarrollar una matriz para el tratamiento por vía oral de las infecciones recurrentes de Pseudomonas aeruginosa en el intestino, principales productoras de bio-películas de alginato. Por este motivo, se seleccionará una matriz adecuada a la patología y se establecerán perfiles de liberación controlada de un antibiótico (para reducir los efectos secundarios de su administración en altas dosis), mediante la acción conjunta de una enzima terapéutica. La co-inmovilización de ambos agentes en una matriz biopolimérica no ha sido descrita y representa un potencial avance en el tratamiento de la enfermedad. En el tercer capítulo se desarrollará una formulación oral mejorada, donde la enzima administrada tenga mayor estabilidad (frente a las condiciones fisiológicas adversas y a su vez para su almacenamiento).

Resolviendo la cuestión oral, en el capítulo 4 nos adentraremos en la formulación de una matriz más compleja, con tamaños adecuados, porosidad y perfiles de liberación de un antibiótico para su administración por vía pulmonar, el cual resulta ser el principal reservorio para lo propagación de la infección. Finalmente, se estudiará el efecto de la co-immobilización de una enzima terapéutica que facilite el accionar del antibiótico al disminuir la mucosidad característica de los pulmones de pacientes con FQ, y se evaluará la capacidad antimicrobiana del prototipo desarrollado contra Pseudomonas aeruginosa. 


\section{Bibliografía general}

Alkawash M. A., Soothill J. S. and Schiller N. L., Alginate lyase enhances antibiotic killing of mucoid Pseudomonas aeruginosa in biofilms. APMIS 2006, 114, 131.

Bosio V. E., Islan G. A., Martinez Y. N., Castro G. R., Control release applications in food technology. In Advances in Bioprocesses in Food Industry - Vol. 4. 2011, 1, 1-13. (C.R.Soccol, A. Pandey, V.T. Soccol, C. Laroche, Eds.) Asiatech, New Delhi, India.

Cantón R., Fernández Olmos A., de la Pedrosa E. G. G., Del Campo R., Antonia Meseguer M., Infección bronquial crónica: el problema de Pseudomonas aeruginosa. Archivos de Bronconeumología 2011, 47, 8.

Castro G. R., Kamdar R., Panilaitis B., Kaplan D., Triggered release of proteins from emulsanalginate beads. Journal of Controlled Release 2005, 109, 149.

Castro G. R., Panilaitis B., Kaplan D., Controlled Release Biopolymers for Enhancing the immune Response. Molecular Pharmaceutics 2006, 4, 33.

Consenso Nacional de Fibrosis Quística, Sociedad Argentina de Pediatría. Arch Argent Pediatr 2008; (Supl) 106(5):e01-52.

Costas L., Bosio V. E., Pandey A., Castro G. R., Properties of immobilized lipase on pectin microspheres in organic solvents. Applied Biochemistry and Biotechnology 2008, 151, 578.

Cystic Fibrosis Foundation. Patient Registry 2007 Annual Report, September 2009. http://www.cff.org/research/ ClinicalResearch/PatientRegistryReport

Dini C., Islan G. A., de Urraza P. J., Castro G. R., Novel Biopolymer Matrices for Microencapsulation of Phages: Enhanced Protection Against Acidity and Protease Activity. Macromol. Biosci. 2012, 12, 1200.

Dockrell D. H., Breen R., Lipman M., Miller R. F., 3 Pulmonary opportunistic infections. HIV Medicine, 2011, 12.

Growcott E. J., Coulthard A., Amison R., Hardaker E. L., Saxena V., Malt L., Jones P., Grevot A., Poll C., Osborne C., Banner K. H., Characterisation of a refined rat model of respiratory infection with Pseudomonas aeruginosa and the effect of ciprofloxacin. J. Cyst. Fibros. $2011,10,166$.

Hatch R. A., Schiller N. L., Alginate lyase promotes diffusion of aminoglycosides through the extracellular polysaccharide of mucoid Pseudomonas aeruginosa. Antimicrob. Agents Chemother. 1998, 42, 974.

Hodges N. A., Gordon C. A., Protection of Pseudomonas aeruginosa against ciprofloxacin and beta-lactams by homologous alginate. Antimicrob. Agents Chemother. 1991, 35, 2450. 
Høiby N., Ciofu O., Bjarnsholt T., Pseudomonas aeruginosa biofilms in cystic fibrosis. Future Microbiol., 2010, 5, 1663.

Islan G. A., Pérez de Verti I., Marchetti S. G., Castro G. R., Studies of Ciprofloxacin Encapsulation on Alginate/Pectin Matrixes and Its Relationship with Biodisponibility. Appl. Biochem. Biotechnol. 2012, 167, 1408.

Luckachan G. E., Pillai C. K. S., Biodegradable Polymers- A Review on Recent Trends and Emerging Perspectives. Journal of Polymers and the Environment 2011, 19, 637.

May T. B., Shinabarger D., Maharaj R., Kato J., Chu L., Devault J. D., Roychoudhury S., Zielinski N. A., Berry A., Rothmel R. K., Misra T. K., Chakrabarty A. M., Alginate synthesis by Pseudomonas aeruginosa: a key pathogenic factor in chronic pulmonary infections of cystic fibrosis patients. Clin. Microbiol. Rev. 1991, 4, 191.

Montes Casas M. M., Estudio de utilización de medicamentos en pacientes con fibrosis quística en Andalucía. Análisis comparativo y fármaco-económico. Tesis doctoral, 2008.

Mrsny R. J., Lazazzera B. A., Daugherty A. L., Schiller N. L., Patapoff T. W., Addition of a bacterial alginate lyase to purulent CF sputum in vitro can result in the disruption of alginate and modification of sputum viscoelasticity. Pulm. Pharmacol. 1994, 7, 357.

Pedersen S. S., H€oiby N., Espersen F., Koch C., Role of alginate in infection with mucoid Pseudomonas aeruginosa in cystic fibrosis. Thorax, 1992, 47, 6.

Ratjen F., Paul K., van Koningsbruggen S., Breitenstein S., Rietschel E., Nikolaizik W., DNA concentrations in BAL fluid of cystic fibrosis patients with early lung disease: influence of treatment with dornase alpha. Pediatr Pulmonol. 2005, 39, 1.

Robinson P. J., Dornase alfa in early cystic fibrosis lung disease. Pediatr Pulmonol. 2002, 34, 237.

Ruckdeschel J. C., Greene J., Sommers K. E., Fields K. K., Respiratory infections in patients with cancer in Holland-Frei Cancer Medicine, ed. D. W. Kufe, R. E. Pollock, R. R. Weichselbaum, et al., BC Decker, Canada, 6th edn., 2003.

Sarles J., Digestive expression (pancreatic and intestinal) of cystic fibrosis: an approach based on physiopathology. Arch. Pediatr. 2012, 19, S20.

Thanki K., Oral delivery of anticancer drugs: Challenges and opportunities. J. Control. Rel. 2013, $170,15$. 


\section{OBJETIVOS GENERELES}

Estudiar el diseño de una matriz biopolimérica para su potencial aplicación en los sistemas gastrointestinal y pulmonar (sitios más afectados por la enfermedad) para la erradicación de la infección bacteriana.

Desarrollar una matriz transportadora de fármacos eficiente, sencilla y de bajo costo para la mejora del tratamiento de Fibrosis Quística.

Este desarrollo implicará la co-inmovilización de dos moléculas con función complementaria y el desarrollo de sistemas de liberación controlada de fármacos para reducir los efectos secundarios generados por las altas dosis empleadas en administraciones convencionales. 


\section{CEPITULO 1}

Selección de un fármaco modelo y matriz para administración oral. Estudios de encapsulación y liberación

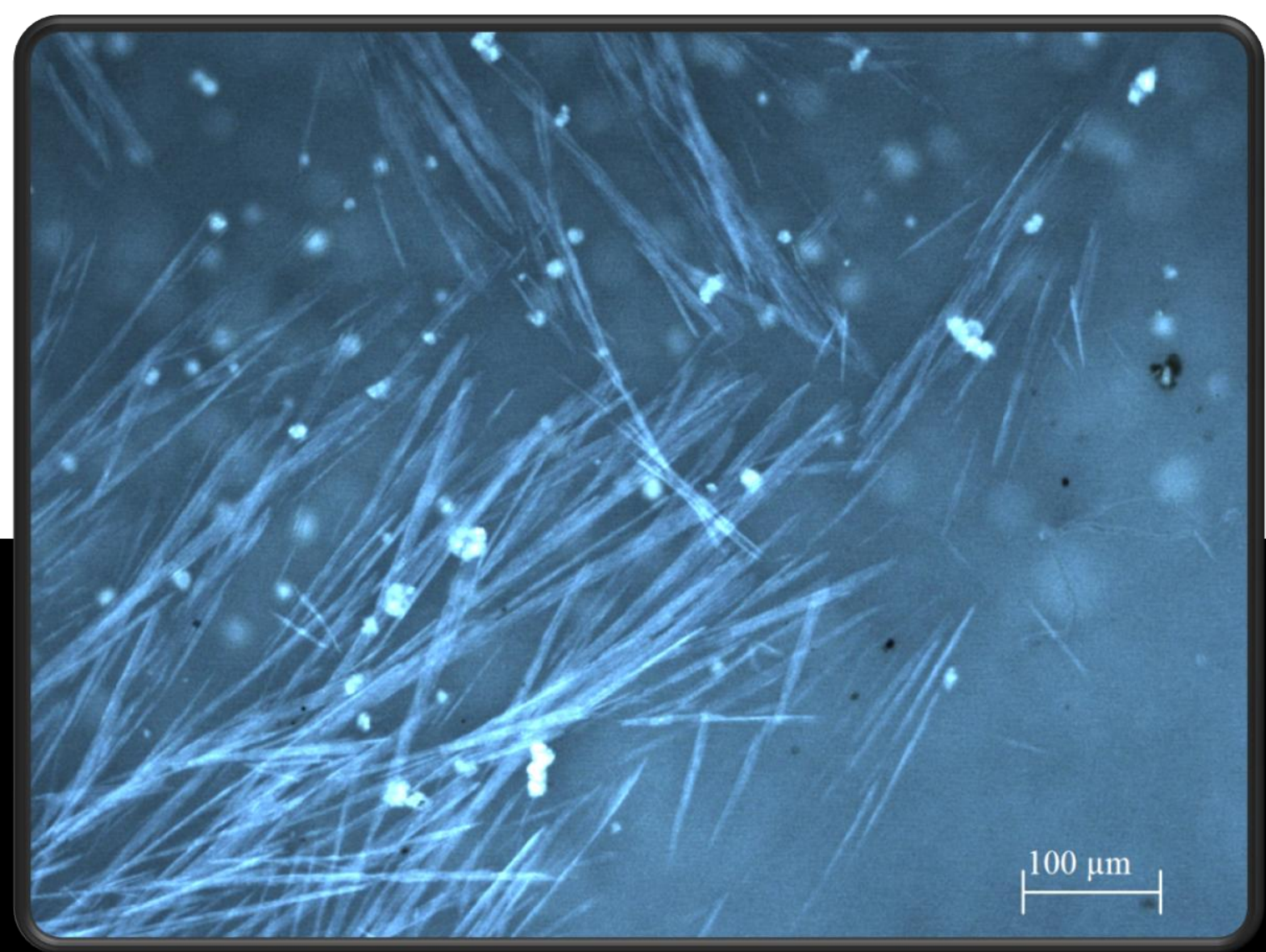

Cristales de Ciprofloxacina observados mediante microscopia de fluorescencia a 1.000x. 


\section{Objetivos específicos}

\# Desarrollar matrices basadas en biopolímeros.

* Establecer las condiciones de gelificación de la matriz.

* Estudios de interacción entre el antibiótico modelo (Ciprofloxacina) y los biopolímeros que constituyen la matriz (precipitación y FTIR).

* Optimización de la encapsulación de Ciprofloxacina.

* Lograr un perfil de liberación controlada.

* Evaluar la capacidad antimicrobiana del sistema contra Pseudomonas aeruginosa.

1.1. Introducción

* Materiales ... 35

* Detección de Cipro ... 35

* Determinación las interacciones entre Cipro y biopolímeros por precipitación ... 35

* Análisis espectroscópico vibracional infra-rojo con transformada de Fourier (FTIR) ... 36

* Análisis espectroscópico vibración por luz Sincrotrón ... 36

* Preparación de microesferas de alginato como matriz base para la encapsulación de Cipro ... 37

* Medición y cálculo del porcentaje de encapsulación de Cipro ... 38

* Saturación de la matriz de base de alginato con Cipro ... 38

* Medición de parámetros texturométricos ... 39

* Microscopía electrónica de barrido (SEM) ... 39

* Análisis de superficie de las imágenes de SEM ... 39

* Microscopía de fuerza atómica (AFM) ... 40

* Cinética de liberación de Cipro a partir de microesferas ... 40

* Evaluación de la actividad antimicrobiana de las microesferas/Cipro contra Ps. aerug. ... 41

* Análisis estadístico ... 41

1.3. Resultados y discusión

* Selección de la matriz biopolimérica ... 42

* Optimización de las condiciones de encapsulamiento ... 44

* Análisis morfológico de las microesferas en medio de síntesis con propilenglicol ... 49

* Saturación de la matriz de alginato con concentraciones crecientes de Cipro ... 51

* Ensayos de liberación de Cipro desde microesferas de alginato para administración oral ... 52

* Optimización de las condiciones de liberación mediante el empleo de mezclas de biopolímeros ... 55

* Incorporación de pectinas a la matriz ... 56

* Incorporación de gelatina a la matriz ... 67

1.3. Conclusiones

1.4. Bibliografía. 


\subsection{Introducción}

Las formulaciones orales representan la plataforma más sencilla para el transporte de fármacos. La FQ afecta el intestino de los pacientes, lo que permite el desarrollo de infecciones recurrentes de Pseudomonas aeruginosa, siendo capaz de producir bio-películas de alginato. Por lo tanto, se buscará desarrollar una matriz para la administración oral de un antibiótico que permita erradicar este microorganismo.

El procedimiento estandarizado por el Consenso Argentino de Fibrosis Quística establece las pautas para el tratamiento de la patología y recomienda que ante el primer aislamiento de Pseudomonas aeruginosa se administre un antibiótico por vía oral más antibiótico inhalado de la siguiente forma: Ciprofloxacina $30 \mathrm{mg} / \mathrm{kg} / \mathrm{día}$ durante 3-4 semanas, y Colistina nebulizado $50-100 \mathrm{mg} /$ día, dos veces por día, durante 3 meses.

Particularmente, la Ciprofloxacina (Cipro) ha sido seleccionada como el antibiótico a estudiar, debido a su amplio espectro de acción contra patógenos microbianos diversos y a los posibles afectos adversos generados por su administración crónica.

\section{Ciprofloxacina}

La Cipro (1-ciclopropil-6-fluoro-1,4-dihidro-4-oxo-7-(1-piperazinil)-3-quinolina ácido carboxílico) pertenece a la familia de las quinolonas de segunda generación, que son inhibidores de la ADN girasa y la topoisomerasa IV causando la muerte bacteriana (Appelbaum y col., 2000). Son actualmente de uso común en toda Europa y Sudamérica para el tratamiento de la FQ (Proesmans y col., 2013). Sin embargo, la Cipro es un antibiótico comúnmente asociado a problemas gástricos e intestinales cuando es

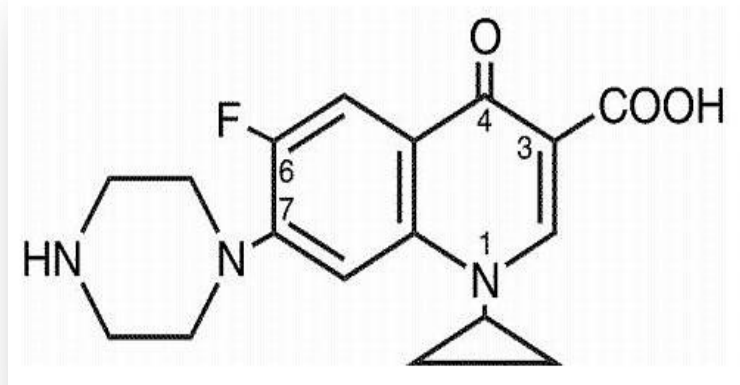
administrado por vía oral. Los 
tratamientos crónicos en FQ implican la utilización de dosis elevadas de antibiótico, con concentraciones que superan en muchos casos la ventana terapéutica, y asociadas a severos efectos secundarios indeseados (ver tabla 1), lo que conduce a una vida media reducida y una pobre calidad en los pacientes (Patterson, 1991).

Para tratar de comprender el comportamiento de la Cipro analizaremos la desde el punto de vista estructural. La molécula Cipro posee dos grupos ionizables: un grupo carboxílico en $\mathrm{C}-3(\mathrm{pKa}=6,16)$, y un grupo piperazinilo en $\mathrm{C}-7$ ( $\mathrm{pKa}=8,62)$ (Barbosa, y col., 2009), los cuales son capaces de formar una estructura de zwiterion en el rango de pH de 6,16 a 8,62. Además, la molécula de Cipro posee un grupo ceto C4 en el anillo quinolónico que es polarizable. El grupo carboxilato en C-3 es capaz de formar puentes de hidrógeno intra- y/o inter- moleculares con el grupo carbonilo en posición C-4. Sobre la base de la presencia de los grupos iónicos y el anillo aromático (motivo hidrofóbico), el comportamiento fisicoquímico de la Cipro es complejo y está fuertemente influenciado por condiciones del medio ambiente. Por este motivo, se cataloga a la Cipro como una droga "pegajosa", capaz de interactuar con muchas moléculas incluyendo membranas lipídicas hasta proteínas como el transportador de glucosa tipo 1 o la albumina de suero bovino (Hernández-Borrell y col., 2003; Seedher y col., 2010). Una de las propiedades más complejas desde el punto de vista farmacológico, es que la Cipro tiene tendencia a producir fenómenos de apilamiento intermolecular (conocido también como apilamiento П-П) cuando las concentraciones son elevadas, determinadas por las interacciones de los electrones localizados en los enlaces $\pi$ entre los anillos aromáticos de sus moléculas (Figura 1.1., a), lo cual lleva la formación de cristales insolubles, que generan una disminución de la biodisponibilidad de la droga y un aumento de su toxicidad (Maurer y col., 2008; Tomišić y col, 2002).

Ha sido observado que los cristales de Cipro llegan a tener tamaños del orden micrométrico (Figura 1.1., b-c) y muchos órganos se ven afectados por su presencia, en particular los riñones, los cuales son los responsables del proceso de excreción de la droga y sufren micro-lesiones que conducen a una insuficiencia renal crónica (Bald y col., 2001). 

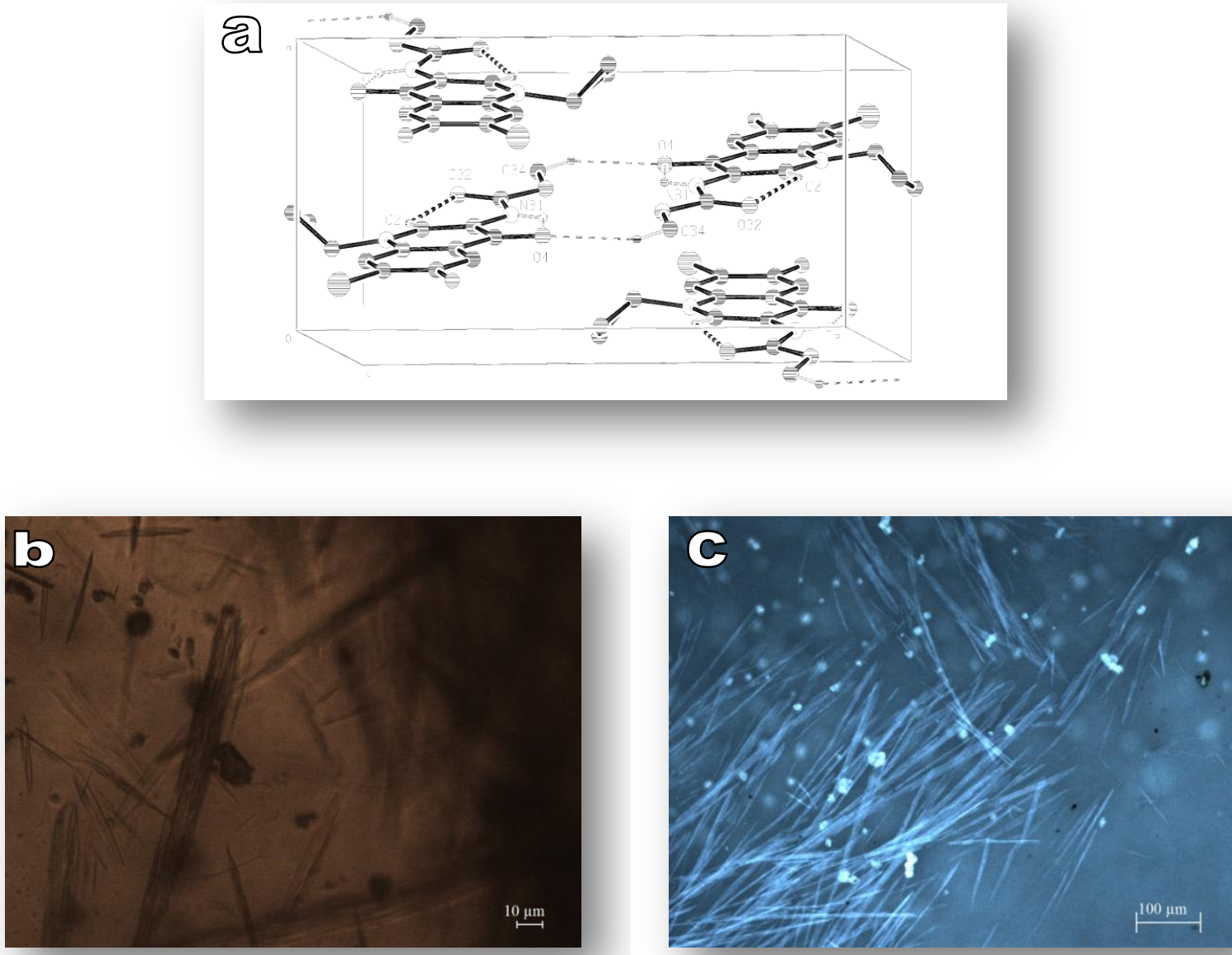

Figura 1.1. a) Esquema de las interacciones $\pi$ entre los anillos aromáticos de las moléculas de Cipro (Tomišić y col, 2002). b-c) Cristales de Cipro observados por microscopia óptica al visible (a $400 x$ ) y por fluorescencia (a 1.000x).

Es dable aclarar que la solubilidad de la Cipro además, se ve disminuida en por las condiciones fisiológicas (a pH neutros posee la menor solubilidad) con lo cual su absorción a nivel intestinal (en donde el pH oscila de 6,3 a 7,4) se ve dificultada. Por el contrario, su solubilidad a pHs bajos (menores a 4,0) aumenta (Figura 1.2, a), lo cual resulta inconveniente, debido a que la mayor parte de la droga se solubiliza durante su pasaje por el estómago ( $\mathrm{pH}$ comprendido entre 1,2 a 3,0), generando no solo irritación gástrica, sino que además disminuye la cantidad de fármaco disponible para ser asimilado en su sitio de absorción, el duodeno, que es la primer porción del tracto intestinal (Rouge y col., 1996). Su comportamiento se puede explicar considerando las estructuras moleculares en equilibrio a los diferentes pHs (Figura 1.2, b). A pHs ácidos la solubilidad de la Cipro aumenta hasta un $\mathrm{pH}$ aproximado de 6,0, debido a la 
presencia de grupos funcionales cargados positivamente, mientras que a partir de $\mathrm{pH}$ 9,0 aumenta con el aumento del pH por la conversión de grupos funcionales cargados negativamente en la molécula. En cambio, a valores cercanos a la neutralidad, predomina la forma switteriónica de la Cipro, en equilibro con la forma neutra, que al tener un grado de ionización mínimo, posee una baja capacidad de ser solvatada por las moléculas de agua, con la concomitante disminución de la solubilidad.
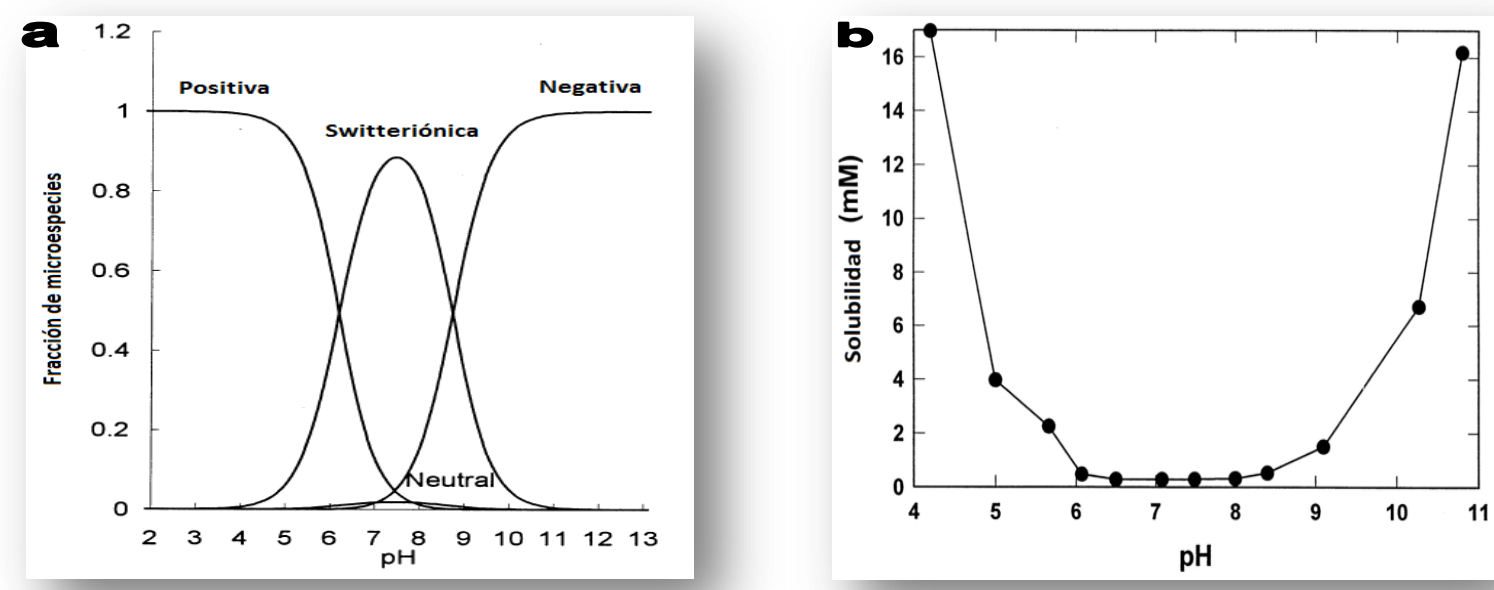

Figura 1.2. a) Especiación de las formas de la molecula de Cipro con la variación de pH (Sun y col., 2002). b) solubilidad de la Cipro en fase acusa en función del cambio de pH (Webb y col., 1998).

En la administración oral, la Cipro se disuelve en el estómago en aproximadamente 2 horas (Breda y col., 2009) y en consecuencia, la biodisponibilidad del antibiótico asociado a la absorción intestinal estará determinada por el tiempo de residencia del fármaco en el estómago, las propiedades fisicoquímicas y biológicas del medio circundante (como fuerza iónica o la presencia de enzimas), la dosis, y los excipientes que acompañan al fármaco en la formulación entre otros factores. En un trabajo reciente, se encontró que los niveles plasmáticos de Cipro en pacientes enfermos se encontraban por debajo de la dosis terapéutica debido a la compleja farmacocinética del antibiótico (Conil y col., 2008). En consecuencia, con el fin de reducir efectos secundarios indeseables, disminuir la dosis administrada y aumentar la biodisponibilidad, se llevara a cabo la encapsulación del fármaco en una matriz biopolimérica que posea un perfil de liberación controlada adecuado.

Dentro de las formulaciones basadas en biopolímeros, buscaremos aquellos que tengan facilidad en su manejo, que permitan ser adaptados y orientados, que 
brinden una buena capacidad de carga del fármaco y alta estabilidad al ser gelificados o entrecruzados y de bajo costo de producción y operación. Entre los biopolímeros más utilizados se encuentran los alginatos, pectinas, goma guar, gelatinas o quitosanos entre otros, los cuales son usados con frecuencia en alimentos y aplicaciones farmacéuticas como la inmovilización y la encapsulación de moléculas biológicamente activas (Augst y col., 2006).

\section{Alginatos}

El alginato es un polisacárido aniónico lineal constituido de residuos de ácidos ß-D-manurónico (M) y ácidos $\alpha$-L-gulurónico (G) unidos por enlaces 1-4. Es obtenido de

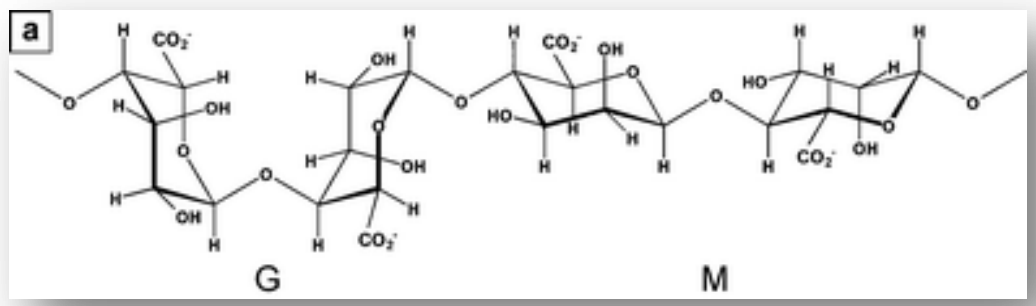
algas $\mathrm{y}$ algunas bacterias son capaces de producirlo, entre las cuales, como se mencionara anteriormente se encuentran ciertas cepas de Pseudomonas aeruginosa. Sus propiedades de ser atóxicos (F.D.A., EE.UU.), no generar respuesta inmune y ser biocompatibles los ha hecho muy adecuados para la administración oral.

Los alginatos puede ser gelificados en presencia de cationes multivalentes en una disposición espacial denominada como "caja de huevos" (Velings y col., 1995). De los alginatos ricos en ácido manurónico $(\mathrm{M})$ se obtiene un gel elástico; mientras que aquellos ricos en ácido gulurónico $(G)$ se obtiene un gel firme y quebradizo (Figura 1.3). Como su pKa se encuentra alrededor de 3,0 los geles de alginato son insolubles a $\mathrm{pHs}$ menores a dicho valor, mientras que a $\mathrm{pH}$ alcalinos tienden a disolverse en medios acuosos, razón por la cual resulta una matriz interesante para la administración oral, debido a que el fármaco encapsulado es liberado mayormente en el intestino, en donde la matriz es disuelta por el propio $\mathrm{pH}$ alcalino circundante. No obstante, los geles de alginato son inestables en presencia de agentes quelantes de cationes (tales como fosfato o EDTA) o cationes no gelificantes que compiten por los sitios ocupados por el calcio dentro de la matriz (tales como el sodio o el potasio), los cuales se encuentran presentes en los fluidos biológicos. 

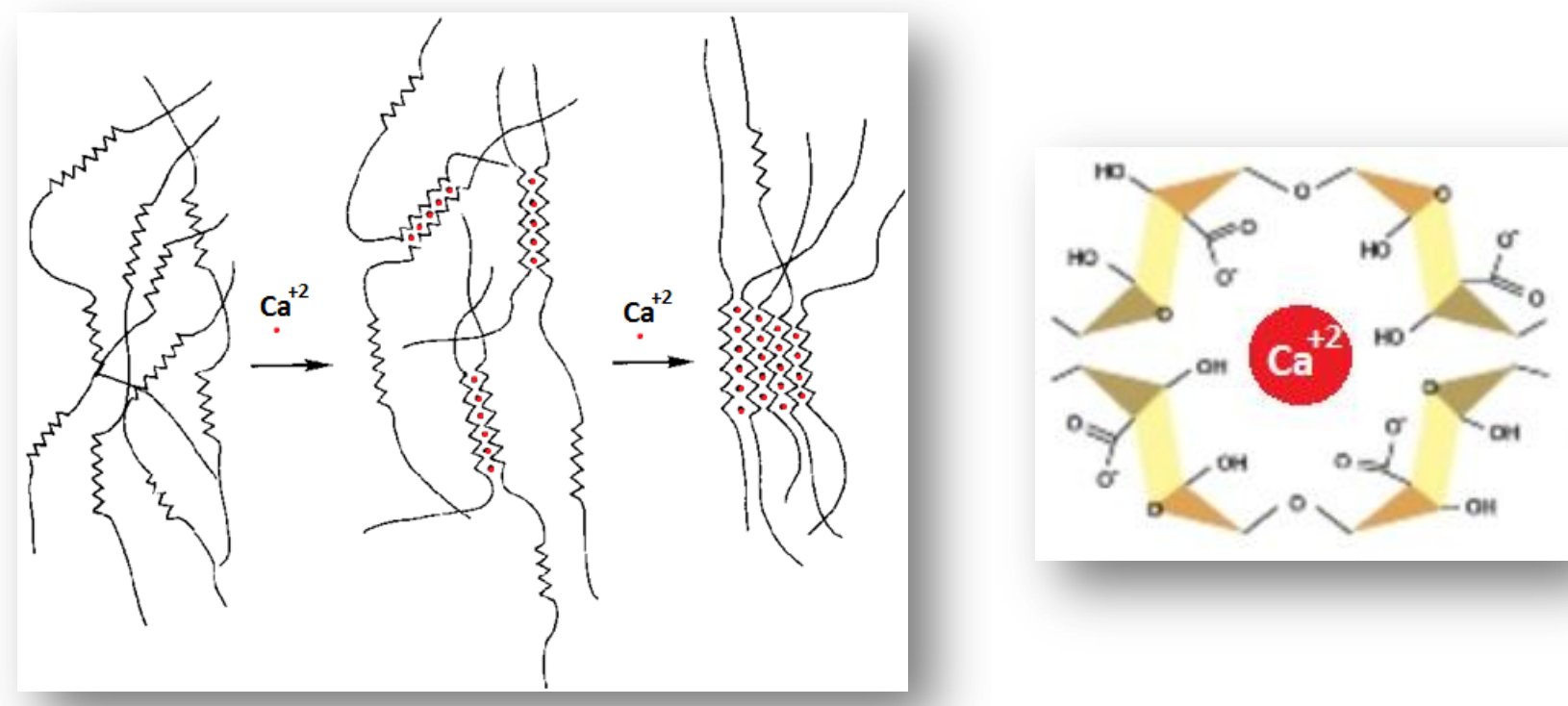

Figura 1.3. Proceso de gelificación iónica de las cadenas de alginato en presencia de iones divalente (en éste caso, ion calcio) que da origen a la formación de un gel compacto (Augst y col., 2006)

\section{Pectinas}

Las pectinas son polisacáridos aniónicos solubles en agua que se encuentran presentes en la pared celular de las plantas. El uso de pectinas ha sido propuesto en varios trabajos como matriz para administración de fármacos por vía oral (Liu y col., 2003; Dini y col., 2012). Las pectinas se componen de polisacáridos lineales con regiones parcialmente metoxiladas de ácido poli- $\alpha$-(1,4)-D-galacturónico. El grado de esterificación (GE) de las pectinas posee una fuerte influencia en sus propiedades fisicoquímicas, y se pueden agrupar en tres grupos: pectinas de bajo contenido de metoxilo (PBM) con GE por debajo del 40\%;

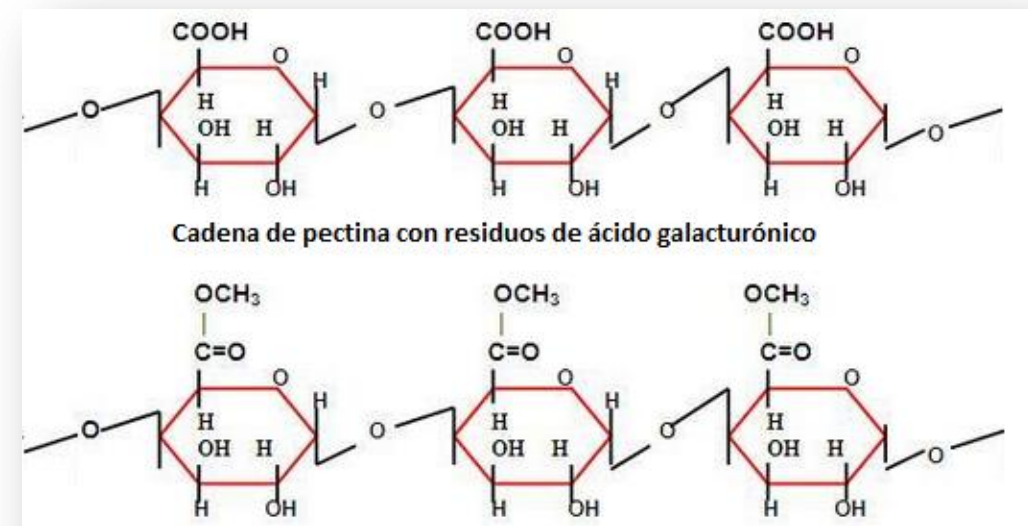

Cadena de pectina esterificada con los residuos de ácido galacturónico metoxilados 
pectinas con contenido medio de metoxilo (PMM) con un rango de GD entre $40-60 \%$, y pectinas de alto contenido de metoxilo (PAM) con GD superiores al 60\%. Las PBM y PMM pueden ser gelificadas por cationes multivalentes, mientras que las PAM gelifican a pHs ácidos y en presencia de solutos. Los pKas de los distintos tipos de pectina se encuentran en el intervalo de $\mathrm{pH}$ de 3,5 a 4,1 (Thakur y col., 1997). Las pectinas no son degradables por las enzimas intestinales, pero si son degradadas por las bacterias que componen la propia flora intestinal, lo cual es una ventaja para direccionar fármacos a dicho tracto debido a que el vehículo puede ser disuelto, liberar el fármaco y sus productos ser absorbidos por la propia flora.

\section{Gelatina}

La gelatina es una proteína de naturaleza animal, que se obtiene por hidrólisis controlada del colágeno. El colágeno es el constituyente principal de la piel, los huesos

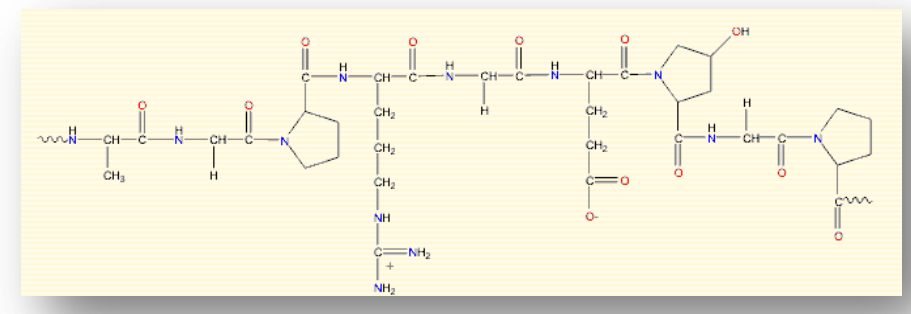
y el tejido conectivo de animales. Sus propiedades de biodegradabilidad $\quad y$ biocompatibilidad hacen de la gelatina un biopolímero apropiado para su aplicación en el campo de la medicina como expansor del plasma, constituyente de vendaje para heridas, adhesivos, almohadillas absorbentes, y como vehículo para la administración de fármacos (Kuijpers y col., 2000).

La gelatina es desde el punto de vista estructural una mezcla heterogénea de polipéptidos individuales o con múltiples hebras, cada uno con conformaciones de hélice tipo prolina, y poseen entre 50 a 1000 aminoácidos. La gelatina contiene residuos de glicina (aproximadamente 1 de cada 3 residuos), prolina y 4hidroxiprolina. Además, posee en promedio los ácidos aspártico $\left(0,50 \mathrm{mmol} / \mathrm{g}, \mathrm{pK}_{\mathrm{a}}=\right.$ 4,0-4,5) y glutámico $\left(0,78 \mathrm{mmol} / \mathrm{g}, \mathrm{pK}_{\mathrm{a}}=4,5\right)$ como principales grupos aniónicos, lisina $\left(0,30 \mathrm{mmol} / \mathrm{g}, \mathrm{pK}_{\mathrm{a}}=10,0-10,4\right)$ y arginina $\left(0,53 \mathrm{mmol} / \mathrm{g}, \mathrm{pK}_{\mathrm{a}}>12\right)$ como principales grupos laterales catiónicos. 
Existen dos tipos de gelatinas dependiendo de si la preparación implica un pretratamiento alcalino, que convierte los residuos de asparagina y glutamina en aspártico y glutámico respectivamente, dando como resultado un incremento en la viscosidad. Un pre-tratamiento ácido deriva en gelatina de tipo $A$, mientras que el tratamiento alcalino da gelatina de tipo B. Esta última, posee un punto isoeléctrico de 4,9, y sus valores de $\mathrm{pKa}$ son $\mathrm{pK}_{\mathrm{a} 1}=3,6$ y $\mathrm{pK}_{\mathrm{a} 2}=7,8$. A pHs por debajo de 5,0 la carga residual es positiva y puede formar coacervados con moléculas cargadas negativamente (por ejemplo, ADN) (Rose, 1990). La gelatina tipo A tiene un punto isoeléctrico comprendido entre 7,0 y 9,0 .

La gelatina es capaz de formar geles termorreversibles elásticos y transparentes al ser enfriada por debajo de los $35^{\circ} \mathrm{C}$. Se puede alterar las propiedades del gel, mediante la introducción de agentes entrecruzantes como transglutaminasa para ligar residuos de lisina a glutamina, o utilizando glutaraldehído para establecer uniones lisina-lisina (Chan y Heng, 2002).

\section{Coacervados o mezclas de biopolímeros en la formulación}

Las mezclas de biopolímeros es una estrategia alternativa para el desarrollo de matrices con propiedades nóveles, a fin de modular la liberación de las moléculas encapsuladas, para aumentar la estabilidad de la formulación, la cantidad de fármaco cargado en la matriz o favorecer el direccionamiento de la matriz a los órganos blanco. Por este motivo, las interacciones entre el fármaco y los componentes de la formulación deben ser determinadas a nivel molecular.

Respecto de los biopolímeros previamente mencionados, los alginatos y pectinas mostraron interesantes propiedades sinérgicas al formar geles mixtos que conducen a una microestructura muy diferente de la de los biopolímeros originales (Islan y col., 2012). Es sabido que el alginato posee la capacidad de generar geles fuertes e insolubles en presencia de iones calcio, por lo cual al ser biocompatible, es muy utilizado para producir microesferas. Sin embargo, la formación de geles de alginato posee una cinética de gelificación muy elevada que puede producir la extrusión de las moléculas a cargar. Por otra parte, las redes del gel de alginato son susceptibles a la desintegración en presencia de iones monovalentes y/o agentes quelantes de calcio. A raíz de ello, la incorporación de pectinas durante la formación 
del gel podría atenuar las condiciones de gelificación, aumentando el tiempo de residencia del fármaco en la matriz. Algunos autores han reportado que los alginatos pueden formar complejos fuertes con otros polielectrolítos naturales como la pectina (Fang y col., 2008). La mezcla de ambos biopolímeros y su posterior gelificación, dio lugar a un formulación que mostró una estabilidad mecánica y química mejorada en comparación con las esferas de alginato (Sandoval-Castilla y col., 2010). De esta manera, la naturaleza de la pectina con diferente GE podría afectar la densidad de la red matricial y las propiedades de hidrofobicidad de las microesferas (Walkenström y col., 2003), lo que repercutirá directamente con el perfil de liberación de la Cipro.

Por otra parte, estudios anteriores se han centrado en el uso de mezclas de alginato y gelatina, debido a las propiedades ventajosas del coacervado para el desarrollo de matrices de liberación de drogas (Klak y col., 2013). Películas de alginatogelatina conteniendo Cipro fueron desarrolladas para el tratamiento local de infecciones cutáneas (Dong y col., 2006; Saarai y col., 2013). De igual manera, comprimidos de alginato-gelatina fueron utilizados para la liberación controlada de clorhidrato de diltiazem y endosulfán fármacos utilizados en el tratamiento de la presión arterial y como pesticida respectivamente (Tapia y col., 2007; Roy y col., 2009). Particularmente, ha sido demostrado que cápsulas de gelatina que contenían proteínas como carga, sufrían una rápida desintegración en el estómago en el lapso de los 15 minutos de ingestión por parte de voluntarios humanos. En cambio, si dichas cápsulas de gelatina eran recubiertas con $20 \%$ de alginato entrecruzado con cloruro de calcio, las mismas se mantenían intactas en el estómago y, a continuación migraban a la región ileocecal del intestino, donde eran desintegradas (Narayani y col., 1996).

Si se consideran las ventajas de los coacervados, se diseñaran microesferas para la administración oral de Ciprofloxacina. En particular, las microesferas poseen la ventaja de permitir un contacto íntimo y prolongado con la membrana de absorción, maximizando tanto la tasa así como la medida de absorción del fármaco (Talukder y col., 2004). 


\subsection{Materiales y métodos}

\section{Materiales}

La Ciprofloxacina fue adquirida a Sigma-Aldrich (St. Louis, MO). Alginato de sodio de baja viscosidad (PM=120 kDa) fue obsequiada por Monsanto (Buenos Aires, Argentina). Las pectinas: PBM (GE 33\%, PM= 156 kDa), PMM (GE 55,3\%, PM= 158 kDa) y PAM (GE 74\%, PM= $160 \mathrm{kDa}$ ) pectinas fueron amablemente proporcionados por C. P. Kelco (Buenos Aires, Argentina). La Gelatina tipo B (PM= $125 \mathrm{KDa}$ ) fue proporcionada por por Kraft (Buenos Aires, Argentina). Los solventes empleados: etanol, etilenglicol, 1-propanol, 1,2-propilenglicol de grado analítico o superior fueron adquiridos de Anedra (Buenos Aires, Argentina). La cepa de Pseudomonas aeruginosa pertenece a la colección ATCC 15442. Otros reactivos y disolventes empleados fueron de grado analítico.

\section{Detección de Ciprofloxacina}

La concentración de antibiótico fue determinada considerando las propiedades de absorción en el UV. De esta forma, dependiendo del $\mathrm{pH}$ o de la presencia de solventes, se realizaron curvas de calibración en cada condición experimental en el rango de 0,0 - 20,0 $\mu \mathrm{g} / \mathrm{ml}$ de Cipro y se determinó la absorbancia al UV en el rango de $270-280 \mathrm{~nm}$ (con un coeficiente de extinción medio de $3,31 \cdot 10^{4} \mathrm{~cm}^{-1} \cdot \mathrm{M}^{-1}$ ).

\section{Determinación las interacciones entre Cipro y biopolímeros por precipitación}

Con el fin de seleccionar el biopolímero apropiado para desarrollar la formulación, fue llevada a cabo la evaluación de la interacción entre el biopolímero y la Ciprofloxacina. De esta manera, se posiblita determinar los polímeros que poseen la mejor interacción con el antibiótico. Para ello, soluciones acuosas del 2,0 al 3,0\% (p/ v) de alginato, pectinas (PBM, PMM O PAM) o de gelatina fueron utilizadas puras 0 mezcladas con otro biopolímero (descripto en cada caso). Un volumen de $410 \mu \mathrm{l}$ de cada solución biopolimérica fue mezclada con $90 \mu \mathrm{l}$ de solución de Cipro (100 $\mu \mathrm{g} / \mathrm{ml})$, posteriormente fue agitada durante 1 hora a temperatura ambiente. A continuación, 
$1,0 \mathrm{ml}$ de etanol absoluto frío $\left(0^{\circ} \mathrm{C}\right)$ fue adicionado a fin de precipitar el biopolímero. La suspensión resultante fue centrifugada a $10.000 \mathrm{xg}$. durante $10 \mathrm{~min}$. El sobrenadante resultante fue retirado de la solución y la Cipro en solución (no unida) fue determinada por espectrofotometría UV $\left(\lambda_{\text {máx }}=277-280 \mathrm{~nm}\right)$. Considerando la cantidad adicionada de antibiótico inicialmente, se calculó el porcentaje de Cipro unida al biopolímero precipitado.

A su vez, se determinó la influencia del pH en la interacción, ajustando el pH de las soluciones biopoliméricas con soluciones reguladoras de $\mathrm{pH}$ 4,0-5,0 (acetato de sodio/acido acético, $50 \mathrm{mM}$ ), 6,3, 6,8, 7,4 (fosfato de sodio, $25 \mathrm{mM}$ ), y 9,0 (borato de sodio, $25 \mathrm{mM})$.

\section{Análisis espectroscópico vibracional infra-rojo con transformada de Fourier (FTIR)}

A fin de corroborar las interacciones establecidas en los ensayos de precipitación, se realizó una espectroscopia FTIR. Para ello, fue preparada una solución conteniendo la Cipro $(1,0 \%(p / v))$ y los biopolímeros $(1,0-2,0 \%(p / v))$. La misma fue congelada y liofilizada. El polvo obtenido fue pesado y se preparó al 5,0\% (p/p) con bromuro de potasio como diluyente. Las muestras fueron colocadas en un portamuestra y escaneadas en un equipo FTIR (JASCO FT/IR-4200). Se realizó un promedio de 256 escaneos con corrección de fondo, contra una fuente de cerámica de alta energía y un detector DLATGS. El intervalo de medida fue de 500 a $4.000 \mathrm{~cm}^{-1}$ para todas las muestras.

\section{Análisis espectroscópico vibración por luz Sincrotrón}

Para el desarrollo de coacervados conteniendo alginato-gelatina, se determinó la homogeneidad de la muestra una vez obtenida la matriz gelificada (microesferas entrecruzadas en presencia de calcio). Una porción de la matriz fue colocada en un portamuestra, observado mediante microscopía óptica acoplada a un equipo de detección FTIR en el modo ATR (atenuación total de la reflexión) bajo un haz de luz de Sincrotrón (línea SMIS, Soleil, Francia). 
Preparación de microesferas de alginato como matriz base para la encapsulación de Ciprofloxacina

$\mathrm{Se}$

prepararon

soluciones

acuosas que

contienen $\quad 36,0$

$\mu \mathrm{g} / \mathrm{ml}$ de Cipro y

$2,0 \% \quad(p / v) \quad$ de

alginato,

ajustando el $\mathrm{pH}$ a

diferentes valores

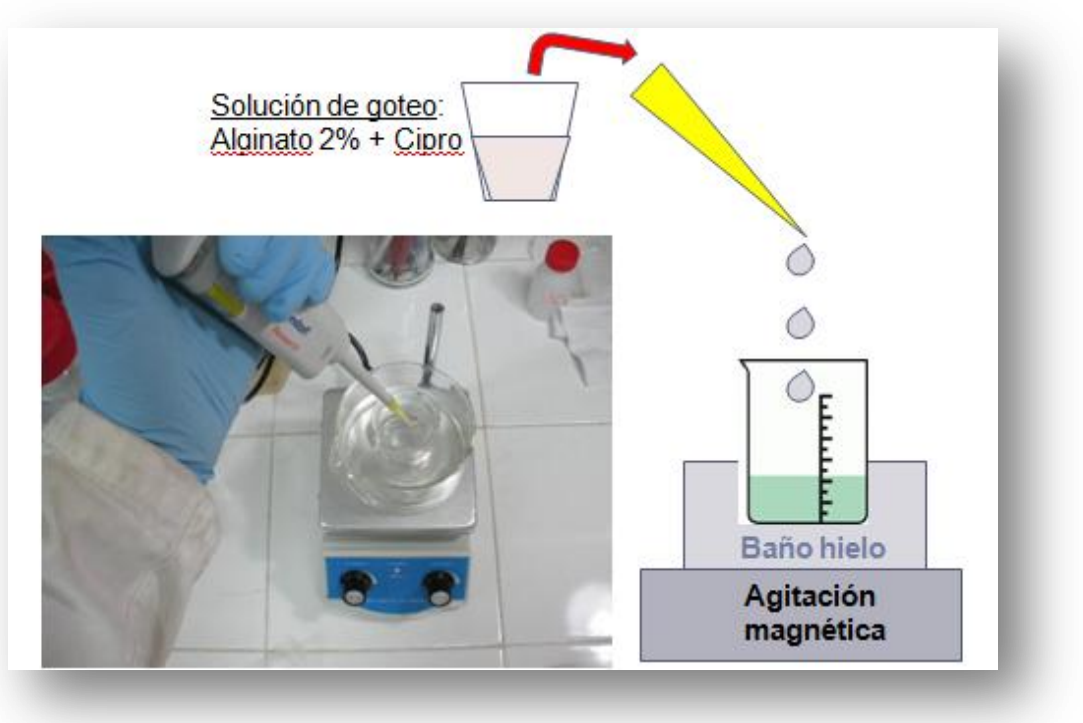

$(4,0,5,0$ y 6,2$)$.

Las microesferas se prepararon mediante la técnica de goteo: un volumen de 2,0 $\mathrm{ml}$ de una solución de alginato/Cipro fue goteada en $10 \mathrm{ml}$ de una solución acuosa de cloruro de calcio. La concentración de $\mathrm{CaCl}_{2}$ estuvo en el rango de 100-500 mM. A su vez, el pH de las soluciones fue ajustado a 4,0, 5,0 o 6,2. Las microesferas se agitaron suavemente en un baño de hielo durante $20 \mathrm{~min}$, para luego ser filtradas, lavadas con agua ultrapura y secadas en papel de celulosa (Whatman \# 1) a $25^{\circ} \mathrm{C}$ durante 5 min.

Con el objeto de determinar cambios en el la cantidad de Cipro encapsulada, las soluciones biopoliméricas conteniendo la Cipro fueron goteadas en soluciones al $25,50,75$ y $100 \%(\mathrm{v} / \mathrm{v})$ de solventes (alcoholes de hasta 3 carbonos, totalmente miscibles con agua): etanol, etilenglicol, 1-propanol y 1,2-propilenglicol.

Alternativamente, se prepararon mezclas de biopolímeros con el antibiótico, conteniendo alginato (en el intervalo de $1,0 \%$ a 2,0\% (p/v)) con pectinas (en el rango de 0,5 a $2,0 \%(p / v))$ y alginato con gelatina $($ al $1,0 \%(p / v))$.

En el caso particular de la mezcla de alginato/gelatina $(2: 1,(\mathrm{p} / \mathrm{v}))$ se prepararon las microesferas en un medio de síntesis conteniendo $\mathrm{CaCl}_{2}(500 \mathrm{mM})$ y glutaraldehído $(2,5 \%,(v / v))$. 


\section{Medición y cálculo del porcentaje de encapsulación de Cipro}

Luego de la síntesis de microesferas, las mismas fueron retenidas en el filtro, mientras que el líquido filtrado fue colectado y su volumen determinado. El contenido de Cipro no encapsulada fue cuantificado en el mismo por espectrofotometría en el máximo de absorción del fármaco (que van desde 270 hasta $280 \mathrm{~nm}$, en función de los valores de $\mathrm{pH}$ o el tipo de solvente). Mediante curvas de calibración del antibiótico respectivas en cada una de las condiciones experimentales fue determinada la cantidad de Cipro libre (no encapsulada), y en base a la cantidad inicial del antibiótico se determinó por diferencia, el porcentaje de encapsulación de la siguiente forma:

$$
\% \text { Enc }=\frac{\mathbf{Q}_{0}-\left(\mathbf{C}_{\mathbf{r}} * \mathbf{V}\right)}{\mathbf{Q}_{0}} * 100
$$

(Ecuación 1)

Donde:

$\mathrm{Q}_{0}=$ Cantidad inicial de Cip

$\mathrm{C}_{\mathrm{r}}=$ Concentración de Cip remanente en la solución filtrada

$V=$ Volumen de la solución filtrada

Por otra parte, el porcentaje de encapsulación fue corroborado pesando 100 $\mathrm{mg}$ de las microesferas recién sintetizadas e incubándolas en 2,0 $\mathrm{ml}$ de solución reguladora fosfato $(100 \mathrm{mM}, \mathrm{pH} 7,40)$ hasta disolución total. La muestra fue centrifugada y la Cipro en el sobrenadante cuantificada por absorbancia en el UV. Teniendo en cuenta la cantidad inicial de Cipro, el peso total de la muestra sintetizada, es posible calcular el porcentaje del fármaco encapsulado.

\section{Saturación de la matriz de base de alginato con Cipro}

Se ensayaron concentraciones crecientes de Cipro encapsulada en la matriz biopolimérica, a fin de ajustar la dosis teniendo en cuenta la relación droga/matriz. Así, soluciones de alginato $(2,0 \% \mathrm{p} / \mathrm{v}))$ conteniendo $36,0-100,0-200,0-500,0-1000,0$ y $2000,0 \mu \mathrm{g} / \mathrm{ml}$ de Cipro, respectivamente, fueron goteadas en soluciones de $500 \mathrm{mM}$ de $\mathrm{CaCl}_{2}$ para formar microesferas mediante el método de gelación iónica. El porcentaje de encapsulación fue determinado como fuera indicado previamente (Ecuación 1). 


\section{Medición de parámetros texturométricos}

La textura de las microesferas fue analizada en un Analizador de Textura TAXT 2i (Stable Micro Systems Ltd, Godalming, UK) equipado con una célula de carga de 25 kg y un plato cilíndrico metálico de compresión de $75 \mathrm{~mm}$ de diámetro (p75). El análisis del perfil de textura (TPA), que consiste en dos ciclos de compresión a 0,6 mm/seg a un $30 \%$ de la altura original de las microesferas. En cada ensayo, tres microesferas fueron simultáneamente comprimidas. Los datos se procesaron con el programa Texture Expert ${ }^{\circledR}$ (Texture Expert, Hamilton, MA) y los parámetros de textura (de dureza y cohesividad) se calcularon a partir la curva TPA de fuerza (N) en función del tiempo (s) con las siguientes definiciones (Bourne y Comstock, 1981): Dureza (N) se define como la fuerza máxima durante el primer ciclo de compresión; cohesividad (adimensional) se define como la relación entre las áreas bajo la segunda y la primer compresión (A2/A1). Los resultados representan los promedios de al menos un triplicado de la muestra.

\section{Microscopía electrónica de barrido (SEM)}

Las microesferas fueron liofilizadas durante 24 horas antes de realizar la microscopía electrónica de barrido (SEM). Luego, las muestras fueron recubiertas en su superficie con oro pulverizado mediante un metalizador Balzers SCD 030 hasta obtener un espesor de capa entre 15 a $20 \mathrm{~nm}$. La superficie y morfología de las microesferas fueron observadas con el equipo Philips SEM 505 (Rochester, EE.UU.), y las imágenes procesadas por un programa digitalizador de imágenes (Soft Imaging System ADDA II $(\mathrm{SIS}))$.

\section{Análisis de superficie de las imágenes de SEM}

Imágenes de SEM fueron analizados con el programa ImageJ (NIH, EE.UU.). La rugosidad de la superficie se determina por la variación en los valores de grises de todos los píxeles de la imagen. En primer lugar, los archivos de imagen de SEM fueron abiertos con el programa y convertidos a una imagen de 8 bits. Luego, se seleccionaron todos los píxeles de la imagen y los parámetros de superficie fueron medidos (histograma, desviación estándar de los valores de grises). Cuanto menor sea el valor 
de la desviación estándar, menos rugosa será la superficie. Los histogramas obtenidos se realizaron por duplicado de las imágenes de SEM con una magnificación de 710x.

\section{Microscopía de fuerza atómica (AFM)}

Todas las imágenes se obtuvieron en condiciones ambientales usando el equipo Multimode-Nanoscope V (Veeco, Santa Barbara, CA) operando en el modo de pequeños pulsos ("tapping") con una sonda de silicio modelo Arrow-NCR-50 Nano World (frecuencia de resonancia del cantiléver: $258 \mathrm{kHz}$, fuerza constante de $42 \mathrm{~N} / \mathrm{m}$; radio de punta de 5-10 nm). Se realizaron barridos a velocidades en el rango de 1,0-1,5 Hz. Debido al tamaño de las microesferas, y a que su concavidad de superficie generaba que la punta del cantiléver se entierre, afectando la señal, las muestras debieron ser preparadas de forma especial. Se utilizó una pieza de vidrio $(1 \mathrm{~cm} \times 1 \mathrm{~cm})$ que fue puesta en contacto con una solución de biopolímero (ej: alginato 2,0\% /gelatina $1,0 \%, \mathrm{p} / \mathrm{v}$ ), para luego ser sumergida en una solución que contiene $500 \mathrm{mM}$ de $\mathrm{CaCl}_{2}$. Los vidrios con el biopolímero entrecruzado en superficie fueron congelados y liofilizados, para su posterior observación por AFM. Las imágenes fueron analizadas con el programa Nanoscope Software 7.30 (Veeco, Santa Barbara, CA).

\section{Cinética de liberación de Cipro a partir de microesferas}

Microesferas húmedas (200 mg) se suspendieron en un buffer adecuado con agitación constante a $100 \mathrm{rpm}$ y $37^{\circ} \mathrm{C}$, simulando las condiciones fisiológicas del tracto gastrointestinal. Se realizó para ello, una cinética de liberación in vitro a un pH gástrico dado por una solución reguladora $\mathrm{KCl} / \mathrm{HCl}(50 \mathrm{mM}, \mathrm{pH} 1,20)$ y otra a $\mathrm{pH}$ intestinal en solución reguladora fosfato de potasio $(40 \mathrm{mM}, \mathrm{pH} 7,40)$. A intervalos de tiempo definidos, un volumen de 1,0 ml fue retirado y se le analizó la absorbancia a la longitud de onda máxima de Cipro en cada solución reguladora (277 y 270 nm, pH 1,2 y 7,4, respectivamente) a fin de evaluar la cantidad de Cipro liberada. Con posterioridad, 1,0 $\mathrm{ml}$ de medio fresco fue repuesto para mantener el volumen del medio de liberación constante. 


\section{Evaluación de la actividad antimicrobiana de las microesferas conteniendo Cipro contra Pseudomonas aeruginosa}

Para determinar que la Cipro es liberada de forma activa desde las microesferas, se realizó una modificación del método de difusión en agar desde discos conteniendo antimicrobianos (antibiograma) establecido por el Comité Nacional de Normas de Laboratorio Clínico (NCCLS, Wayne, PA, EE.UU.) mediante el uso microesferas que contienen Cipro. Las mismas fueron testeadas contra Pseudomonas aeruginosa. Brevemente, se tomaron 4-5 colonias del microorganismo crecido en una placa de agar nutritivo y se resuspendieron en solución fisiológica estéril $(\mathrm{NaCl}$ 0,85\%, $\mathrm{p} / \mathrm{v}$ ), ajustando la turbidez al 0,5 de la escala Mc Farland (escala realizada con diferentes concentraciones de sales de bario para obtener un gradiente de grados de opalescencia). Placas de Petri conteniendo $25 \mathrm{ml}$ de agar Mueller-Hinton fueron inoculadas utilizando un hisopo de algodón estéril embebido con el inóculo en suspensión. En el lapso de los 10 minutos, las microesferas fueron colocadas en la superficie de las placas inoculadas, en contacto íntimo con el agar, y se llevaron a incubación a $37^{\circ} \mathrm{C}$, tiempo a partir del cual se inicia la cinética de liberación de Cipro en placa. A continuación fueron retiradas a cada tiempo (20,40,60, 90, 120, y $180 \mathrm{~min}$ ) una de las microesferas que estaba en contacto con el agar. Una microesfera es dejada durante 24 horas para determinar el 100\% de Cipro liberada desde la misma. Finalmente, las placas se incubaron a $37^{\circ} \mathrm{C}$ durante 24 horas. Las zonas de inhibición fueron determinadas para cada tiempo de contacto de la microesfera y medidas con un calibre. Los ensayos se realizaron por duplicado.

\section{Análisis estadístico}

Los experimentos se llevaron a cabo en dos ensayos independientes por triplicado. Las comparaciones de la media se realizaron mediante análisis de varianza (ANOVA) con un nivel de significación de 5,0\% $(p<0,05)$, seguido por una prueba de Fisher para diferencias significativas a un $p<0,05$. 


\subsection{Resultados y discusión}

\section{Selección de la matriz biopolimérica}

Como fuera mencionado en la introducción del presente capítulo, dentro de los biopolímeros considerados para el desarrollo de una matriz de liberación controlada por vía oral, el alginato es el candidato más fuerte debido a que reúne las características adecuadas. En particular, su propiedad de formar geles resistentes en presencia de calcio, de permanecer prácticamente inalterado a $\mathrm{pH}$ ácido (estomacal) y disolverse en medio alcalino y presencia de iones fosfato (condiciones intestinales) remarca su importancia para la eficiente administración de la Ciprofloxacina al intestino. El aumento de la concentración de calcio durante el proceso de gelificación iónica produce geles de mayor resistencia, debido a un reticulado mayor entre las cadenas de alginato en una disposición espacial tipo "caja de huevos" (Simpson y col., 2004). Su facilidad de manejo en la forma líquida (baja viscosidad) permite la formación de microesferas de tamaño controlado, tal como se

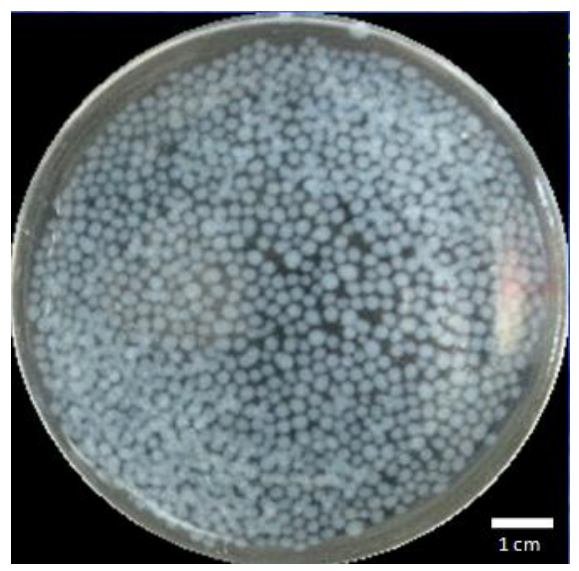
observa en la imagen. Una variable a tener en cuenta, además de la concentración de iones calcio es el $\mathrm{pH}$ al cual se produce la formación de las microesferas. Su relación con la encapsulación de Cipro se ve reflejada en la Tabla 1.

\begin{tabular}{|c|c|c|c|}
\hline \multicolumn{4}{|c|}{$\begin{array}{l}\text { Tabla } 1 \text { Efecto del pH y concentración de } \mathrm{Ca}^{+2} \text { en la } \\
\text { encapsulación de Ciprofloxacina en microesferas de alginato }\end{array}$} \\
\hline$\left[\mathrm{Ca}^{+2}\right]$ & \multicolumn{3}{|c|}{ Encapsulación de Cipro (\%) } \\
\hline \multirow[t]{2}{*}{ (mM) } & \multicolumn{3}{|c|}{ pH } \\
\hline & 4,0 & 5,0 & 6,2 \\
\hline 100 & $42,0 \pm 0,6$ & $44,8 \pm 0,9$ & $40,0 \pm 1,8$ \\
\hline 250 & $45,3 \pm 3,1$ & $42,1 \pm 2,0$ & $38,1 \pm 1,9$ \\
\hline 500 & $46,4 \pm 1,7 *$ & $42,9 \pm 2,9$ & $37,2 \pm 3,7^{*}$ \\
\hline 750 & $46,8 \pm 2,5$ & $42,1 \pm 1,8$ & $37,8 \pm 0,2$ \\
\hline
\end{tabular}


De acuerdo a los resultados de la Tabla 1, el porcentaje de encapsulación (PE) de Cipro no varió significativamente $(p>0,05)$ a $\mathrm{pHs}$ comprendidos entre 4,0 y 5,0 , y alcanzó un valor cercano al $45 \%$ de encapsulamiento. Por otro lado, si bien a simple vista se observaron geles más densos y resistentes, a su vez tampoco se evidenciaron grandes cambios en el PE de Cipro al incrementar la concentración del ion calcio. Sin embargo, fue observada una menor encapsulación de Cipro a pH 6,2 (menor al 40 \%) y al incrementar la concentración de calcio. Estos hechos pueden ser atribuidos teniendo en cuenta dos factores propios de la estructura de la Cipro: por un lado, la interacción del grupo carboxílico de la molécula de Cipro con el ion calcio en solución, formando un complejo de alta solubilidad (Ebokwa y col., 2007), razón por la cual es menos encapsulado en la matriz de alginato (Figura 1.4).

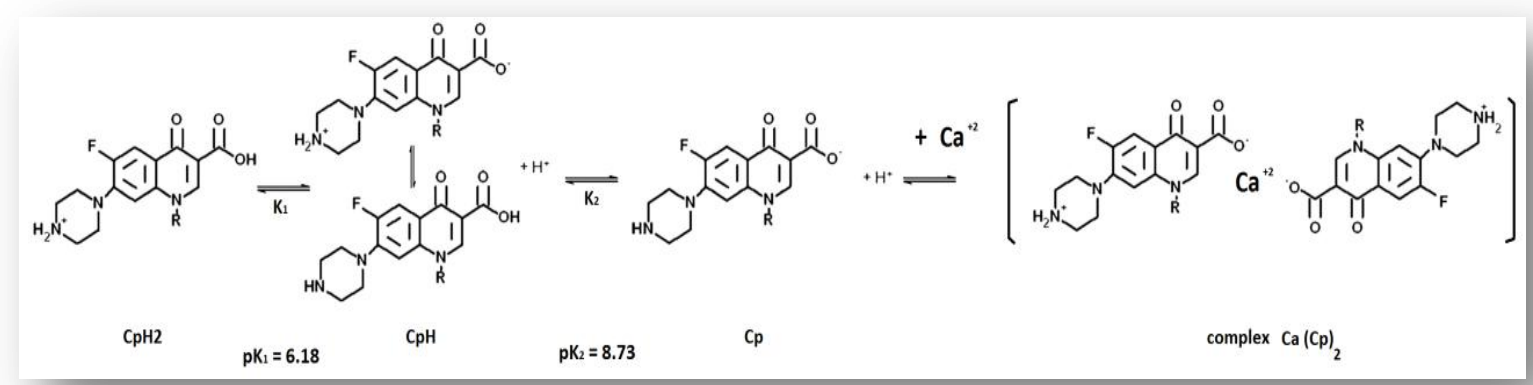

Figura 1.4. Especiación de Ciprofloxacina a diferentes valores de $\mathrm{pH}$ y el desplazamiento del equilibrio hacia la formación de complejos Cipro-calcio a pHs alcalinos (Islan y col., 2012).

Por otro lado, el aumento del pH en la solución genera un incremento en la proporción de estructuras moleculares de Cipro cargadas negativamente (Figura 1.2.a), las cuales son capaces de formar el complejo previamente mencionado. Razón por la cual, el incremento de $\mathrm{pH}$ lleva a una mayor formación del complejo Cipro-Calcio y por consiguiente a una disminución de la Cipro encapsulada en la microesfera de alginato.

La formación de este tipo de complejo no solo que ha sido reportada en bibliografía (Ebokwa y col., 2007), sino que puede ser sencillamente puesta de manifiesto en diferentes condiciones experimentales (Tabla 2). 
Tabla 2 Desplazamiento del máximo de absorción de

Cipro a diferentes pHs por la presencia del ion $\mathrm{Ca}^{+2}$

\begin{tabular}{lccc}
\hline \multicolumn{1}{c}{$\mathrm{pH}$} & \multicolumn{3}{c}{ Longitud de onda máxima $(\mathrm{nm})$} \\
& $\boldsymbol{\lambda}_{\mathbf{1}}$ & $\boldsymbol{\lambda}_{\mathbf{2}}$ & $\boldsymbol{\lambda}_{\mathbf{3}}$ \\
1,20 & 277 & 314 & 330 \\
$1,20+\mathrm{Ca}^{+2}$ & 277 & 314 & 330 \\
12,00 & 271 & 323 & 333 \\
$12,00+\mathrm{Ca}^{+2}$ & 274 & 320 & 330 \\
\hline
\end{tabular}

A pHs ácidos, la molécula de Ciprofloxacina todos sus grupos funcionales se hallan protonados con lo cual es incapaz de formar un complejo con el $\mathrm{Ca}^{+2} \mathrm{y}$ por consiguiente no se observan cambios en los máximos de absorción por espectroscopia UV-visible. En cambio, a pH 12,00 la mayor parte de las moléculas de Cipro se hallan

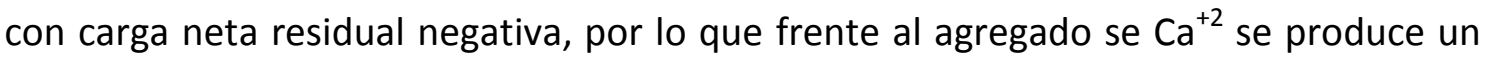
corrimiento de los máximos en $3 \mathrm{~nm}$ de longitud de onda, indicando la formación del complejo Cipro-Ca ${ }^{+2}$ (Figura 1.4).

Para evitar estos inconvenientes, la formulación se realizará a pH 4,0, en donde la formación del complejo es menos favorecida y condición en la cual se obtuvieron los mayores porcentajes de encapsulación de Cipro. Vale aclarar que en los resultados de la Tabla 1 tanto el pH del medio de síntesis como el pH de la formulación fue ajustado al mismo valor.

\section{Optimización de las condiciones de encapsulamiento}

A fin de incrementar el contenido del antibiótico en la matriz de alginato se procedió a sintetizar las microesferas en diferentes condiciones ambientales. Para ello, se modificó la solución de calcio $\left(\mathrm{CaCl}_{2}, 500 \mathrm{mM}\right)$ mediante el uso de solventes miscibles con agua, con la hipótesis de que las propiedades fisicoquímicas del medio ambiente de síntesis tendrán una influencia en la capacidad de la matriz de alginato de encapsular mayores cantidades de Cipro.

De esta forma, los solventes elegidos serán polioles miscibles en agua con una máxima longitud de cadena de 3 carbonos, diferentes grados de hidroxilación, capacidad de solubilizar $\mathrm{CaCl}_{2}$, distintos log $\mathrm{P}$ (coeficiente de reparto de una sustancia 
entre un disolvente hidrofóbico y uno polar/hidrofílico) y tener reducida toxicidad al ser administrados por vía oral y metabolizados por el hígado. Sobre la base de las consideraciones mencionadas fueron seleccionados etanol, etilenglicol (EG), 1propanol, y 1,2-propilenglicol (PG). El metanol fue descartado debido a su toxicidad hepática en mamíferos, donde la alcohol deshidrogenasa genera formaldehido, un compuesto altamente tóxico. Además, no se utilizó glicerol, debido a su elevada viscosidad, lo que dificulta el control del proceso de gelificación. Las propiedades de los solventes selectos se listan en la Tabla 3.

\begin{tabular}{|c|c|c|c|c|c|c|c|}
\hline \multirow[t]{3}{*}{ Solvente } & \multicolumn{2}{|c|}{ Numero de: } & \multirow[t]{3}{*}{$\log P$} & \multirow{3}{*}{$\begin{array}{c}\text { Viscosidad } \\
\text { (Cpoise) } \\
\text { a } 25^{\circ} \mathrm{C}\end{array}$} & \multirow{3}{*}{$\begin{array}{l}\text { Momento } \\
\text { dipolar } \\
\text { (Debye) }\end{array}$} & \multirow{3}{*}{$\begin{array}{l}\text { Constante } \\
\text { dieléctrica }\end{array}$} & \multirow{3}{*}{$\begin{array}{c}\text { Solubilidad Cipro } \\
\left(\mathrm{mg} \mathrm{m}^{-1}\right) \\
\text { at } 20^{\circ} \mathrm{C}\end{array}$} \\
\hline & $\mathrm{C}$ & $-\mathrm{OH}$ & & & & & \\
\hline & & & & & & & \\
\hline Etanol & 2 & 1 & $-0,31$ & 1,07 & 1,71 & 25,70 & 0,13 \\
\hline Etilenglicol & 2 & 2 & $-1,36$ & 14,78 & 2,28 & 38,00 & 45,15 \\
\hline 1-Propanol & 3 & 1 & 0,28 & 1,95 & 1,68 & 20,00 & 0,40 \\
\hline 1,2-Propilenglicol & 3 & 2 & $-0,92$ & 45,70 & 3,70 & 32,00 & 7,41 \\
\hline
\end{tabular}

Considerando que la Cipro es una molécula con carácter hidrofóbico (log P= $2,3)$ se espera que la encapsulación en un ambiente altamente hidrofílico se vea favorecida. Un log $\mathrm{P}$ positivo de la molécula sugiere la capacidad de difundir a través de las biomembranas (siempre y cuando el valor de log $\mathrm{P}$ no exceda el límite de 5), pero que el fármaco podría ser simplemente insoluble o agregado en medio acuoso, y en especial, en la ausencia de un vehículo adecuando (Botté y col., 2012). En la lista de la Tabla 3 se podría especular que los mejores candidatos para darle un ambiente más hidrofílico a la encapsulación son el etilenglicol y el 1,2-propilenglicol.

Se realizó la encapsulación ensayando cantidades crecientes $(25,50,75$ y $100 \%$, $\mathrm{v} / \mathrm{v}$ ) de los mencionados solventes en las condiciones experimentales antes mencionadas. En todos los casos, el porcentaje de encapsulación fue mayor al 50\%, superando así, los valores obtenidos con microesferas de alginato sintetizadas en medio acuoso (Tabla 4). Este hecho podría deberse no sólo a la variación de las propiedades fisicoquímicas de las soluciones (viscosidad, momento dipolar, constante 
dieléctrica, o solubilidad de Cipro en dichas condiciones), sino también a un proceso de deshidratación de la matriz de gel alginato producida el efecto higroscópico de los alcoholes de bajo peso molecular. Además, la interacción entre el calcio y las cadenas de alginato se ve reforzada por el proceso de deshidratación y debido a una contracción de la matriz de gel. Por otro lado, se ve disminuido la difusión de la Cipro iónica desde el interior del gel hacia el entorno de encapsulación. Por otro lado, no fueron observados cambios significativos $(p>0,05)$ en la encapsulación de Cipro por el aumento de la concentración de solvente en la mezcla mayor al 50\% (v/v).

Tabla 4 Encapsulación de Cipro mediante el empleo de ingeniería de solventes

\begin{tabular}{cccccc} 
Proporción de & \multicolumn{5}{c}{ Encapsulación de Cipro (\%) } \\
Solvente (\%, v/v) & Acuoso & Etanol & Etilenglicol & 1-Propanol & 1,2-Propilenglicol \\
25,0 & - & $65,5 \pm 3,7$ & $51,0 \pm 1,5^{\text {a) }}$ & $59,3 \pm 4,0$ & $74,6 \pm 3,1^{\text {a) }}$ \\
50,0 & - & $68,2 \pm 1,3$ & $64,0 \pm 2,3$ & $58,3 \pm 4,5$ & $96,4 \pm 3,9$ \\
75,0 & - & $68,7 \pm 2,4$ & $65,8 \pm 3,5$ & $55,5 \pm 4,8$ & $99,9 \pm 0,2$ \\
100,0 & $46,4 \pm 1,7$ & $65,0 \pm 2,7$ & $73,0 \pm 1,7^{\text {b) }}$ & $51,8 \pm 4,2$ & $99,0 \pm 0,8$ \\
\hline
\end{tabular}

Los superíndices indican diferencias significativas con los valores de cada columna $(p<0,05)$

Otro factor relevante a considerar para la encapsulación de Cipro fueron los cambios de la viscosidad en el caso de los algunos de los alcoholes ensayados. Por ejemplo, las soluciones que contienen $25,50,75$ y $100 \%$ (v/v) de etilenglicol poseen viscosidades aproximadamente 1,9,5,3, 7,3 y 40 veces mayores que el agua respectivamente a $0^{\circ} \mathrm{C}$ (Tabla 5). Además, se puede observar una relación lineal entre el aumento de la proporción de etilenglicol en agua y la encapsulación de Cipro en la matriz de alginato $\left(R^{2}=0,96\right)$. Este resultado puede ser explicado en términos de los coeficientes de difusión en Cipro en las soluciones orgánicas/acuosas que van disminuyendo con el aumento de la viscosidad de la mezcla. Por otra parte, la viscosidad en mezclas de PG al 25, 50, 75 y $100 \%$ (v/v) se incrementa drásticamente en $4,12,45$, y 140 veces en relación con la del agua (a $0^{\circ} \mathrm{C}$ ). Este caso es de particular interés debido a que en una solución de PG/agua 50:50 debido a la encapsulación de Cipro fue cercana al $100 \%$, lo que podría atribuirse al aumento de viscosidad a esa concentración de solvente. En los casos de etanol y 1 -propanol, la viscosidad de la 
mezcla aumenta alrededor de cuatro y dos veces respectivamente en comparación con la del agua cuando la concentración de los solventes está en el intervalo de $25-50 \%$ $(v / v)$ y se observan porcentajes de encapsulación en el rango de 60 y $70 \%$. A raíz de todas estas observaciones, es interesante destacar que la encapsulación de Cipro puede aumentar (respecto de la encapsulación en medio acuoso) cuando las viscosidades de las soluciones aumentan al menos el doble de la viscosidad del agua (Figura 1.5.a).
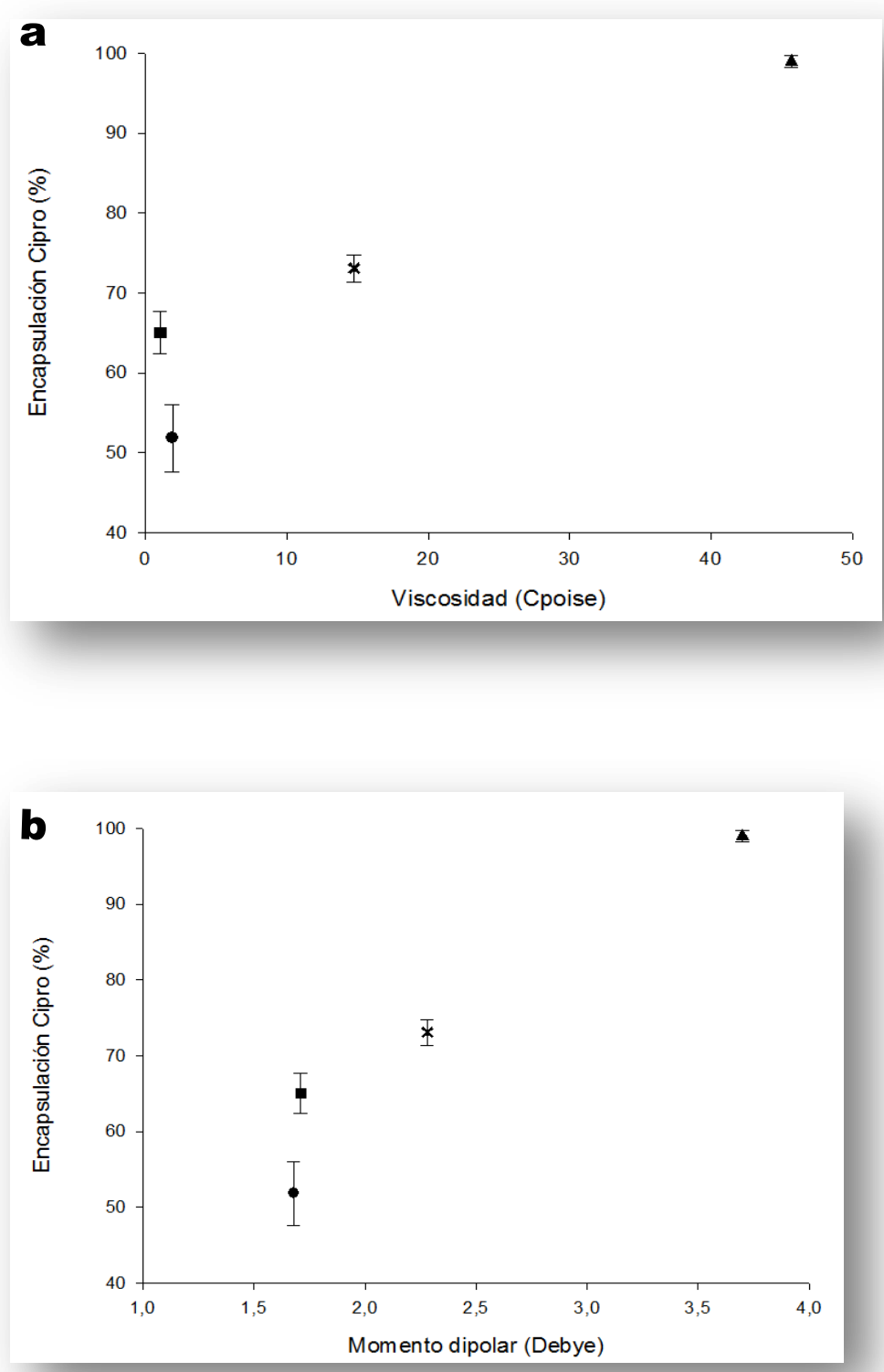

Figura 1.5. Relación entre la encapsulación de Cipro y las propiedades fisicoquímicas de los solventes puros utilizados durante la síntesis de microesferas: a) viscosidad; b) momento dipolar. Solventes: etanol ( $\mathbf{\square})$, etilenglicol (x), 1-propanol $(\bullet)$ y propilenglicol $(\mathbf{\Delta})$. 
Asimismo, fue estudiada la relación entre la encapsulación de Cipro y otras propiedades fisicoquímicas de los polioles puros tales como momento dipolar, constante dieléctrica y solubilidad de Cipro (Tabla 3). Se observó un aumento en la encapsulación al incrementar el momento dipolar de los solventes (el valor máximo corresponde al PG que con un momento dipolar de 3,70 Debye alcanza un $100 \%$ de eficiencia de encapsulación). El momento dipolar proporciona información sobre la distribución de las cargas eléctricas de las moléculas, estos resultados sugieren que las moléculas de solvente con un alto momento dipolar pueden actuar como puentes entre la matriz (con carga negativa) y la Cipro (positiva), reteniendo mayor cantidad de droga en la matriz durante la encapsulación (Figura 1.5.b). Por el contrario, fue difícil establecer una relación con la constante dieléctrica (parámetro que define la solvatación, y la capacidad de estabilización de cargas). No obstante, se observó que los porcentajes de encapsulación fueron superiores al $70 \%$ en solventes cuyas constantes dieléctricas estaban en el rango de 30 a 40 unidades. Finalmente, no se observó correlación entre la solubilidad de Cipro en los solventes del medio de gelificación y su encapsulación en la matriz de alginato, al menos con los solventes testeados.

A raíz del presente estudio, se establecieron las condiciones de encapsulación, un medio de síntesis conteniendo $\mathrm{CaCl}_{2}(500 \mathrm{mM})$ en 1,2-propilengicol y fueron determinadas las concentraciones de solvente de acuerdo a los experimentos que se mencionan a continuación.

\begin{tabular}{c|ccccc}
\hline \multicolumn{5}{c}{ Tabla 5 Viscosidades de mezclas de soluciones acuosas/solvente a $0^{\circ} \mathrm{C}$} \\
\hline $\begin{array}{c}\text { Proporción de } \\
\text { solvente }(\%, v / v)\end{array}$ & Agua & Etanol & Etilenglicol & 1-Propanol & 1,2-Propilenglicol \\
25,0 & - & 6,13 & 3,40 & 3,35 & 7,16 \\
50,0 & - & 6,58 & 9,49 & 4,37 & 21,48 \\
75,0 & - & 4,23 & 13,07 & 4,11 & 80,55 \\
100,0 & 1,79 & 1,77 & 71,60 & 3,20 & 250,60 \\
\hline
\end{tabular}




\section{Análisis morfológico de las microesferas en medio de síntesis con propilenglicol}

Con el objetivo de establecer el efecto del propilenglicol sobre la formación de la matriz de alginato, se estudiaron los cambios morfológicos y superficiales de las microesferas observados por microscopia electrónica de barrido (SEM) (Figura 1.6). Las imágenes de microesferas de alginato $(2,0 \%, p / v)$ conteniendo Cipro y producidas en una solución de $\mathrm{CaCl}_{2}$ en medio acuoso, revelaron una matriz con baja estabilidad al proceso de deshidratación por liofilización, generando efectos de superficie y grietas que atraviesan la muestra (Figura 1.6. a-b). Por otro lado, la síntesis en presencia de una solución PG/agua 50:50 en presencia de cloruro de calcio produjo micropartículas con una mayor morfología esférica y una superficie más homogénea (Figura 1.6. c- d). Al aumentar la concentración de PG en el medio de síntesis al 100\% (v/v), se generaron partículas que mantenían la esfericidad, pero se observaron pliegues en superficie en diversas zonas de la muestra (Figura 1.6. e-f). Estos resultados sugieren que la presencia de PG en la síntesis, facilitaría la estabilización de la matriz y ejercería un efecto crio-protector durante le proceso de congelado y posterior liofilizado de la matriz. Por otro lado, se estableció un retardo de la difusión, no solo de la Cipro desde la matriz en formación hacia el medio de síntesis (con lo cual el porcentaje de encapsulación resulta elevado) sino también de los iones calcio desde el medio de síntesis hacia el interior de la microesfera. Por este motivo, al incrementar al $100 \%$ la concentración de PG, el porcentaje de encapsulación se mantiene en el orden del $100 \%$, pero el retardo en la difusión de iones $\mathrm{Ca}^{+2}$ genera una disminución de la reticulación del gel, dando como resultado patrones de plegamiento irregular en superficie.
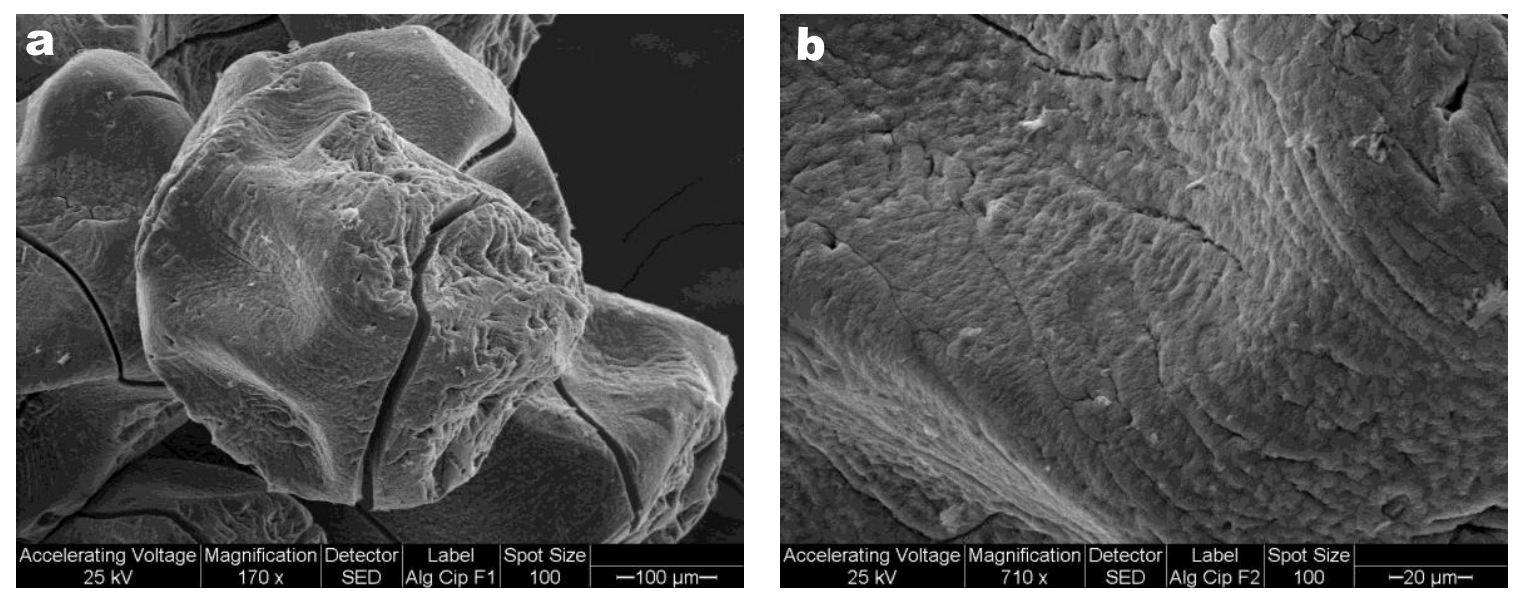

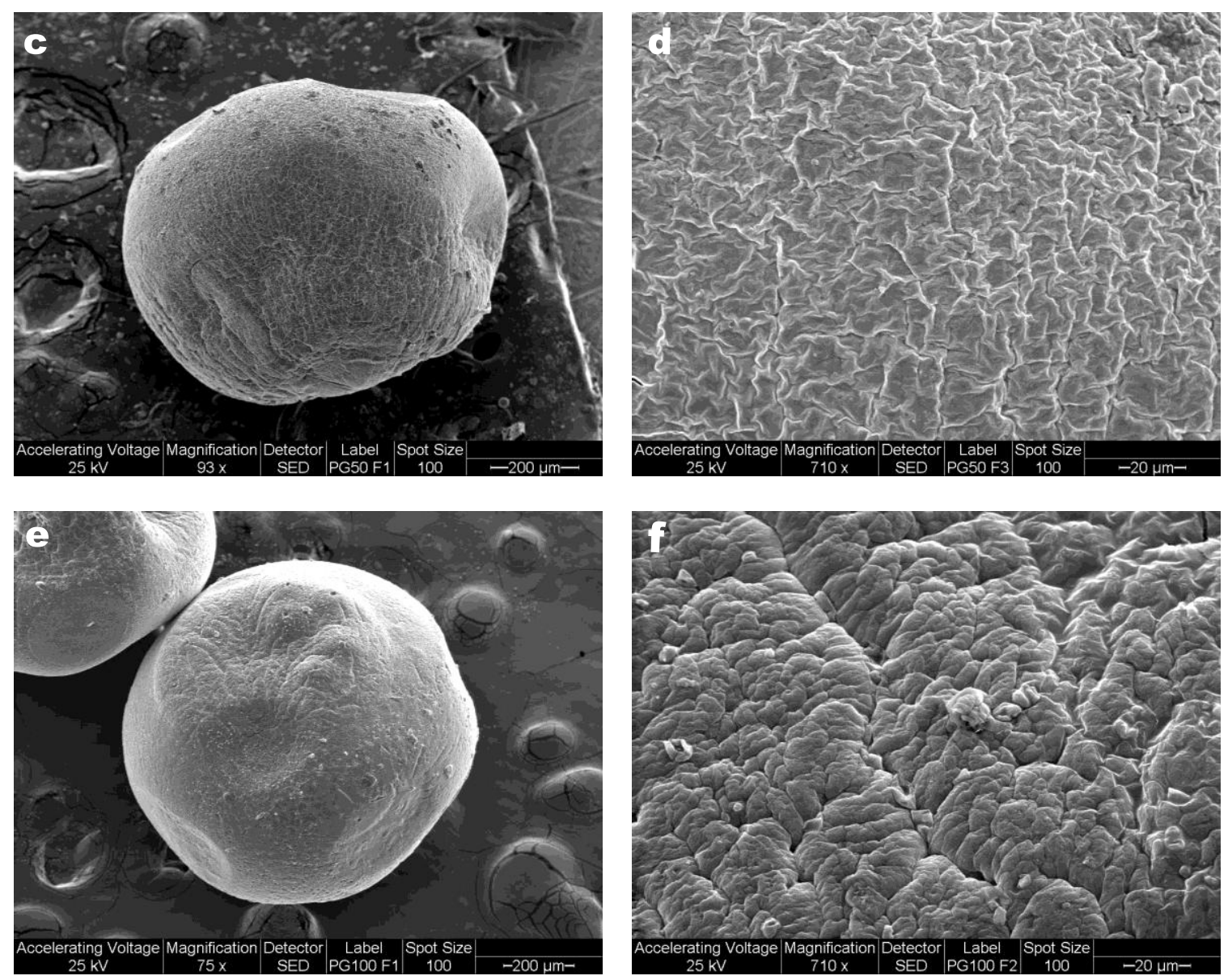

Figura 1.6. Imágenes de SEM: efecto de la concentración de PG $(\%, v / v)$ en la morfología y la superficie de microesferas de alginato: PG 0\% a 170x (a) y 710x (b); PG 50\% a 93x (c) y 710x (d); PG $100 \%$ a $75 x$ (E) y $710 x$ (f) de ampliación.

Mediante el análisis cuantitativo de las imágenes SEM con el programa ImageJ, se corroboró lo observado previamente, considerando que la rugosidad de la superficie está vinculada con un aumento en la variación estándar de la valores de grises de todos los pixeles de la imagen de SEM (Tabla 6). Un valor de desviación estándar baja se correlaciona con una superficie de la microesfera menos rugosa (Wang y col., 2005). La formación de microesferas de alginato con concentraciones crecientes de PG, puso de manifiesto un aumento de la rugosidad superficial, tal como refleja el aumento en los valores de desviación estándar de la Tabla 6. El valor de la media calculada se relaciona con la estructura espacial de la alineación de las cadenas de polímero. Sin embargo, el tratamiento con PG no estaría afectando la alineación espacial de las cadenas de alginato, con una distribución parecida de la escala de grises, tal como se muestra en los histogramas de la tabla (no se observaron diferencias $(p>0,05))$. 


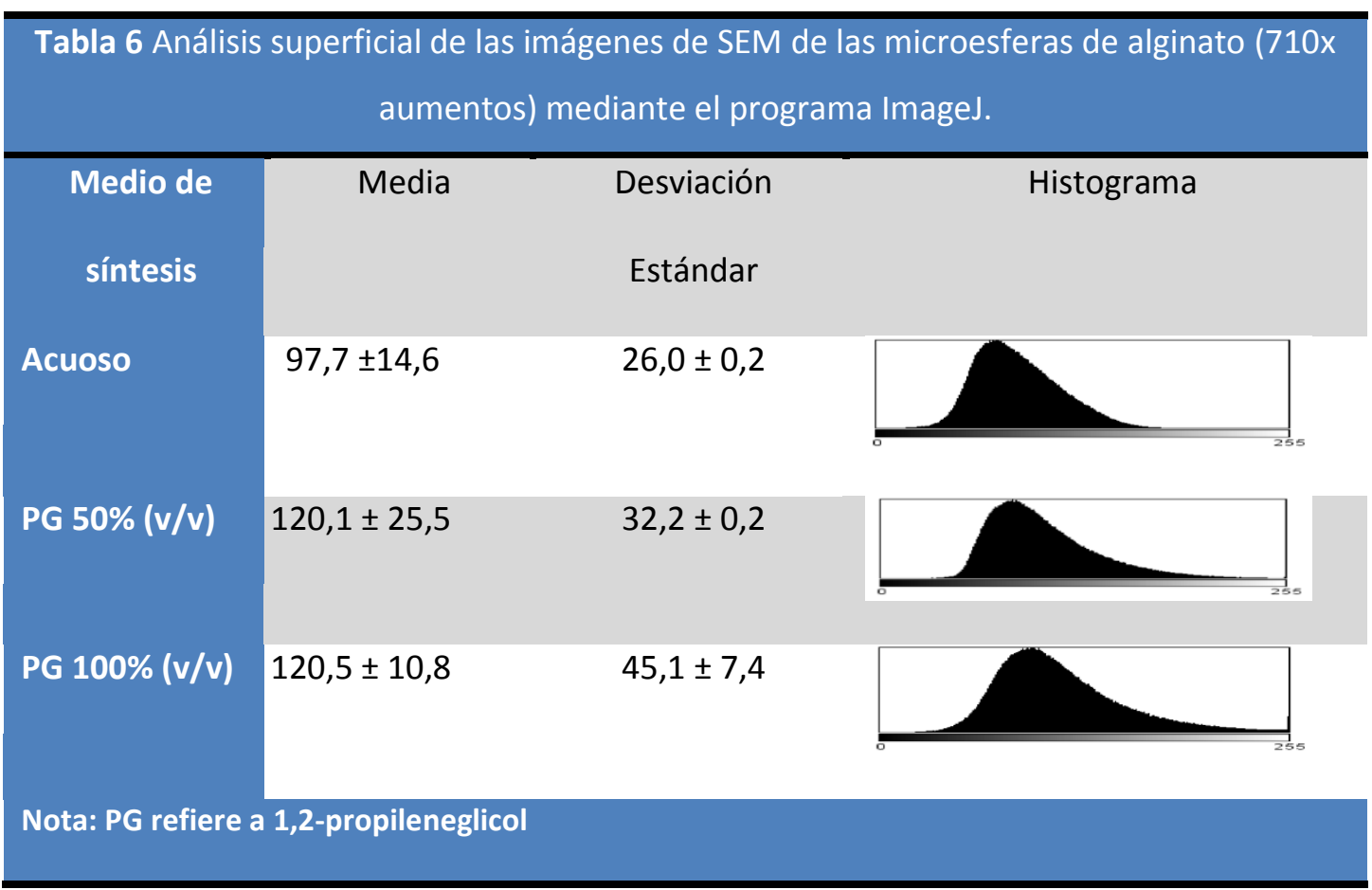

En base a los resultados obtenidos en la encapsulación de Cipro y los análisis superficiales de las imágenes de SEM de las microesferas, se seleccionara como medio óptimo de síntesis, una solución de calcio con PG al 50\%. Por un lado, éste medio de síntesis proporciona un elevado porcentaje de encapsulación del fármaco $(96,4 \pm 3,9$ $\%)$ y por otro, no afecta la estabilidad de la matriz, en el sentido que le ofrece crioprotección a la liofilización, sin generar irregularidades en superficie.

\section{Saturación de la matriz de alginato con concentraciones crecientes de Cipro}

Se evaluó si la matriz de alginato desarrollada en presencia de PG $50 \%$ era capaz de incorporar crecientes concentraciones de Cipro (Tabla 7).

\begin{tabular}{|c|c|c|}
\hline \multicolumn{3}{|c|}{$\begin{array}{l}\text { Tabla } 7 \text { Eficiencia de encapsulación de Cipro en microesferas de } \\
\text { alginato con concentraciones inciales crecientes de Cipro. }\end{array}$} \\
\hline \multicolumn{2}{|c|}{ Concentración de Cipro ( $\mu \mathrm{g} \mathrm{ml}^{-1}$ ) } & \multirow{2}{*}{$\begin{array}{c}\text { Eficiencia de } \\
\text { encapsulación }(\mathrm{CE} / \mathrm{Cl})\end{array}$} \\
\hline Inicial (CI) & Encapsulada (CE) & \\
\hline 36,0 & $34,7 \pm 1,4$ & 0,96 \\
\hline 100,0 & $71,0 \pm 1,7$ & 0,71 \\
\hline 200,0 & $142,0 \pm 1,2$ & 0,71 \\
\hline 500,0 & $378,5 \pm 0,5$ & 0,77 \\
\hline 1000,0 & $797,0 \pm 32,0$ & 0,80 \\
\hline 2000,0 & $1794,0 \pm 136,0$ & 0,90 \\
\hline
\end{tabular}


Se observó que la cantidad de antibiótico encapsulado en la matriz después del proceso de gelificación iónica aumentó linealmente $\left(r^{2}=0,996\right)$ cuando la concentración inicial de antibiótico en la mezcla no entrecruzada fue aumentada. Sin embargo, no se encontró un punto de saturación, incluso a altas concentraciones de hasta $2,0 \mathrm{mg} / \mathrm{ml}$ de Cipro inicial. A medida que se incrementó la cantidad inicial de Cipro en solución hasta $200 \mu \mathrm{g} / \mathrm{ml}$, se observó que la eficiencia de encapsulación disminuyo hasta un valor del $71 \%$. Esto podría deberse a una posible saturación de los sitios de interacción propiciados por el alginato para retener el antibiótico. No obstante, a partir de concentraciones iniciales de $500 \mu \mathrm{g} / \mathrm{ml}$ de antibiótico se determinó un incremento de los porcentajes de encapsulación por encima del 77\%. Esta elevada encapsulación podría deberse a un proceso de apilamiento $\pi$ entre las moléculas de Cipro, fenómeno comúnmente asociado a este tipo de antibióticos como se mencionara en la introducción del presente capítulo. Este proceso de apilamiento genera que un mayor número de moléculas de Cipro puedan ser incorporadas a la matriz, mediante una interacción especifica Cipro-Cipro y no una Cipro-alginato. Se trata de una interesante ventaja de la matriz, porque la dosis se puede ajustar alterando las concentraciones iniciales de Cipro en solución, obteniendo elevados porcentajes de encapsulación y diferentes radios de masa de droga-matriz.

\section{Ensayos de liberación de Cipro desde microesferas de alginato en condiciones fisiológicas simuladas para administración oral}

Se evaluó la liberación de Ciprofloxacina desde las microesferas en ambientes fisiológicos simulados del tracto gastrointestinal: $\mathrm{pH}$ gástrico $(1,20)$ y $\mathrm{pH}$ intestinal $(7,40)$. Fue estudiado el efecto de la síntesis sobre la liberación, comparando las microesferas sintetizadas en medio acuoso con las sintetizadas en presencia de PG $50 \%(v / v)$. Las primeras, mostraron una liberación total a las dos horas de ensayo, mientras que las segundas liberaron el $85,1 \pm 4,1 \%$ en el mismo periodo de tiempo (Figura 1.7.a). 

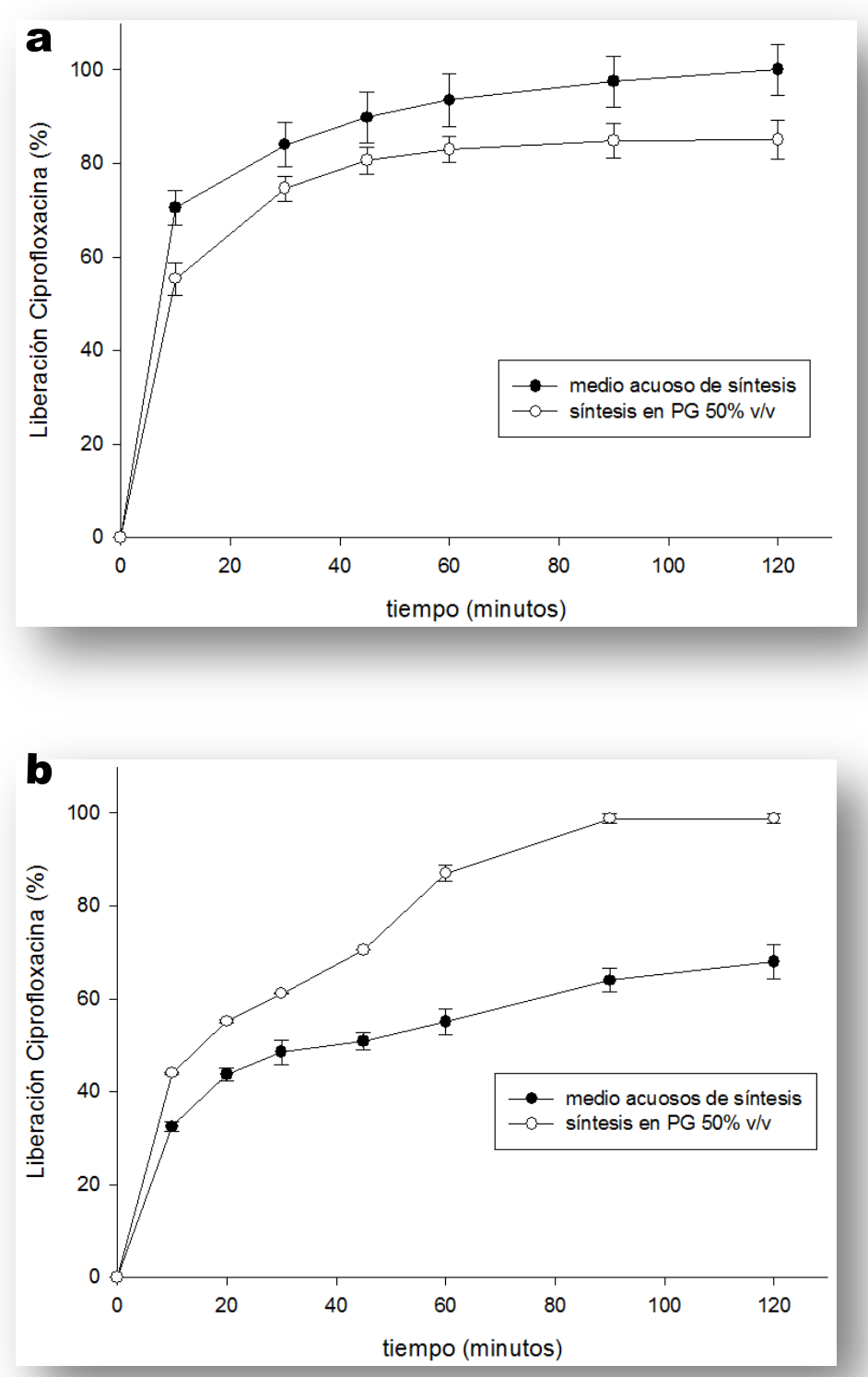

Figura 1.7. Ensayos de liberación de Ciprofloxacina desde microesferas de alginato sintetizadas en medio acuoso o en presencia de PG 50\% (v/v). a) liberación a $\mathrm{pH}=1,20$ (gástrico); b) liberación a $\mathrm{pH}=7,40$ (intestinal).

Por otra parte, las liberaciones a $\mathrm{pH}$ intestinal presentaron comportamientos diferentes. Las microesferas sintetizadas en presencia de PG 50\% (v/v), mostraron una liberación del 98,7 $\pm 1,1 \%$ de Cipro en dos horas. Por el contrario, las microesferas preparadas en medio acuoso liberaron al menos un 30\% menos de Cipro en las mismas condiciones experimentales. Esta diferencia puede deberse en parte a la diferencia de carga de las microesferas (la de PG 50\% cargan al menos el doble que las sintetizadas en medio acuoso). Además es probable que se pueda explicar teniendo en cuenta el 
grado de reticulación de cada matriz. Las microesferas sintetizadas en PG 50\% liberan el fármaco rápidamente a $\mathrm{pH}$ alcalino (y en presencia de iones fosfato) debido al débil grado de entrecruzamiento de la matriz. El medio viscoso generado por la presencia del PG, genera un retardo en la difusión de los iones calcio hacia la matriz durante la formación del gel. Como consecuencia, la matriz resulta más erodable en presencia de agentes secuestradores de iones calcio (como el fosfato) y, por lo tanto, libera más rápidamente la Cipro.

Para confirmar dicha teoría, fue realizada una liberación de Cipro en matrices sintetizadas en soluciones de $\mathrm{Ca}^{+2}(500 \mathrm{mM})$ conteniendo PG $50 \%(\mathrm{v} / \mathrm{v})$ pero maduradas a distintos tiempos (Tabla 8).

\begin{tabular}{cc}
\hline \multicolumn{3}{|c}{ Tabla 8 Liberación de Cipro desde } \\
microesferas de alginato maduradas a \\
distintos tiempos
\end{tabular}

Un aumento del tiempo de maduración de las microesferas, genera un aumento en el grado de reticulación de la matriz, lo cual puede asociarse directamente con una mejorada estabilidad y menor capacidad de ser erosionada por el medio alcalino y presencia de fosfato (condiciones intestinales simuladas). A raíz de ello, se observa que a medida que se aumenta el tiempo de maduración, menor es la liberación de Cipro (evaluada a un tiempo determinado, en este caso 45 minutos). Las microesferas sintetizadas en PG 50\% durante 20 minutos, mostraron una liberación al menos $20 \%$ superior al de las microesferas preparadas en medio acuoso. Al aumentar el tiempo de maduración, las microesferas alcanzan una liberación muy similar a la de las microesferas de medio acuoso. Esto ocurre exactamente a los 150 minutos de maduración de las microesferas, es decir, un tiempo cerca de 7,5 veces mayor que el de la síntesis en agua. Estos resultados, confirman el efecto de retardo del PG durante la formación de gel de microesferas, no sólo en la difusión de la Cipro durante el 
proceso de encapsulación, sino también en la penetración de calcio durante el desarrollo de la matriz.

No obstante, los perfiles de liberación obtenidos no son los ideales, por lo que se realizarán estudios adicionales en la formulación a fin de reducir la liberación de Cipro por debajo del $50 \%$ en condiciones de pH estomacal. De esta forma, se evitaría la pérdida del antibiótico en dicha región y aumentaría su biodisponibilidad en el sitio de absorción (intestino).

Optimización de las condiciones de liberación mediante el empleo de mezclas de biopolímeros

El primer acercamiento para reducir la rápida liberación de Cipro al pH ácido y de esta forma incrementar la cantidad de antibiótico dentro de la matriz hasta su llegada al intestino, consistirá en una nueva formulación compuesta por una mezcla de alginato con otro biopolímero de naturaleza hidrofílica pero que posea sitios de hidrofobicidad en su cadena, en donde la Cipro pueda ser incorporada de forma más eficiente.

En este sentido, y como fuera descrito en la introducción general, dos biopolímeros serán tenidos en cuenta: las pectinas y la gelatina. Las pectinas poseen zonas metoxiladas a lo larga de su cadena, que aportan zonas de hidrofobicidad. Por su parte, la gelatina, al ser una proteína, posee regiones constituidas por residuos de aminoácidos con carácter hidrofóbico.

Para la realización de las mezclas biopoliméricas, primero se ensayará la posible interacción del biopolímero adicionado con la Cipro, para luego constituir la matriz final y evaluar su liberación. 


\section{Incorporación de pectinas a la matriz}

Mediante el ensayo de interacción por precipitación (descripto en materiales y métodos del presente capítulo) se determinó que tipo de pectina (con diferentes grados de metoxilación) era la que presentaba una mayor interacción con la Cipro (Figura 1.8). De acuerdo a los resultados anteriores (Tabla 1) el pH óptimo para armar la formulación era de 4,00, motivo por cual las interacciones entre Cipro y pectinas se realizaron al mencionado $\mathrm{pH}$. La unión entre el alginato $(2,0 \%, \mathrm{p} / \mathrm{v})$ y la Cipro se produjo en un 47,2\% y aumentó 1,5 veces (a 71,1\%) cuando la concentración de alginato pasó de $2,0 \%$ a 3,0\%. Los datos sugieren que la principal interacción en esas condiciones entre Cipro y alginato sería principalmente a través de fuerzas electrostáticas, dado que a $\mathrm{pH} 4,00$ el alginato posee todos los grupos carboxilos ionizados y por lo tanto una carga negativa en la molécula. Por otro lado, la Cipro posee carga positiva (si el pH del medio es menor a su pKa de aproximadamente 6,1 ) y que posee sus grupos ionizables (carboxilo y amino) en el estado protonado.

Sin embargo, las interacciones entre la Cipro con las pectinas resultaron ser más eficientes que las interacciones con el alginato. Con solo una concentración del $1,0 \%(\mathrm{p} / \mathrm{v})$ de las pectinas (en lugar del $2,0 \%$ de alginato) se observa un grado de interacción con Cipro superiores al 40\%. En particular, se encuentran diferencias significativas $(p<0,01)$ entre la pectina $\operatorname{BM}(43,1 \pm 1,7 \%)$ y la pectina $\operatorname{AM}(52,0 \pm 2,3 \%)$. Estas diferencias podrían explicarse considerando el grado de metoxilación de ambas. Los resultados sugieren la presencia de más de un tipo de interacción, y no solo a través de una interacción iónica con Cipro (recordemos que la pectina se encuentra cargada negativamente en esas condiciones experimentales), sino que pueden intervenir las regiones metoxiladas de la pectina, los cuales se denominan bolsillos hidrofóbicos y permitirían una posible localización de la Cipro. Por este motivo, la pectina AM sería un buen candidato para desarrollar un coacervado con la matriz base de alginato. Si bien los coacervados alginato-pectinas no mostraron entre ellas diferencias significativas $(p>0,05)$ en la interacción con Cipro, la interacción total resultó cercana al $100 \%$ y al menos un $15 \%$ mayor que la de alginato al $3,0 \%(p / v)(p<$ $0,05)$. 


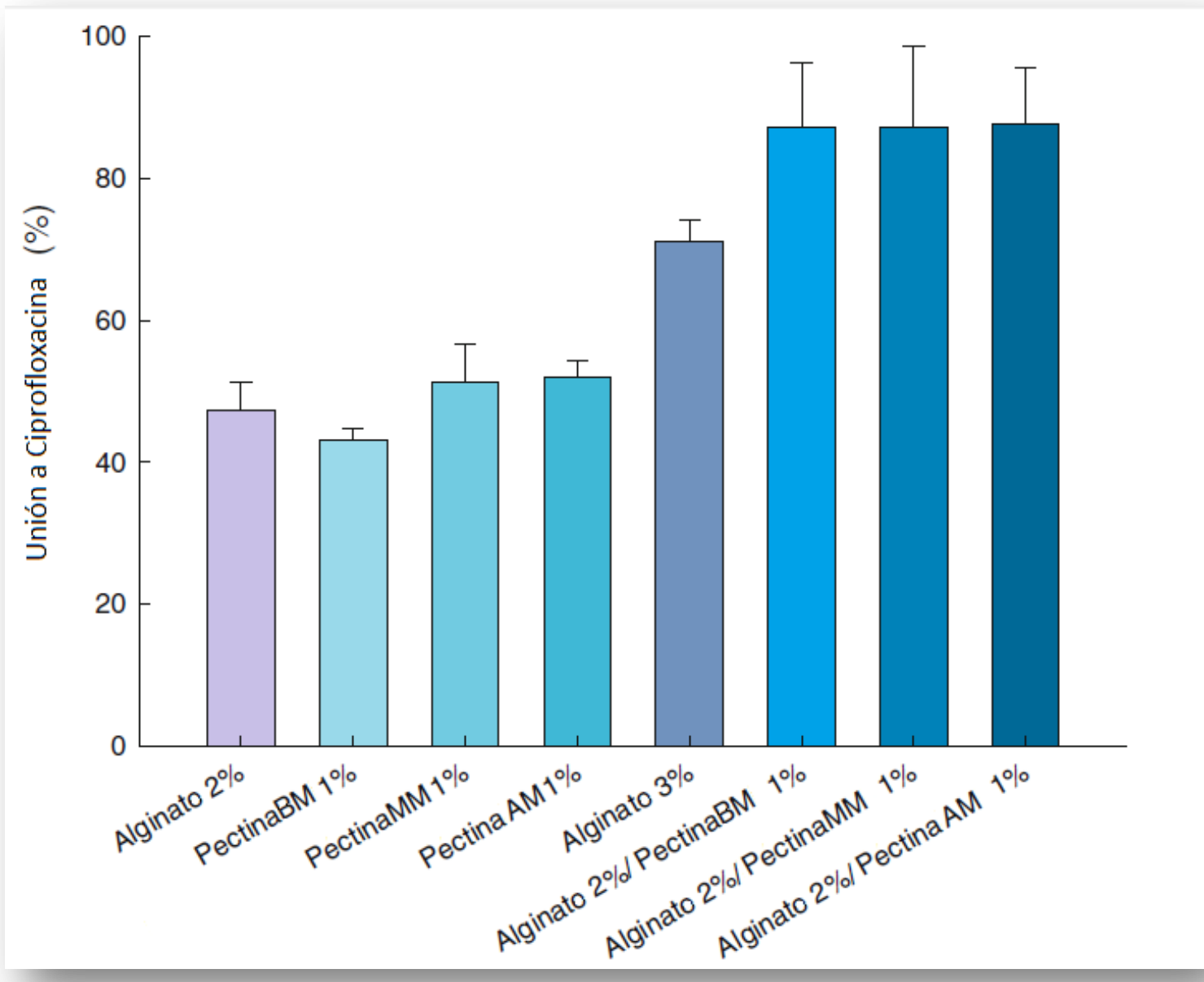

Figura 1.8. Ensayos de interacción entre Ciprofloxacina y biopolímeros a $\mathrm{pH} 4,0$. Los grados de metoxilación de la pectina se abreviaron como: BM (bajo); MM (medio) y AM (alto).

A fin de corroborar el tipo de interacción establecida entre la Cipro y la pectina de alto metoxilo, se llevó a cabo un análisis de FTIR de los componentes puros y de una mezcla de ambos en diferentes proporciones (Figura 1.9). 

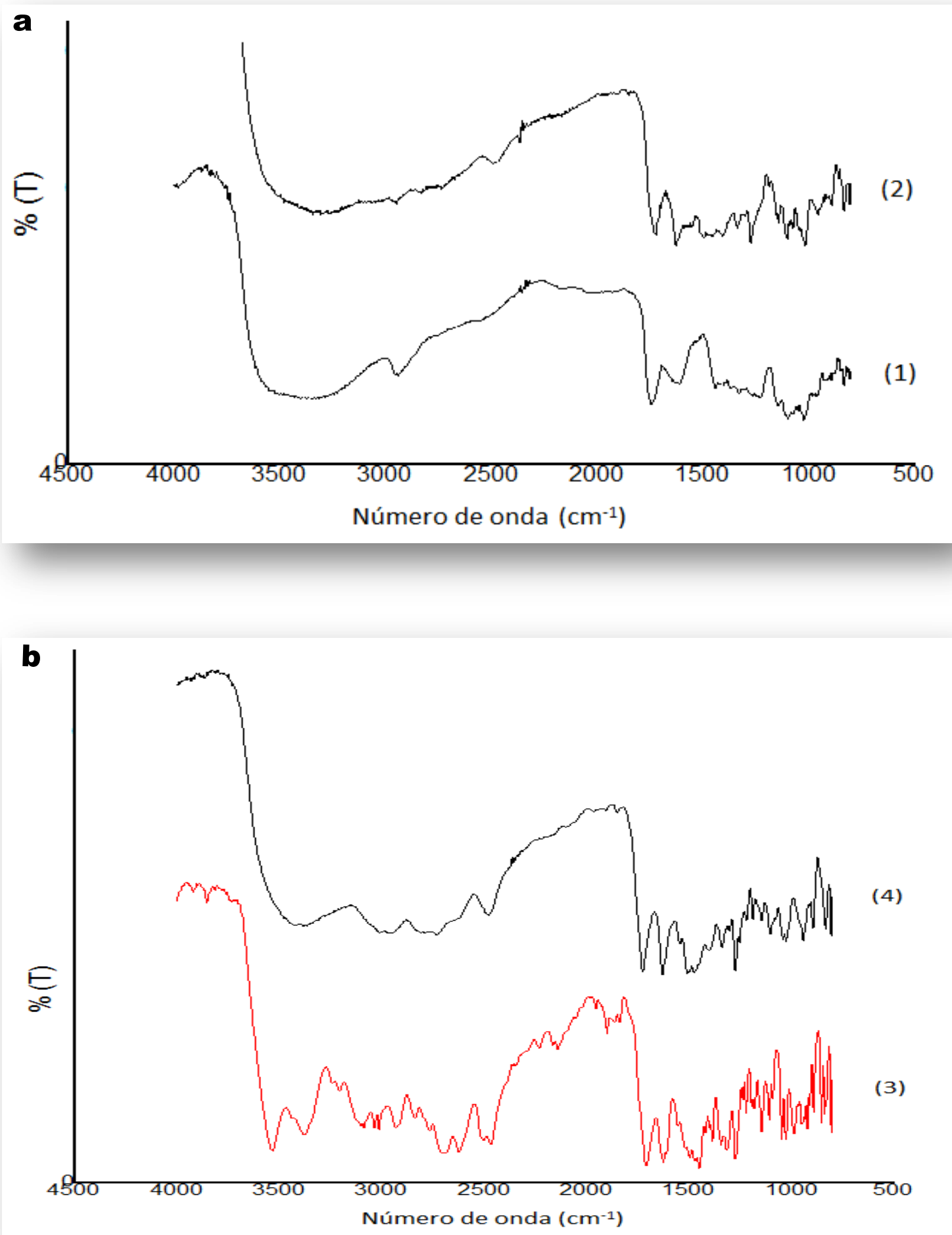

Figura 1.9. Espectros de FTIR de pectina de alto metoxilo (PAM), Ciprofloxacina y mezclas de ambos. a) espectro de pectina de alto metoxilo pura (1) y una mezcla PAM $1 \%$ - Cipro $1 \%(p / p)(2)$. b) espectro de Ciprofloxacina pura (3) y una mezcla PAM $1 \%$ - Cipro $4 \%(p / p)$.

La parte "a" de la figura muestra el espectro de la pectina de alto metoxilo (PAM) pura y un coacervado compuesto de alginato-pectina 1:1 entre la PAM y la 
Cipro, a fin de evidenciar los corrimientos en los números de onda de los picos característicos de la PAM debido a la interacción con la Cipro. Por el otro lado, a fin de evidenciar los corrimientos generados en los picos correspondientes a la Cipro, en la parte " $b$ " se muestran los espectros correspondientes a la Cipro pura y a la mezcla con la PAM en una relación 4:1 a favor de la Cipro.

Las asignaciones de los picos característicos y los corrimientos producidos debido a las interacciones se listan en la Tabla 9 (Socrates, 2004).

\begin{tabular}{|c|c|c|c|}
\hline \multicolumn{3}{|c|}{ Tabla 9 Bandas típicas del espectro FTIR $\left(\mathrm{cm}^{-1}\right)$ y las asignaciones para la molécula de Cipro, pecina } \\
de alto metoxilo y la mezcla de ambos a $\mathrm{pH}=4,00$.
\end{tabular}

Se puede observar un desplazamiento de la frecuencia (o número de onda) característico del grupo carboxilo de la Cipro a un valor más alto desde 1709 a 1725 $\mathrm{cm}^{-1}$. Además, la banda asociada a la protonación del grupo amino de la piperazina se desplaza a $4 \mathrm{~cm}^{-1}$ más. Por otra parte, el valor máximo del grupo carboxilo de la PAM se desplazó de 1609 a $1626 \mathrm{~cm}^{-1}$. Todo ello indica una posible interacción iónica entre la Cipro y la pectina AM. Otro tipo posible de interacción es elucidada cuando las bandas asociadas al anillo aromático de las quinolonas se modifican en la formulación (incluso la banda a $987 \mathrm{~cm}^{-1}$ desaparece), mientras que los grupos de ésteres metílicos de la pectina AM se desplazaron de 1743 a $1726 \mathrm{~cm}^{-1}$. Esto sugiere claramente una interacción hidrofóbica establecida posiblemente por los "bolsillos" de la pectina compuestas por zonas metoxiladas. Por otro lado, es posible que haya interacciones del tipo puentes de hidrógeno contribuyendo a la fuerza total de interacción entre la Cipro y la pectina AM. 
Una vez establecida la existencia de una interacción especifica entre Cipro y pectina, se procedió a la síntesis de las microesferas. Se evaluaron distintas proporciones de alginato-PAM: $2,0-0,5 ; 2,0-1,0$ y $1,0-2,0 \%(p / v)$ y su relación con la encapsulación de Cipro (Tabla 10) y su liberación (Figura 1.10).

\begin{tabular}{|c|c|c|c|}
\hline Biopolímero & \multicolumn{3}{|c|}{ Composición de la matriz $(\%, p / v)$} \\
\hline Alginato & 2,00 & 2,00 & 1,00 \\
\hline Pectina AM & 0,50 & 1,00 & 2,00 \\
\hline Encapsulación Cipro (\%)* & $43,6 \pm 3,2$ & $46,8 \pm 5,0$ & $49,6 \pm 0,9$ \\
\hline
\end{tabular}

Se puede observar que el encapsulamiento de Cipro, con y sin pectina de AMs se mantiene en similares niveles comparado con la de alginato sintetizada en medio acuoso (46,4\%). Sin embargo, se observa que el encapsulamiento es mayor al incrementar el contenido de pectina en el coacervado desde $20 \%$ a $66 \%(p<0,05)$ y que sea probablemente el resultado de interacciones entre los componentes de la matriz coacervada.

Respecto de la liberación de Cipro, partiendo de las matrices coacervadas de pectina y alginato se observaron perfiles de liberación controlada mejorados en comparación con la matriz de alginato (que liberaba el 100\% de la droga en dos horas). Se logró un porcentaje de liberación de Cipro a pH estomacal por debajo del 50\%. La proporción de biopolímeros alginato-pectina AM de 2,0\%-1,0\% (p/v) presentó el mejor perfil, liberando un $42,7 \pm 0,3 \%$ en dos horas a $37^{\circ} \mathrm{C}$. 


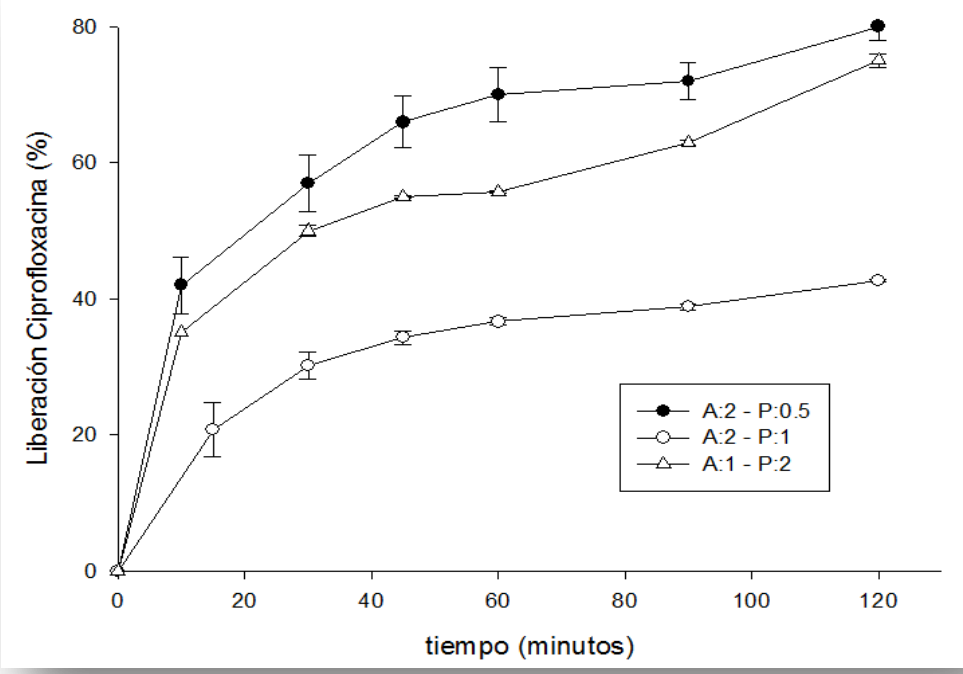

Figura 1.10 Perfiles

de liberacion de

Ciprofloxacina desde microesferas con diferentes radio de alginato-pectina alto metoxilo evaluada a pH gástrico $(1,20)$.

Cuando la proporción de pectina es superior al $66,0 \%(p / p)$, la liberación aumenta a un $75 \%$ en dos horas, posiblemente por la generación de una matriz con menor rigidez estructural de acuerdo a los modelos de gelificación descriptos para ambos polímeros, debido a que la proporción de alginato baja al 1,0\% (p/v) (Braccini y Perez, 2001).

El efecto de la incorporación de pectina AM a la matriz de alginato y sus diferentes radios, se observa en la Figura 1.11. En la misma se pueden visualizar la morfología y superficie de las microesferas mediante microscopia electrónica de barrido (SEM). Las imágenes SEM de la matriz alginato 2,00\%-pectina AM 0,50\% (p/v) mostraron una estructura rígida pero más suavizada en superficie y con menos grietas que los geles de alginato puro (Figura 1.6.a-b). La morfología esférica se conserva y es observada una buena compatibilidad entre los biopolímeros (Figura 1.11.a-b). Si bien la incorporación de PAM 1,0\% a la matriz genera una microesfera más laxa, se observa un efecto cohesivo entra los polímeros al observar una superficie alisada y menos porosa (Figura 1.11.c-d). No obstante, al incrementar la proporción de pectina en una relación 2:1 respecto de la de alginato, la matriz evidentemente pierde su esfericidad y se generan grandes pliegues en superficie, que posiblemente se puedan atribuir a la pectina no entrecruzada o parcialmente entrecruzada (Figura 1.11.e-f). 

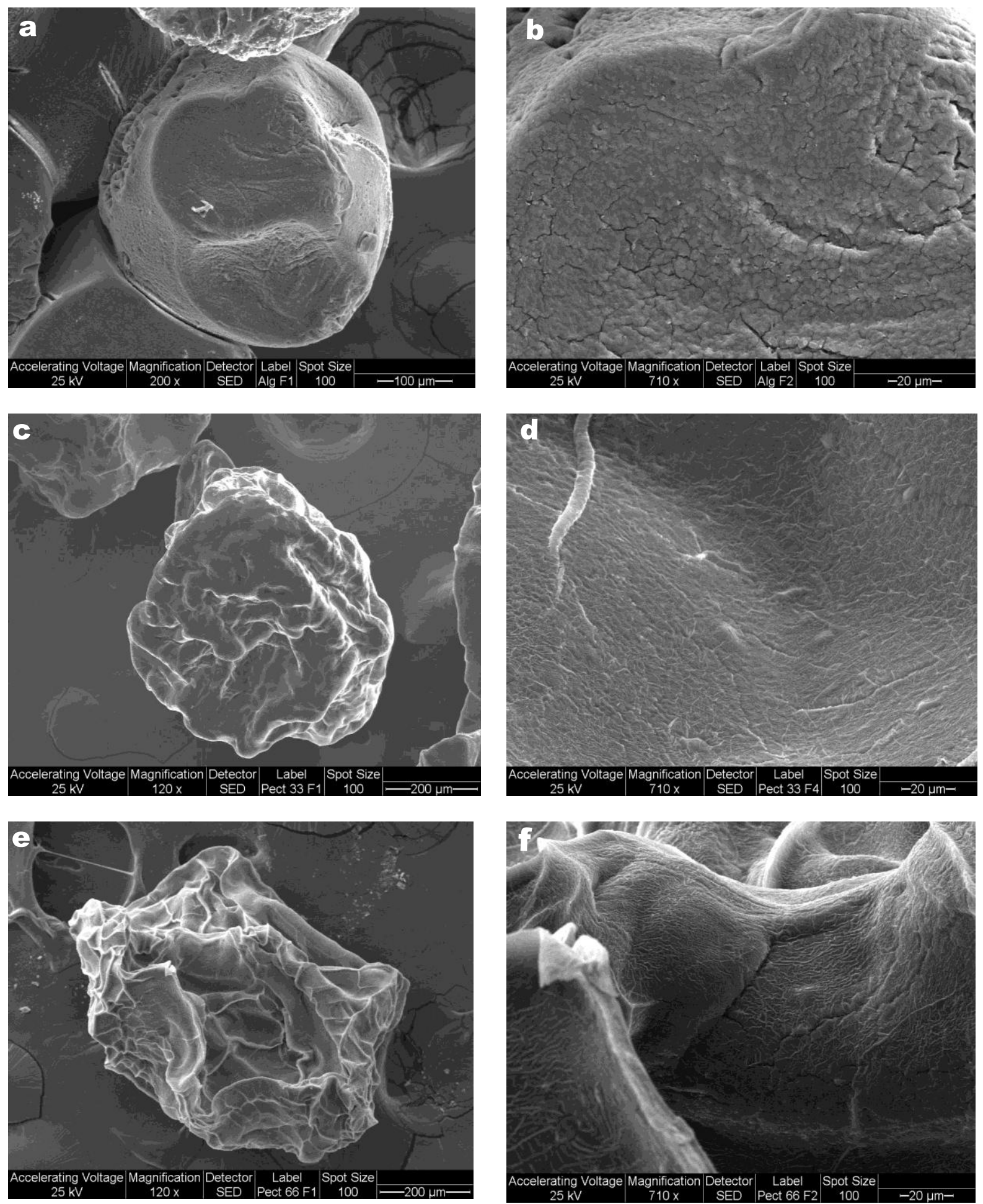

Figura 1.11. Imágenes de SEM: microesferas con diferentes radios de alginato:pectina alto metoxilo $(\%, \mathrm{p} / \mathrm{v})$ y su relación con la morfología (izquierda a 120 aumentos) y patrón de superficie (derecha a 710 aumentos): 2,00:0,50 (a-b); 2,00;1,00 (c-d) y 1,00:2,00 (e-f).

Por lo expuesto hasta aquí, la matriz de alginato-PAM en una proporción de 2:1 $(\mathrm{p} / \mathrm{v})$ presenta un perfil de liberación menor al $50 \%$ a $\mathrm{pH}$ estomacal y una buena 
compatibilidad entre los biopolímeros, con lo cual sería una candidata para desarrollar microesferas para la administración oral. A fin de mejorar el porcentaje de encapsulamiento de Cipro, se ha recurrido a la técnica desarrollada previamente en donde fue realizada la encapsulación en presencia de PG $50 \%(\mathrm{v} / \mathrm{v})$ en la solución de calcio.

Los porcentajes de encapsulación obtenidos luego de la síntesis de microesferas (Tabla 11), mostraron que los resultados obtenidos previamente en la Tabla 4 para la matriz de alginato, son extrapolables a una matriz con mezcla de biopolímeros y permite obtener porcentajes de encapsulación de Cipro mayores al $90 \%$.

\begin{tabular}{|c|c|c|c|}
\hline \multicolumn{4}{|c|}{ AM en presencia de 1,2-propilenglicol 50\% (v/v). } \\
\hline Biopolímero & & osición de I & $\mathrm{p} / \mathrm{v})$ \\
\hline Alginato & 2,00 & 2,00 & 1,00 \\
\hline Pectina AM & 0,50 & 1,00 & 2,00 \\
\hline Encapsulación Cipro (\%) & $95,6 \pm 2,1$ & $93,8 \pm 3,0$ & $90,5 \pm 1,9$ \\
\hline
\end{tabular}

Después de la incubación de las microesferas durante 2 horas en un medio a pH ácido simulando condiciones gástricas humanas, se encontraron porcentajes de liberación de Cipro similares a los obtenidos para las microesferas sintetizadas en medio acuoso (Figura 1.12.a). Se observa la misma tendencia, debido a que se necesitan concentraciones de pectina mayores al 20\% (p/p) para lograr liberaciones menores al 50\%, y no se debe superar una concentración de $60 \%(p / p)$ debido a que aumenta la liberación por encima del mencionado valor. Para una proporción de alginato-PAM de $2,00-0,50 ; 2,00-1,00$ y $1,00-2,00$ se obtuvieron porcentajes de liberación a las 2 horas del 71,6 $\pm 2,9 \%, 44.0 \pm 2.9 \%$ y $64,7 \pm 1,1 \%$ respectivamente. El efecto de la coacervación de los biopolímeros seleccionados sobre la estabilidad de la matriz resultante fue nuevamente observado. En este caso, la microscopia óptica permitió establecer que la morfología y la superficie homogénea de las microesferas se mantienen, siempre y cuando la concentración de PAM en la matriz no supere el $50 \%$ 
$(p / p)$ (Figura 1.12.b-d). Los resultados sugieren un importante papel de PAM en la disminución de la liberación de Cip.

Finalmente, en base a los estudios realizados, la matriz coacervada compuesta de alginato al $2,0 \%$ y PAM al $1,0 \%(p / v)$ fue elegida por poseer las propiedades deseadas: estabilidad de la matriz, buena compatibilidad entre biopolímeros y liberación a pH gástrico menor al 50\%. A su vez, la síntesis de las microesferas en presencia de una solución de calcio $(500 \mathrm{mM})$ y 1,2-propilenglicol al $50 \%$ (v/v) ha brindado la posibilidad de encapsular la Ciprofloxacina en porcentajes mayores al $90 \%$, sin afectar drásticamente los perfiles de liberación y morfología.

En una última etapa, fue evaluada la liberación de la Cipro en un ambiente intestinal simulado y las propiedades bactericidas de la matriz.

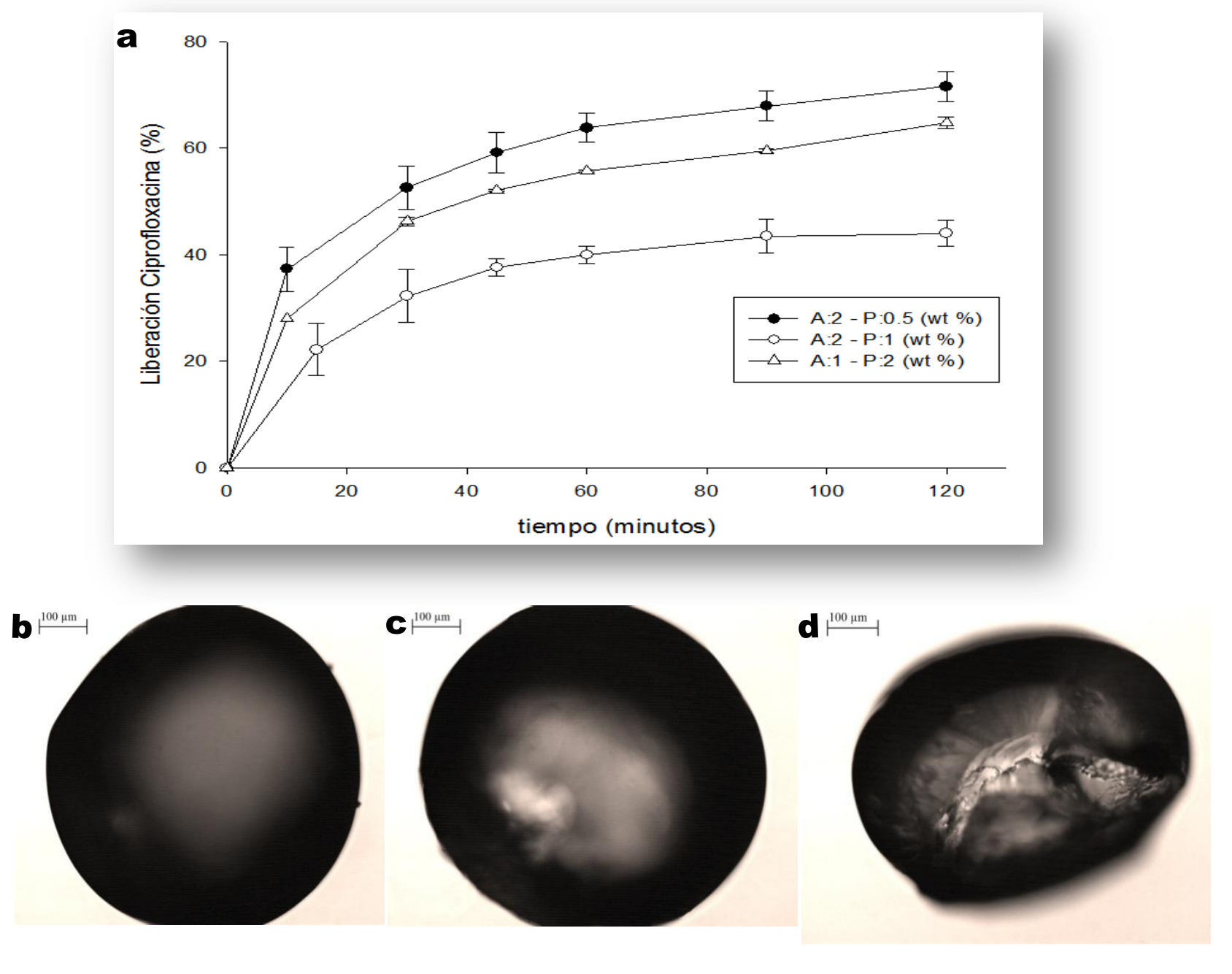


Figura 1.12. Efecto de la modificación de la relación alginato:pectina alto metoxilo en microesferas: a) Efecto sobre la liberación de Ciprofloxacina a pH gástrico b-d) Efecto sobre la morfología de las microesferas, en radios de alginato-PAM de 2-0.5 (a), 2-1 (b) y 1-2 (c) \% p/v. Observación al microscopio óptico a 100 aumentos.

El comportamiento de las microesferas a $\mathrm{pH}=7,40$ (intestinal) fue evaluado, a fin de evidenciar si la matriz es capaz de liberar el antibiótico en su zona de mayor absorción y de qué manera. La Figura 1.13 muestra los perfiles de liberación de microesferas de alginato 2,0\% - PAM 1,0\% sintetizadas en medio acuoso o en presencia de PG 50\% (v/v). Se puede observar que las primeras liberan un $68 \%$ del fármaco en 2 horas y las segundas 93\%. Ello puede explicarse, si se considera el grado de entrecruzamiento de cada matriz, como fuera discutido previamente en el presente capítulo. Es un hecho destacable que las matrices sean capaces de liberar el antibiótico en el sitio de infección, y en particular las microesferas sintetizadas en presencia de PG $50 \%$ que poseen una alta carga de fármaco suficiente para alcanzar concentraciones inhibitorias.

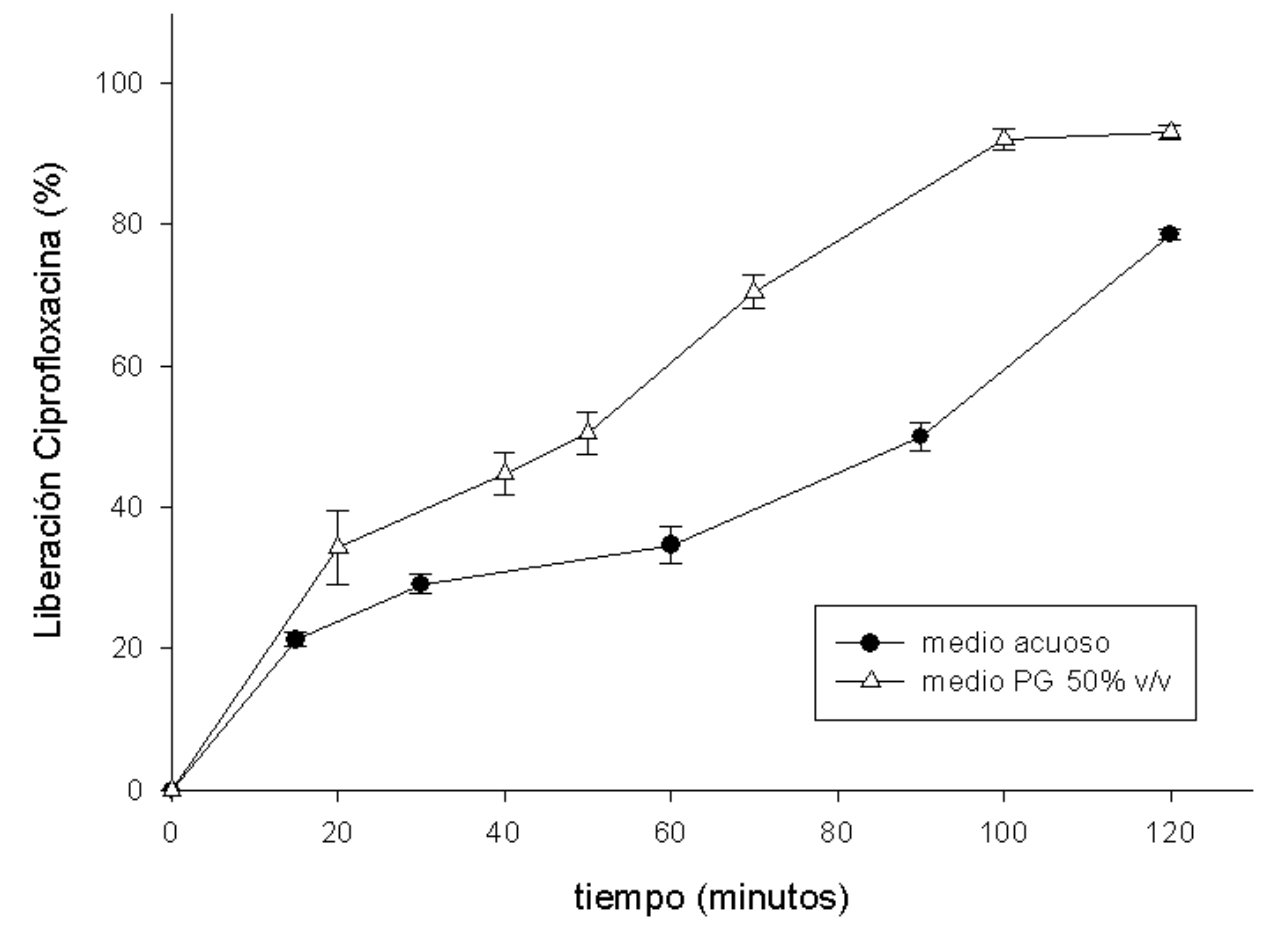

Figura 1.13. Perfiles de liberación de Ciprofloxacina a pH intestinal (solución reguladora fosfato $40 \mathrm{mM}, \mathrm{pH} 7,40$ ) de microesferas de alginato 2,0\% - PAM 1,0\% sintetizadas en medio acuoso 0 en presencia de $P G 50 \%(v / v)$. 
Finalmente, se evaluaron las propiedades bactericidas de las microesferas de alginato 2,0\% - PAM 1,0\% sintetizadas en PG 50\% (v/v), a fin de corroborar que el antibiótico encapsulado puede ser liberado de la matriz en forma activa y ser capaz de mantener su capacidad antimicrobiana. Para ello, se colocaron microesferas en una placa de agar sembrado con Pseudomonas aeruginosa. A diferentes tiempos se retiraron microesferas, de forma tal que la inhibición de la bacteria se produzca por el antibiótico que se ha liberado de la microesfera hasta ese instante en el que se la retira. De esta forma, se desarrolló una cinética de liberación de Cipro en placa (Figura 1.14). En concordancia con los resultados obtenidos en las liberaciones en condiciones fisiológicas simuladas (gástrica e intestinales) se observa una rápida liberación de Cipro inicial (sobre todo en las primeras dos horas) que genera halos de inhibición de hasta $12 \mathrm{~mm}$. A medida que transcurre la cinética, la liberación de Cipro comienza a ser menor, hasta alcanzar un halo de final de $17 \mathrm{~mm}$ a las 12 horas.

De esta forma, se ha corroborado que la Cipro liberada de la matriz de alginatoPAM es capaz de generar una inhibición con Pseudomonas aeruginosa en placa, lo cual resulta de interés para el tratamiento de este patógeno comúnmente encontrado en pacientes con fibrosis quística.

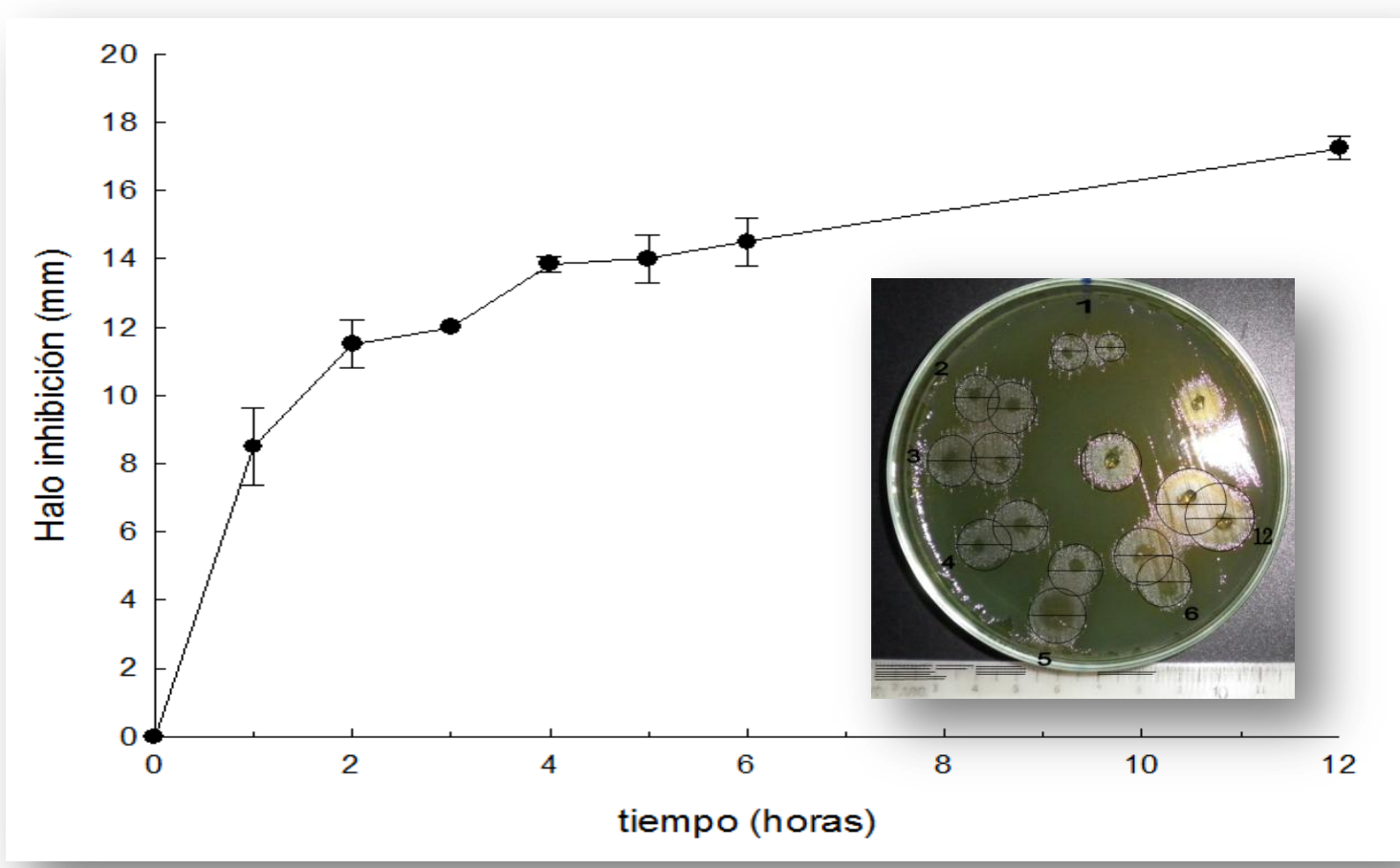

Figura 1.14. Cinética de inhibición de Pseudomonas aeruginosa producida por microesferas de Alginato 2,0\%/Pectina AM 1,0\% (p/v) conteniendo Ciprofloxacina. 


\section{Incorporación de gelatina a la matriz}

De manera alternativa y con el objeto de reducir el perfil de liberación de Ciprofloxacina de la matriz base de alginato, se procedió a incorporar un biopolímero de naturaleza proteica a la formulación (gelatina), bajo la consideración de reportes previos que demuestran que la Cipro es capaz de interactuar con estructuras proteicas (Seedher y col., 2010). Se especula así, que dichas interacciones tendrán un efecto sobre la liberación de la Cipro de la matriz gelificada.

Mediante el ensayo de interacción por precipitación (descripto en materiales y métodos del presente capítulo) se determinaron las condiciones óptimas de interacción entre los biopolímeros y Cipro en función del pH. En éste caso, se partió de la comparación entre las matrices compuestas de alginato al 2,0\% (p/v) y un coacervado alginato 2,0\% (p/v)-gelatina 1,0\% (p/v) (Figura 1.15).

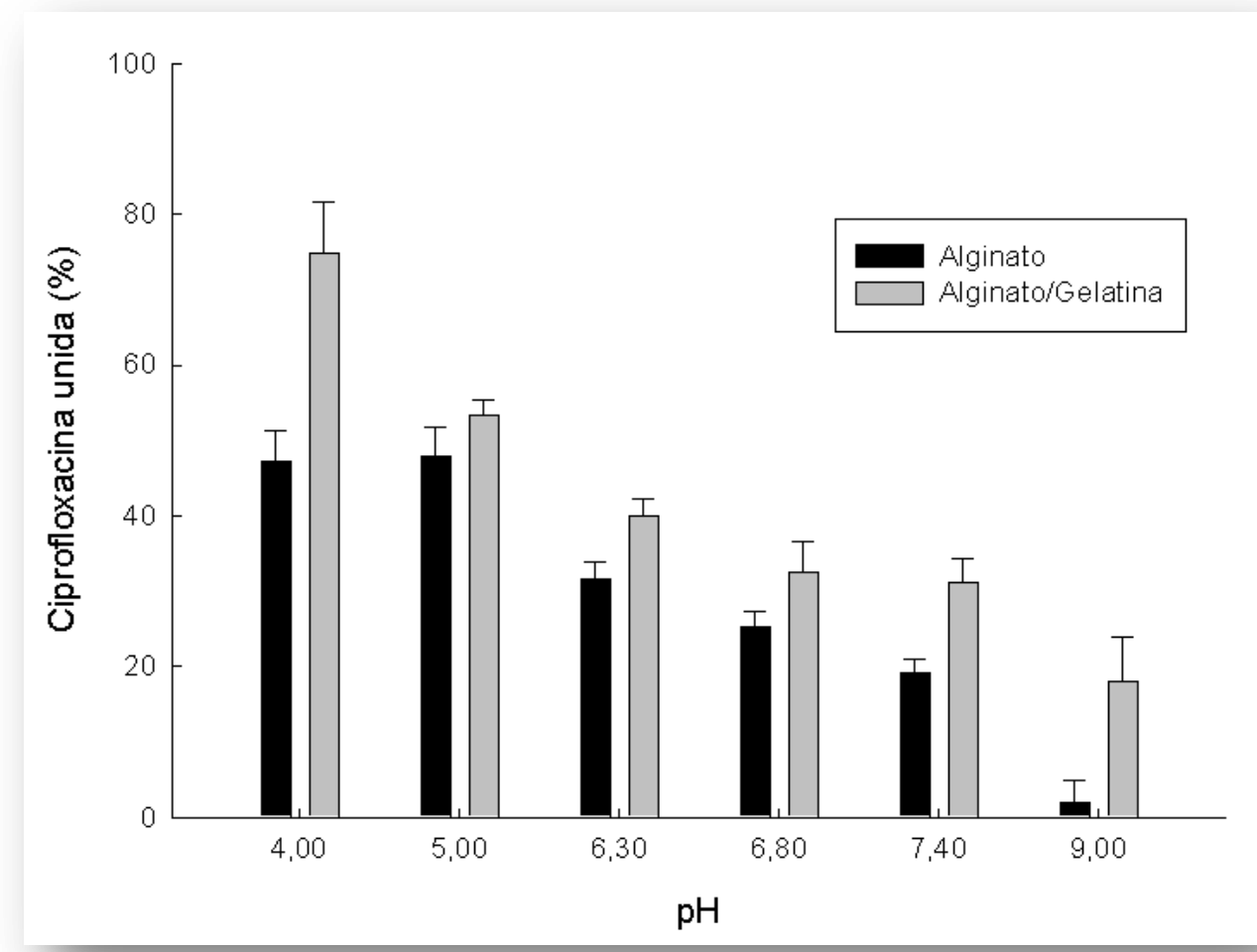

Figura 1.15. Ciprofloxacina unida (\%) a alginato $2,0 \%(\mathrm{p} / \mathrm{v})$ y a la mezcla formada por alginato $2,0 \%(\mathrm{p} / \mathrm{v})$ - gelatina $1,0 \%(\mathrm{p} / \mathrm{v})$ a diferentes $\mathrm{pHs}$.

La interacción de Cipro con alginato se incrementa cuando el pH disminuye. Por un lado, se observa que a $\mathrm{pH}$ bajos las interacciones posiblemente sean de tipo electrostáticas entre el alginato cargado negativamente y la Cipro en su forma 
catiónica, alcanzando un máximo en el intervalo de $\mathrm{pH}$ 4,0-5,0. Por debajo de $\mathrm{pH}$ 3,5, no se evaluó la interacción, debido a que la solución de alginato se vuelve inestable y precipita como ácido algínico (datos no mostrados). Por otro lado, la interacción de la Cipro y alginato disminuyó a valores de pH cerca de 6,0 o superior, debido a que se produce la ionización del grupo carboxílico de la Cipro $(\mathrm{pKa}=6,1)$ y luego la del grupo piperazinilo en C-7 ( $\mathrm{pKa}=8,2)$ con lo cual lo molécula posee carga negativa progresivamente. La incorporación de gelatina tipo B en la solución de alginato genero un incremento de la interacción de los biopolímeros con la Cipro del $80 \%$ a un valor de $\mathrm{pH}$ de 4,0 . Este incremento de un $30 \%$ en la interacción, es atribuible a la presencia de la gelatina, que puede aportar sitios hidrofóbicos para una fuerte interacción con la Cipro. Ello se justificaría debido a la presencia de altos niveles de residuos de ácido aspártico y glutámico en gelatina con pKas cercanos a 4,0 (Rose, 1990).

La disminución de la unión de Cipro al coacervado de alginato-gelatina con el aumento del $\mathrm{pH}$ podría explicarse principalmente por los cambios de densidad de carga superficial de la gelatina al alcanzar el punto isoeléctrico (PIE), que se encuentra en el intervalo de pH 4,6 a 5,2 (Harrington y col., 2009). Cuando el pH está alcanzando el PIE de la gelatina, la interacción asociativa entre alginato (negativo) y gelatina (positiva a $\mathrm{pH}$ menor a 4,0 ) se debilita, y tiende a ser repulsiva con una consecuente separación de fases (Antonov y col., 1996). El proceso se considera como segregativo entre los dos polímeros debido a un aumento del orden en la proteína que va de forma coloidal extendida a la forma de triple hélice, una forma más ordenada (Gilsenan y col., 2003). En tal conformación, la gelatina reduce la cantidad de residuos de aminoácidos disponibles para la unión a Cipro.

En una siguiente etapa, la formulación de alginato-gelatina $(2,0-1,0 \%, p / v)$ conteniendo la Cipro fue entrecruzada con $\mathrm{CaCl}_{2} 500$ mM para dar lugar a la formación de microesferas. A fin de determinar la homogeneidad de la matriz a lo largo de sus dimensiones se realizó un análisis de FTIR (modo ATR) de una porción representativa de la microesfera utilizando como fuente de energía la sensibilidad aportada por la luz Sincrotrón (estación SMIS, Sincrotrón Soleil, Saint-Aubin, Francia) (Figura 1.16). EI objetivo de este ensayo fue determinar si hay una buena cohesividad entre los polímeros y la Cipro, si no se produce la segregación de los biopolímeros, y si hay presencia de cristales de Cipro en el interior de la matriz (considerando su tamaño en 
la escala micrométrica). La homogeneidad de la formulación fue comparada con la matriz de alginato $2,0 \%(\mathrm{p} / \mathrm{v})$.
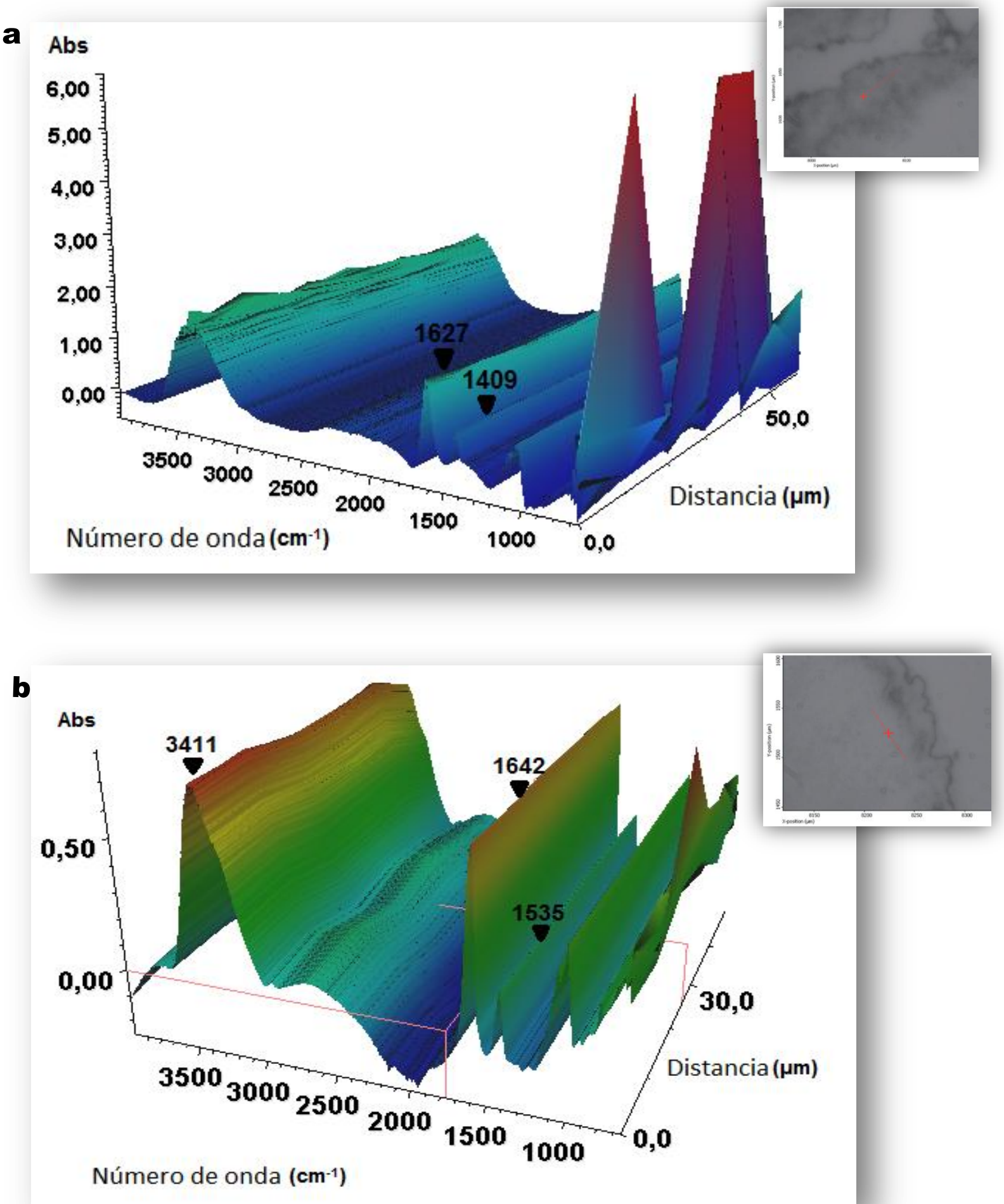

Figura 1.16. Caracterización de matrices de alginato y alginato/gelatina por microscopía óptica y FTIR simultáneas usando radiación de luz Sincrotrón. a) alginato 2,0\%, p/v. b) alginato $2,0 \%, p / v$-gelatina $1,0 \%, p / v$. En los recuadros superiores se muestra la imagen de microscopía óptica de la porción de matriz analizada. La línea roja indica la zona donde se hizo el barrido de espectros FTIR. 
La matriz de alginato presentó dos máximos característicos atribuidos a los modos de vibración asimétrica y estiramiento simétrico del grupo R-COO-, a $1627 \mathrm{~cm}^{-1}$ y $1409 \mathrm{~cm}^{-1}$, respectivamente (Figura 1.16.a).

Las frecuencias máximas características de la gelatina a $1653 \mathrm{~cm}^{-1}, 1546 \mathrm{~cm}^{-1}, \mathrm{y}$ $1236 \mathrm{~cm}^{-1}$ fueron atribuidos a las siguientes bandas: amidas, producidos por los modos de vibración de estiramiento de $\mathrm{C}=\mathrm{O}$ y $\mathrm{C}-\mathrm{N}$, y los modos de flexión $\mathrm{N}-\mathrm{H}$. La vibración de estiramiento del $\mathrm{O}-\mathrm{H}$ unido a $\mathrm{N}-\mathrm{H}$ produce una banda ancha de absorción alrededor de los $3421 \mathrm{~cm}^{-1}$ (Dong y col., 2006). El espectro de FTIR en el espacio de la matriz de alginato-gelatina mostró la bandas de absorción características de la gelatina de 1653 y $1546 \mathrm{~cm}^{-1}$ pero desplazadas a números de onda inferiores: $1642 \mathrm{~cm}^{-1}$ y $1535 \mathrm{~cm}^{-1}$ respectivamente (Figura 1.16.b). Del mismo modo, la banda de absorción alrededor de los $3421 \mathrm{~cm}^{-1}$ se desplazó a un menor valor de número de onda correspondiente a $3411 \mathrm{~cm}^{-1}$, lo que puede sugerir un aumento de las interacciones mediadas por puentes de hidrógeno. Estos resultados evidencian fuertemente la presencia de interacciones moleculares y la compatibilidad entre el alginato y la gelatina. Por otro lado, y considerando la alta sensibilidad de la luz de sincrotrón para obtener espectros de FTIR, las bandas típicas de la Cipro no fueron evidenciadas, debido a la baja sensibilidad de la espectroscopía infrarroja sumado a una baja concentración del antibiótico en relación a los polímeros presentes en la formulación. Sin embargo, considerando que las moléculas Cip tienden a apilarse entre sí y producir cristales de aproximadamente $5 \mathrm{~mm}$ de tamaño que pueden ser claramente observados por microscopía óptica (Figura 1.1), es muy probable que su presencia interfiera con la detección FTIR, por lo cual, frente a la homogeneidad observada en los espectros de ambas matrices, no habría indicios de ninguna agregación de moléculas Cipro durante la formación de gel. De hecho, la presencia de los biopolímeros podría estar estabilizando las moléculas de Cipro en la formulación.

En una siguiente etapa, fue evaluada la encapsulación de Cipro en las matrices estudiadas (Tabla 12). Como se ha mencionado previamente en el presente capítulo (Tabla 4), el porcentaje de encapsulación en la matriz de alginato se incrementó alrededor de dos veces cuando el medio de síntesis de las microesferas está compuesto por $50 \%(\mathrm{v} / \mathrm{v})$ de 1,2- propilenglicol. Sin embargo, cuando un 1,0\% (p/v) de gelatina fuera incorporada a la matriz de alginato (en relación 2:1) se observó una 
significativa disminución de alrededor del $10 \%$ de Cipro encapsulada $(p<0,05)$. El mencionado resultado podría explicarse teniendo en cuenta el punto isoeléctrico de la gelatina: a pH 4,0 de encapsulación tanto la Cipro como la gelatina se encuentran positivamente cargadas, por lo que compiten por los sitios cargados de forma negativa de la cadena de alginato.

\begin{tabular}{|c|c|c|c|c|c|}
\hline \multirow[t]{2}{*}{ Matriz } & \multirow{2}{*}{$\begin{array}{c}\text { Biopolímero } \\
(p / v, \%)\end{array}$} & \multicolumn{3}{|c|}{ Medio de síntesis } & \multirow{2}{*}{$\begin{array}{c}\text { Encapsulación } \\
\text { (\%) }\end{array}$} \\
\hline & & $\mathrm{Ca}^{+2}$ & $1,2-\mathrm{PG}^{a}$ & Glutaraldehído & \\
\hline \multirow[t]{2}{*}{ Alginato } & \multirow[t]{2}{*}{2,0} & + & - & - & $44 \pm 3$ \\
\hline & & + & + & - & $96 \pm 4$ \\
\hline \multirow{3}{*}{$\begin{array}{l}\text { Alginato- } \\
\text { gelatina }\end{array}$} & \multirow[t]{3}{*}{$2,0-1,0$} & + & - & - & $33 \pm 5$ \\
\hline & & + & + & - & $77 \pm 3$ \\
\hline & & + & + & + & $83 \pm 2$ \\
\hline
\end{tabular}

Como la gelatina posee un mayor peso molecular que la Cipro, tiene sitios de unión más disponibles para interactuar con las cadenas de alginato, produciendo la exclusión de Cipro de la matriz entrecruzada. En este sentido, este resultado difiere de lo observado en los ensayos de interacción, donde se observada que la adición de gelatina aumentaba la unión de Cipro. No obstante, debemos considerar que en ese caso se utilizaba la formulación liquida, y en el caso de la encapsulación se utiliza la matriz entrecruzada con calcio.

Sin embargo, cuando las microesferas de alginato-gelatina se sintetizaron en presencia de 1,2-propilenglicol $50 \%(\mathrm{v} / \mathrm{v})$, nuevamente fue observado un aumento de al menos el doble de Cipro encapsulada (de 33 a 77\%). Finalmente y teniendo en cuenta que la gelatina es una proteína, se entrecruzó la matriz con glutaraldehído, a fin de crear una malla más cerrada, con una posible disminución del tamaño de poro de la matriz y un consecuente incremento de la encapsulación de Cipro. Tal como se ha especulado, en presencia de calcio, PG $50 \%(\mathrm{v} / \mathrm{v})$ y glutaraldehído $2,5 \%(\mathrm{p} / \mathrm{v})$ la encapsulación de Cipro aumentó en un $6 \%$ alcanzando un valor final de $83 \%(p<0,05)$.

Un análisis de superficie de las microesferas de alginato-gelatina mediante SEM revela características particulares de cada entorno de síntesis al ser observadas (Figura 1.17). La incorporación de gelatina a la matriz de alginato mostró una homogénea 
distribución de microesferas con forma esférica (Figura 1.17, superior), lo que sugiere una buena compatibilidad entre ambos biopolímeros como fuera observado por FTIR Sincrotrón. Sin embargo, la superficie de las microesferas parece ser más granulada en comparación con la matriz a base de alginato (Figura 1.6.c-d). Las diferencias se atribuyen fundamentalmente a la presencia de pequeños valles que probablemente estén compuestos por gelatina no entrecruzada. Cuando las microesferas son sintetizadas en presencia tanto de iones calcio (que generan el entrecruzado de las cadenas de alginato) como de glutaraldehído (que es capaz de entrecruzar proteínas) se producen matrices con una doble reticulación y una estructura superficial más compacta. Las microesferas mostraron una superficie más lisa en comparación con las anteriores (Figura 1.17, inferior).
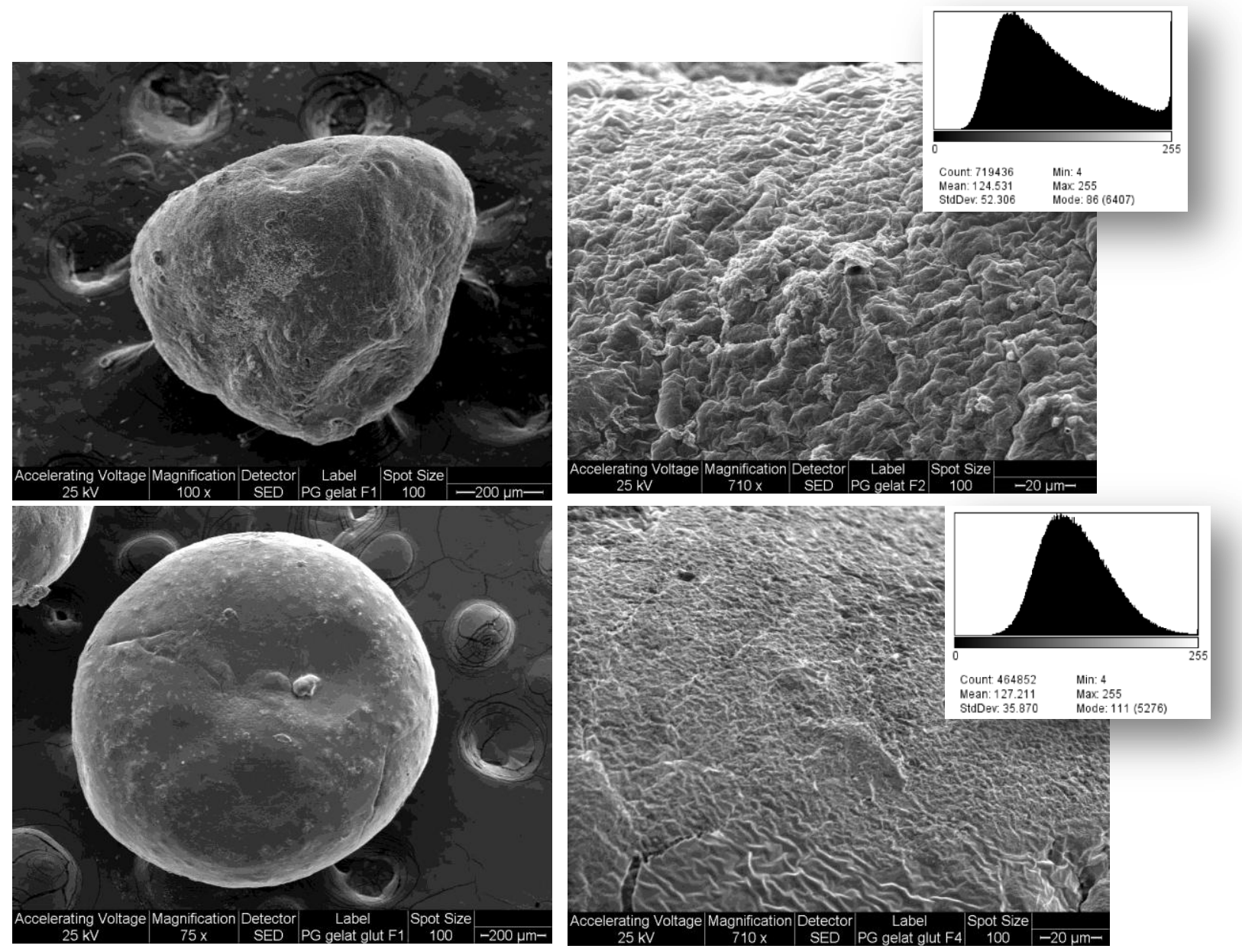

Figura 1.17. Imágenes de SEM de microesferas de alginato/gelatina sintetizadas en presencia de PG 50\% (v/v) (superior) y de alginato/gelatina entrecruzada en presencia de PG 50\% (v/v) y glutaraldehído (inferior). Los recuadros superiores muestran el histograma del análisis de superficie de las imágenes a 710x con el programa ImageJ. 
Se analizaron las imágenes de microscopía con el programa ImageJ para cuantificar las diferencias entre ambas matrices. La matriz de alginato-gelatina mostro una desviación estándar de 52 y 35 cuando fue sintetizada en ausencia y presencia de glutaraldehído respectivamente, lo que sugiere que la técnica de doble reticulación aumenta la suavidad de las microesferas $y$, en consecuencia se reducen los poros de la superficie de manera que la Cipro es más retenida en la matriz en esas condiciones.

Los resultados obtenidos se corroboraron por microscopia de fuerza atómica (AFM). La observación de la matriz de alginato-gelatina con y sin el agregado de glutaraldehído durante la síntesis mostro diferencias significativas en la rugosidad superficial de la muestra (Figura 1.18).

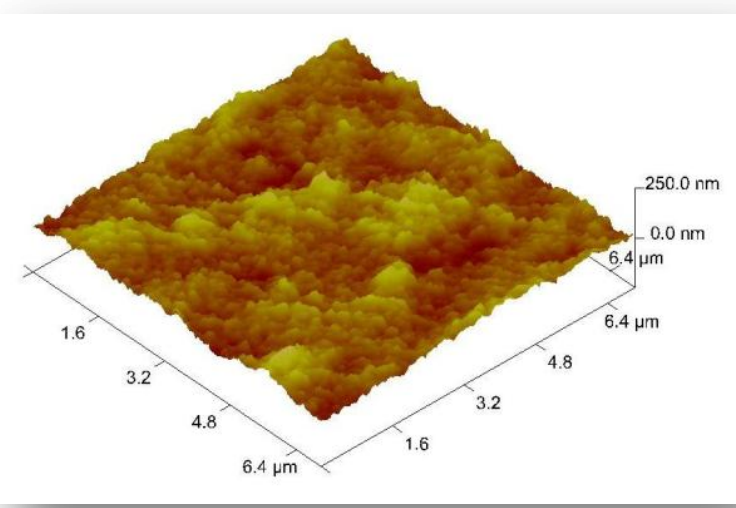

(1)
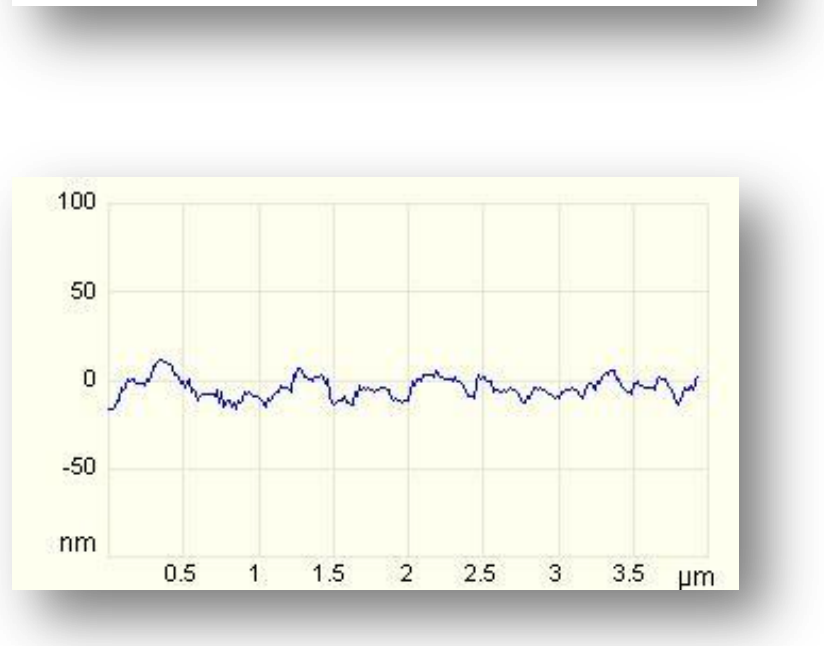
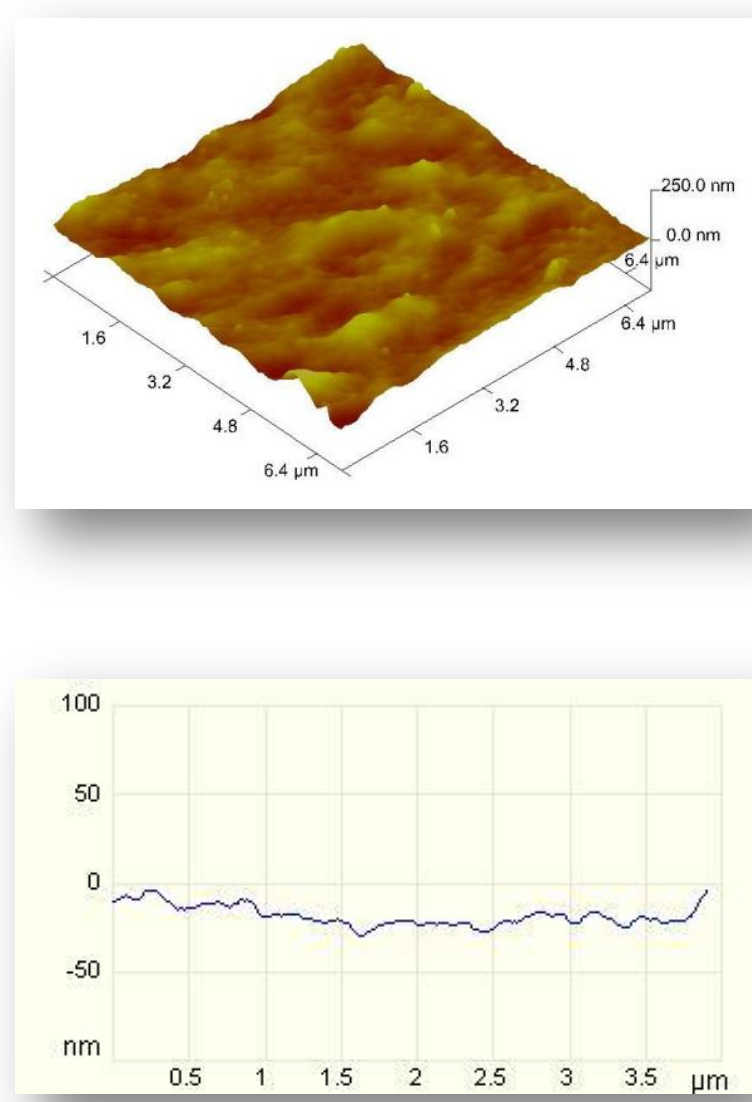

Figura 1.18. Imágenes de AFM de microesferas de alginato/gelatina sintetizadas en ausencia (izquierda) y presencia (derecha) de glutaraldehído. Se muestran los perfiles de rugosidad correspondientes analizados con el programa Nanoscope 7.30.

El análisis de las imágenes de AFM utilizando el programa Nanoscope 7.30 puso de manifiesto la reducción de los agregados de superficie (que tenían dimensiones de $10 \mathrm{~nm}$ de altura, y alrededor de $500 \mathrm{~nm}$ de diámetro) por la presencia de 
glutaraldehído y muestra marcadas diferencias en el perfil de rugosidad de la superficie en comparación con la matriz sin tratar. Este parámetro posiblemente tenga un impacto directo sobre el perfil de liberación de las moléculas encapsuladas, debido a que se modifica la porosidad de la matriz, lo cual representa una barrera física para la salida de dichas moléculas.

Se realizaron liberaciones de Ciprofloxacina desde las microesferas sintetizadas para predecir su posible comportamiento en condiciones fisiológicas simuladas. Como fuera evaluado previamente, la matriz de alginato 2,0\% (p/v) (sintetizada en presencia de PG $50 \%$, v/v) presentó una liberación abrupta del 75\% cuando se incubó a pH estomacal simulado $\left(\mathrm{pH}=1,2\right.$ y $\left.37{ }^{\circ} \mathrm{C}\right)$ durante 30 min (Figura 1.19.a). Cuando se incorpora un $1,0 \%(p / v)$ de alginato a la formulación se produce una reducción de casi el doble en el perfil de liberación de Cipro en las mismas condiciones experimentales. Así, a un tiempo de una hora de liberación, se detecta un $83 \%$ y un $56 \%$ de Cipro para la matriz de alginato y la de alginato/gelatina. Esta rápida liberación puede atribuirse a la disolución de las moléculas de Cipro alojadas mayormente en la superficie de las microesferas. Luego de esa primer hora, en ambas matrices se observa una meseta, donde la liberación es más lenta (menos del $10 \%$ en la siguiente hora), lo cual puede deberse a la liberación del fármaco alojado más profundamente en los intersticios de la matriz. Éste es un fenómeno comúnmente encontrado en la mayoría de las matrices para la administración de fármacos y es conocido como el "efecto del canal" (Huang y col., 2001).

Por su parte, las microesferas de alginato-gelatina tratadas con glutaraldehído liberan sólo un $25 \%$ de la concentración inicial de Cipro durante la primer media hora de incubación a pH 1,20 evitando de esta forma ese perfil de liberación abrupta observado en las matrices anteriores. Teniendo en cuenta que el tiempo de residencia de las microesferas en los líquidos del estómago puede ser menor a los 30 min (para un paciente en ayunas, con el estómago vacío), más del $75 \%$ de la Cipro estaría disponible para su absorción en el intestino, evitando así una potencial irritación estomacal. Esta reducción en la liberación sugiriere la presencia de una barrera difusional generada por la capa de gelatina entrecruzada sobre la superficie de las microesferas. 
Las microesferas de alginato-gelatina mostraron un perfil de liberación de Cipro que se ajustaba a una ecuación de polinomio de cuarto grado $\left(r^{2}=0,99\right)$. Mientras que las microesferas tratadas con glutaraldehído mostraron una relación lineal con un $\mathrm{r}^{2}$ de 0,94 .

Se estudió la liberación de Cipro de las microesferas bajo un medio intestinal simulado $\left(\mathrm{pH}=7,40\right.$ y $\left.37^{\circ} \mathrm{C}\right)$ a fin de establecer si las mismas son capaces de liberar el contenido del antibiótico encapsulado (Figura 1.19.b).
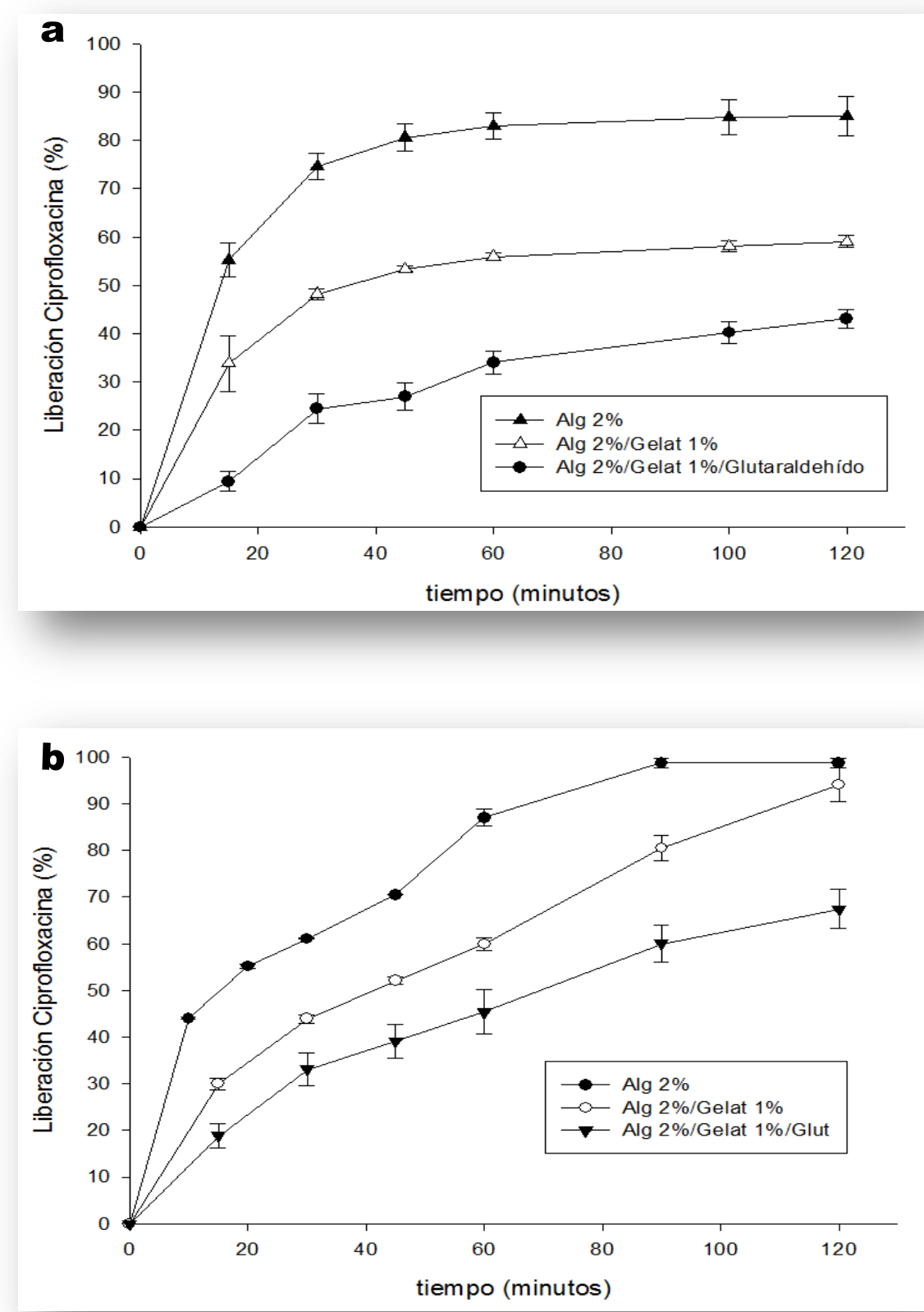

Figura 1.19 Liberación Ciprofloxacina desde microesferas de alginato 2,0\%; de alginato $2,0 \%$-gelatina $1,0 \%$; $y$ de alginato $2,0 \%$-gelatina $1,0 \%$ entrecruzadas con glutaraldehído a un pH gástrico de 1,20 (a) y un pH intestinal de 7,40 (b). 
Las microesferas de alginato mostraron una alta cinética de liberación, alcanzando un $100 \%$ de liberación en tan solo 90 minutos. Por su parte, la matriz compuesta de alginato-gelatina presentó una liberación de Cipro reducida de al menos 20\%. Sin embargo, el $100 \%$ de la Cipro inicial es liberado a las dos horas, hecho producido principalmente por la erosión de la matriz debido a la presencia de los iones fosfato en el medio de liberación, los cuales pueden secuestrar el calcio que se encuentra en la matriz. Tambièn a la difusión de iones monovalentes presentes en la solución, los cuales compiten con el calcio por los sitio de interacción de la matriz. Cuando las microesferas fueron tratadas con glutaraldehído, se encontró una disminución en el perfil de liberación (aproximadamente un $68 \%$ a las 2 horas) debido a la presencia de una capa superficial compuesta de la gelatina entrecruzada, que le brinda una barrera difusional a la salida de Cipro y más resistencia al proceso de erosión por parte de los iones fosfato.

Adicionalmente a estos ensayos, fue estudiado el efecto de las condiciones ambientales en la estabilidad de las microesferas. Para ello, se determinó la dureza y la cohesividad de las mismas en sus formas nativas, y luego de ser incubadas a pH 1,20 y 7,40 durante 2 horas (Tabla 13).

\begin{tabular}{|c|c|c|c|c|}
\hline \multirow[t]{2}{*}{$\mathrm{pH}$} & \multicolumn{2}{|c|}{ Alginato-gelatina } & \multicolumn{2}{|c|}{ Alginato-gelatina/glutaraldehído } \\
\hline & Dureza & Cohesividad & Dureza & Cohesividad \\
\hline $\begin{array}{l}\text { Antes de } \\
\text { incubar }\end{array}$ & $2,36 \pm 0,35$ & $0,44 \pm 0,02$ & $2,19 \pm 0,26$ & $0,45 \pm 0,02$ \\
\hline 1,20 & $1,77 \pm 0,14$ & $0,40 \pm 0,01$ & $1,81 \pm 0,10$ & $0,42 \pm 0,02$ \\
\hline 7,40 & ND & ND & $0,72 \pm 0,05$ & $0,21 \pm 0,14$ \\
\hline
\end{tabular}

En principio no se observaron diferencias significativas $(p>0,05)$ en la dureza y cohesividad de las microesferas de alginato-gelatina tratadas y no tratadas con glutaraldehído. Este hecho indica dos cosas: primero, que la resistencia a la compresión de las matrices gelificadas es similar y que presentan el mismo grado de dificultad en romper la estructura interna del gel. En este sentido, se puede especular que el tratamiento con glutaraldehído de la matriz de alginato-gelatina produce 
principalmente cambios a nivel superficial de la microesfera (tal como se observa en las imágenes de SEM y AFM) pero que no se modifica la estructura interna del gel.

Por otro lado, se evaluó la estabilidad en condiciones fisiológicas simuladas del tracto gastrointestinal. Las microesferas de alginato-gelatina con y sin tratamiento de glutaraldehído mostraron los mismos parámetros texturométricos $(p>0,05)$ incubadas en condiciones gástricas simuladas $(\mathrm{pH}=1,20)$ durante dos horas. No obstante, las mismas presentaron una disminución en la dureza y cohesividad de alrededor del $25 \%$ y $10 \%$ respectivamente en comparación con las microesferas no incubadas. El hecho se puede atribuir principalmente a que el extremo pH ácido afecta el grado de ionización de los componentes de la matriz, reduciendo su grado de entrecruzamiento. Sin embargo, hubo diferencias significativas en la dureza y cohesividad $(p<0,05)$ entre ambos tipos de microesferas cuando se incubaron a $\mathrm{pH} 7,40$ (medio intestinal simulado). Por un lado, las microesferas de alginato-gelatina entrecruzada sólo por iones calcio sufrieron una total desestabilización después de las dos horas de incubación a pH 7,40, por lo que los valores de dureza y cohesividad resultaron por debajo del límite de detección de la técnica. Por otra parte, las microesferas con doble reticulado (vía calcio y glutaraldehído) mostraron una mayor estabilidad, preservando un $35 \%$ de su dureza inicial y casi el $50 \%$ de la cohesividad. Los resultados sugieren un aumento en estabilidad de la matriz debido a la síntesis realizada en presencia de glutaraldehído, y atribuida principalmente a la capa superficial compuesta de la gelatina entrecruzada que reduce la erosión de las microesferas.

Finalmente, una vez estudiado el posible comportamiento de las matrices, se procedió a evaluar su capacidad antimicrobiana contra Pseudomonas aeruginosa. Se realizó una cinética de liberación en placa, colocando microesferas y retirándolas a distintos tiempos. El porcentaje de inhibición se estableció midiendo los halos a diferentes tiempos y considerando en forma relativa como $100 \%$ el halo a las 12 horas (Figura 1.20). Se observó un incremento de los halos de inhibición en el tiempo para las microesferas de alginato-gelatina con y $\sin$ tratamiento con glutaraldehído. El diámetro de inhibición final para las primeras fue de 14,8 $\pm 1,1 \mathrm{~mm}$, mientras que para las segundas de 12,8 $\pm 0,1 \mathrm{~mm}$. Esta diferencia se puede atribuir a la mayor carga de Cipro que poseen las microesferas tratadas con glutaraldehído (Tabla 12). Además, se observa que la liberación de antibiótico desde las microesferas tratadas es más 
controlada en el tiempo. Este resultado confirma la presencia de una barrera difusional adicional producida en la reticulación de la gelatina en superficie por acción del glutaraldehído. A su vez, estos resultados se condicen con los hallados para las liberaciones en fluidos fisiológicos simulados.

De esta forma, se confirma que la Cipro es liberada de forma activa desde éstas matrices biopoliméricas, las cuales son capaces de producir una inhibición del crecimiento del microorganismo en el tiempo.

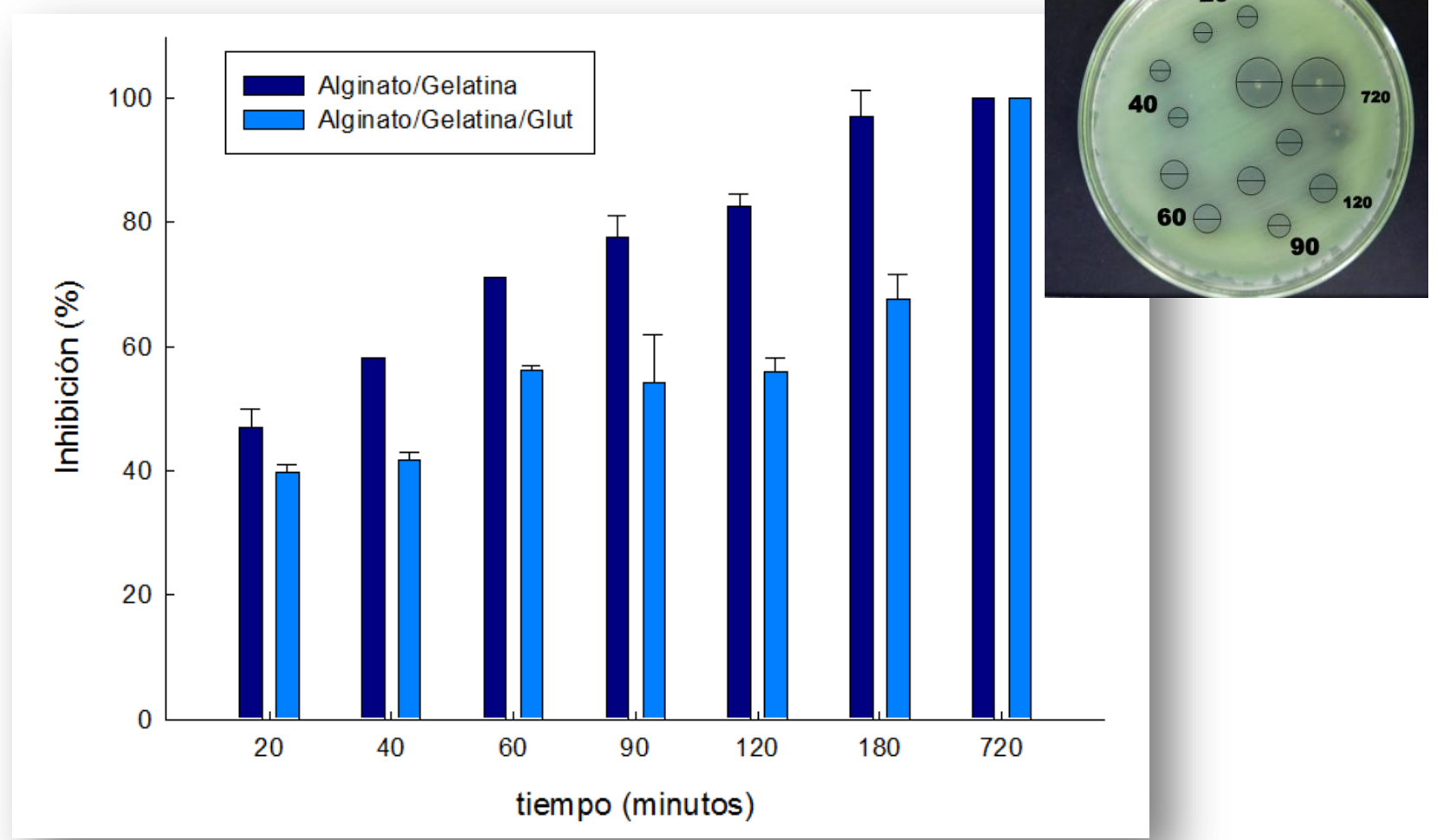

Figura 1.20 Actividad antimicrobiana contra Pseudomonas aeruginosa de Ciprofloxacina liberada desde microesferas de alginato-gelatina con y sin tratamiento con glutaraldehído. 


\subsection{Conclusiones}

A largo del presente capitulo se han logrado los objetivos planteados inicialmente y las conclusiones obtenidas se enumeran a continuación:

- Se establecieron las condiciones de gelificación de matrices compuestas de alginato. Se generaron microesferas en presencia de $\mathrm{CaCl}_{2} 500 \mathrm{mM}$.

- La formulación de alginato conteniendo Ciprofloxacina se sintetizó a pH=4,0, condición en donde el antibiótico posee una alta estabilidad y es encapsulado en mayor porcentaje.

- Fue estudiada la influencia de la formación de un complejo de alta solubilidad entre el ión calcio y la Ciprofloxacina durante el desarrollo del proceso de encapsulamiento.

- Se determinaron las mejores condiciones de gelificación y encapsulamiento de Cipro, empleando 1,2-propilenglicol en el medio de síntesis, hecho que permite encapsular la Ciprofloxacina en porcentajes mayores al $90 \%$ en matrices biopoliméricas.

- A su vez, se demostró que las soluciones acuosas de 1,2-PG (1:1) son óptimas para generar una matriz estable, actuando como crio-protector y favoreciendo el ordenamiento de los biopolímeros para formar una malla ordenada.

- Se demostró que la matriz de alginato puede cargar concentraciones crecientes de Ciprofloxacina (desde $36,0 \mu \mathrm{g} / \mathrm{ml}$ a $2,0 \mathrm{mg} / \mathrm{ml}$ ), debido en una primera etapa a los sitios de interacción del polímero con el fármaco, y en una segunda por procesos de apilamiento entre las mismas moléculas de antibiótico.

- Se determinó que la presencia de aditivos como pectinas y gelatinas en la formulación brindan perfiles de liberación menores al $50 \%$ en dos horas de incubación en condiciones de $\mathrm{pH}$ estomacal humano y se detectaron dos candidatos: pectinas y gelatina. 
- Dentro de las pectinas, las de alto metoxilo poseen una interacción preferencial con la Ciprofloxacina. La misma fue corroborada mediante ensayos de coprecipitación del polímero con la droga unida y mediante FTIR.

- A su vez, se detectaron interacciones entre la Cipro y la gelatina de tipo B determinadas mediante ensayos de precipitación y FTIR.

- Las matrices compuestas en una proporción de alginato $2,0 \%(p / v)$ biopolímero (sea pectina o gelatina) $1,0 \%(\mathrm{p} / \mathrm{v})$ mostraron homogeneidad $y$ perfiles de liberación adecuados para su administración por vía oral.

- La doble reticulación de la matriz de alginato-gelatina en presencia de iones calcio y glutaraldehído permite aumentar la estabilidad de la matriz y disminuir los perfiles de liberación de Ciprofloxacina.

- Se comprobó que la Ciprofloxacina liberada de estas matrices era capaz de inhibir en el tiempo a la cepa patógena Pseudomonas aeruginosa. 


\subsection{Bibliografía}

Antonov Y. A., Lashko N. P., Glotova Y. K., Malovikova A., Markovich O., Effect of the structural features of pectins and alginates on their thermodynamic compatibility with gelatin in aqueous media. Food Hydrocolloid 1996, 10, 1.

Appelbaum P. C., Hunter P. A., The fluoroquinolone antibacterials: past, present and future perspectives. International Journal of Antimicrobial Agents 2000, 16, 5.

Augst A. D., Kong H. J., Mooney D. J., Alginate Hydrogels as Biomaterials. Macromol. Biosci. 2006, 6, 623.

Bald M., Ratjen F., Nikolaizik W., Wingen A. M., Ciprofloxacin induced acute renal failure in a patient with cystic fibrosis. Pediatr Infect Dis J 2001, 20, 320.

Barbosa J., Barrón D., Jiménez-Lozano E., Sanz-Nebot V., Comparison between capillary electrophoresis, liquid chromatography, potentiometric and spectrophotometric techniques for evaluation of pKa values of zwitterionic drugs in acetonitrile-water mixtures. Analytical Chimica Acta 2001, 437, 309.

Botté C. Y., Dubar F., McFadden G. I., Maréchal E., Biot C., Plasmodium falciparum apicoplast drugs: targets or off-targets? . Chem Rev. 2012, 112, 1269.

Bourne M. C., Comstock S. H., Effect of degree of compression on texture profile analysis. J Texture Stud 1981, 12, 201.

Braccini I., Perez S., Molecular basis of $\mathrm{Ca}^{2+}$-induced gelation in alginates and pectins: the eggbox model revisited. Biomacromolecules 2001, 2, 1089.

Breda S. A., Jimenez-Kairuz A. F., Manzo R. H., Olivera M. E. Solubility behavior and biopharmaceutical classification of novel high-solubility ciprofloxacin and norfloxacin pharmaceutical derivatives. International Journal of Pharmaceutics 2009, 371, 106.

Chan L. W., Heng P. W., Effects of aldehydes and methods of crosslinking on properties of calcium alginate microspheres prepared by emulsification. Biomaterials 2002, 23, 1319.

Conil J. M., Georges B., de Lussy A., Khachman D., Seguin T., Ruiz S., y col., Ciprofloxacin use in critically ill patients: pharmacokinetic and pharmacodynamic approaches. International Journal of Antimicrobial Agents 2008, 32, 505.

Dini C., Islan G. A., de Urraza P. J., Castro G. R., Novel Biopolymer Matrices for Microencapsulation of Phages: Enhanced Protection Against Acidity and Protease Activity. Macromol. Biosci. 2012, 12, 1200. 
Dong Z., Wang Q., Du Y., Alginate/gelatin blend films and their properties for drug controlled release. J Membr Sci 2006, 280, 37.

Ebokwa C. J., Okeri H. A., Aqueous solubility of ciprofloxacin in the presence of metal cations. Tropical Journal of Pharmaceutical Research 2007, 4, 349.

Fang Y., Al-Assaf S., Phillips G. O., Nishinari K., Funami T., Williams P. A., Binding Behavior of Calcium to Polyuronates. Part II. Comparison of Pectin with Alginate. Carbohydrate Polymers 2008, 72, 334

Gilsenan P., Richardson R., Morris E., Associative and segregative interactions between gelatin and low-methoxy pectin: part 1.Associative interactions in the absence of $\mathrm{Ca}^{2+}$. Food Hydrocolloid 2003, 17, 723.

Harrington J. C., Morris E. R., Conformational ordering and gelation of gelatin in mixtures with soluble polysaccharides. Food Hydrocolloid 2009, 23, 327.

Hernández-Borrell J., Montero M. T., Does ciprofloxacin interact with neutral bilayers? An aspect related to its antimicrobial activity. International Journal of Pharmaceutics 2003, 252, 149.

Huang X., Brazel C. S., On the importance and mechanisms of burst release in matrix-controlled drug delivery systems. J Control Release 2001, 73, 121.

Islan G. A., Perez de Verti I., Marchetti S. G., Castro G. R., Studies of ciprofloxacin encapsulation on alginate/pectin matrixes and its relationship with biodisponibility. Appl. Biochem. Biotechnol. 2012, 167, 1408.

Klak M. C., Lefebvre E., Rémy L., Agniel R., Picard J., Giraudier S., Larreta-Garde V., Gelatinalginate gels and their enzymatic modifications: controlling the delivery of small molecules. Macromol Biosci 2013, 6, 687.

Kuijpers A. J., Engbers G. H., Krijgsveld J., Zaat S. A., Dankert J., Feijen J., Cross-linking and characterisation of gelatin matrices for biomedical applications. J Biomat Sci - Polym E 2000, 11, 225.

Liu L., Fishman M. L., Kost J., Hicks K. B. Pectin-based systems for colon-specific drug delivery via oral route. Biomaterials 2003, 24, 3333.

Maurer N., Wong K. F., Hope M. J., Cullis P. R., Anomalous solubility behavior of the antibiotic ciprofloxacin encapsulated in liposomes : $a{ }^{1} \mathrm{H}-\mathrm{NMR}$ study. Biochim. Biophys. ActaBiomembr. 1998, 1374, 9.

Narayani R., Rao K. P., Polymer-coated gelatin capsules as oral delivery devices and their gastrointestinal tract behaviour in humans. J Biomat Sci - Polym E 1996, 7, 39.

Patterson D. R., Quinolone toxicity: methods of assessment. Am J Med 1991, 91, 35 S. 
Proesmans M., Vermeulen F., Boulanger L., Verhaegen J., De Boeck V., Comparison of two treatment regimens for eradication of Pseudomonas aeruginosa infection in children with cystic fibrosis. J. Cyst. Fibro. 2013, 12, 29.

Ramesh E., Manian R. D. R. S., Raghunathan R., Sainath S., Raghnathan M., Synthesis and antibacterial property of quinolines with potent DNA gyrase activity. Bioorg. Med. Chem. $2009,17,660$.

Rose P., Gelatin. In: KroschWitz Jl ed. Concise enciclopedia of polymer science and engineering. New York, NY: Wiley, 1990.

Rouge N., Buri P., Doelker E., Drug absorption sites in the gastrointestinal tract and dosage forms for site-specific delivery. International Journal of Pharmaceutics 1996, 136, 117.

Roy A., Bajpai J., Bajpai A., Development of calcium alginate-gelatin based microspheres for controlled release of endosulfan as a model pesticide. Indian J Chem Tech 2009, 16, 388.

Saarai A., Kasparkova V., Sedlacek T., Saha P., On the development and characterisation of crosslinked sodium alginate/gelatin hydrogels. J Mech Behav Biomed Mater 2013, 18, 152.

Sandoval-Castilla O., Lobato-Calleros C., García-Galindo H. S., Alvarez-Ramírez J., Vernon-Carter E. J., Textural properties of alginate-pectin beads and survivability of entrapped Lb. casei in simulated gastrointestinal conditions and in yoghurt. Food Research Internat. 2010, 43, 111.

Seedher N., Agarwal P., Complexation of fluoroquinolone antibiotics with human serum albumin: A fluorescence quenching study. Journal of Luminescence 2010, 130, 1841.

Simpson N. E., Stabler C. L., Simpson C. P., Sambanis A., Constantinidis I., The role of the $\mathrm{CaCl}_{2}$ guluronic acid interaction on alginate encapsulated BTC3 cells. Biomaterials 2004, 25, 2603.

Socrates G., Infrared and Raman characteristic group frequencies: tables and charts. 2004, 3th Edition, John Wiley \& Sons, USA.

Sun J., Sakai S., Tauchi Y., Deguchi Y., Chen J., Zhang R., Morimoto K., Determination of lipophilicity of two quinolone antibacterials, ciprofloxacin and grepafloxacin, in the protonation equilibrium. Eur. J. of Pharmaceutics and Biopharmaceutics 2002, 54, 51.

Talukder R., Fassihi R., Gastroretentive delivery systems: a mini review. Drug Dev. Ind. Pharm. 2004, 30, 1019.

Tapia C., Ormazabal V., Costa E., Yazdani-Pedram M., Study of dissolution behavior of matrices tablets based on alginate-gelatin mixtures as prolonged diltiazem hydrochloride release systems. Drug Dev Ind Pharm 2007, 33, 585.

Thakur B. R., Singh R. K., Handa A. K., Chemistry and uses of pectin - A review. Critical Reviews in Food Science and Nutrition 1997, 37, 47.

Tomišić Z. B., Kujundžić N., Krajačić M. B., Višnjevac A., Kojić-Prodić B., Molecular structures of new ciprofloxacin derivatives. Journal of Molecular Structure, 2002, 611, 73. 
Velings N. M., Mestdagh M. M., Physico-Chemical Properties of Alginate Gel Beads. Polym. Gels Netw. 1995, 3, 311.

Walkenström P., Kidman S., Hermansson A. M., Rasmussen P. B., Hoegh L., Microstructure and rheological behaviour of alginate/pectin mixed gels. Food Hydrocolloids 2003, 17, 593.

Wang Y. W., Wu Q., Chen G. Q., Gelatin blending improves the performance of poly(3hydroxybutyrate-co-3-hydroxyhexanoate) films for biomedical application. Biomacromolecules 2005, 6,566.

Webb M. S., Boman N. L., Wiseman D. J., Saxon D., Sutton K., Wong K. F., Logan P., Hope M. J., Antibacterial Efficacy against an In Vivo Salmonella typhimurium Infection Model and Pharmacokinetics of a Liposomal Ciprofloxacin Formulation. Antimicrob. Agents Chemother. 1998, 42, 45. 


\section{CAPITULO 2}

\section{Incorporación de una enzima}

\section{hidrolítica a la matriz; Efectos de}

\section{la co-inmovilización}

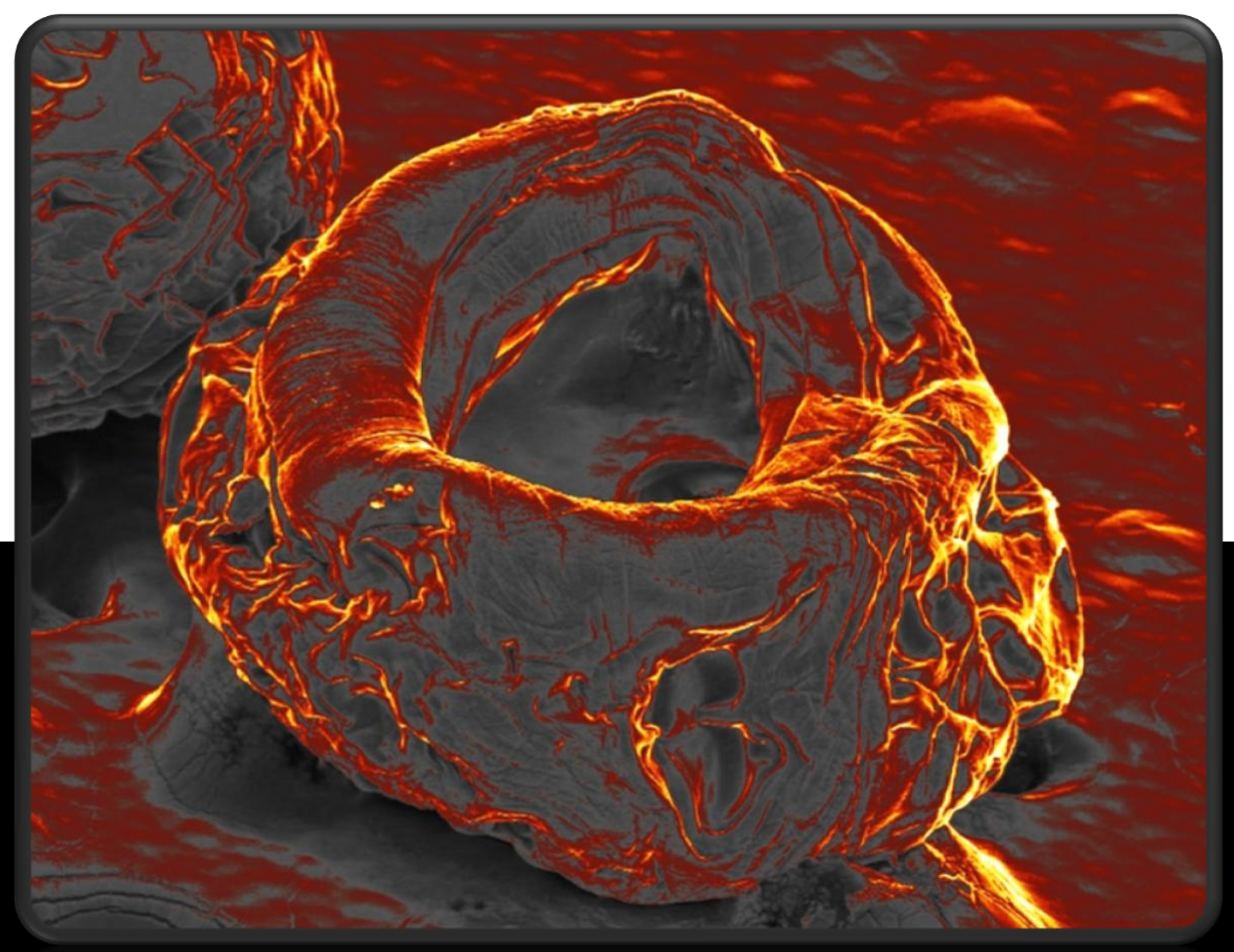

Matriz de alginato conteniendo Ciprofloxacina y Alginato Liasa. Imagen de microscopia electrónica de barrido a $100 x$ 


\section{Objetivos específicos}

* Selección de una enzima hidrolítica de la mucosidad típica de pacientes con FQ.

* Estudio de los principales parámetros característicos de la enzima.

* Establecimiento de las condiciones óptimas de incorporación de la enzima en una matriz biopolimérica.

* Evaluación de la actividad enzimática en condiciones fisiológicas.

* Efecto de la co-inmovilización de la enzima y la Ciprofloxacina sobre la encapsulación, liberación y actividad de ambos.

Evaluación de la citotoxicidad de la matriz desarrollada.

2.1. Introducción

2.2. Materiales y métodos

* Materiales ... 89

* Preparación de microesferas de alginato como matriz base para la encapsulación de Cipro y AL ... 89

* Medición y cálculo del porcentaje de encapsulación de Cipro y AL ... 89

* Cinética de liberación de Cipro y AL a partir de microesferas ... 89

* Evaluación de la actividad de Alginato Liasa ... 90

* Medición de la proteína liberada ... 90

* Recubrimiento de microesferas con proteína modelo: Albumina de suero bovino (BSA) ... 91

* Evaluación de la actividad de la AL en presencia de Ciprofloxacina ... 91

* Evaluación de la actividad bactericida de la Cipro frente a Ps. aerug. en presencia de AL ... 92

* Ensayos de hinchamiento de la matriz ... 92

* Calorimetría diferencial de barrido (DSC) ... 93

* Medición de parámetros texturométricos ... 93

* Microscopia electrónica de barrido (SEM) ... 93

* Análisis de superficie de las imágenes de SEM ... 94

* Ensayo de citotoxicidad in vitro ... 94

2.3. Resultados y discusión

* Propiedades de la Alginato Liasa ... 96

* Selección de la matriz apta para encapsular la AL ... 99

* Matriz de alginato-gelatina ... 99

* Matriz de alginato-pectina ... 101

* Efecto de la co-inmovilización de AL y Cipro en matriz de alginato-PAM ... 104

* Caracterización de la matriz de alginato-PAM en ambientes fisiológicos ... 105

2.4. Conclusiones 


\subsection{Introducción}

Las formulaciones orales representan la plataforma más sencilla para la administración de fármacos en los pacientes. En el capítulo anterior, se planteó el desarrollo de dos tipos de microesferas basadas en biopolímeros: unas a base de alginato/pectina de alto metoxilo y otras de alginato/gelatina. Ambas fueron diseñadas para encapsular Ciprofloxacina en altos porcentajes y proporcionaron perfiles de liberación controlada del antibiótico.

No obstante, considerando que la cepa mucoide de Pseudomonas aeruginosa es capaz de producir grandes cantidades de alginato, el mismo constituye una biopelícula que representa una barrera difusional, con lo cual la administración de antibióticos libres no resulta eficaz para el tratamiento de la patología (Suci y col., 1994). En este sentido, la utilización de alginato liasa, enzima capaz de hidrolizar alginato, surge como una alternativa para el tratamiento de los pacientes (Mrsny y col., 1994; Alkawash y col., 2006). La utilización de esta enzima podría ser de gran utilidad para la reducción de la viscoelasticidad del esputo y la erradicación de la infección (Hatch y col. 1998).

La alginato liasa (AL) es una poli( $\beta$-D-manuronato) liasa (E.C. 4.2.2.3) con características de endo-hidrolasa, que actúa sobre las uniones $\beta$-1,4-glicosídicos a través de una reacción de $\beta$-eliminación para producir mono-, di- y tri-oligosacáridos (Wong y col., 2000). Como consecuencia de la hidrólisis del alginato, se observa una disminución de la viscosidad de la solución. Se pueden caracterizar como liasas específicas de PoliM-, polig-, y poliMG basados en la especificidad de sustrato (Figura 2.1) (Kim y col., 2011). Trabajos previos han demostrado que la AL promueve la difusión de aminoglucósidos a través del polisacárido extracelular de las cepas mucoides (Hatch y col. 1998; Alkawash y col., 2006). Teniendo en cuenta que la concentración de alginato en el esputo se ha detectado en el intervalo comprendido entre 78 a 192 Mg/ml en pacientes con FQ, (Mrsny y col., 1994) sólo pocas unidades de AL serían necesaria para reducir la viscosidad de las exacerbaciones purulentas presentes en el intestino (An y col., 2008). 


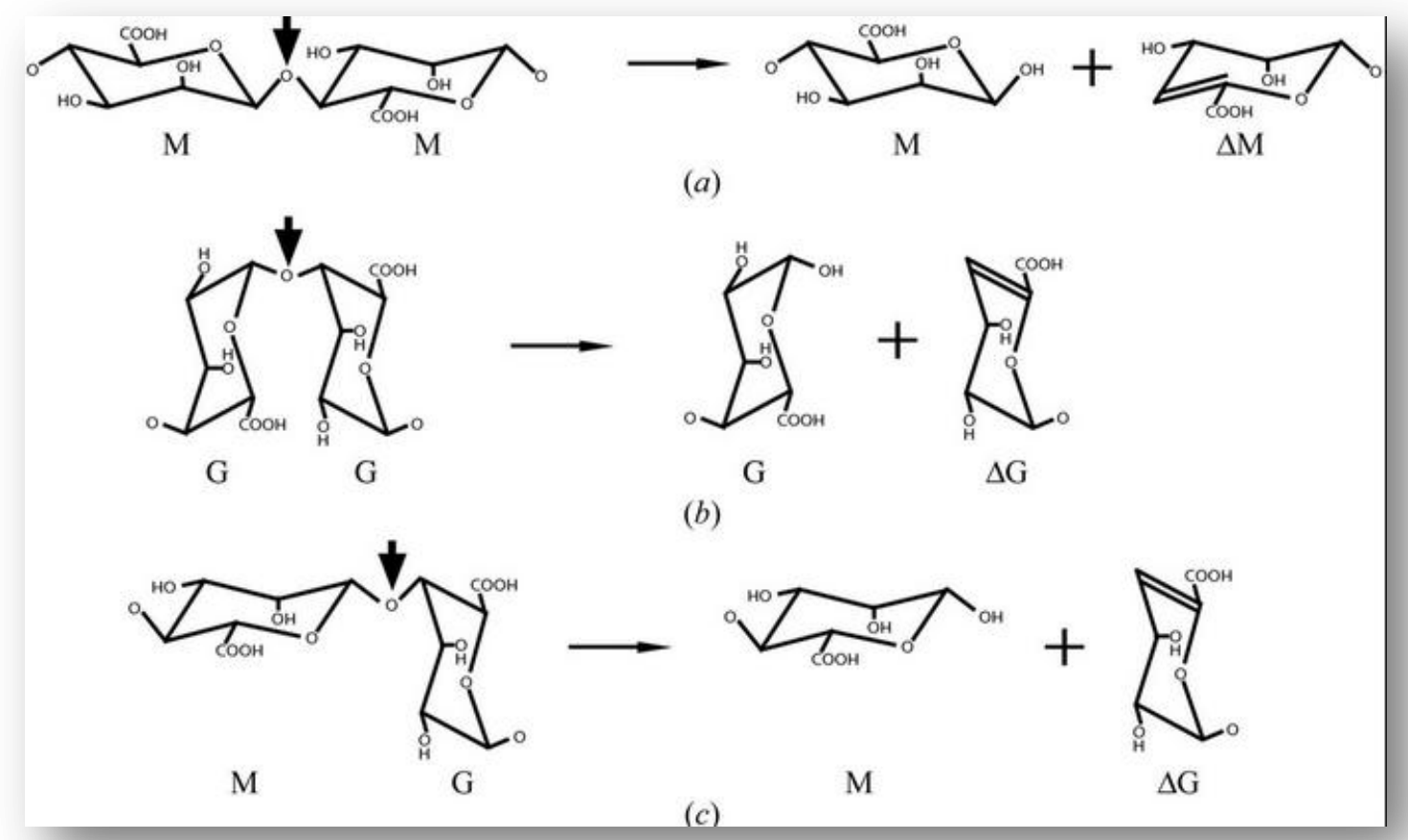

Figura 2.1 Reacción enzimática de la alginato liasa (AL) sobre la cadena de alginato. La AL puede tener especificidad sobre uniones poliM (a); poliG (b) y poliMG (c). Imagen (Yamasaki y col., 2005).

Por todo lo descripto anteriormente, en éste capítulo estudiaremos la coinmovilización de la Ciprofloxacina con una alginato liasa, mediante el desarrollo de una matriz que permita encapsular y liberar ambos agentes de forma eficaz, de conservar la actividad biológica de ambos, de no presentar efectos tóxicos para las células de mamífero, y de mostrar algún tipo de efecto sinérgico en la acción conjunta del antibiótico con la enzima hidrolítica, como potencial herramienta para la erradicación de la infección producida por Pseudomonas aeruginosa en pacientes con Fibrosis Quística. 


\subsection{Materiales y métodos}

\section{Materiales}

La alginato liasa ( $\mathrm{AL}$ ) de Flavobacterium sp. fue adquirida de Sigma-Aldrich (St. Louis, MO, EE.UU.). La albumina de suero bovino (BSA) conjugada con AlexaFluor ${ }^{\circledR} 488$ $\left(\mathrm{BSA}^{*}\right.$ ) se adquirió a Molecular Probes (Invitrogen, Eugene, OR). La cepa de colección Pseudomonas aeruginosa ATCC 15442 fue utilizada en los experimentos.

Preparación de microesferas de alginato como matriz base para la encapsulación de Ciprofloxacina y Alginato Liasa

Fue preparada una solución de alginato de sodio al 2,0\% (p/v) con otro biopolímero al 1,0\% (p/v) (pectina de alto metoxilo o gelatina tipo B) en una solución reguladora de acético/acetato de sodio $25 \mathrm{mM}(\mathrm{pH}=4,00)$. A su vez, a esta solución se le adicionó Ciprofloxacina $(36,0 \mu \mathrm{g} / \mathrm{ml})$ y alginato liasa $(1,0 \mathrm{mg} / \mathrm{ml} ; 40,0$ Unidades $/ \mathrm{ml})$ bajo agitación suave en baño de hielo (para evitar que la AL degrade el alginato). Las microesferas se prepararon goteando la mezcla polimérica resultante en una solución de $\mathrm{CaCl}_{2} 500 \mathrm{mM}$ y 1,2-propilenglicol 50\% (v/v) en baño de hielo. Después de 20 minutos, las microesferas se filtraron, se lavaron con agua bidestilada, se secaron 5 minutos a $25^{\circ} \mathrm{C}$ y se guardaron a $5^{\circ} \mathrm{C}$ para su posterior utilización.

\section{Medición y cálculo del porcentaje de encapsulación de Cipro y AL}

El cálculo de la encapsulación de Cipro ha sido descrito en la sección mat. y met. del capítulo 1 (página 13). En el caso de la AL, se evaluó la actividad resultante y la proteína total en el filtrado. Considerando la cantidad de unidades enzimáticas iniciales y la enzima remanente en el sobrenadante, se pudo estimar el porcentaje encapsulado.

\section{Cinética de liberación de Cipro y AL a partir de microesferas}

Una masa de $200 \mathrm{mg}$ de microesferas húmedas se incubaron en 2,0 $\mathrm{ml}$ de una solución reguladora $\mathrm{KCl} / \mathrm{HCl}(50 \mathrm{mM}, \mathrm{pH} \mathrm{1,20)}$ o de una de fosfato $(40 \mathrm{mM}, \mathrm{pH} 7,40)$ 
simulando el pH estomacal y el intestinal respectivamente, bajo agitación constante a $100 \mathrm{rpm}$ y $37^{\circ} \mathrm{C}$. A intervalos de tiempo definidos, un volumen de $1,0 \mathrm{ml}$ fue retirado y se realizo la medida de la concentración de Cipro liberada por absorbancia al pH correspondiente. A su vez, se determinó la cantidad de proteína liberada y la actividad enzimática de la AL. Finalmente, $1,0 \mathrm{ml}$ de medio fresco fue repuesto para mantener el volumen del medio de liberación constante, bajo un modelo que supone un estado de "no equilibrio" de las microesferas en solución, similar a las condiciones dinámicas que experimentarían en el tracto gastrointestinal.

\section{Evaluación de la actividad de Alginato Liasa}

Se mezclaron $75 \mu \mathrm{l}$ de solución de Alginato Liasa con 1,925 ml de solución de alginato al 2,0\% (p/v) (preparado en una solución reguladora fosfato $25 \mathrm{mM}, \mathrm{pH}=7,40$ ) y se incubo a $37^{\circ} \mathrm{C}$ durante 30 minutos. La reacción se detuvo mediante la adición de 2,0 $\mathrm{ml}$ de $\mathrm{NaOH}(100 \mathrm{mM}$ ) y se midió la absorbancia resultante a $233 \mathrm{~nm}$.

Efecto del pH sobre la actividad de AL se determinó como se mencionó previamente, pero ajustando el $\mathrm{pH}$ de la solución de alginato $2,0 \%(\mathrm{p} / \mathrm{v})$ con una solución reguladora acético/acetato de sodio $50 \mathrm{mM}(\mathrm{pH}=4,00$ y 5,00) y en solución reguladora fosfato $25 \mathrm{mM}$ (pH 6,30; 6,80; 7,40 y 8,20).

Una unidad de AL se definió como la cantidad de enzima capaz de aumentar 1 unidad de absorbancia a $233 \mathrm{~nm}$ en $1 \mathrm{~min}$ por $\mathrm{ml}$ de solución de alginato a $\mathrm{pH}=7,40$ y $37^{\circ} \mathrm{C}$.

\section{Medición de la proteína liberada}

La concentración de proteínas fue determinada utilizando fluorescamina. La técnica empleada fue la siguiente: $50 \mu \mathrm{l}$ de la muestra se mezclaron con $350 \mu \mathrm{l}$ de solución reguladora borato 0,0125 M (pH=9,00) y $125 \mu \mathrm{l}$ de fluorescamina $(300 \mu \mathrm{g} / \mathrm{ml}$ en acetona). Después de 2 minutos, se determinó la fluorescencia con un $\lambda_{\mathrm{ex}}=390 \mathrm{~nm}$ y $\lambda_{\mathrm{em}}=478 \mathrm{~nm}$ en un espectrofluorímetro (Perkin Elmer modelo LS 50B). Para estimar la concentración de proteínas se desarrollo una curva de calibración en función de la concentración de una proteína estándar, en nuestro caso se empleó BSA (albumina de suero bovino fracción V). 
Recubrimiento de microesferas con proteína modelo: Albumina de suero bovino (BSA)

Se utilizó BSA como proteína modelo para ensayar la capacidad de las microesferas de alginato/gelatina (previamente activadas por el tratamiento con glutaraldehído) de unir proteínas a superficie. Brevemente, microesferas sintetizadas en la presencia de 1,2-propilenglicol y glutaraldehído se filtraron, se lavaron con agua ultrapura, y se colocaron en contacto con una solución de BSA $(10,0 \mathrm{mg} / \mathrm{ml})$ a pH 4,0 durante $10 \mathrm{~min}$ a $0^{\circ} \mathrm{C}$. Posteriormente, las microesferas se lavaron y se almacenaron a $5^{\circ} \mathrm{C}$. La presencia de BSA en la superficie de las microesferas fue observado mediante imágenes de SEM, y se evaluó su influencia sobre la liberación de Ciprofloxacina.

Para confirmar la interacción de BSA con las microesferas y descartar posibles cambios en la superficie por posible degradación de la matriz, el protocolo se repitió mediante el uso de BSA fluorescente, conjugada con Alexa Fluor 488. Microesferas tratadas con glutaraldehído y no tratadas se observaron al microscopio de epifluorescencia Leica DM 2500 (Leica Microsystems, Buffalo Grove, IL) en modo visible y de fluorescencia con un filtro de excitación azul (450-490 nm).

Por último, se realizó la cuantificación de BSA para determinar las relaciones de masa de proteína/microesfera. Se repitió el protocolo de incubación, y luego de filtrar las microesferas se almacenó el líquido remanente. En el mismo, fue determinada la cantidad de BSA no unida mediante espectrofotometría UV-Visible a $280 \mathrm{~nm}$, y se la correlaciono con una curva de calibración adecuada. Por diferencia entre la cantidad inicial y la BSA determinada en el filtrado se efectuó el cálculo de la cantidad de BSA adsorbida en las microesferas.

\section{Evaluación de la actividad de la AL en presencia de Ciprofloxacina}

Microesferas (200 mg) que contienen $\mathrm{AL}(40,0 \mathrm{U} / \mathrm{ml})$ se disolvieron en 2,0 $\mathrm{ml}$ de solución reguladora fosfato $50 \mathrm{mM}(\mathrm{pH}=7,40)$. Un mililitro de volumen de la muestra se mezcló con 1,0 $\mathrm{ml}$ de alginato 2,0\% (p/v) (preparada en solución reguladora fosfato $25 \mathrm{mM}, \mathrm{pH}$ 7,40) en presencia y ausencia de 36,0 $\mathrm{mg} / \mathrm{ml}$ de Ciprofloxacina fueron incubados a $37^{\circ} \mathrm{C}$ durante $30 \mathrm{~min}$. La actividad fue determinada como se mencionara previamente y comparada entre ambas condiciones experimentales (con y sin Cipro). 
Evaluación de la actividad bactericida de la Ciprofloxacina frente a Pseudomonas aeruginosa en presencia de concentraciones crecientes de $\mathrm{AL}$

La actividad de la Ciprofloxacina fue ensayada en Pseudomonas aeruginosa ATCC 15442 (bacteria Gram-negativa no fermentadora) utilizando el método de difusión en agar de acuerdo con CLSI/NCCLS, pero sustituyendo los discos por cilindros de vidrio estériles de $8 \mathrm{~mm}$ × $6 \mathrm{~mm}$ × $10 \mathrm{~mm}$ (diámetro externo e interno y longitud). Brevemente, se tomaron de cuatro a cinco colonias del microorganismo y se resuspendieron en solución fisiológica estéril para ajustar la turbidez del cultivo a menos de $3 \times 10^{8}$ UFC/ml (0,5 en la escala Mc Farland). Vale aclarar que dicha escala se prepara a partir de diluciones de una solución de cloruro de bario al $1 \%$ con ácido sulfúrico al $1 \%$, cuya densidad óptica se utiliza como referencia de un número determinado de bacterias por mililitro. Placas de agar de $10 \mathrm{~cm}$ de diámetro fueron cargadas con $25 \mathrm{ml}$ de agar Mueller-Hinton y secada en flujo laminar durante 30 minutos. Luego, fueron inoculadas con la suspensión bacteriana, usando un hisopo de algodón estéril. Dentro de los 5 minutos se colocan los cilindros y se siembran $25 \mu \mathrm{lde}$ cada una de las soluciones conteniendo Cipro $10 \mu \mathrm{g} / \mathrm{ml}$ con diferentes cantidades de $\operatorname{AL}(0,4 ; 2,0 ; 4,0$, y $20,0 \mathrm{U} / \mathrm{ml})$ dentro de los cilindros. Las placas se incuban a $37^{\circ} \mathrm{C}$ durante 24 h. Finalmente, los halos de inhibición fueron medidos.

\section{Ensayos de hinchamiento de la matriz}

Se pesaron $100 \mathrm{mg}$ de microesferas secas (liofilizadas) y se colocaron en tubos plásticos de 1,0 ml (tipo Eppendorf previamente tarados). Se agregó 1,0 $\mathrm{ml}$ de solución reguladora de TRIS- $\mathrm{HCl} 10 \mathrm{mM}$ o de fosfato $10 \mathrm{mM}, \mathrm{pH}=7,0$, y se comenzó a cronometrar el tiempo. A diferentes tiempos, se removió la totalidad del medio líquido y se pesaron las microesferas hidratadas. Luego se repuso $1,0 \mathrm{ml}$ de medio fresco y se continúo con la cinética de hinchamiento. 


\section{Calorimetría diferencial de barrido (DSC)}

Se obtuvo el perfil de DSC de las muestras utilizando el equipo DSC Q2000-TA Instrument. Brevemente, se colocaron 5,0 mg de microesferas liofilizadas en una cápsula estándar de aluminio, se cerró herméticamente y posteriormente fue calentado a una velocidad constante de $10^{\circ} \mathrm{C} / \mathrm{min}$ desde temperatura ambiente hasta $225^{\circ} \mathrm{C}$, bajo purga de nitrógeno a $20 \mathrm{ml} / \mathrm{min}$. Todas las muestras se ensayaron por triplicado.

\section{Medición de parámetros texturométricos}

La textura de las microesferas fue analizada en un Analizador de Textura TAXT 2i (Stable Micro Systems Ltd, Godalming, UK) equipado con una célula de carga de 25 kg y un plato cilíndrico metálico de compresión de $75 \mathrm{~mm}$ de diámetro (p75). El análisis del perfil de textura (TPA), que consiste en dos ciclos de compresión a 0,6 mm/seg a un $30 \%$ de la altura original de las microesferas. En cada ensayo, tres microesferas fueron simultáneamente comprimidas. Los datos se procesaron con el programa Texture Expert ${ }^{\circledast}($ Texture Expert, Hamilton, MA) y los parámetros de textura (de dureza y cohesividad) se calcularon a partir la curva TPA de fuerza (N) en función del tiempo (s) con las siguientes definiciones (Bourne y Comstock, 1981): Dureza (N) se define como la fuerza máxima durante el primer ciclo de compresión; cohesividad (adimensional) se define como la relación entre las áreas bajo la segunda y la primer compresión (A2/A1). Los resultados representan los promedios de al menos un triplicado de la muestra.

\section{Microscopia electrónica de barrido (SEM)}

Las microesferas fueron liofilizadas durante 24 horas antes de realizar la microscopía electrónica de barrido (SEM). Luego, las muestras fueron recubiertas en su superficie con oro pulverizado mediante un metalizador Balzers SCD 030 hasta obtener un espesor de capa entre 15 a $20 \mathrm{~nm}$. La superficie y morfología de las microesferas fueron observadas con el equipo Philips SEM 505 (Rochester, EE.UU.), y las imágenes procesadas por un programa digitalizador de imágenes (Soft Imaging System ADDA II (SIS)). 


\section{Análisis de superficie de las imágenes de SEM}

Imágenes de SEM fueron analizados con el programa ImageJ (NIH, EE.UU.). La rugosidad de la superficie se refleja por la variación en los valores de grises de todos los píxeles de la imagen. En primer lugar, los archivos de imagen de SEM fueron abiertos con el programa y convertidos a una imagen de 8 bits. Luego, se seleccionaron todos los píxeles de la imagen y los parámetros de superficie fueron medidos (histograma, desviación estándar de los valores de grises). Cuanto menor sea el valor de la desviación estándar, menos rugosa será la superficie. Los histogramas obtenidos se realizaron por duplicado de las imágenes de SEM a 710x.

\section{Ensayo de citotoxicidad in vitro}

Reducción de sales de metiltetrazolio (MTT)

Como alternativa para evaluar el potencial daño citotóxico de la matriz obtenida y de la Cipro encapsulada en dicha matriz, se realizó el test de citotoxicidad MTT (Weyermann y col., 2005). El método se basa en que las células viables y metabólicamente activas en cultivo son capaces de reducir sales de tetrazolio a un producto insoluble de coloración intensa (formazán) a través de reductasas mitocondriales, con lo que la actividad enzimática se detecta colorimétricamente debido al cambio de color.

Se utilizó la línea celular CHO-K1, células epiteliales de ovario de hámster chino, por ser de amplia respuesta en evaluaciones de citotoxicidad para un amplio rango de sustancias. Las células fueron mantenidas en cultivo en medio Ham's F10, 10\% Suero fetal bovino (SFB) a $37^{\circ} \mathrm{C}$ y $5 \% \mathrm{CO}_{2}$. Las concentraciones de Cipro elegidas para la evaluación se definieron en base a ensayos de citotoxicidad entre valores de 0 y 500 $\mu \mathrm{g} / \mathrm{ml}$. A partir de $100 \mathrm{ug} / \mathrm{ml}$ la viabilidad celular disminuye proporcionalmente por lo que se eligieron los valores de 0,50, 100 y $200 \mathrm{ug} / \mathrm{ml}$ como puntos de evaluación. Se partió de una solución stock $10 \mathrm{mg} / \mathrm{ml}$ en solución reguladora acético/acetato $0,1 \mathrm{M}$ $\mathrm{pH}=4,0$, que se diluyó con agua destilada estéril a $4 \mathrm{mg} / \mathrm{ml}$ y a partir de la cual se prepararon las diluciones correspondientes en medio de cultivo.

Las microesferas se acondicionaron por disgregación total. Para ello, $250 \mathrm{mg}$ se incubaron con $2,0 \mathrm{ml}$ de solución reguladora fosfato $0,1 \mathrm{M}$ a $\mathrm{pH}=7,4$ durante 30 
minutos a $37^{\circ} \mathrm{C}$. La suspensión obtenida se centrifugó por 5 minutos a $9000 \mathrm{rpm}$ para eliminar los restos agregados de matriz y se trabajó con el sobrenadante.

Se sembraron 10.000 células/pocillo en una placa de 96 pocillos. Se cultivaron durante 24 horas en las condiciones antes descriptas, permitiendo su adherencia y replicación. Luego, se expusieron las células a las diluciones correspondientes de Cipro $(0,50,100$ y $200 \mu \mathrm{g} / \mathrm{ml})$ y de la matriz, así como de sus combinaciones (considerando un $70 \%$ de encapsulamiento de Cipro, que corresponde a $11 \mu \mathrm{g} / \mathrm{mg}$ matriz, y un $100 \%$ de liberación) durante otras 24 horas. Así, cada dilución fue evaluada por sextuplicado. Finalizado el período de exposición se colocaron $100 \mu \mathrm{l}$ de solución de MTT $(0,5 \mathrm{mg} / \mathrm{ml}$ conc. final, disuelto en medio de cultivo sin SFB y sin Rojo Fenol) en cada pocillo y se incubó durante 3 hs. Luego, se monitoreo microscópicamente la presencia de cristales violáceos dentro de las células, indicativos del formazán precipitado. Se quitó el sobrenadante cuidadosamente, se lavó con PBS y se agregaron $100 \mu \mathrm{l}$ de DMSO. Luego de una corta incubación a temperatura ambiente para permitir la completa disolución, se leyó la absorbancia en un lector de placas a $550 \mathrm{~nm}$. El ensayo fue realizado por triplicado. Los datos de absorbancia obtenidos fueron analizados de manera de obtener el porcentaje de viabilidad celular en función de las distintas concentraciones y condiciones ensayadas. Los resultados fueron analizados por medio del test estadístico Anova y post tests de Bonferroni y de Tuckey para determinar diferencias significativas entre las poblaciones analizadas, considerando $p<0,05$.

Prueba de Rojo Neutro

El método determina la acumulación del colorante Rojo Neutro en los lisosomas de las células viables. El procedimiento experimental fue similar al descripto anteriormente para el ensayo con MTT, con la modificación de que luego de exponer las células a los agentes a testear (Cipro, matriz y ambas) se adicionaron $100 \mu \mathrm{l}$ de solución de Rojo Neutro (30 mg/ml en solución reguladora fosfato) y se incubó por dos horas. Finalizado el proceso de incubación se procedió a realizar los lavados con PBS y resuspensión en DMSO. Finalmente la absorbancia a $540 \mathrm{~nm}$ fue determinada (Fotakis y col., 2006). 


\subsection{Resultados y discusión}

En base a los estudios realizados en el capítulo anterior, dos matrices biopoliméricas cumplieron con las características buscadas:

* Microesferas de alginato 2,0\% (p/v)- gelatina 1,0\% (p/v) (formulación a $\mathrm{pH}=4,0)$ gelificadas en presencia de $\mathrm{CaCl}_{2} 500 \mathrm{mM}$, 1,2-propilenglicol $50 \%$ (v/v) y glutaraldehído $2,5 \%(\mathrm{p} / \mathrm{v})$. La liberación a pH estomacal a las 2 horas fue del $43 \%$ y encapsulaba un $83 \%$ de Ciprofloxacina ( $40 \mu \mathrm{g} / \mathrm{gramo}$ microesferas).

* Microesferas de alginato 2,0\% (p/v)- pectina alto metoxilo 1,0\% (p/v) (formulación a $\mathrm{pH}=4,0)$ gelificadas en presencia de $\mathrm{CaCl}_{2} 500 \mathrm{mM}$ y 1,2-propilenglicol 50\% (v/v). La liberación a pH estomacal a las 2 horas fue del $44 \%$ y encapsulaba un $94 \%$ de Ciprofloxacina (45 $\mu \mathrm{g}$ /gramo microesferas).

Como se ha mencionado anteriormente, el tratamiento con antibióticos solamente no resulta efectivo para erradicar patógenos asociados a los casos de Fibrosis quística. Por este motivo, en un siguiente paso, se incorporó la enzima "Alginato Liasa" ( $A L)$ a la matriz, de forma que se encuentre de forma inactiva en el momento de la preparación, pero que sea liberada funcionalmente al llegar al intestino $(\mathrm{pH}=7,40)$.

Antes, se analizarán algunas propiedades de la AL, necesarias para determinar sus condiciones de encapsulación.

\section{Propiedades de la Alginato Liasa}

Para el estudio del comportamiento de la AL libre se comenzó por establecer las condiciones en las cuales la enzima alcanzaba su punto de saturación al incrementar la concentración de sustrato (alginato en solución reguladora fosfato 25 $\mathrm{mM}, 37^{\circ} \mathrm{C}$ ). Tal como se observa en la Figura 2.2, se observó un perfil Michaeliano de la enzima. Mientras que con una concentración de enzima de 0,10 y 0,50 U/ml se alcanza la saturación con una concentración de alginato del 1,0\% $(\mathrm{p} / \mathrm{v})$, para una de 1,0 $\mathrm{U} / \mathrm{ml}$ se alcanza con alginato al 2,0\% (p/v). 
Para esta última condición, Por la ecuación de Hanes-Hultine que establece una relación lineal entre S/v frente a S (Murzin y col., 2005):

$$
\frac{[\mathrm{S}]}{v}=\frac{K_{\mathrm{m}}}{V}+\frac{1}{V} \cdot[\mathrm{S}]
$$

En donde:

S: concentración de sustrato

v: actividad enzimática medida

V: velocidad máxima a una concentración de sustrato

$\mathrm{K}_{\mathrm{m}}$ : constate Michaeliana

Los resultados muestran una relación lineal $\left(r^{2}=0,99\right)$ y los valores de los parámetros cinéticos fueron $\mathrm{K}_{\mathrm{m}}=4,42 \times 10^{-6} \mathrm{M}$ y el valor de $\mathrm{V}_{\max }=4,42 \mathrm{U} / \mathrm{mL}$.

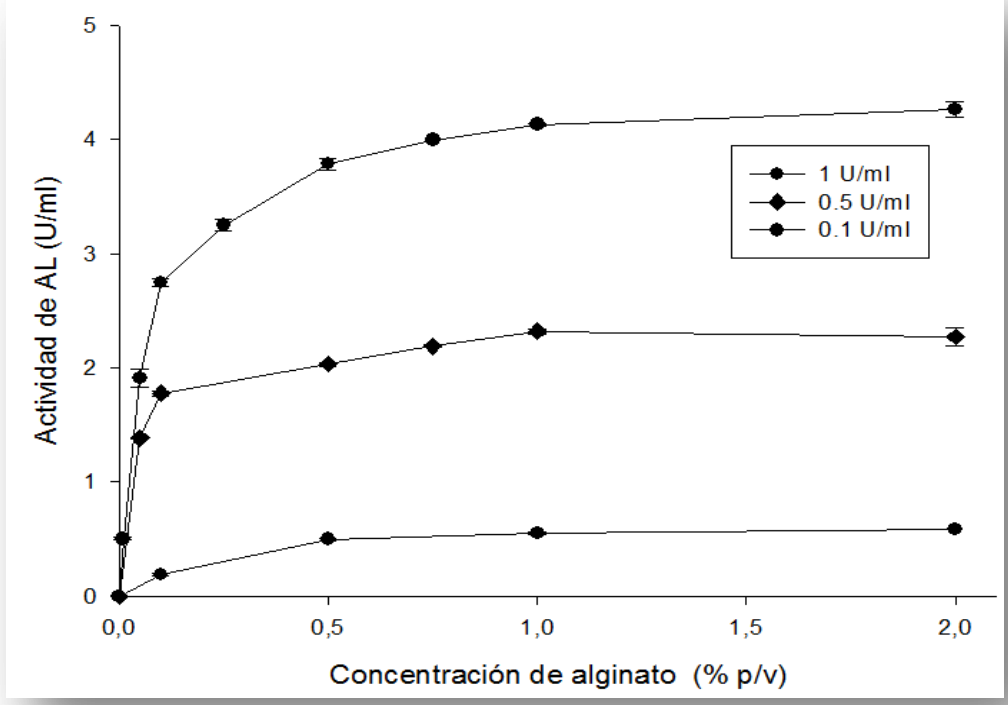

Figura 2.2 Actividad de la Alginato Liasa en función de la concentración de sustrato. Se ensayaron 3 concentraciones de enzima: 0,10 - 0,50 y 1,00 unidades enzimáticas $/ \mathrm{ml}$ a $\mathrm{pH} 7,40$ y $37^{\circ} \mathrm{C}$.

Una vez establecida la relación entre cantidad de enzima y sustrato necesario estar en condiciones saturantes, se evaluó la actividad y estabilidad de la AL en función del $\mathrm{pH}$ y de la temperatura a fin de predecir su comportamiento en el tracto gastrointestinal (Figura 2.3). Se observó que al incrementar la temperatura desde $5^{\circ} \mathrm{C}$ hasta $42^{\circ} \mathrm{C}$ la actividad enzimática se incrementa (Figura 2.3.a). Este hecho resulta 
interesante, porque en condiciones patológicas de incremento de temperatura local o corporal (cuadro febril) la actividad se ve incrementada. No obstante, cuando se evalúa la estabilidad de la enzima en las mencionadas temperaturas durante 30 minutos (a pH $7,40)$, se observa que hasta $37^{\circ} \mathrm{C}$ la estabilidad de la enzima permanece inalterada, pero a $42^{\circ} \mathrm{C}$ comienza un proceso de desactivación, con la cual la actividad se reduce en un 35\% (Figura 2.3.b).
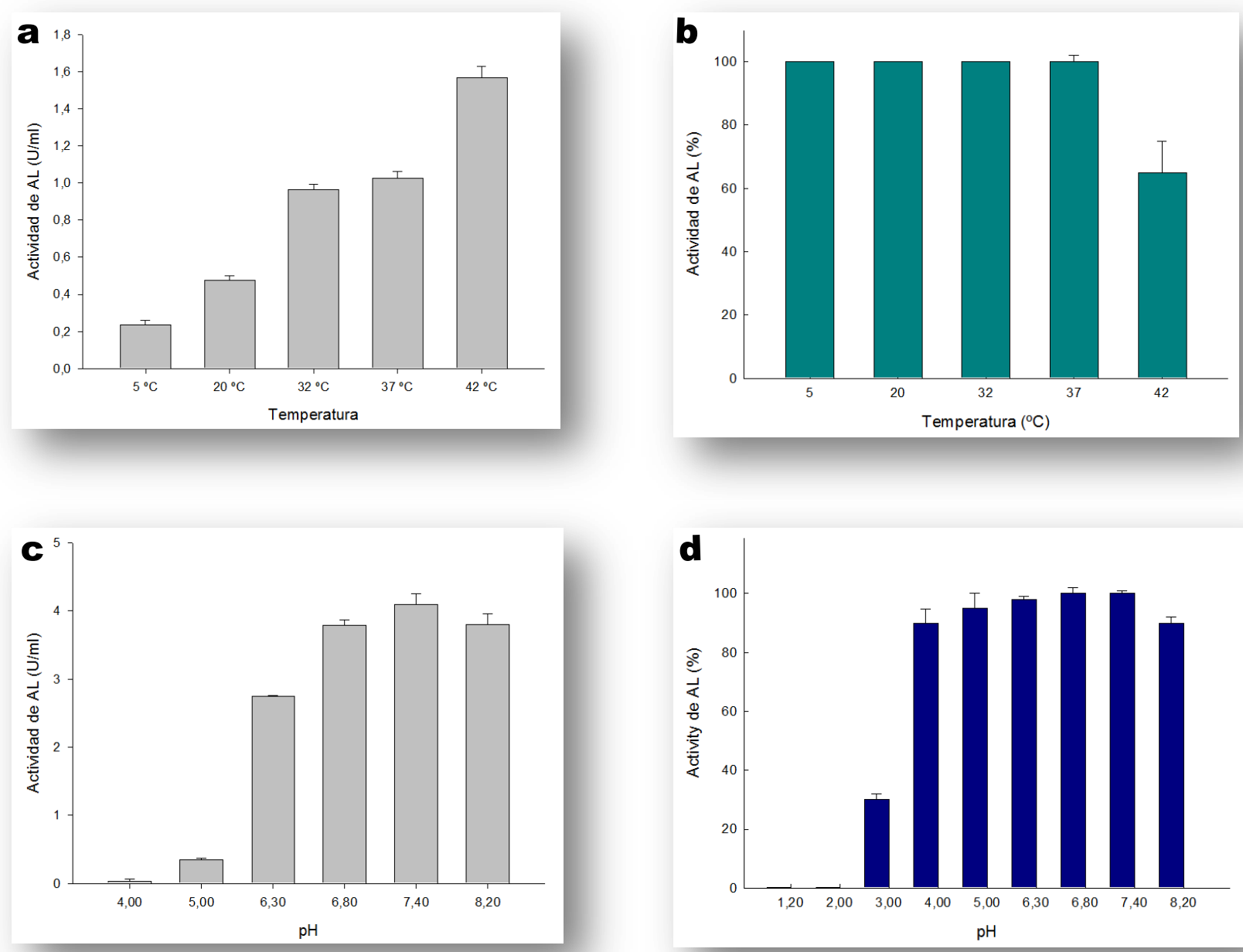

Figura 2.3 Actividad (izquierda) y estabilidad (derecha) de la Alginato Liasa en función de la Temperatura ( $a$ y b) y del pH ( $c$ y d). En la figura c, la actividad a valores de $\mathrm{pH}$ por debajo de 4,00 es nula.

Por otra parte, la evaluación de la actividad de la AL en función del pH, brinda interesantes perspectivas en lo que respecta a la formulación de la matriz. Se observa que la actividad enzimática disminuye conforme disminuye el pH (Figura 2.3.c). A un valor de $\mathrm{pH} 4,00$, la $\mathrm{AL}$ prácticamente no posee actividad. El resultado es interesante considerando que las matrices previamente desarrolladas (tanto la de alginato-gelatina como la de alginato-PAM) fueron formuladas a un $\mathrm{pH}$ de 4,00 por lo que al incorporar 
la enzima en la mezcla va a ser incapaz de degradar el alginato de la matriz. Además, cuando se evalúa la estabilidad de la enzima en dichas condiciones, se observa que luego de ser incubada a dicho pH durante 30 minutos y de medir la actividad residual en condiciones óptimas, la actividad enzimática es recuperada casi en un 100\% (Figura 2.3.d). Otro aspecto interesante, es que a $\mathrm{pH} \mathrm{7,40} \mathrm{(pH} \mathrm{del} \mathrm{intestino} \mathrm{en} \mathrm{condiciones}$ fisiológicas no patológicas) la enzima posee la mayor actividad enzimática, y su estabilidad es del $100 \%$. Esto quiere decir, que cuando la AL llegue al intestino podrá ejercer su función al reducir la viscoelasticidad del alginato producido por Pseudomonas aeruginosa, siempre y cuando dichas condiciones ambientales no se vean modificadas por la patogenicidad.

Por otra parte, nos encontramos con un desafío a considerar si se piensa en una formulación para la administración oral: el pasaje de la enzima por el estómago. Tal como se observa en el gráfico de actividad y de estabilidad, la AL es inactiva y a su vez, desnaturalizada a pH entre 1,2 y 2,0, que corresponde al pH extremo hallado en el jugo gástrico, con lo cual no llegaría de forma activa al intestino. Por este motivo se evaluará si la encapsulación de la enzima en las matrices desarrolladas le brinda protección a la inactivación por pH.

\section{Selección de la matriz apta para encapsular la AL}

\section{Matriz de alginato-gelatina}

Se incorporaron un total de 40 Unidades enzimáticas de AL por mililitro de la formulación, constituida por alginato 2,0\%-gelatina 1,0\% (p/v)-Cipro $36 \mu \mathrm{g} / \mathrm{ml}$. La eficiencia de incorporación para las matrices entrecruzadas de diferente forma fue del $100 \%$ para ambas (ensayadas como proteína total). Para determinar la preservación de la actividad luego de la encapsulación, las microesferas fueron degradadas completamente en solución reguladora fosfato $(100 \mathrm{mM}, \mathrm{pH} 7,40)$ y se determinó la actividad. Mientras que la matriz reticulada en presencia de $\mathrm{CaCl}_{2}$ y PG $50 \%$ mostró una actividad enzimática de alrededor del 100\%, la misma matriz entrecruzada con la adición de 2,5\% ( $p / v)$ de glutaraldehído solo presento un 25\% de actividad (Tabla 14). 
Tabla 14 Encapsulación de Alginato Liasa condiciones de síntesis de matriz de alginato-gelatina

\begin{tabular}{|c|c|c|c|c|c|c|}
\hline \multirow[t]{2}{*}{ Matriz } & \multirow{2}{*}{$\begin{array}{c}\text { Biopolímero } \\
\text { (p/v, \%) }\end{array}$} & \multicolumn{3}{|c|}{ Medio de síntesis } & \multirow{2}{*}{$\begin{array}{c}\text { Encapsulación } \\
\text { (\%) }\end{array}$} & \multirow{2}{*}{$\begin{array}{c}\text { Actividad } \\
\text { (\%) }\end{array}$} \\
\hline & & $\mathrm{Ca}^{+2}$ & $1,2-\mathrm{PG}^{a}$ & Glutaraldehído & & \\
\hline \multirow{2}{*}{$\begin{array}{l}\text { Alginato- } \\
\text { gelatina }\end{array}$} & \multirow[t]{2}{*}{$2,0-1,0$} & + & + & - & $99,7 \pm 0,5$ & $99,5 \pm 0,1$ \\
\hline & & + & + & + & $101,0 \pm 3,0$ & $25,4 \pm 1,5$ \\
\hline
\end{tabular}

Estos resultados sugieren una posible inactivación de la alginato liasa por la presencia del glutaraldehído, que estaría afectando su sitio activo.

Las microesferas fueron incubadas por 2 horas a diferentes $\mathrm{pHs}$ en el rango de extremo acido $(1,20)$ a levemente alcalino $(7,40)$ simulando el recorrido de las mismas por el tracto gastrointestinal. En la Figura $\mathbf{2 . 4}$ se muestra la actividad residual luego de la incubación. Si bien se observa que la actividad enzimática total se mantiene casi al $100 \%$ para microesferas incubadas a $\mathrm{pH} 7,40$, se produce una completa pérdida de actividad a pHs menores a 3,0 luego de 2 horas de incubación (posible tiempo de residencia en el estómago). Tampoco se evidencia un mecanismo de protección a pHs bajos para las microesferas entrecruzadas en presencia de glutaraldehído, lo cual se suma como aspecto negativo a la baja actividad observada luego de la inmovilización, debido a la posible inactivación producida por el agente entrecruzante al rigidificar el sitio activo de la enzima.

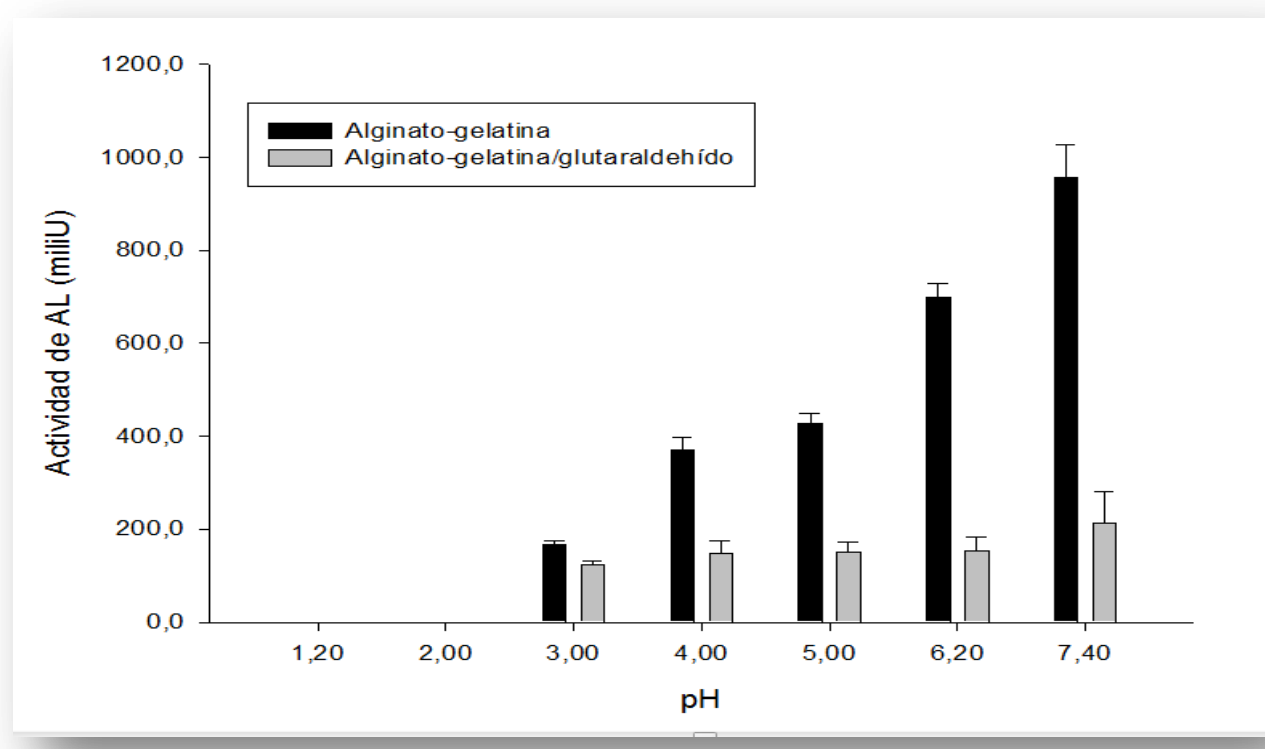

Figura 2.4 Actividad de AL luego de incubación por 2 horas en microesferas de alginatogelatina (sintetizadas en ausencia y presencia de glutaraldehído) a pHs de 1,20 a 7,40.

En éste sentido, la matriz de alginato-gelatina resulta apta para la encapsulación de alginato liasa, pero podría no serlo para administración por vía oral 
en nuestras condiciones de desarrollo experimental. A su vez, al ser entrecruzada en presencia de glutaraldehído se observa una pérdida del 75\% de actividad de la enzima, por lo que, sumado a la ausencia de un efecto protector al $\mathrm{pH}$, esta matriz tampoco resulta ser eficiente.

\section{Matriz de alginato-pectina}

Al igual que en la matriz de alginato-gelatina, se incorporaron un total de 40 $\mathrm{UE} / \mathrm{ml}$ de $\mathrm{AL}$ en la formulación. La misma está constituida por alginato 2,0\%, pectina de alto metoxilo $1,0 \%(\mathrm{p} / \mathrm{v})$ y Cipro $36 \mu \mathrm{g} / \mathrm{ml}$ y el $\mathrm{pH}$ fue ajustado a $4,00(\mathrm{pH}$ al cual $\mathrm{AL}$ posee una actividad reducida), para luego agregar la $A L(1,0 \mathrm{mg} / \mathrm{ml})$ y homogeneizar a $0^{\circ} \mathrm{C}$ (baño de hielo). Se sintetizaron microesferas al gotear la mezcla en una solución de $\mathrm{CaCl}_{2} 500 \mathrm{mM}$ en presencia de 1,2-propilenglicol 50\% (v/v).

Las microesferas mostraron una incorporación de la enzima mayor al $90 \%$ (proteínas totales), y la actividad observada luego de la degradación de las mismas fue del $76 \%$. Esta reducción de AE posiblemente pueda deberse a la presencia de la pectina, la cual de alguna forma estaría interaccionando con la enzima. Esta hipótesis surge a raíz de que la $A L$ encapsulada en la matriz de alginato posee una actividad del $90 \%$.

Para validar la protección de los biopolímeros (y en particular de la PAM), se incubaron las microesferas por 2 horas a $\mathrm{pH}$ 1,20 para simular su pasaje por el estómago. Y como se mencionara previamente, cuando la AL libre es incubada en estas condiciones resulta en una completa inactivación. Lo mismo ocurre con la $A E$ de la $A L$ encapsulada en la matriz de alginato, la cual no posee un efecto protector sobre la enzima pHs ácidos. Sin embargo, cuando la AL fue encapsulada en microesferas de alginato-PAM un $26 \%$ de actividad enzimática residual (9,0 Unidades/gramo de matriz) fue detectada en comparación con la actividad inicial luego de la inmovilización. Este efecto de protección, puede atribuirse a las propiedades de la pectina AM, que por un lado, tiende a producir geles resistentes en presencia de condiciones ambientales ácidas (Braccini y col., 1995) y por otro ofrece regiones hidrofóbicas correspondientes 
a
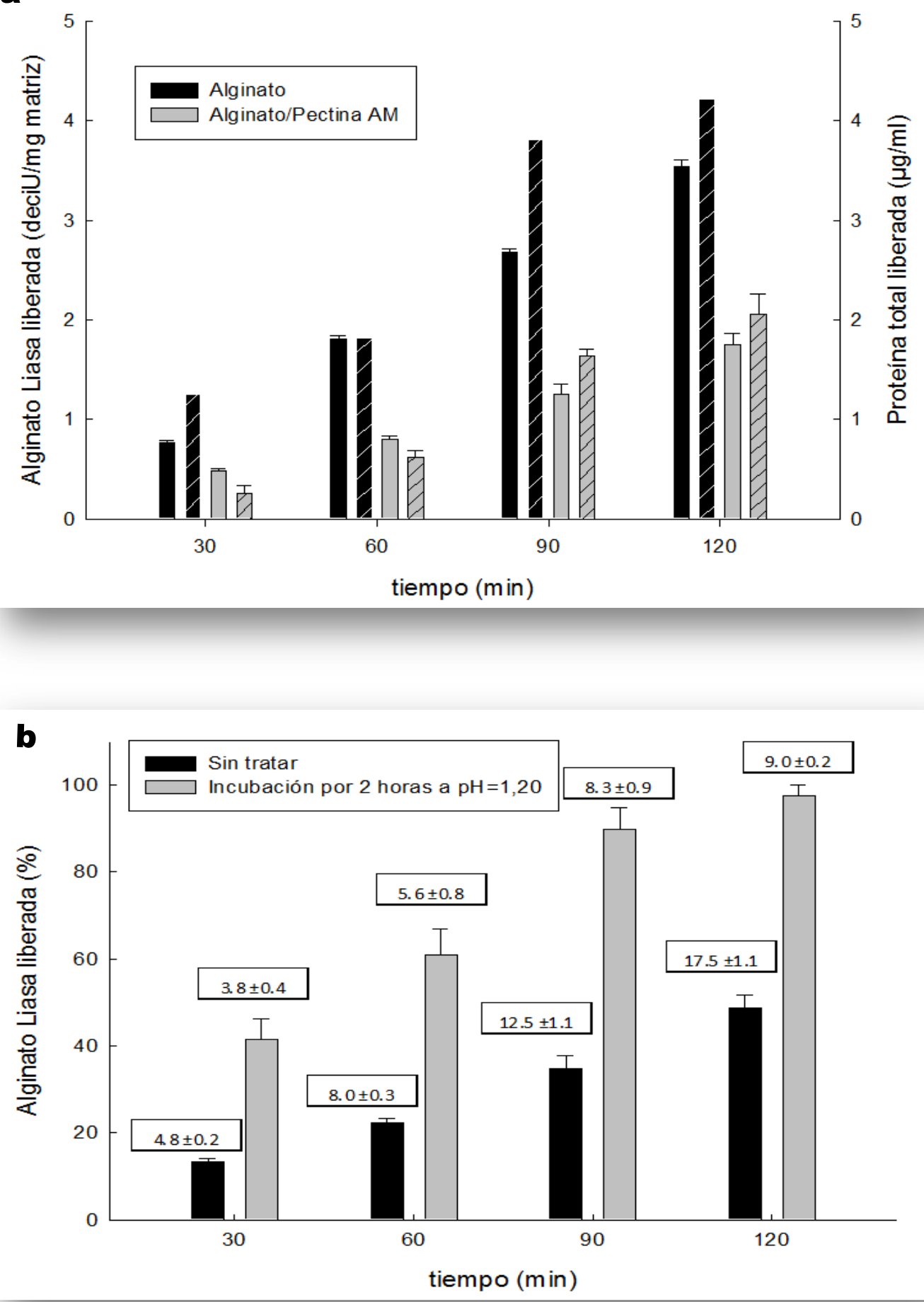

Figura 2.5 Ensayos de liberación de alginato liasa ( $A L)$ desde matrices biopoliméricas. a) Comparación de dos tipos de microesferas en la cinética de liberación de AL: actividad (barras sólidas) y proteínas totales (barras rayadas) a pH intestinal. b) liberación AL desde microesferas de alginato-pectina $\mathrm{AM}$ a $\mathrm{pH} 7,40$ antes y después de la incubación a pH gástrico. Los recuadros indican la actividad de AL (Unidades de AL por gramo de matriz). 
a las zonas metoxiladas en donde la enzima puede ser ubicada. Estas zonas impedirían la difusión de protones hacia el interior de la matriz a pHs bajos, y protegerían a la AL de la inactivación.

Como era de prever, se observó una liberación controlada de la AL desde la matriz biopolimérica cuando se la incubo a pH intestinal (Figura 2.5.a).

La liberación de AL de las microesferas alginato-PAM fue reducida a la mitad respecto de la liberación desde la matriz de alginato. En ambos casos, la actividad específica de la enzima se mantuvo constate. Esto quiere decir que a medida que la $\mathrm{AL}$ fue liberada (detectada por proteínas totales) se observó un aumento concomitante de la actividad enzimática. El resultado es significativo, al confirmar que la enzima se libera de forma activa de una matriz base de alginato gelificado que, por ser su propio sustrato, podría generarle algún tipo de inhibición.

Cuando se considera el pasaje por el estómago de las microesferas de alginatoPAM incubadas por 2 horas a $\mathrm{pH}$ 1,20 fueron transferidas a una solución reguladora fosfato $25 \mathrm{mM}(\mathrm{pH} \mathrm{7,40)}$ para poder predecir su comportamiento en un ambiente intestinal simulado. La liberación de AL fue evaluada a diferentes tiempos (Figura 2.5.b). Los resultados indican que si bien las microesferas mantienen la capacidad de proporcionar un perfil de liberación controlada de AL, el 100\% es liberado en 2 horas después de haber sido expuesto a condiciones ácidas. Estos resultados representan un aumento del $50 \%$ en la liberación respecto de la matriz sin tratar. Vale aclarar, como se observa en los recuadros a cada tiempo de la Figura 2.5.b, la actividad de AL liberada luego del tratamiento de 2 horas a pH ácido es menor que el control sin tratar. Estos resultados sugieren que el pasaje por el estómago, no solo genera una reducción del $74 \%$ de la actividad de AL encapsulada inicialmente, sino que también se ve un efecto de desestabilización de la matriz, por lo que su capacidad de controlar la liberación se ve reducida.

Sin embargo, se observa un claro efecto protector respecto del $\mathrm{pH}$ de la matriz biopolimérica sobre la actividad de la $\mathrm{AL}$, validando este sistema como potencial vehículo para la administración de la enzima por vía oral y mejorar la administración de Ciprofloxacina para la mejora de las terapias de pacientes con FQ. 


\section{Efecto de la co-inmovilización de AL y Cipro en matriz de alginato-PAM}

En primer lugar, se estudió el efecto de la co-inmovilización sobre el perfil de liberación de Ciprofloxacina. Como muestra la Figura 2.6.a, no se observaron modificaciones de la Cipro liberada a pH gástrico. Esto se debe a dos hechos: primero, que la enzima no es activa, y segundo, que la matriz a ese pH tiende a volverse más rígida, independientemente de la molécula cargo. No obstante, cuando se evaluó la liberación a pH intestinal, se observó un cambio en los perfiles. Mientras que la matriz $\sin \mathrm{AL}$, libera un $90 \%$ del antibiótico a las 2 horas, la matriz compuesta con la AL libera un 60\% de la Cipro (Figura 2.6.b). Esta reducción en la liberación está sugiriendo la existencia de un impedimento de tipo estérico de la enzima a la salida de la Cipro desde la matriz.
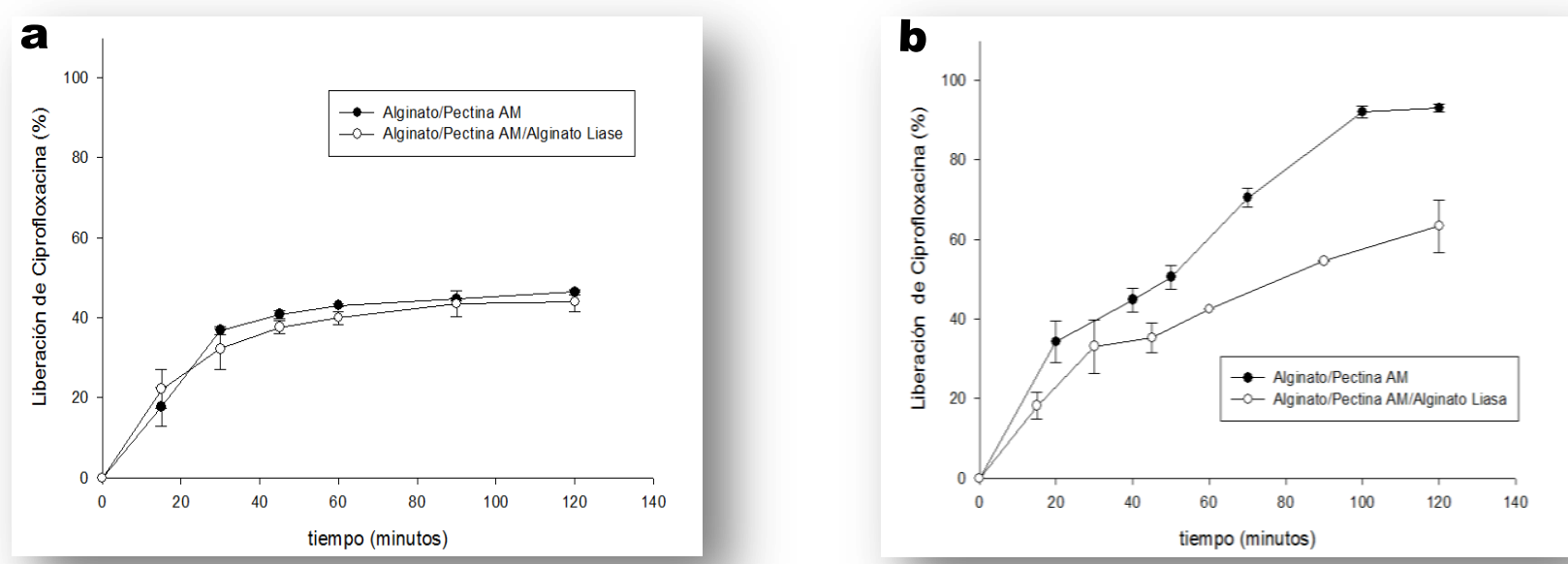

Figura 2.6 La liberación de Ciprofloxacina desde microesferas con o sin alginato liasa: a) pH 1,20 y b) pH 7,40.

Por otro lado, resulta de gran importancia evaluar posibles interferencias en las actividades biológicas de ambas moléculas co-inmovilizadas. Se estudió el efecto de cantidades crecientes de $\mathrm{AL}$ (de 0,4 a 20,0 U/ml) sobre la actividad antimicrobiana de Cipro contra el patógeno oportunista Pseudomonas aeruginosa (Figura 2.7). Se observó que la Cipro en una concentración de 10,0 $\mathrm{gg} / \mathrm{ml}$ era capaz de generar un halo de inhibición promedio de $20 \mathrm{~mm}$ y dicho valor se mantenía constante pese al agregado de la $\mathrm{AL}$, incluso a concentraciones altas como $20 \mathrm{U} / \mathrm{ml}$. Así, la enzima no estaría interfiriendo con la capacidad antimicrobiana de la Cipro.

A su vez, se evaluó de la actividad de la AL en presencia de Cipro. Para ello, se sintetizaron dos tipos de microesferas de alginato-PAM: unas conteniendo AL (40U/ml) 
y otras conteniendo ambos Cipro $(36 \mu \mathrm{g} / \mathrm{ml})$ y $\mathrm{AL}(40 \mathrm{U} / \mathrm{ml})$. Las microesferas fueron disueltas en solución reguladora fosfato $100 \mathrm{mM}(\mathrm{pH} 7,40)$ y se les determinó la actividad enzimática en presencia de alginato $2,0 \%$ en solución. Ambos tipos de microesferas mostraron una actividad total de $76 \mathrm{U} /$ gramo de matriz, sin diferencias significativas en la actividad de $A L(p>0,05)$. Ello sugiere que la Cipro no afecta la actividad de la AL.
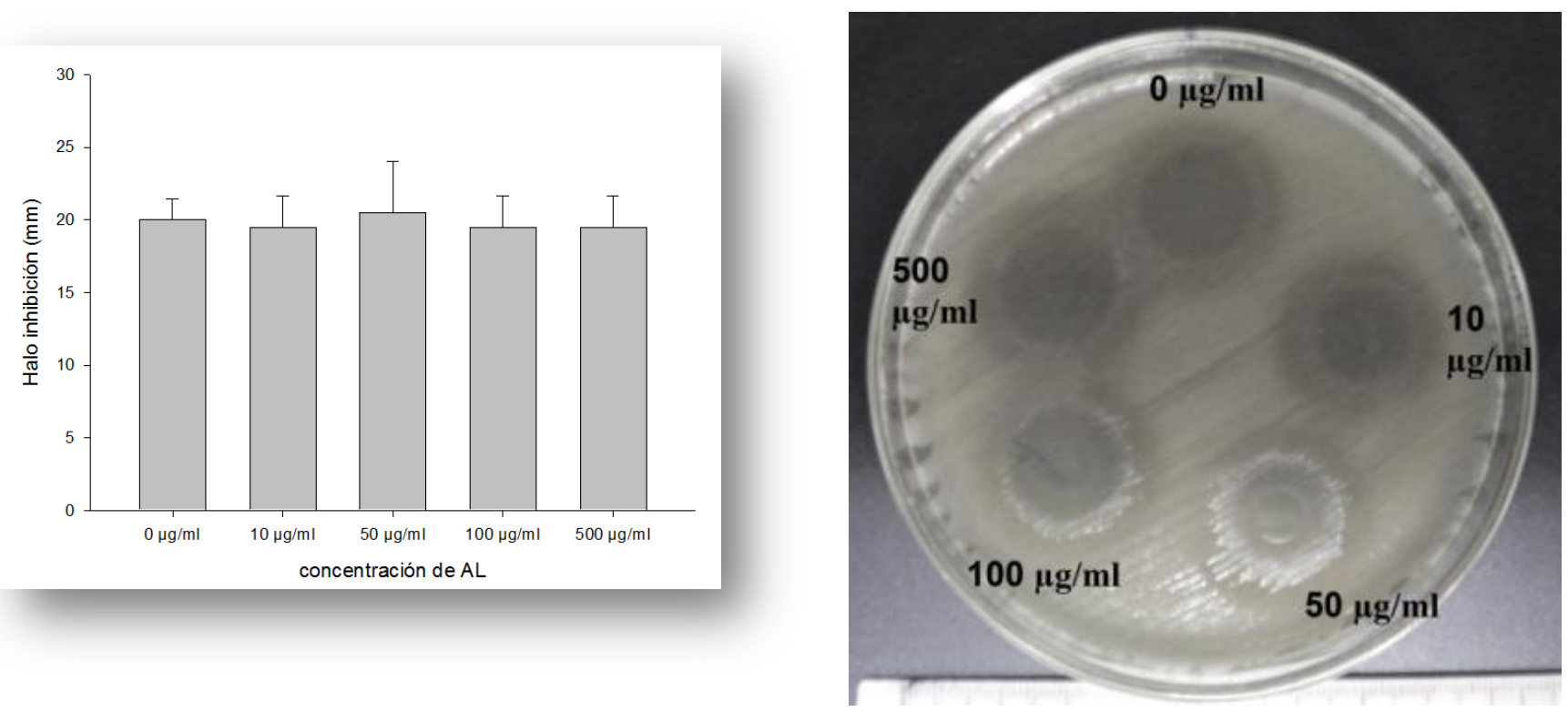

Figura 2.7 Halo de inhibición de Cipro $(\mathrm{mm})$ a una concentración de $10 \mu \mathrm{g} / \mathrm{ml}$ en presencia de cantidades crecientes de AL contra Pseudomonas aeruginosa ATCC 15442.

\section{Caracterización de la matriz de alginato-PAM en ambientes fisiológicos simulados}

Se realizó una microscopia SEM de las microesferas de alginato-PAM conteniendo la AL (Figura 2.8). Dicha matriz conservó su esfericidad, pero se observaron ciertos pliegues y efectos de superficie cuando fue incorporada la enzima.

El histograma revela un aumento en la rugosidad superficie respecto a la matriz $\sin \mathrm{AL}$ (valores de desviación estándar de 32 y 24 respetivamente). Dichos pliegues no se observaron en el caso de la matriz de alginato (datos no mostrados), por lo que se puede especular que dicha rugosidad es generada por la presencia de la pectina.

Cuando la matriz es incubada a pH 7,40, la condición FQ del tracto intestinal, se observa no solo una liberación de la AL (tal como muestra la Figura 2.5) sino que hay una evidente activación de la enzima dentro de la matriz, que comienza a generar un proceso de autodegradación de la microesfera. Las imágenes de SEM, pusieron de 
manifiesto este fenómeno, en el cual la microesfera comienza a auto-degradarse hasta llegar a ser reducida a un particulado micrométrico (Figura 2.9).
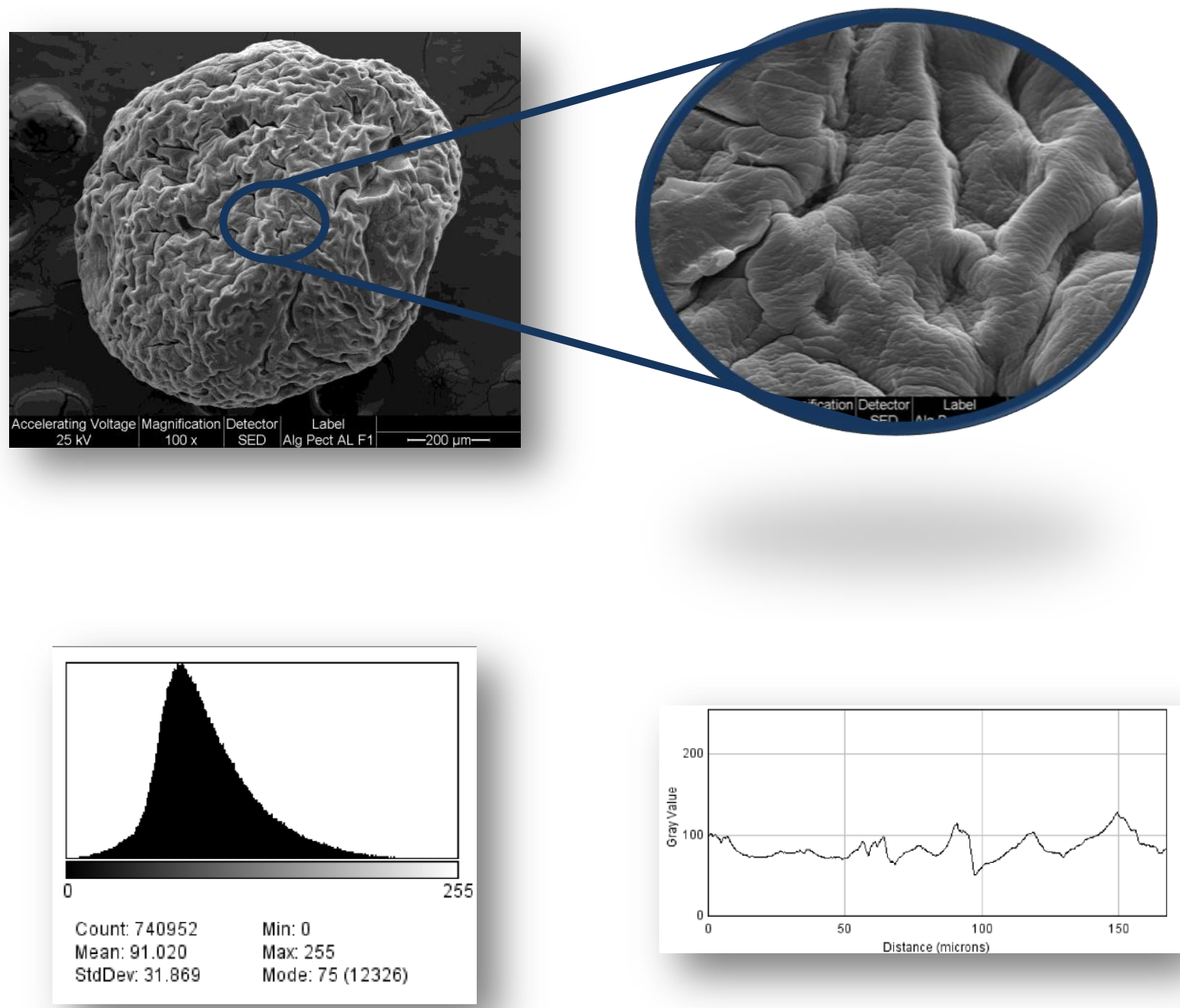

Figura 2.8 Imágenes de microscopía SEM de matriz alginato-pectina AM conteniendo Cipro y AL, observada a 100 y $710 \mathrm{X}$. En las imágenes inferiores se muestra el análisis superficial con el programa ImageJ.

Este resultado es de gran interés a los fines de la aplicación terapéutica para los pacientes con FQ. El hecho de que la matriz sea capaz de liberar a la AL de forma simultánea con la Ciprofloxacina de las microesferas biopoliméricas, es una ventaja dados los perfiles de liberación, la protección a la inactivación por pH de la AL y la permanencia de las actividades biológicas de ambos agentes. Sin embargo, otra interesante ventaja que se debe destacar es la actividad autodegradativa de la matriz en el sitio de acción. De esta forma, la matriz una vez que ha liberado los agentes terapéuticos es reducida a un micro-particulado que puede ser fácilmente eliminado por la vía intestinal. Además, debido a la presencia del espeso moco encontrado en el 
trayecto, la capacidad auto-degradativa perimiría que la matriz administrada no se acumule ciertas regiones del intestino (cosa que si podría ocurrir con otro tipo de matrices) provocando una posible obstrucción intestinal.
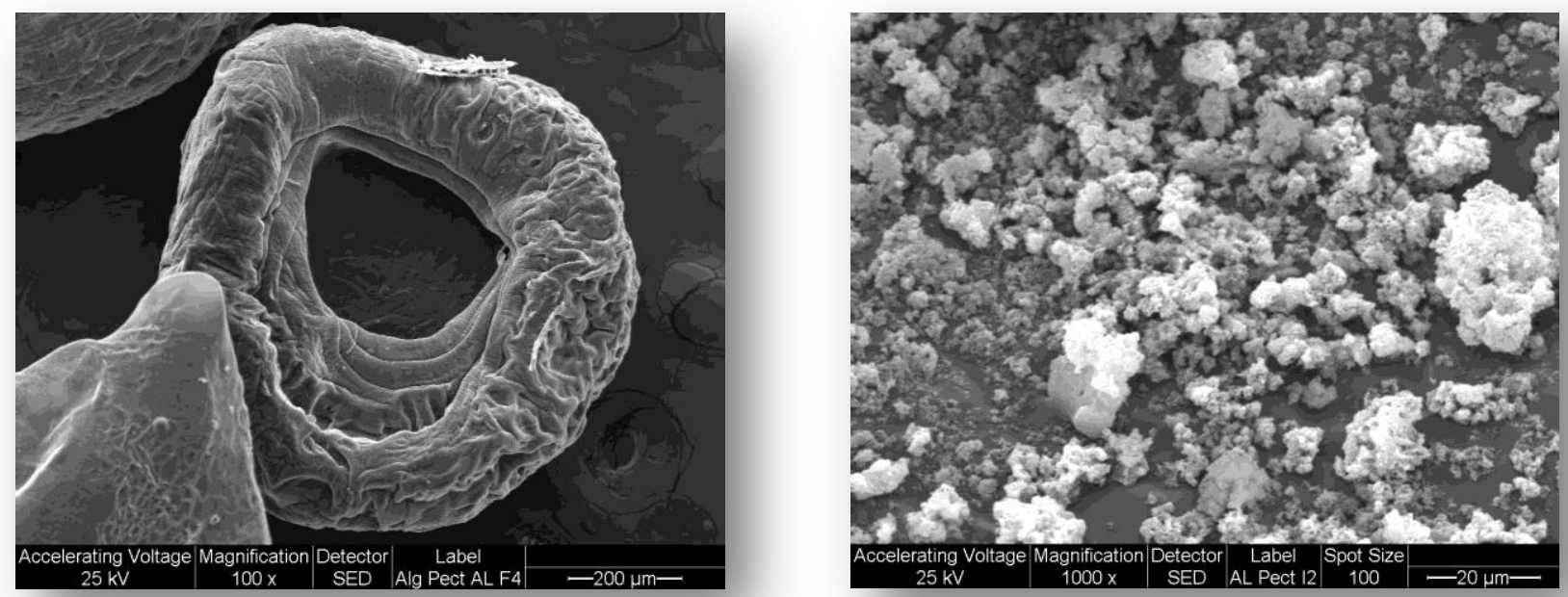

Figura 2.9 Imágenes de microscopía SEM de matriz de alginato-pectina AM conteniendo Ciprofloxacina y la alginato liasa incubadas a pH 7,40 luego de 2 (izquierda) y 4 horas (derecha). Es posible observar el proceso de autodegradación de la matriz.

En otros ensayos, se evaluó la capacidad de hinchamiento de la matriz (referido a la capacidad de incorporar moléculas de agua) en respuesta a la presencia de un ambiente intestinal a $\mathrm{pH}$ 7,40. Para ello, se incubaron las microesferas en dos condiciones experimentales a $\mathrm{pH}$ 7,40: un medio en presencia de iones fosfato (quelante de iones calcio) y en una solución reguladora de $\mathrm{pH}$ no quelante (TRIS-HCl). En TRIS- $\mathrm{HCl}$, se puede observar que las microesferas sin la enzima van incorporando cantidades crecientes de moléculas de agua, hasta llegar a una saturación de los sitios alcanzadas las 12 horas. En cambio, la matriz conteniendo la AL sufre un proceso de hinchamiento inicial hasta las 3 horas, luego del cual el entorno generado favorece la activación de la $\mathrm{AL}$ (que permanecía inactivada al $\mathrm{pH} 4,0$ de la formulación) y se da inicio al proceso de autodegradación donde se comienza a ver una paulatina pérdida de masa de la matriz, hasta desintegrarse completamente a las 5 horas (Figura 2.10.a).

Cuando las microesferas son incubadas en la solución reguladora de $\mathrm{pH}$ fosfato, el comportamiento es diferente. Si bien en ausencia de la $\mathrm{AL}$, la matriz comienza a hincharse hasta las 4 horas, luego de dicho tiempo comienza un proceso de 
erosión de la matriz, producido por el secuestro por parte de los iones fosfato de aquellos iones calcio que constituyen la red matricial. Por su parte, en presencia de la AL encapsulada el proceso de autodegradación se ve favorecido previamente, y se puede observar que a las 4 horas de incubación la matriz ya ha sido totalmente disuelta (Figura 2.10.b).
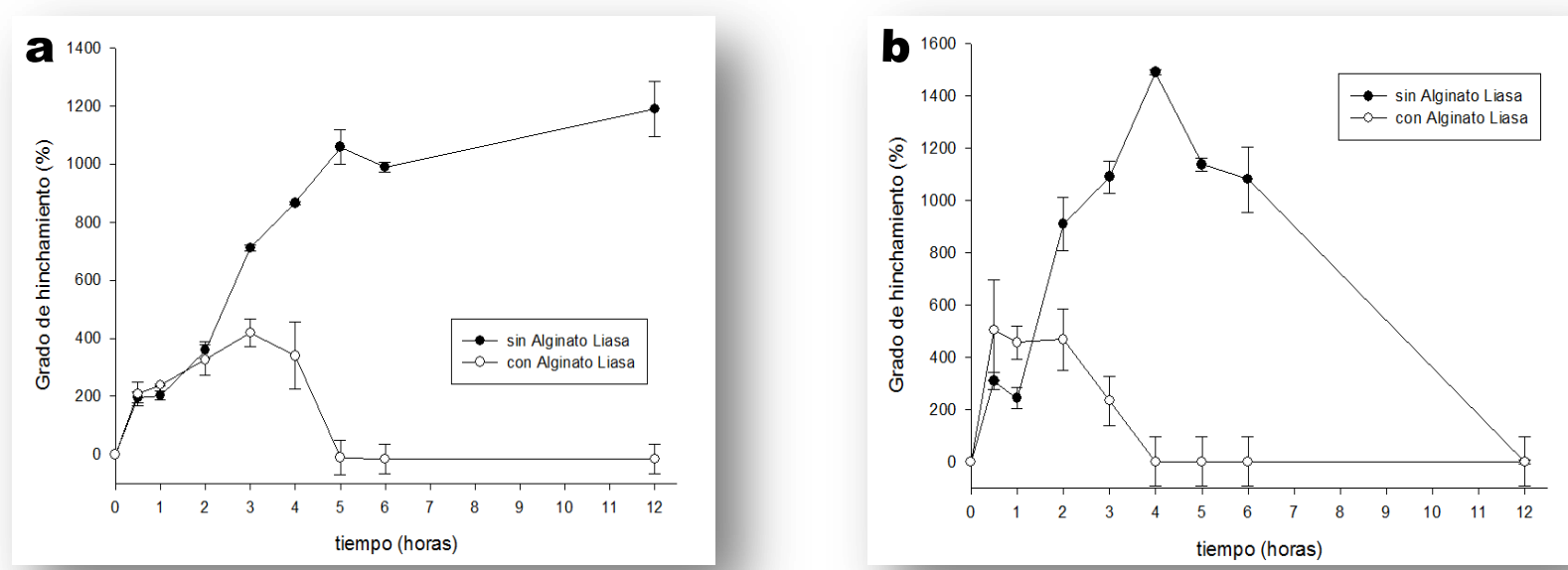

Figura 2.9 Ensayos de hinchamiento de las microesferas de alginato-pectina AM (con y $\sin \mathrm{AL}$ ) en dos condiciones en soluciones reguladoras de $\mathrm{pH}$ a 7,40: a) TRIS-HCl; b) fosfato.

Debido a que la matriz posee un comportamiento relativamente similar hasta las dos horas de incubación, se decidió evaluar la dureza y cohesividad de las microesferas en dichas condiciones (Figura 2.10) y determinar que factor posee mayor influencia en la estabilidad de la red matricial. Se puede observar que la dureza de las microesferas luego de la incubación en ambas soluciones reguladoras de pH disminuye respecto del control sin incubación. Se observa una disminución significativa $(p<0,05)$ de la dureza en la matriz que posee la AL cuando se incuba en solución reguladora fosfato. 

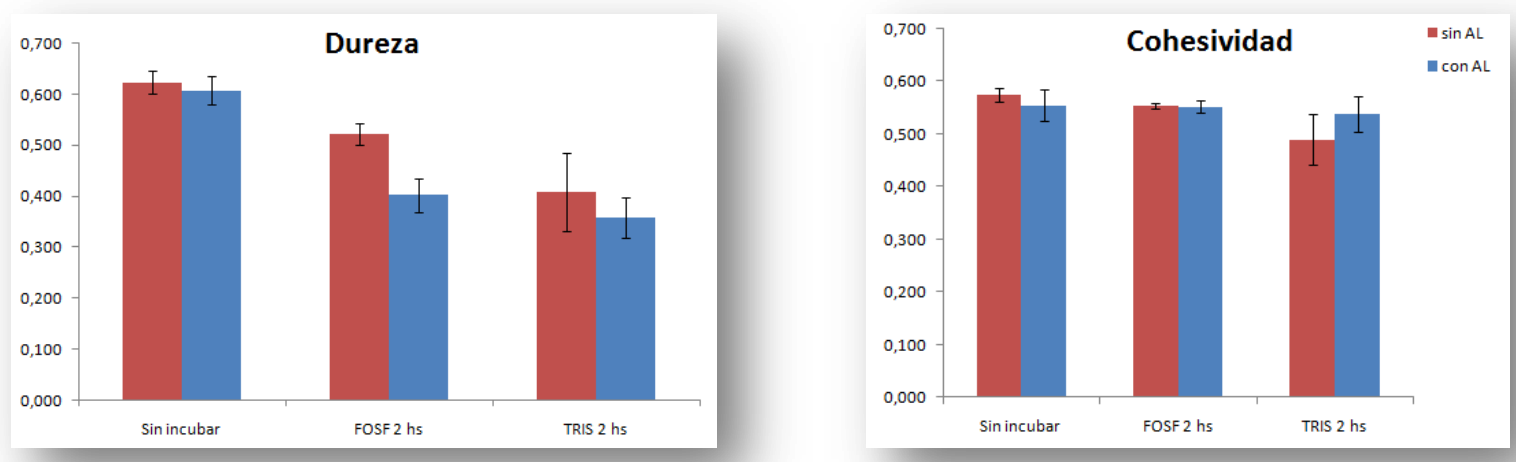

Figura 2.10 Ensayos texturométricos (dureza y cohesividad) de microesferas de alginato-PAM (con y sin la AL encapsulada) luego de una incubación de 2 horas solución reguladora fosfato o TRIS/HCl. Se midieron las propiedades de las matrices previo a la incubación.

No se observan diferencias significativas al incubar en solución reguladora de TRIS-HCl. Por su parte, la cohesividad no cambia luego de la incubación (no se observan diferencias significativas) en ambas condiciones, e incluso en presencia de la enzima, lo cual refiere a que las uniones internas dentro del gel se mantienen en las condiciones testeadas. Dicha ausencia de un efecto posiblemente se deba a la capacidad del buffer a pH 4,0 de la formulación para mantener estable la red y sus interacciones, al menos por dos horas.

Una vez caracterizadas las propiedades fisicoquímicas de la formulación en condiciones intestinales, fue evaluado el efecto bactericida de la matriz conteniendo la AL contra un biofilm artificial de Pseudomonas aeruginosa (Figura 2.11). 


\section{Cipro \& AL}

\section{Cipro}

Figura 2.11 Ensayo antimicrobiano de microesferas de alginato-PAM contra Pseudomonas aeruginosa sobre la cual se colocó una capa de alginato de sodio $(2 \%(p / v))$. Se colocaron microesferas conteniendo la Cipro y la AL (izquierda) y solo Cipro (derecha).

Se puede observar claramente que ambas matrices generan un halo de inhibición (ambas poseen la misma carga de Ciprofloxacina) contra la cepa. No obstante, el halo generado por la matriz que posee tanto Cipro como AL resultó de mayor tamaño. Esto se debe a la acción de la AL sobre el film de alginato colocado sobre la cepa, que favoreció la difusión del antibiótico. Este resultado es significativo debido a que valida la presencia de $\mathrm{AL}$ en la formulación para potenciar la actividad antimicrobiana de Cipro. De hecho, este ambiente simulado es muy parecido al que encontrarían las microesferas al arribar al intestino, donde no solo se halla la infección, sino también exceso del polisacárido viscoso recubriéndolo.

Corroborando lo observado previamente, se observa que luego de las 24 horas de incubación, la matriz que contiene la enzima se autodegrada completamente, mientas que la que no la posee permanece como microesfera intacta.

Por último, y para confirmar que la matriz es apta para administración en sistemas vivos y carece de efectos tóxicos considerables, se decidió evaluar la citotoxicidad de las microesferas en cultivo celular por el método del MTT 
(Weyermann y col., 2005). Se eligieron células CHO K1, las cuales se caracterizan por ser elevadamente sensibles a la presencia de diferentes agentes (Figura 2.12).

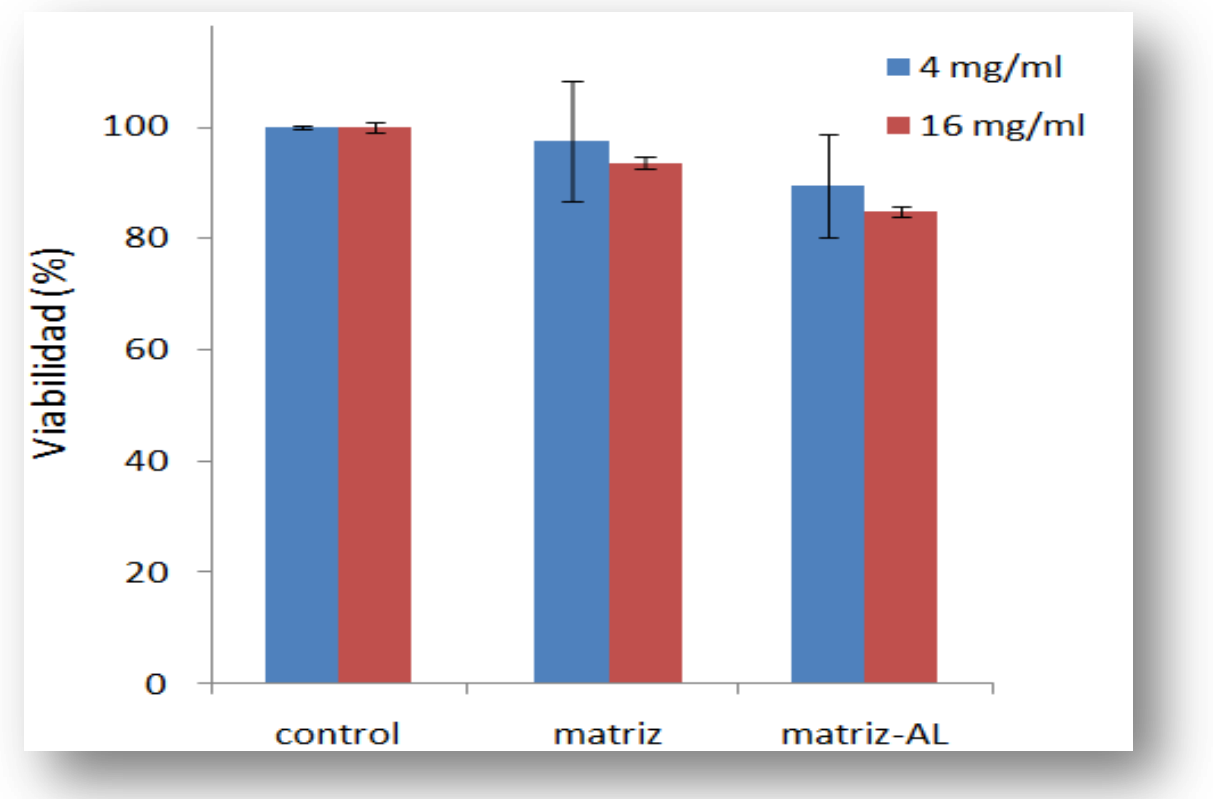

Figura 2.12 Ensayos de citotoxicidad por MTT de la matriz de alginato-PAM (a dos concentraciones) sola y conteniendo la alginato liasa (AL). Se utilizaron células $\mathrm{CHO} \mathrm{K} 1$. El control corresponde a células sin tratar.

Las microesferas fueron disueltas en solución reguladora fosfato $100 \mathrm{mM}(\mathrm{pH}=$ $7,40)$ y, a causa de la acidez de la mismas, fue necesario neutralizar la solución con $\mathrm{NaOH}$. Este paso resulta clave, debido a que el estado de disolución de la formulación determina la vía de absorción y el mecanismo de toxicidad (Misra y col., 2012). Este procedimiento fue realizado estrictamente debido a que si se agregaban las microesferas intactas (con un diámetro aprox. de 500 micrones) el contacto mismo con las células inhibía el crecimiento. Además, el estado disuelto seria la forma adecuada a ensayar, debido a que si bien durante el pasaje por el estómago las microesferas permanecen intactas, al llegar al intestino las mismas serán auto-degradadas como fuese previamente descripto. Experimentalmente se ensayaron dos concentraciones de microesferas disueltas. Se observó que la exposición de las células a una concentración de $4,0 \mathrm{mg} / \mathrm{ml}$ no generó cambios significativos en la viabilidad celular ( $p>0,05)$, incluso en presencia de la AL. Por el contrario, si se utilizaba una concentración de matriz cuatro veces mayor, los restos de matriz generaban una leve disminución de la viabilidad celular de un 10 y $15 \%$ para la matriz sola y con la AL respectivamente. Esta disminución de viabilidad, podría ser atribuida a una limitante 
del método in vitro, debido a que el agregado de mayores cantidades de matriz disueltas genera no solo efectos estéricos sobre el crecimiento celular, sino también aumento en la viscosidad del medio de cultivo, con lo cual la oxigenación puede ser menor, o incluso la difusión de nutrientes (Toye y col., 2010). No obstante, se observa que la matriz no muestra efectos citotóxicos considerables y se obtienen altos porcentajes de viabilidad celular.

Por otra parte, se estudió el efecto de la presencia de la Ciprofloxacina libre y encapsulada en la matriz sobre la citotoxicidad celular de la línea CHO K1 (Figura 2.13). Se evaluaron tres concentraciones de Cipro encapsulada, considerando el porcentaje incorporado en la matriz de Alginato/PAM (y suponiendo un 100\% de liberación luego de su procesamiento) y se lo comparo con la Cipro libre. A su vez, se realizaron controles de viabilidad (células sin tratamiento) y células tratadas con las tres diferentes concentraciones de matriz disuelta sin Cipro, por medio del método de metiltiazoltetrazolio (MTT). Tal como fuera demostrado anteriormente, no se observaron diferencias significativas entre el control de viabilidad celular sin tratamiento y la viabilidad por exposición a la matriz en todo el rango analizado ( $p>$ 0,05). Por su parte, se observó que la Cipro libre no presentaba efectos citotóxicos a una concentración de $50 \mu \mathrm{g} / \mathrm{ml}$, pero si ejercía toxicidad a los 100 y $200 \mu \mathrm{g} / \mathrm{ml}$ observándose una reducción de la viabilidad celular del 20 y $28 \%$ respectivamente. Este hecho resulta lógico considerando las propiedades de la molécula en el metabolismo celular (Patterson, 1991), motivo por el cual se consideró su encapsulación como alternativa para reducir dichos efectos secundarios (Islan y col., 2012; 2013). Resulta interesante observar que luego de ser encapsulada la Cipro posee una toxicidad reducida, incluso a concentraciones de hasta $200 \mu \mathrm{g} / \mathrm{ml}$. En este sentido, al no se observarse diferencias significativas con las células sin tratar en todo el rango de estudio ( $p>0,05)$, se podría especular que la presencia de los biopolímeros disueltos estarían disminuyendo la toxicidad de la droga en células de mamífero (Figura 2.13). 


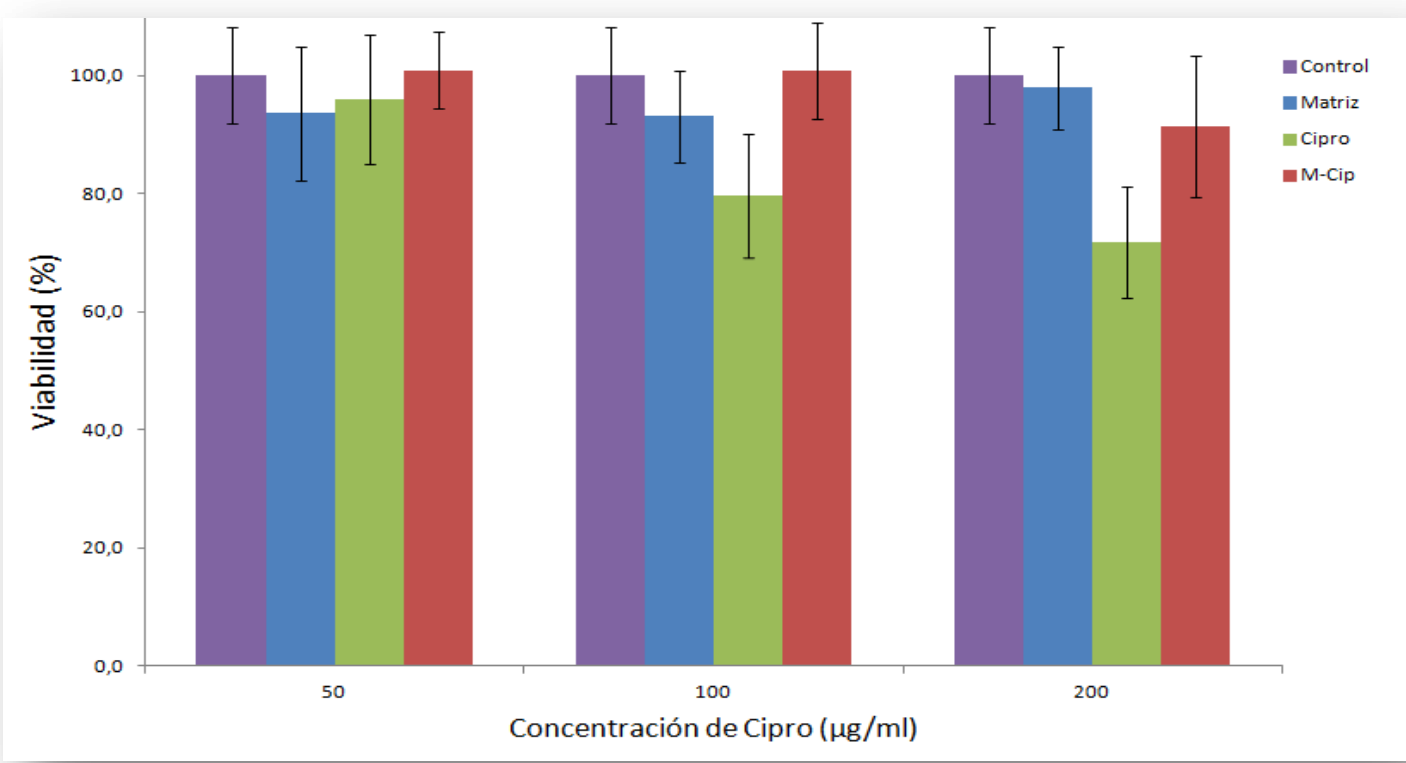

Figura 2.13 Ensayos de citotoxicidad en células CHO K1 por la presencia de Ciprofloxacina libre a distintas concentraciones $(\mu \mathrm{g} / \mathrm{ml})$ y en la matriz de alginato-PAM disuelta, determinados por el método de MTT.

Similar comportamiento se observó al realizar los ensayos de citotoxicidad mediante la técnica de Rojo Neutro (Figura 2.14). Si bien dicha técnica resulta poco sensible y con mucha variabilidad, los resultados obtenidos muestran una tendencia similar (Fotakis y col., 2006). Se puede observar que la Cipro encapsulada no muestra diferencias significativas $(p>0,05)$ con el control en el rango de $30-200 \mu \mathrm{g} / \mathrm{ml}$. Nuevamente, cuando se compara la toxicidad de la Cipro a $200 \mu \mathrm{g} / \mathrm{ml}$, se observa que en su forma libre genera una reducción del $40 \%$ de la viabilidad respecto de la Cipro encapsulada.

Estos resultados estarían demostrando que, en las condiciones ensayadas, la matriz de alginato-PAM prácticamente no presentaría toxicidad sobre células de mamífero y permitiría reducir los efectos tóxicos asociados a la administración de la Ciprofloxacina en su forma libre. 


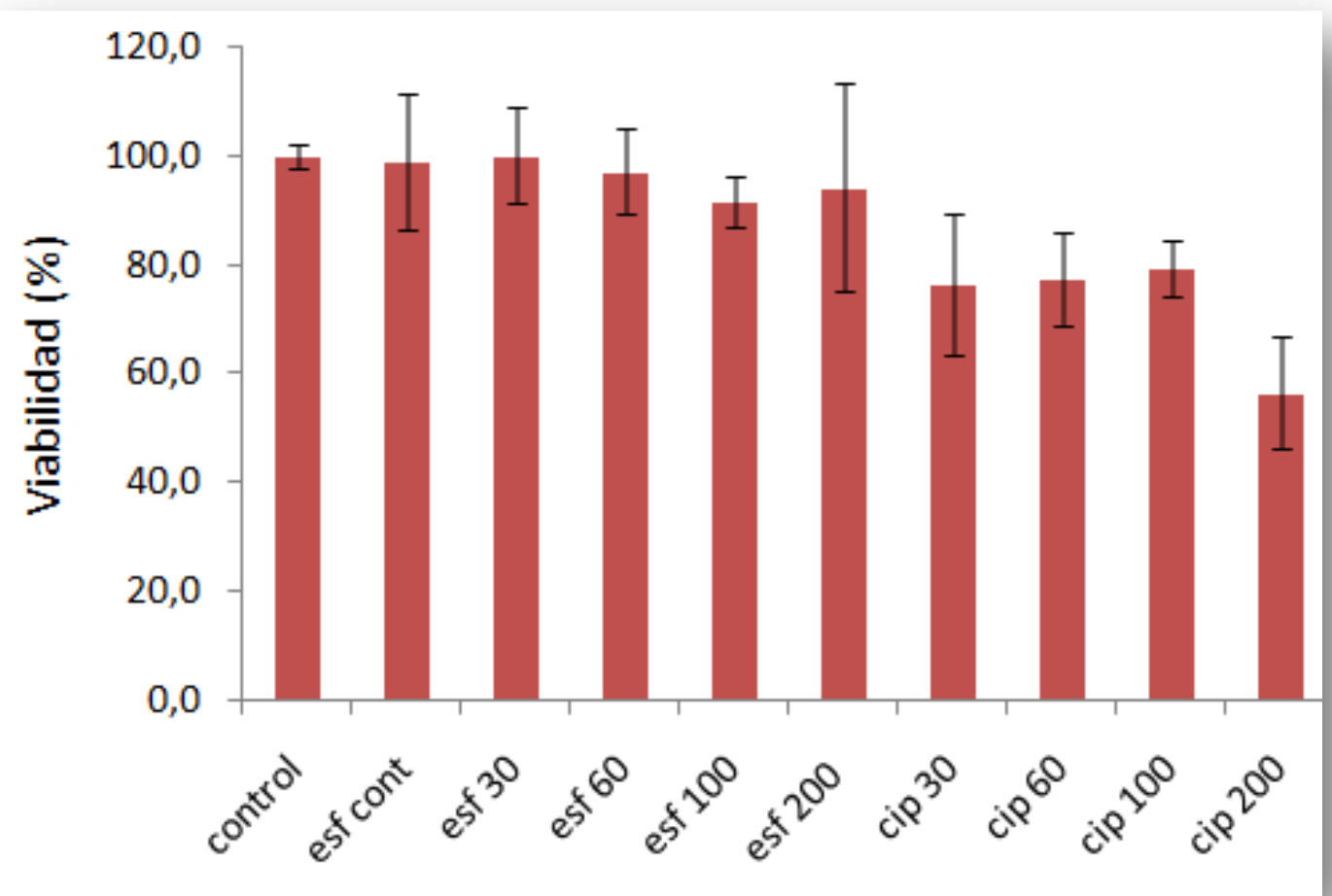

Figura 2.14 Ensayos de citotoxicidad en células CHO K1 por la presencia de Ciprofloxacina libre a distintas concentraciones $(\mu \mathrm{g} / \mathrm{ml})$ y en la matriz de alginato-PAM disuelta, determinados por la técnica de Rojo Neutro. 


\subsection{Conclusiones}

En el presente capítulo se desarrollaron los estudios de los objetivos específicos planteados, los cuales permitieron obtener conclusiones interesantes sobre algunos aspectos de la matriz:

- La alginato liasa puede ser encapsulada en la matriz de alginato-gelatina, pero no se observa efecto protector al $\mathrm{pH}$, con lo cual su administración por la via oral, generaría la llegada de la enzima inactiva al intestino.

- La presencia de glutaraldehído genera una desnaturalización irreversible de la enzima, posiblemente al afectar la dinámica estructural de la enzima y/o afectar su sitio activo.

- La matriz de alginato-pectina alto metoxilo, no solo es capaz de encapsular la enzima, sino que ejerce un efecto protector al $\mathrm{pH}$, de modo que luego de 2 horas de incubación a pH gástrico, se retiene un $25 \%$ de la actividad encapsulada inicialmente y es capaz de liberar la AL de forma controlada y en su forma activa.

- La presencia de la enzima, no afecta la liberación de Cipro a pH estomacal, pero si a pH intestinal, probablemente debido a un efecto estérico.

- No se observa una disminución de la actividad enzimática por la presencia de Cipro, y tampoco una pérdida de la actividad antimicrobiana del antibiótico en presencia de la AL.

- La enzima es encapsulada a pH 4,00 donde permanece inactiva, para luego recuperar su actividad a $\mathrm{pH}$ intestinal y mostrar propiedades auto-degradativas sobre la matriz.

- La matriz es auto-degradada totalmente, y la liberacion de la enzima facilitaría la difusión de la Cipro y potenciaría su actividad contra Pseudomonas aeruginosa.

- La matriz de alginato-PAM no mostraría efectos citotóxicos sobre células de mamíferos y estaría disminuyendo la toxicidad de la Ciprofloxacina respecto de su administración de forma libre. 


\subsection{Bibliografía}

Alkawash M. A., Soothill J. S., Schiller N. L., Alginate lyase enhances antibiotic killing of mucoid Pseudomonas aeruginosa in biofilms. APMIS 2006, 114, 131.

An Q. D., Zhang G. L., Wu H. T., Zhang Z. C., Gong W., Liu Y., Li X. Z., Murata Y., Production and partial properties of alginase from newly isolated Flavobacterium sp. LXA. Process Biochem. $2008,43,842$.

Braccini I., Perez S., Molecular basis of $\mathrm{Ca}^{2+}$-induced gelation in alginates and pectins: the eggbox model revisited. Biomacromolecules 2001, 2, 1089.

Fotakis G., Timbrell J. A., In vitro cytotoxicity assays: comparison of $L D H$, neutral red, MTT and protein assay in hepatoma cell lines following exposure to cadmium chloride. Toxicology letters 2006, 160, 171.

Hatch R. A., Schiller N. L., Alginate lyase promotes diffusion of aminoglycosides through the extracellular polysaccharide of mucoid Pseudomonas aeruginosa. Antimicrob. Agents Chemother. 1998, 42, 974.

Islan G. A., Bosio V. E., Castro G. R., Alginate Lyase and Ciprofloxacin Co-Immobilization on Biopolymeric Microspheres for Cystic Fibrosis Treatment. Macromol. Biosci., 2013, 13, 1238.

Islan G. A., Perez de Verti I., Marchetti S. G., Castro G. R., Studies of ciprofloxacin encapsulation on alginate/pectin matrixes and its relationship with biodisponibility. Appl. Biochem. Biotechnol. 2012, 167, 1408.

Kim H. S., Lee C. G., Lee E. Y., Alginate lyase: Structure, property, and application. Biotechnology and Bioprocess Engineering 2011, 16, 843.

Misra S. K., Dybowska A., Berhanu D., Luoma S. N., Valsami-Jones E., The complexity of nanoparticle dissolution and its importance in nanotoxicological studies. Science of the Total Environment 2012, 438, 225.

Mrsny R. J., Lazazzera B. A., Daugherty A. L., Schiller N. L., Patapoff T. W., Addition of a Bacterial Alginate Lyase to Purulent CF Sputum In Vitro Can Result in the Disruption of Alginate and Modification of Sputum Viscoelasticity. Pulm. Pharmacol. 1994, 7, 357.

Murzin D., Salmi T., Enzymatic kinetics. in: Catalytic Kinetics, Vol. 6, 1st edition, Elsevier B.V., Netherlands 2005, 189.

Patterson D. R., Quinolone toxicity: methods of assessment. Am J Med 1991, 91, 35 S.

Suci P. A., Mittelman M. W., Yu F. P., Geesey G. G., Investigation of ciprofloxacin penetration into Pseudomonas aeruginosa biofilm. Antimicrob. Agents Chemother. 1994, 38, 2125. 
Toye D., Galifi A., Salmon T., Marchot P., Verdin E., Crine M., Influence of medium composition on oxygen transfer rate in animal cell culture. The Canadian J. of Chem. Eng. 2010, 88, 671.

Weyermann J., Lochmann D., Zimmer A., A practical note on the use of cytotoxicity assays. International journal of pharmaceutics 2005, 288, 369.

Wong T. Y., Preston L. A., Schiller N. L., Alginate lyase: review of major sources and enzyme characteristics. Annu. Rev. Microbiol. 2000, 54, 289.

Yamasaki M., Ogura K., Moriwaki S., Hashimoto W., Murata K., Mikami B., Crystallization and preliminary X-ray analysis of alginate lyases A1-II and A1-II' from Sphingomonas sp. A1. Acta Crystallograph. Section F: Structural Biology and Crystallization Communications 2005, 61, 288. 


\section{CAPITULO 8}

Estabilización de la Alginato liasa: desarrollo de agregados enzimáticos entrecruzados

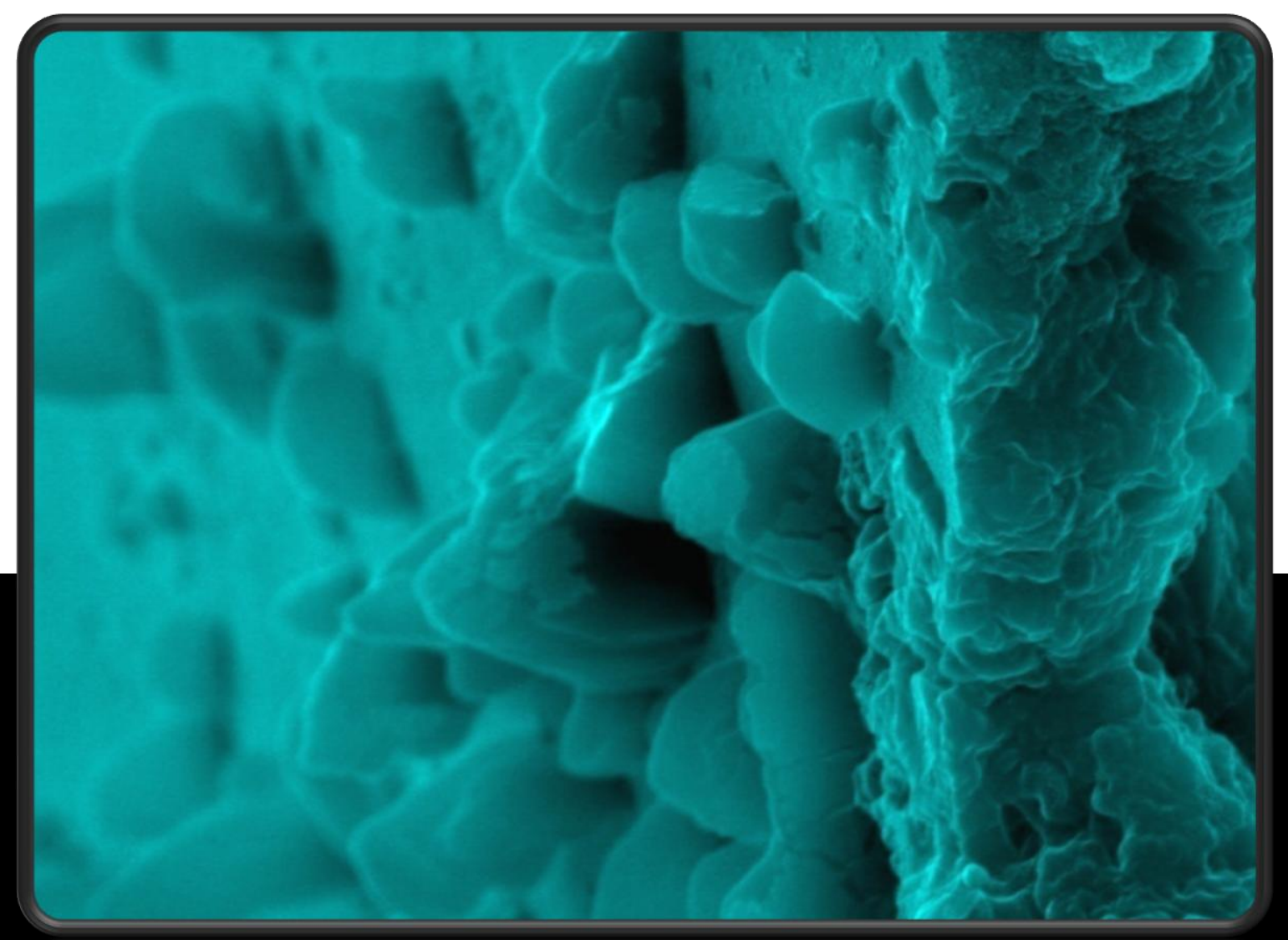




\section{Objetivos específicos}

* Establecer las condiciones de síntesis de un agregado enzimático entrecruzado de Alginato Liasa.

* Optimización de la formulación para obtener la mayor actividad enzimática después del proceso de inmovilización.

* Estudiar la estabilidad de los agregados enzimáticos en condiciones fisiológicas extremas: $\mathrm{pH} 1,20$ (estomacal) o temperaturas superiores a $37^{\circ} \mathrm{C}$ (patologías).

* Analizar la capacidad del sistema conteniendo la enzima de reducir la viscosidad de una solución de alginato de sodio.

* Materiales ... 123

* Ensayo enzimático ... 123

* Preparación de la soluciones biopolímericas ... 123

* Precipitación de la AL ... 124

* Producción de CLEAs ... 124

* Actividad de AL en presencia de agentes de entrecruzamiento y de BSA ... 125

* Rendimiento del CLEAs ... 125

* Análisis de microscopía SEM de los AL-CLEAs ... 125

* Estabilidad al pH de la AL soluble y de la AL-CLEAs ... 125

* Estabilidad térmica de la AL soluble y de la AL-CLEAs ... 125

* Efecto de disolventes orgánicos en la estabilidad ... 126

* Efecto de la fuerza iónica ... 126

* Reutilización del biocatalizador ... 126

* Ensayos reológicos ... 126

3.3. Resultados y discusión

* Determinación de las condiciones óptimas para la síntesis de AL-CLEAs ... 127

* Caracterización de los AL-CLEAs ... 132

* Estabilidad de la AL soluble y AL-CLEAs ... 135

* Reutilización ... 139

* Reducción de la viscosidad de una solución de alginato ... 140

3.4. Conclusiones

3.5. Bibliografía 


\subsection{Introducción}

Como fuera descrito en el Capítulo 2, en los últimos años el uso de la enzima alginato liasa $(A L)$ ha ganado la atención de investigadores debido a su capacidad de hidrolizar el alginato bacteriano producido por el patógeno oportunista Pseudomonas aeruginosa (Hatch y col., 1998). Se ha demostrado que AL es capaz de promover la difusión de antibióticos a través del polisacárido extracelular producido por las cepas bacterianas mucoides. De otra forma, dichas cepas son capaces de sobrevivir a los tratamientos agresivos de antibióticos y una vez establecida la infección se vuelve extremadamente difícil de erradicar (Hodges y col., 1991). Los microorganismos colonizan en primer lugar la superficie de los pulmones y luego la infección se extiende hasta colonizar el tracto intestinal. Como consecuencia, las vías que comunican con el páncreas están obstruidas y se disminuye la absorción de los nutrientes, lo que aumenta la mortalidad debido a cuadros de malnutrición.

La co-inmovilización de la AL con Ciprofloxacina en microesferas biopoliméricos se planteo y caracterizo en el capitulo anterior como un sistema prometedor para reducir la visco-elasticidad de las secreciones de paciente con $\mathrm{FQ}$, lo que facilitaría la difusión de los antibióticos y permitiría atacar la bio-película bacteriana. Sin embargo, existen tres principales obstáculos en el uso de $A L$ en la administración oral y/o pulmonar:

(1) Sensibilidad de la enzima a ambientes desnaturalizantes tales como sales y solventes comúnmente utilizados en las formulaciones,

(2) la pérdida irreversible de la actividad a valores de $\mathrm{pH}$ por debajo de 3,0.

(3) inactivación enzimática a temperaturas superiores a $37^{\circ} \mathrm{C}$.

Estas condiciones adversas están presentes en la administración oral, debido al ambiente ácido gástrico, o cuando la temperatura corporal se incrementa por encima de los $40^{\circ} \mathrm{C}$ en pacientes con cuadros patológicos (febriles).

En este sentido, el desarrollo de "agregados enzimáticos entrecruzados" (CLEAs por sus siglas en Inglés) de alginato liasa (AL-CLEAs) se ha propuesto como una alternativa a la inmovilización convencional en la superficie de soportes y con el fin de 
incrementar la estabilidad de la enzima, y prevenir su inactivación. Los CLEAs se han desarrollado con una amplia variedad de enzimas, tales como lacasas, fitasas, oxidasas de galactosa, tripsina, oxidasas de glucosa, $\beta$-galactosidasas y alcohol deshidrogenasas. En todos los casos, la actividad de la enzima no sólo se mantenía sino también que se mejoraba, destacando las cualidades de los CLEAs como vehículos versátiles y reutilizables de biocatalizadores (Wilson y col., 2006; Talekar y col., 2012). El proceso de síntesis comienza por un paso de precipitación de la enzima en condiciones no desnaturalizantes y un entrecruzado con reactivos bifuncionales (tal como glutaraldehído) (Schoevaart y col., 2004). Los agentes de precipitación y agentes de reticulación químicos tienen que ser cuidadosamente seleccionados de forma tal de optimizar las condiciones de síntesis y obtener la mayor actividad de la enzima en la forma de agregados proteicos y evitar la desnaturalización y/o inactivación de la misma durante el proceso (Figura 3.1).

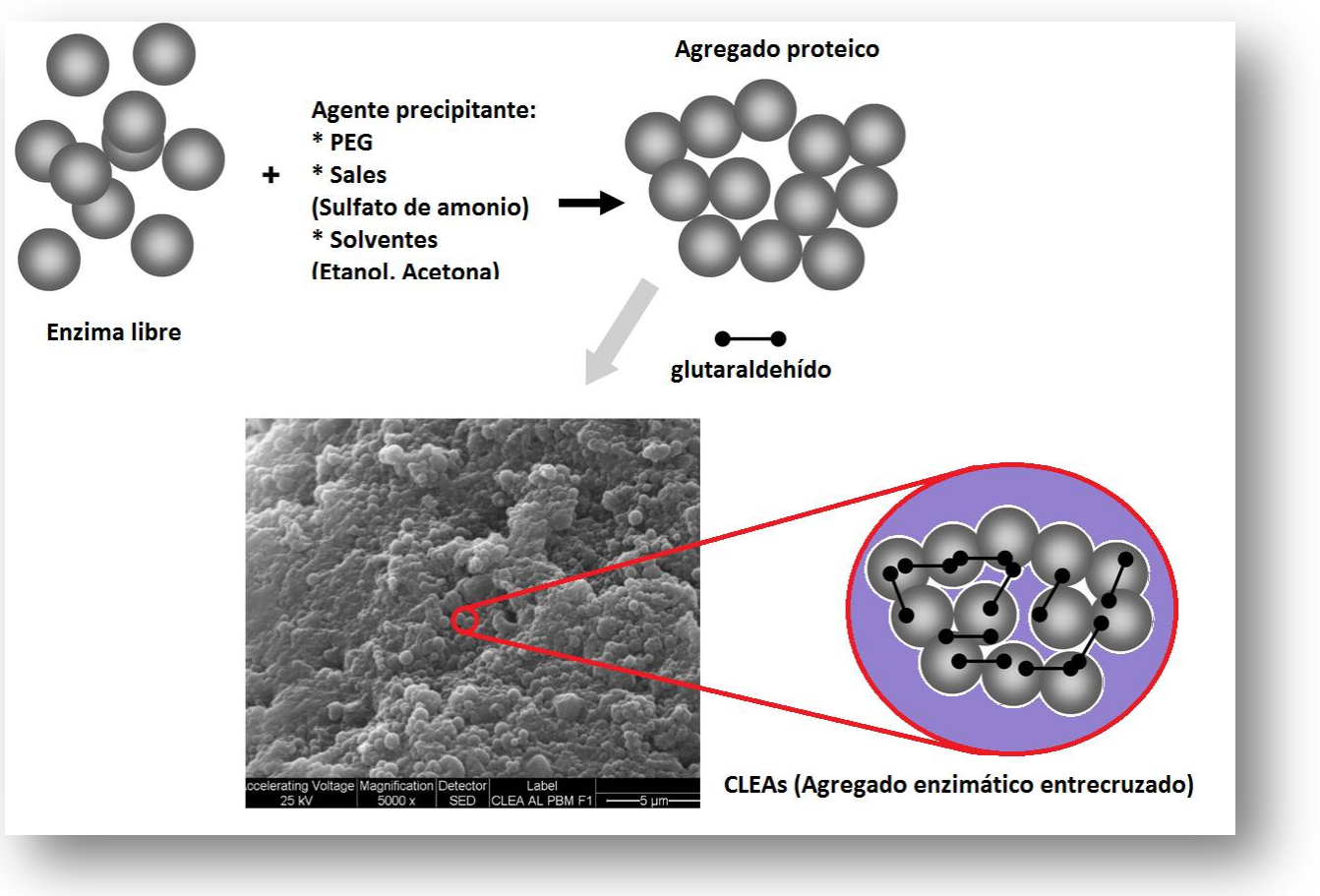

Figura 3.1 Proceso de formación de un agregado enzimático entrecruzado.

El uso de biopolímeros aniónicos para co-precipitar la $\mathrm{AL}$ representa una alternativa atractiva para conseguir CLEAs físicamente estables, debido al condiciones de entorno que ofrece el biopolímero para la enzima (Wilson y col., 2006). En este sentido, el alginato y las pectinas son biopolímeros que actualmente se utilizan en 
aplicaciones biomédicas por ser no tóxicos, no inmunogénicos y altamente biocompatibles (Augst y col., 2006; Braccini y col., 2001).

El objetivo del presente capítulo es producir CLEAs de AL por co-precipitación de la enzima con biopolímeros (pectinas y alginato) y reticulación con reactivos bifuncionales. Las formulaciones serán incubadas bajo diferentes condiciones experimentales de desnaturalización incluyendo valores de $\mathrm{pH}$ extremos, altas temperaturas, disolventes y alta fuerza iónica. La actividad enzimática residual será determinada y comparada con la enzima nativa. 


\subsection{Materiales y métodos}

\section{Materiales}

Alginato Liasa de Sphingobacterium multivorum (CE 4.2.2.11, poli ( $\alpha$-Lguluronato) liasa) fue suministrada por Sigma-Aldrich (Buenos Aires, Argentina). Los solventes: acetona, etanol y 1,2-propilenglicol fueron de grado analítico y proporcionados por Anedra S.A. (Buenos Aires, Argentina). El sulfato de amonio de grado analítico fue suministrado por Merck (Darmstadt, Alemania). El alginato fue suministrado por Monsanto (St. Louis, MO, EE.UU.) y las pectinas (PAM y PBM) fueron donados gentilmente por CP Kelco (Buenos Aires, Argentina).

\section{Ensayo enzimático}

La actividad AL se determinó mediante la detección de los productos de degradación de la molécula de alginato (monosacáridos), que absorben a $233 \mathrm{~nm}$. Para la AL libre, se siguió el mismo protocolo mencionado en el Capítulo 2 (ver Evaluación de la actividad de Alginato Liasa).

Los estudios comparativos de actividad de la AL inmovilizada en CLEAs se realizaron de acuerdo al siguiente protocolo: $25 \mathrm{mg}$ de CLEAs de cada formulación se pesaron y mezclaron con $500 \mu$ de una solución de alginato al 2,0\% (p/v) en solución reguladora fosfato $25 \mathrm{mM}(\mathrm{pH}=7,40)$ y se incubaron a $37^{\circ} \mathrm{C}$ durante 1 hora. La reacción se detuvo mediante la adición de $500 \mu \mathrm{l}$ de $\mathrm{NaOH}(100 \mathrm{mM})$. La solución resultante se diluyó 20 veces y se determinó la absorbancia a $233 \mathrm{~nm}$. Una unidad de AL se definió como la cantidad de enzima que produce un aumento de 1 unidad de absorbancia a $233 \mathrm{~nm}$ por minuto en nuestras condiciones experimentales.

\section{Preparación de la soluciones biopolímericas}

Las soluciones de alginato y las pectinas (PAM y PBM) se prepararon al 2,0\% $(\mathrm{p} / \mathrm{v})$ en $25 \mathrm{mM}$ de solución reguladora fosfato $(\mathrm{pH}=7,40)$. En el caso de las pectinas, el pH se ajustó mediante la adición de $\mathrm{NaOH}(1,0 \mathrm{~N})$. Se preparó una solución patrón de albúmina de suero bovino (BSA) de $20 \mathrm{mg} / \mathrm{ml}$ a pH neutro. 


\section{Precipitación de la AL}

Un volumen de metanol, etanol, acetona o sulfato de amonio $(76 \%(p / v)$ a $\left.25^{\circ} \mathrm{C}\right)$ se añadió lentamente a $500 \mu \mathrm{l}$ de $\mathrm{AL}(1,0 \mathrm{mg} / \mathrm{ml})$ en baño de hielo, para obtener concentraciones de dichos agentes de precipitación de 75, 88 y 95\% (v/v). Las suspensiones resultantes se centrifugaron instantáneamente a 1.000 xg durante 10 minutos y luego se determinó la actividad de $A L$ en el sobrenadante. El pellet se disolvió en $500 \mu \mathrm{l}$ de solución reguladora fosfato $25 \mathrm{mM}(\mathrm{pH}=7,40)$ y se determinó la actividad de AL.

En el caso de co-precipitación de la enzima con los biopolímeros (alginato, PAM o PBM), $250 \mu \mathrm{l}$ de AL $(2,0 \mathrm{mg} / \mathrm{ml})$ se mezclaron con $250 \mu \mathrm{l}$ de la solución de biopolímero $(2,0 \%, p / v)$ y se fue añadiendo lentamente sulfato de amonio en frío. Luego se procedió a determinar las actividades de AL en el sobrenadante y el pellet de acuerdo al mismo procedimiento previamente mencionado.

\section{Producción de CLEAs}

Los AL-CLEAs se prepararon por precipitación de la enzima en presencia de los biopolímeros seleccionados (alginato, PAM O PBM) y posterior reticulación con glutaraldehído. Brevemente, $10 \mathrm{mg}$ de $\mathrm{AL}$ se añadió a $10 \mathrm{ml}$ de una solución que contiene 100 mg de biopolímero y se mezcló con agitación a 600 rpm (50mg de BSA fueron añadidos en el caso del CLEAs de AL/BSA y AL/BSA/PBM). Posteriormente, se añadieron $90 \mathrm{ml}$ de sulfato de amonio saturante en frío lentamente a través de las paredes del vaso de precipitados y se dejó en agitación suave durante 30 minutos. Luego, se añadieron $8,65 \mathrm{ml}$ de glutaraldehído $(25 \%, \mathrm{p} / \mathrm{v})$ bajo agitación a $0^{\circ} \mathrm{C}$ durante 1 hora y la suspensión se centrifugó a 10.000 xg durante 10 minutos. Se descartó el sobrenadante, y el precipitado se lavó con $10 \mathrm{ml}$ de solución reguladora fosfato $25 \mathrm{mM}$ $(\mathrm{pH}=7,40)$ y se centrifugó a $10.000 \times \mathrm{g}$ durante 10 minutos. Las etapas de lavado y centrifugación se repitieron hasta que no fuera detectada actividad $A L$ en el sobrenadante. El CLEAs resultante se sometió a un ensayo para medir la actividad de AL y se almacenó a $5^{\circ} \mathrm{C}$ hasta su posterior uso. 


\section{Actividad de AL en presencia de agentes de entrecruzamiento y de BSA}

Un volumen de $50 \mu \mathrm{l}$ de $\mathrm{AL}$ soluble $(1,0 \mathrm{mg} / \mathrm{ml})$ se mezclaron con $50 \mu \mathrm{l}$ de una solución de glutaraldehído $(25 \%, p / v)$ en un volumen total de $500 \mu \mathrm{l}$, la solución resultante fue incubada durante 1 hora a temperatura ambiente, para luego determinar la actividad de AL remanente. Se ensayó además la actividad de AL en presencia de BSA, debido a que se propone como una proteína protectora de la inactivación por glutaraldehído. De esta manera se mezclaron 5,0 y $10,0 \mathrm{mg} / \mathrm{ml}$ de BSA con AL y glutaraldehído y la actividad enzimática se midió como se describió previamente.

\section{Rendimiento del CLEAs}

El rendimiento de los CLEAs formulados se determinó como la relación entre las unidades de actividad de AL en una masa dada de CLEAs después de la síntesis y las unidades de actividad AL añadidas inicialmente a la mezcla de reacción (400 unidades).

\section{Análisis de microscopía SEM de los AL-CLEAs}

Similar al procesamiento de muestras descriptos en el Capítulo 1.

\section{Estabilidad al pH de la AL soluble y de la AL-CLEAs}

La $\mathrm{AL}$ soluble y la $\mathrm{AL}-\mathrm{CLEAs}$ fueron expuestos a un rango de $\mathrm{pH}$ que varía desde 1,2 hasta 8,2 a $37^{\circ} \mathrm{C}$ durante 1 hora, simulando las condiciones de residencia de la formulación en los fluidos fisiológicos. La técnica desarrollada fue la siguiente: $50 \mathrm{mg}$ de AL-CLEAs o $100 \mu \mathrm{g} / \mathrm{ml}$ de $\mathrm{AL}$ soluble se incubaron con un volumen de soluciones reguladoras de $\mathrm{pH}$ de $50 \mathrm{mM} \mathrm{KCl} / \mathrm{HCl}(\mathrm{pH}=1,20$ y 2,00), de citrato $25 \mathrm{mM}(\mathrm{pH}=3,00)$, de acetato $(\mathrm{pH}=4,00$ y 5,00$)$ y de fosfato $(\mathrm{pH}=6,30-6,80-7,40$ y 8,20$)$. Después de la incubación, la actividad de AL se ensayó como se ha descripto previamente.

\section{Estabilidad térmica de la AL soluble y de la AL-CLEAs}

La estabilidad térmica de la enzima se determinó por incubación de la AL libre y la $\mathrm{AL}$-CLEAs a $\mathrm{pH}=7,40$ y temperaturas de $25,37,45$ y $60{ }^{\circ} \mathrm{C}$ durante 1 hora y luego la actividad de AL se determinó como se ha descripto previamente. 


\section{Efecto de disolventes orgánicos en la estabilidad}

AL-CLEAs y AL soluble se incubaron en $50 \%(v / v)$ de etanol, acetona y 1,2propilenglicol a $37^{\circ} \mathrm{C}$ durante 1 hora. Luego, la actividad residual de la enzima se midió en condiciones óptimas como se ha mencionado previamente.

\section{Efecto de la fuerza iónica}

AL-CLEAs y AL soluble fueron incubadas en solución reguladora de $\mathrm{pH}$ fosfato $25 \mathrm{mM}(\mathrm{pH}=7,40)$ conteniendo cantidades crecientes de $\mathrm{NaCl}$ en el intervalo de 0,05 $\mathrm{M}$ a $1,0 \mathrm{M}$ a $37{ }^{\circ} \mathrm{C}$ durante una hora. La actividad enzimática residual se determinó como fuera descrito anteriormente.

\section{Reutilización del biocatalizador}

En un primer ciclo de uso, $50 \mathrm{mg}$ de AL-CLEAs se mezcló con $500 \mu \mathrm{l}$ de solución de alginato $2,0 \%(\mathrm{p} / \mathrm{v})$ en una solución reguladora fosfato $25 \mathrm{mM}(\mathrm{pH}=7,40)$ y se incubó a $37^{\circ} \mathrm{C}$ durante 1 hora. La suspensión se centrifugó a 10.000 xg durante 5 minutos, y a continuación se determinó la actividad en el sobrenadante. Para el segundo ciclo y los siguientes, el pellet se lavó dos veces con solución reguladora fosfato $(\mathrm{pH}=7,40)$ para eliminar restos de producto ( $y$ evitar una posible inhibición de la enzima) y la actividad enzimática se determinó nuevamente como se ha descrito antes.

\section{Ensayos reológicos}

La tecnica desarrollada fue la siguiente: $50 \mathrm{mg}$ de AL-CLEAs se colocaron en 10 $\mathrm{ml}$ de solución de alginato de sodio $2,0 \%(\mathrm{p} / \mathrm{v})$ en una solución reguladora fosfato 25 $\mathrm{mM}(\mathrm{pH}=7,40)$ y se incubaron a $37^{\circ} \mathrm{C}$ durante diferentes intervalos de tiempo. En cada intervalo, se tomó una alícuota de $500 \mu \mathrm{l}$, se diluyó 20 veces en solución reguladora fosfato y se determinó la viscosidad relativa a $37^{\circ} \mathrm{C}$ mediante un viscosímetro $\mathrm{S} 100$ Ubbelohde. 


\subsection{Resultados y discusión}

\section{Determinación de las condiciones óptimas para la síntesis de AL-CLEAs}

La precipitación de la AL se llevó a cabo mediante agentes comúnmente utilizados en la purificación de proteínas (Illanes, 2008) Metanol, etanol y acetona $(75 \%, v / v)$ precipitaron completamente la AL. Las propiedades de estos disolventes polares, como la constante dieléctrica y log $\mathrm{P}$, los hacen adecuados para desplazar las macromoléculas de agua, las cuales participan directamente en la solvatación de la enzima, pero también estarían afectando los residuos que constituyen el sitio activo de la enzima y son responsable de la unión al sustrato y posterior hidrólisis del alginato (Wong y col., 2000). Por ello, la utilización de estos disolventes como agentes precipitantes fue descartada debido a que generaban una completa inactivación de la AL.

Otra alternativa, fue precipitar la proteína por el mecanismo de "incremento de fuerza iónica" (efecto salino o salting-out). La misma se basa en la de-solvatación de los residuos polares de la proteína por la presencia de altas concentración de sal en el medio y el aumento de las interacciones hidrófobas en el centro de la proteína (Wingfield, 2001). En este sentido, y para precipitar una proteina se debe seleccionar una sal cosmotrópica (Moelbert y col., 2004). El sulfato de amonio (SA) se utilizó como agente de desplazamiento salino evitando así una mínima inactivación de la enzima. El aumento de la concentración de $\mathrm{SA}$ en solución condujo a un aumento en la precipitación de la AL sin perder la actividad (Figura 3.2). 


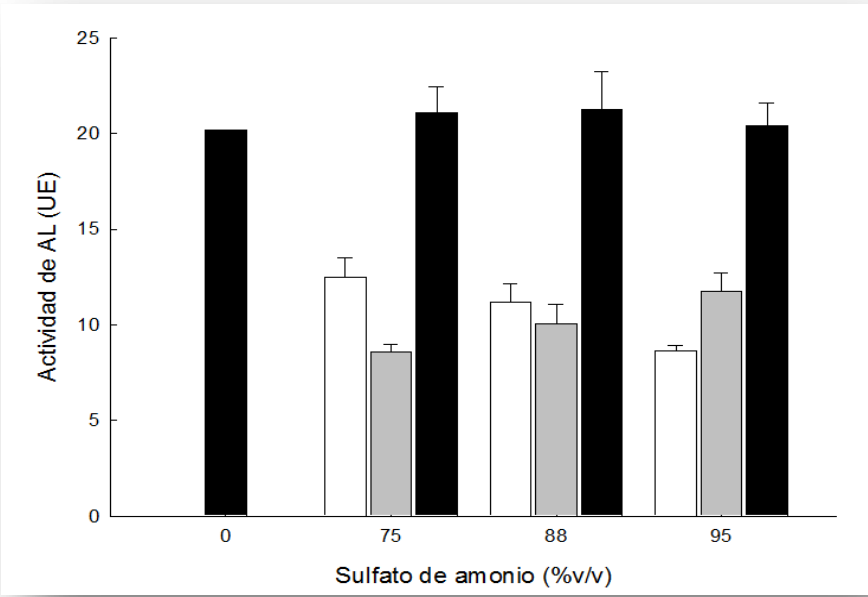

Figura 3.2. Precipitación de AL con el aumento de las concentraciones de sulfato de amonio: $\square$, sobrenadante; $\square$, precipitado resuspendido; $\square$, total.

Sin embargo, se observa que el rendimiento de precipitación de la enzima era de sólo un $60 \%$ con una concentración final de SA del 95\% (v/v). En este escenario, la co-precipitación de la enzima con la ayuda de un biopolímero podría ser una alternativa viable para conseguir aumentar el rendimiento de precipitación, al combinar el mecanismo de incremento de fuerza iónica con el proceso de de floculación con poli-electrolitos. El alginato y pectina fueron seleccionados debido a que su presencia no genera una inactivación de la AL (datos no mostrados). Los rendimientos de co-precipitación fueron del 30 y el $70 \%$ con PAM y alginato, respectivamente, mientras que con PBM se alcanzo un 100\% (Figura 3.3.a).

a

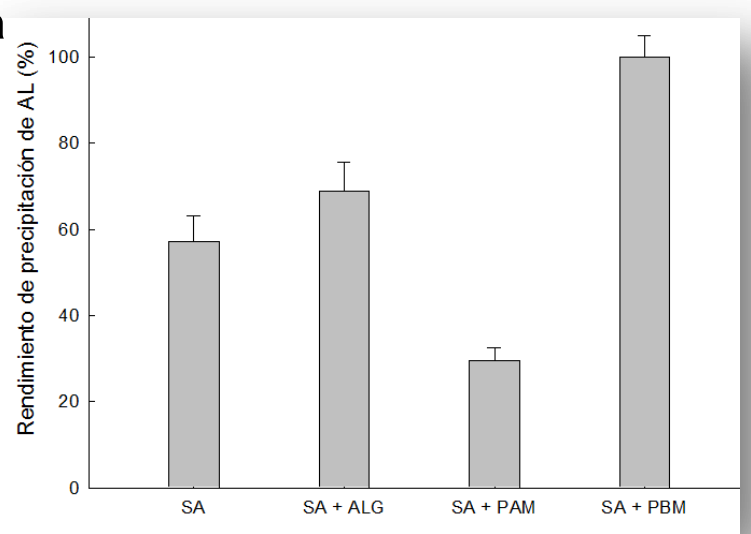

b

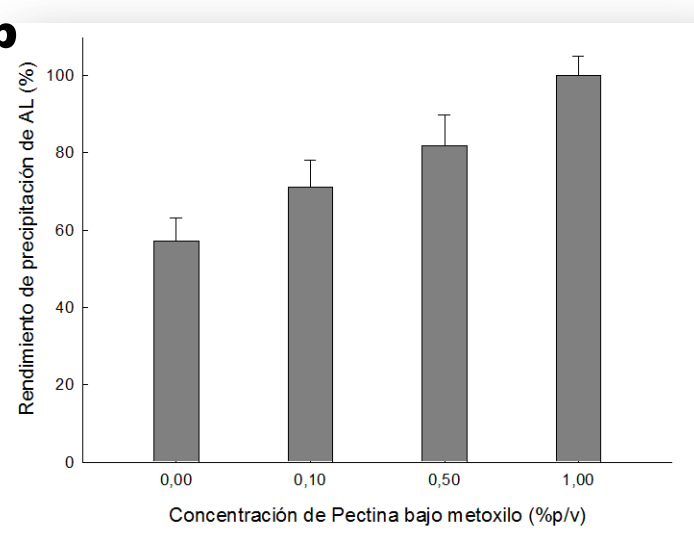

Figura 3.3 Rendimiento de precipitación de la $A L$ en una relación enzima/biopolímero 0,1/1,0 \%, p/v. a) co-precipitación con sulfato de amonio (SA) combinado con alginato (ALG), pectina AM (PAM) o pectina $\mathrm{BM}(\mathrm{PBM})$. b) efecto del incremento de la concentración de PBM en la precipitación de AL. 
La diferencia en la precipitación de la enzima por la PBM podría explicarse en términos de su estructura molecular (Braccini y col., 2001). La PBM es más polar que la PAM, debido a la mayor disponibilidad de grupos carboxílicos libres, y las pectinas comúnmente precipitan en presencia de altas concentraciones de sulfato de amonio como pectinato de amonio (Fan y col., 2012). De esta forma, los grupos carboxilato libres de la PBM (no metoxilados) son los responsables de producir rendimientos de precipitación más altos, y son capaces de mejorar la precipitación de la AL.

Por otro lado, las PBM tienen regiones hidrófobas debido a zonas metoxiladas en la cadena biopolimérica que podrían estar interactuando con residuos hidrofóbicos de la AL (Figura 3.4). En consecuencia, el rendimiento de la precipitación es más alto utilizando PBM que el obtenido con la PAM y alginato debido a la contribución de dos factores: las zonas hidrófobas y las regiones iónicas. Este fenómeno no se observa para la PAM, posiblemente porque si bien posee regiones hidrofóbicas que interactúan fuertemente con la AL, el biopolímero no es capaz de ser totalmente precipitado por la sal de amonio y queda remanente en solución unido a la enzima.

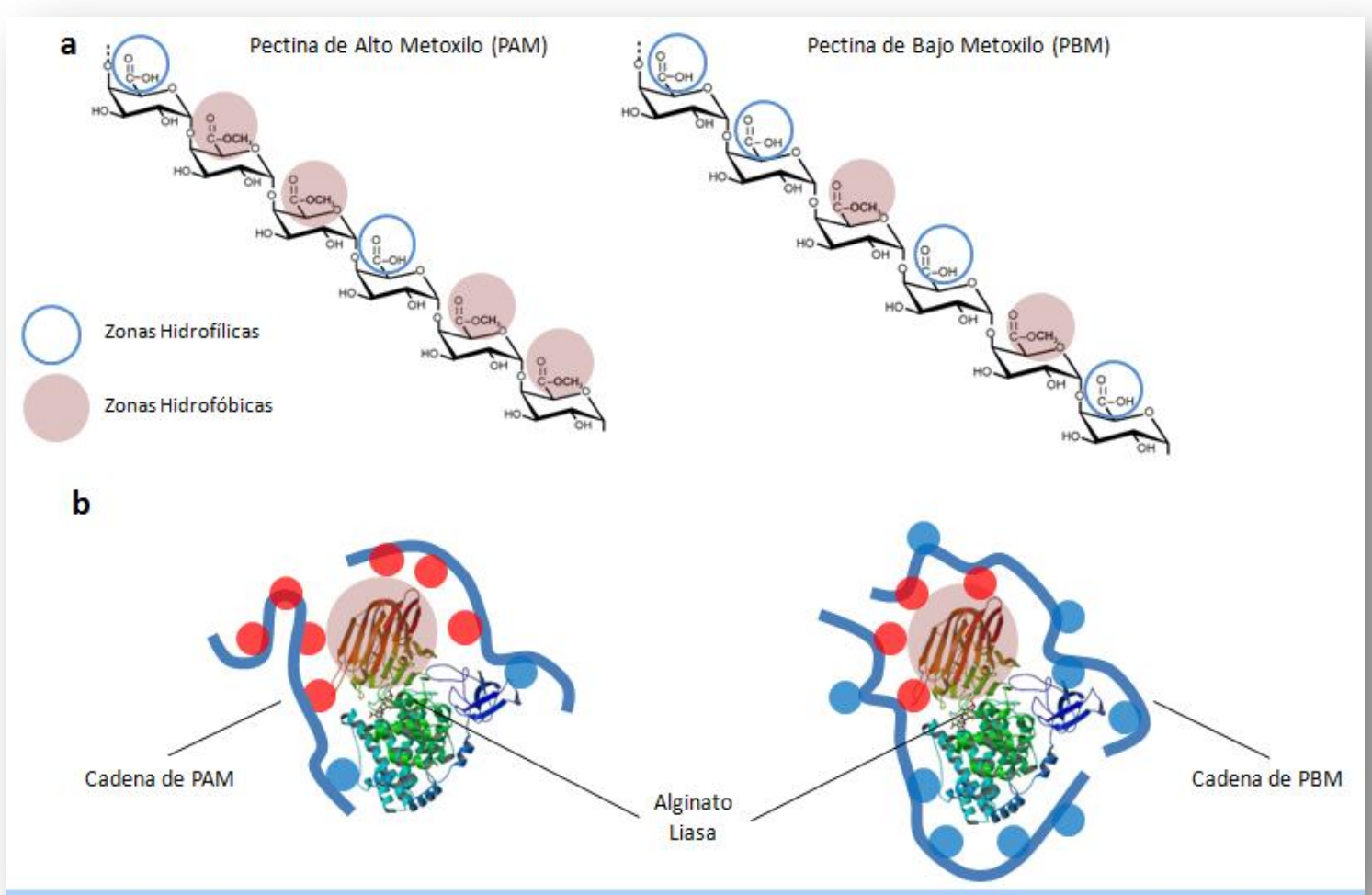

Figura 3.4 Esquema de estructura de las pectinas de alto metoxilo y de bajo metoxilo (a) y posibles interacciones de las cadenas biopoliméricas con la alginato liasa (b). 
Con el fin de determinar la concentración mínima de PBM requerida para precipitar completamente la $\mathrm{AL}$, se ensayó el rendimiento de precipitación disminuyendo la concentración de PBM. Así, se observa que se obtiene una precipitación completa de la AL sólo cuando la enzima está en la mezcla con PBM al $1,0 \%(p / v)$, en una relación enzima/biopolímero de 1:10. Cuando la concentración de PBM se reduce, la precipitación disminuye a menos de $60 \%$ por debajo del $0,1 \%(\mathrm{p} / \mathrm{v})$ (Figura 3.3.b).

El agente de reticulación más comúnmente utilizado en la preparación de CLEAs es el glutaraldehído. Sin embargo, la AL es inactivada casi completamente en presencia de este agente luego de una hora de incubación (Tabla 15). Con el fin de evitar dicha inactivación, la BSA se propuso como un agente protector (Dong y col., 2010). Así, el glutaraldehído podría interactuar principalmente con los residuos de BSA, debido a que su peso molecular es casi dos veces mayor que el de la AL (66 KDa. y $39 \mathrm{KDa}$ respectivamente; fuente: protein data bank).

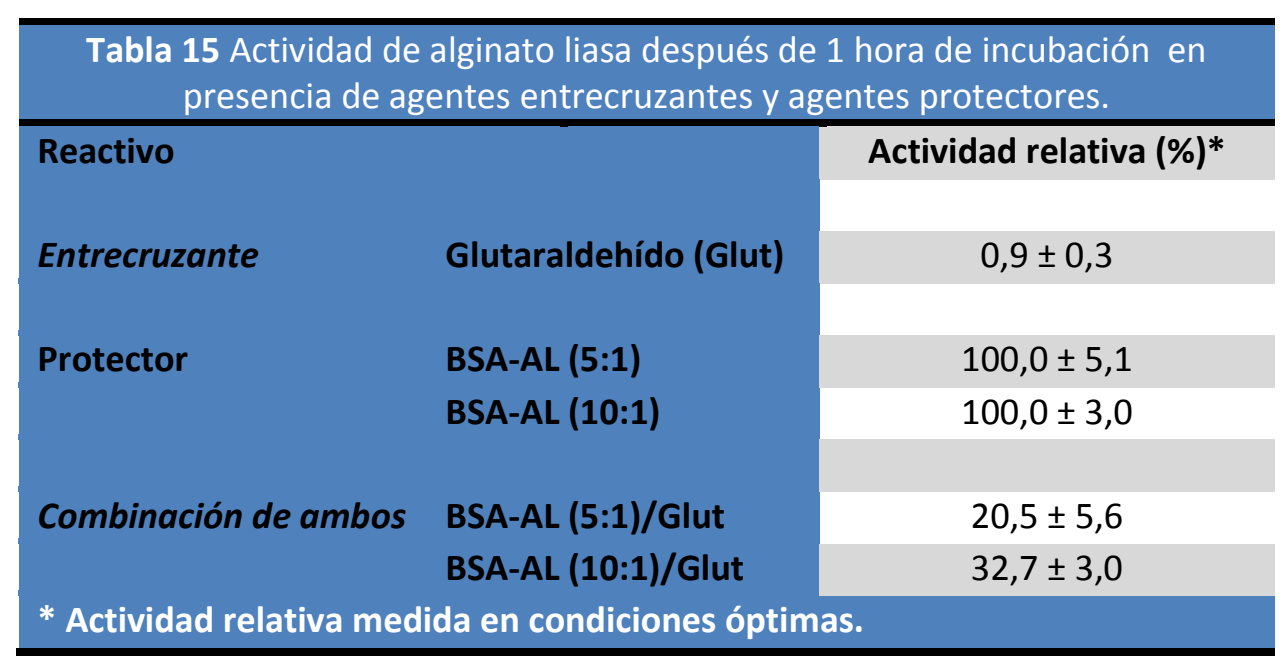

Se observó que en una relación de BSA/AL de 5:1 y 10:1 no se afectaba la actividad de AL en solución acuosa. A continuación, se puso de manifiesto el efecto protector de la BSA al incubar la AL soluble y la BSA en presencia del glutaraldehído. La protección fue más alta en una relación BSA/AL de 10:1, siendo la actividad residual de AL 36 veces mayor que en ausencia de esta proteína (y con glutaraldehído). La Figura 3.5 muestra un esquema del posible mecanismo de inactivación del glutaraldehído en el sitio activo de la AL y el efecto protector dela BSA. 
Teniendo en cuenta los resultados anteriores, se evaluó el efecto de los diferentes componentes en la síntesis de cuatro formulaciones diferentes de CLEAs. La Tabla 16 muestra los rendimientos de AL-CLEA (es decir, la actividad enzimática observada luego de la inmovilización respecto de la actividad inicial) en los cuatro casos.

\begin{tabular}{l|c}
\hline \multicolumn{2}{|c|}{$\begin{array}{c}\text { Tabla } 16 \text { Rendimientos de AL-CLEAs en diferentes } \\
\text { formulaciones. }\end{array}$} \\
\hline Formulación & Rendimiento AL-CLEAs (\%) \\
AL/PAM & $0,05 \pm 0,00$ \\
AL/PBM & $0,35 \pm 0,04$ \\
AL/BSA & $4,53 \pm 0,36$ \\
AL/PBM/BSA & $14,74 \pm 1,72$ \\
\hline
\end{tabular}

a

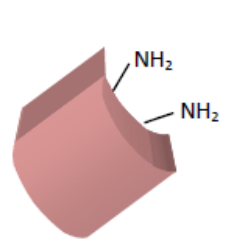

$\mathrm{AL}$

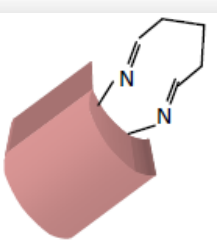

Sitio activo de la AL inactivado

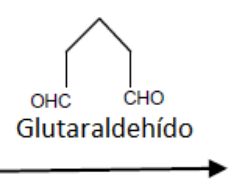

\section{b}
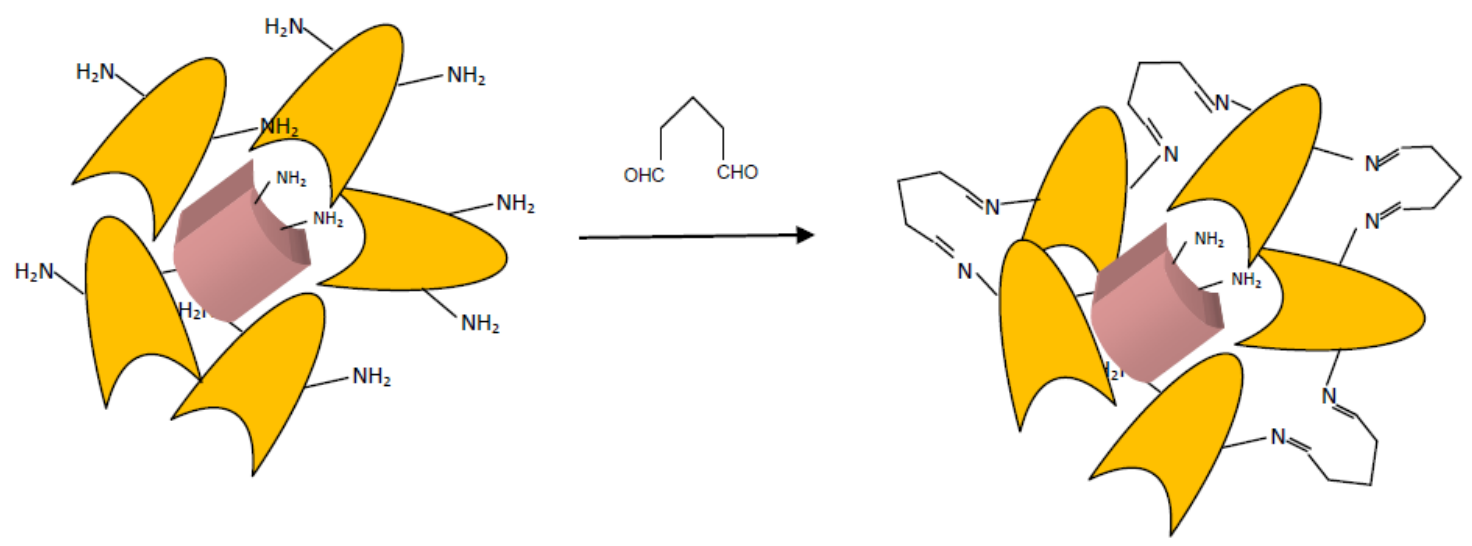

Figura 3.5 Esquema de la reacción del glutaraldehído: a) con los grupos amino presentes en el sitio activo de la AL, generando su inactivación; b) con los grupos amino presentes en su mayor parte en la BSA, previniendo la inactivación de la AL.

Los AL-CLEAs basado en pectinas mostraron los valores más bajos, con rendimientos de 0,05 y 0,35\% para PAM y PBM respectivamente. Se observa que la presencia de glutaraldehído en el medio de síntesis del CLEA estaría generando la 
inactivación de la $\mathrm{AL}$, lo cual explica los bajos rendimientos. En presencia de BSA, sin embargo, el rendimiento de AL-CLEA se incrementó a 4,5\%, lo que confirma el efecto protector de BSA (Tabla 15). En presencia de BSA, el agente de reticulación reacciona principalmente con los residuos carboxilato y amino de la BSA en lugar del sitio activo de AL tal como se muestra en la Figura 3.5. Considerando estos resultados, se propuso una combinación de BSA con PBM en la formulación, alcanzando un rendimiento de AL-CLEA del $14,7 \%$. El efecto sinérgico de protección sobre la AL se podría explicar en términos de los biopolímeros que estarían afectando el microambiente de síntesis del agregado enzimático. Posiblemente la movilidad de la estructura de la enzima este afectada por la interacción multipunto entre el polímero y la enzima (Wilson y col., 2006).

\section{Caracterización de los AL-CLEAs}

Imágenes de microscopía SEM de las diferentes formulaciones de AL-CLEAs son mostradas en la Figura 3.5. En el caso de AL/PAM-CLEAs, se observó una distribución de tamaño heterogénea con agregados de tamaños entre los 300 y $700 \mathrm{~nm}$ de diámetro, con una baja producción de agregados (Figura 3.6, a). Aparentemente, y en concordancia con los datos anteriores, la pectina AM posee una baja eficiencia de precipitación, con lo cual solo unos pocos agregados de la enzima con el biopolímeros son observados, mientras que el resto del material se detecta como una película.

En el caso de del CLEA compuesto de AL/PBM, se encontró una distribución de tamaño bimodal de nanopartículas, con poblaciones de $400 \mathrm{~nm}$ y $700 \mathrm{~nm}$, y un rendimiento de agregados mucho mayor (Figura 3.6, b). Estas diferencias pueden explicarse sobre la base de los resultados obtenidos durante los experimentos de precipitación de la AL donde el rendimiento se incrementó en la presencia de PBM. 

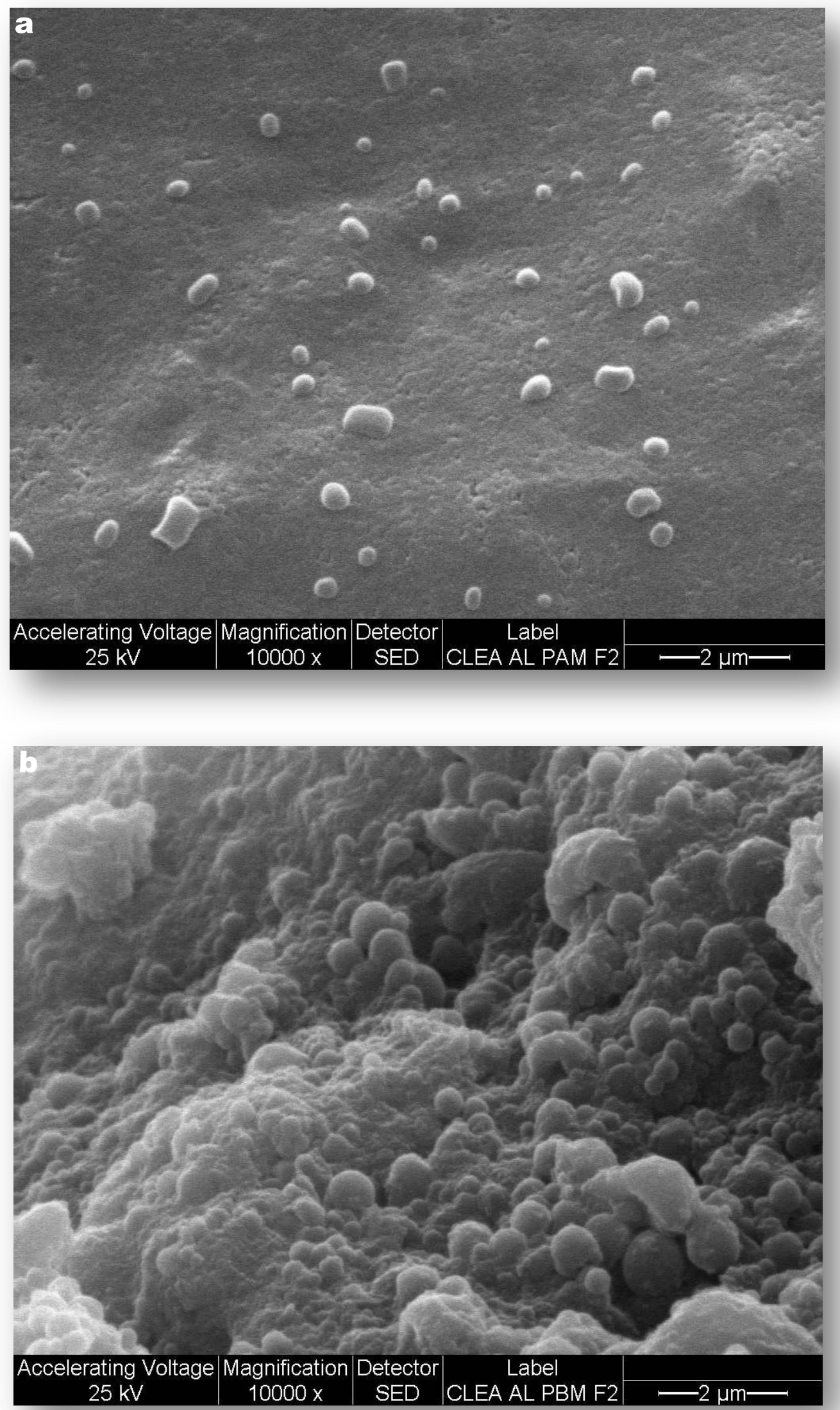

Figura 3.6 Imágenes SEM de los CLEAs de alginato liasa con pectinas: a) AL/PAM; b) AL/PBM; a 10.000x. 
Por otra parte, las formulaciones a base de BSA mostraron una distribución de tamaño homogénea con agregados con un promedio de $135 \pm 21 \mathrm{~nm}$ (Figura 3.7, a). Se observaron resultados similares en un "Combi-CLEA" compuesto de una lipasa de Pseudomonas cepacia y una penicilin acilasa, donde en presencia de BSA la actividad enzimática se incrementó y el tamaño y distribución de los agregados fue más homogéneo (Shah y col., 2006). Finalmente, el CLEA formado por AL/PBM/BSA mostró principalmente agregados con forma de "ñoquis" de un tamaño medio de alrededor de los $3 \mu \mathrm{m}$, aunque se observaron agregados de tamaño inferior (Figura 3.7, b).

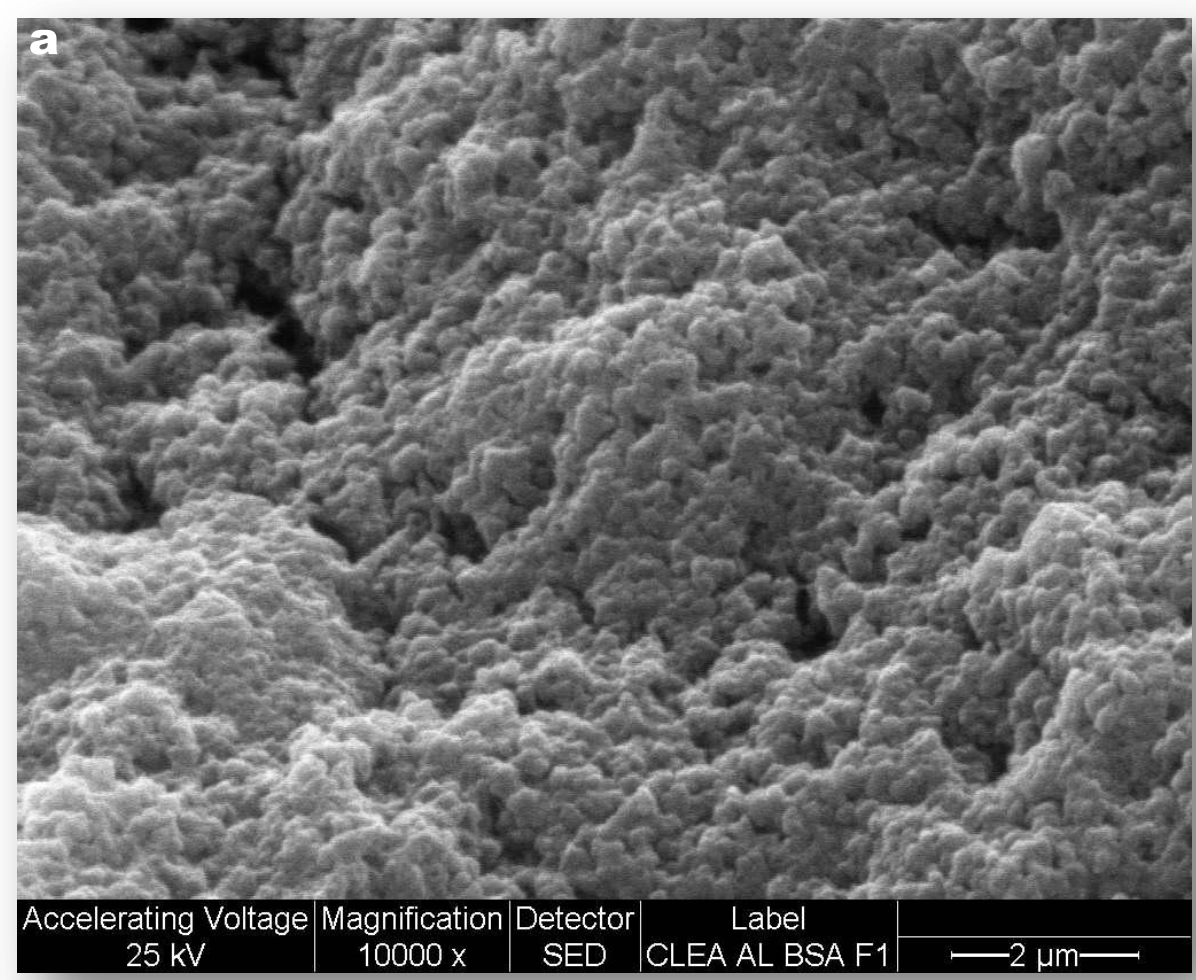




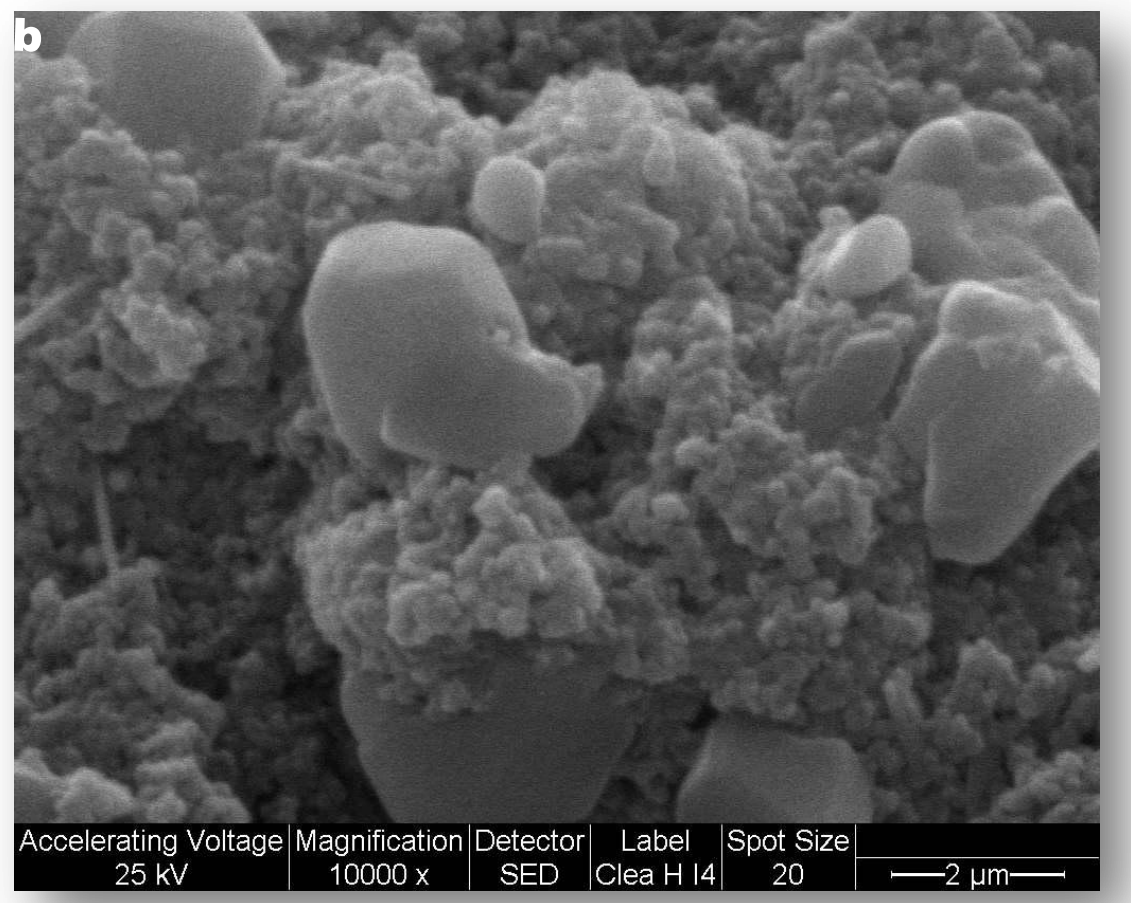

Figura 3.7 Imágenes SEM de los CLEAs de alginato liasa: a) AL/BSA; b) AL/PBM/BSA; a 10.000x.

\section{Estabilidad de la AL soluble y AL-CLEAs}

Al incubar la formulación de CLEAs de AL/PBM/BSA bajo condiciones que son desnaturalizantes para la enzima libre $(\mathrm{pH}=1,20$ por 30 y $120 \mathrm{~min})$, se obtuvo una elevada protección al pH, observando una actividad residual del 80 y $60 \%$ respecto de la actividad inicial (Figura 3.8).

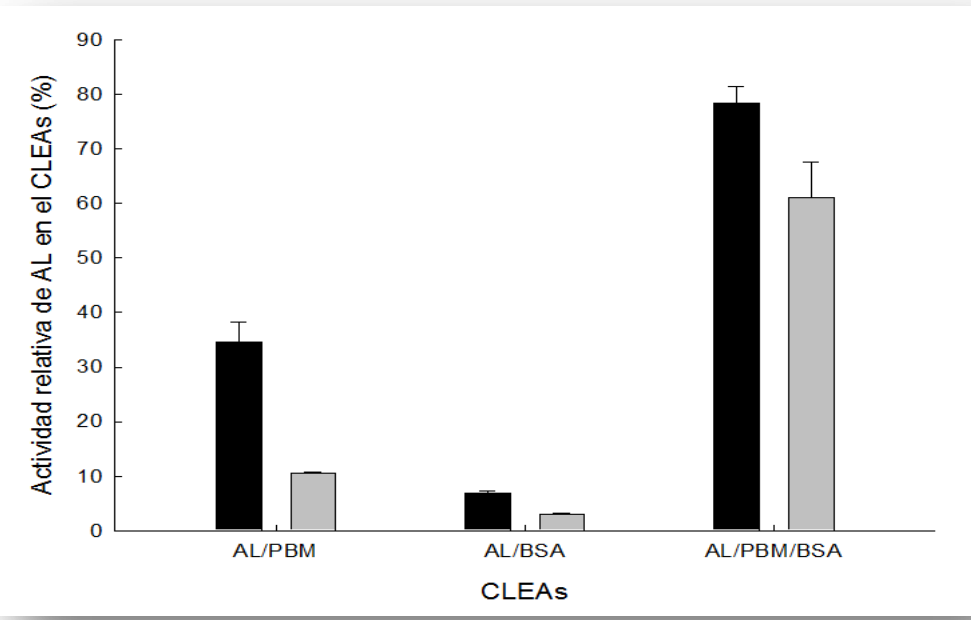

Figura 3.8 Estabilidad al pH de las formulaciones de AL-CLEAs incubadas a $\mathrm{pH}=1,20$ y $37^{\circ} \mathrm{C}$ por $30(\square)$ y $120(\square)$ minutos. 
Con el fin de determinar cuál de los componentes de la formulación ofreció el efecto protector, también se incubaron los CLEAs de AL/PBM y AL/BSA en las mismas condiciones experimentales. La figura muestra que se requiere la presencia de PBM para obtener una actividad enzimática al menos 3,5 veces superior después de $30 \mathrm{~min}$ y de 2,0 veces después de 120 minutos de incubación que la que se obtuvo con el CLEAs con BSA. Por otra parte, la combinación de ambos componentes PBM y BSA produjo un efecto protector sinérgico sobre el AL-CLEA. Dichas observaciones sugieren que las regiones hidrofóbicas de la BSA y la PBM podrían evitar la difusión protones hacia regiones sensibles de la AL, evitando así la inactivación de la enzima (Krall y col., 1998).

En base a los ensayos realizados, la formulación CLEAs compuesta de AL/PBM/BSA fue seleccionada para experimentos adicionales.

La estabilidad enzimática del biocatalizador seleccionado y la AL soluble fue estudiada en el intervalo de $\mathrm{pH}$ de 1,20 a 8,20, a fin de evaluar su pasaje por los $\mathrm{pH}$ fisiológicos del tracto gastrointestinal. Se determinó la actividad residual después de 1 hora de incubación a dichos pHs (Figura 3.9).

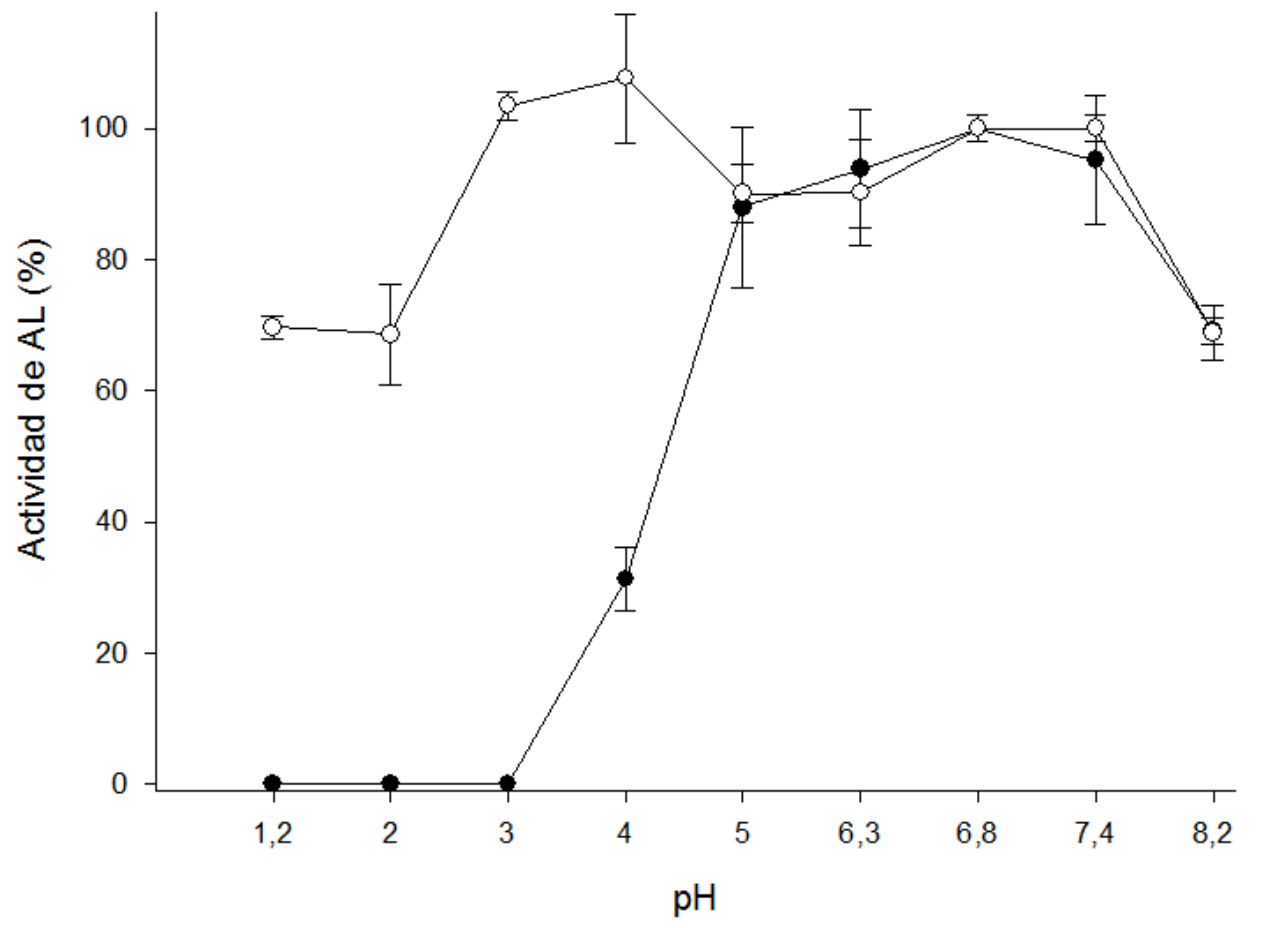

Figura 3.9 Efecto del pH sobre la estabilidad (actividad residual después de 1 hora de incubación a $37^{\circ} \mathrm{C}$ ) de la AL soluble (•) y el AL/PBM/BSA CLEAs (O). 
La AL soluble como el AL-CLEAs se mantuvieron estables en el rango de $\mathrm{pHs}$ comprendido entre 5,00 a 7,40. Sin embargo, la actividad enzimática de la AL soluble disminuyó en más de un $60 \%$ a pH 4,00 y fue completamente inactivada por debajo de $\mathrm{pH}$ 3,00 después de 1 hora de incubación. Por el contrario, el AL-CLEAs fue completamente activo después de la incubación a pH 3,0 y la actividad disminuyó sólo en un $30 \%$ después de la incubación a pHs 1,2 y 2,0 en las mismas condiciones experimentales, por lo que se destacan las propiedades de estabilización de la enzima mediante la formación del CLEAs.

Por otra parte, se estudió la estabilidad térmica en el rango de $25^{\circ} \mathrm{C}$ a $60^{\circ} \mathrm{C}$ mediante la medición de la actividad residual luego de 1 hora de incubación a pH=7,40 (Figura 3.10). Se encontraron diferencias significativas $(p \leq 0,05)$ en los valores de actividad residual del AL-CLEAs y la AL soluble después de la incubación a temperaturas superiores a $40^{\circ} \mathrm{C}$. En este sentido, el AL-CLEAs mostró una actividad enzimática del 35,60 y $10 \%$ más alto que la AL libre a 40,45 y $60^{\circ} \mathrm{C}$ respectivamente.

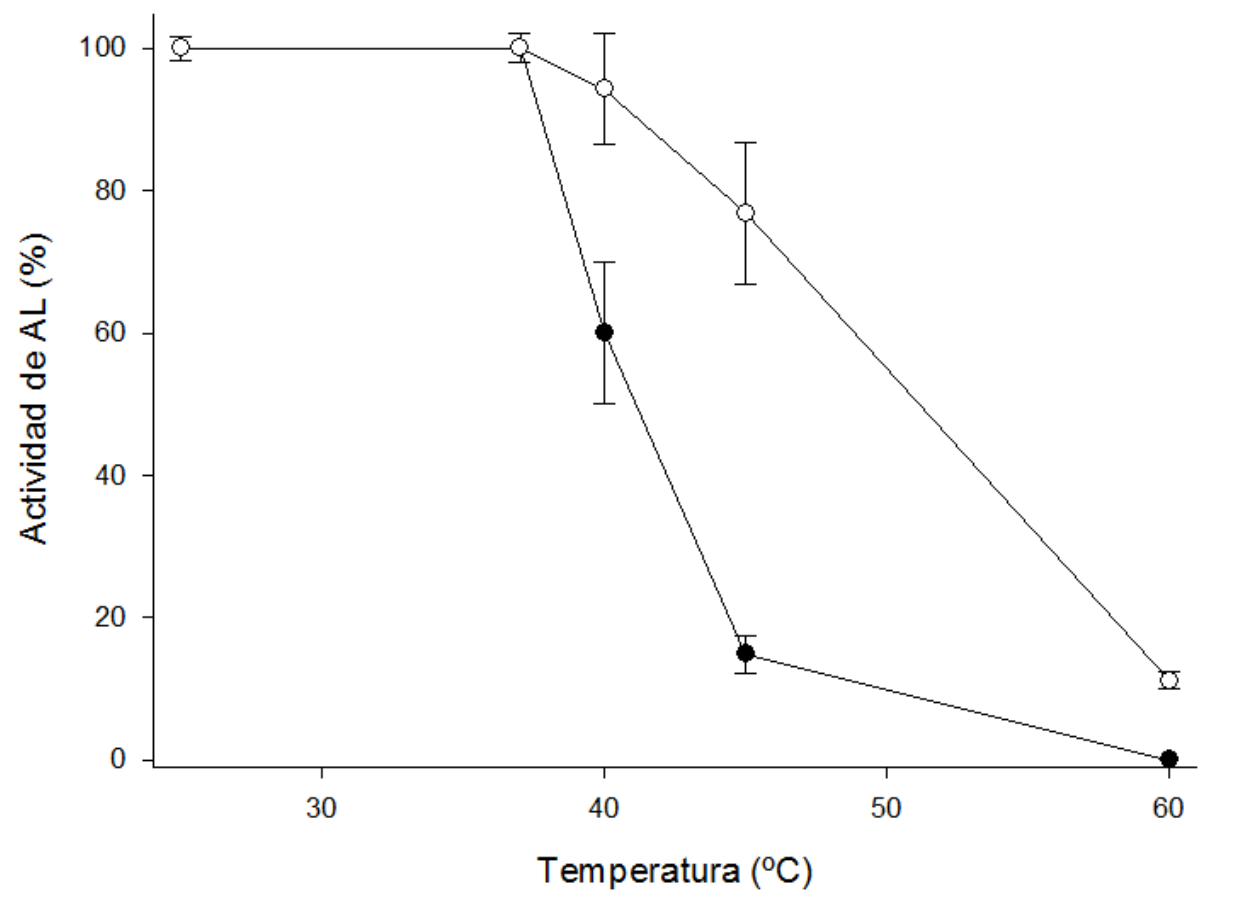

Figura 3.10 Efecto sobre la estabilidad de la AL (actividad residual) después de una hora de incubación a pH 7,40 a diferentes temperaturas: $(\bullet)$ AL soluble y (O) AL/PBM/BSA CLEAs. 
A su vez y para tener una aproximación al entorno fisiológico generado en un paciente con una patología febril, la estabilidad de la AL soluble y AL-CLEAs se ensayó a $\mathrm{pH}=1,2$ ( $\mathrm{pH}$ gástrico) y temperaturas de incubación de 40 y $45^{\circ} \mathrm{C}$ por una hora. Mientras que la enzima soluble mostró una rápida inactivación en ambas condiciones experimentales, los AL-CLEAs (compuesto de AL/PBM/BSA) mostraron un 52,6 $\pm 5,0 \%$ y $43,0 \pm 2,1 \%$ de actividad residual a los 40 y $45^{\circ} \mathrm{C}(\mathrm{pH}=1,2)$ respectivamente. Los resultados validan el uso de la formulación de AL-CLEAs para su posible administración oral en pacientes con fibrosis quística que puedan presentar síntomas febriles.

Con el fin de estudiar cuál de los componentes ofreció el efecto de protección térmica, se incubaron los CLEAs de BSA y $\mathrm{PBM}$ a $60^{\circ} \mathrm{C}$, condiciones en las que la enzima libre es completamente inactivada (Tabla 17).

Se observó que la PBM es necesaria para promover protección térmica a la AL, mientras que no se observó ningún efecto de protección térmica cuando sólo la BSA fue incorporada en la formulación del AL-CLEA.

\begin{tabular}{lc}
\hline $\begin{array}{l}\text { Table } 17 \text { Estabilidad térmica (actividad residual después de } 1 \text { hora } \\
\text { de incubación a pH 7,40) de la AL soluble y AL-CLEAs a } 60^{\circ} \mathrm{C} .\end{array}$ \\
\hline Formulación & $\begin{array}{c}\text { Actividad residual (\%) } \\
\text { AL soluble }\end{array}$ \\
AL/PBM CLEAs & 14,0 \\
AL/BSA CLEAs & $0,7 \pm 0,1$ \\
AL/PBM/BSA CLEAs & $11,1 \pm 1,2$ \\
\hline
\end{tabular}

En otro experimento, se puso de manifiesto si el AL-CLEA era capaz de ser estable en presencia de solventes orgánicos, debido a que como bien se había mencionado anteriormente, la $\mathrm{AL}$ soluble es sometida a un proceso de desnaturalización en presencia de varios de ellos. Se seleccionaron disolventes usados comúnmente en la industria farmacéutica y relevantes para los propósitos de administración de fármacos, ya que la disponibilidad de agua en la interfaz de los tejidos será escasa. Así, la formulación AL/PBM/BSA CLEAs fue incubada en etanol, acetona y 1,2-propilenglicol $(50 \%, \mathrm{v} / \mathrm{v})$ por una hora, los resultados experimentales indican una actividad residual de 6,$4 ; 18,0$ y $37,5 \%$ respectivamente. Por otro lado, la 
AL soluble mostró actividad enzimática menor al 2,0\% para todos los disolventes ensayados (Figura 3.11, a).
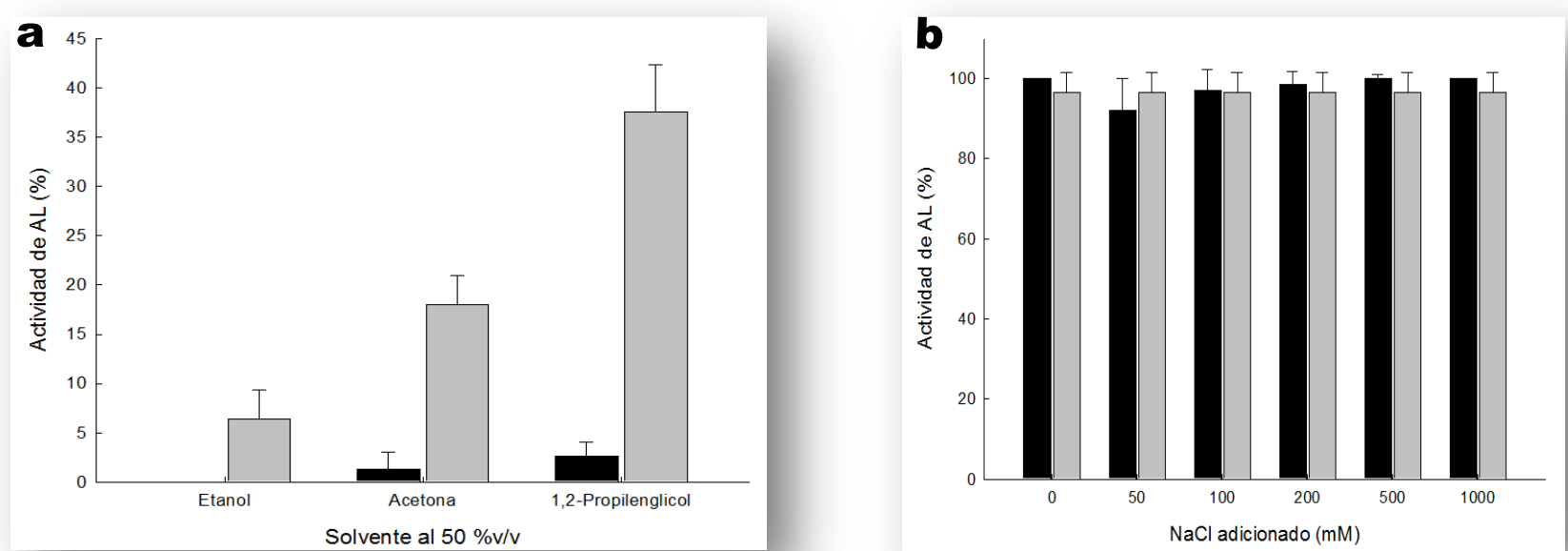

Figura 3.11 Actividad residual de AL libre ( $\square$ ) y AL-CLEAs ( $\square$ ): a) en presencia de solventes; b) en presencia de fuerza iónica creciente. Se incubó por 1 hora a $37^{\circ} \mathrm{C}$.

Asimismo, se analizó el efecto del incremento de la fuerza iónica (agregado de $\mathrm{NaCl}$ hasta $1.0 \mathrm{M}$ ) en la estabilidad de la AL soluble y el AL/PBM/BSA-CLEAs, y se determinó la actividad residual después de una hora de incubación a $37^{\circ} \mathrm{C}$ y $\mathrm{pH}=7,40$. La actividad de ambos biocatalizadores no se vio afectada después de la exposición, sin observarse diferencias significativas $(p \geq 0,05)$ entre las muestras (Figura 3.11, b).

\section{Reutilización}

La reutilización del biocatalizador seleccionado (AL/PBM/BSA-CLEAs) resulta relevante, debido a que el potencial uso de la enzima en los dispositivos de administración de fármacos se basa en el pasaje por zonas fisiológicas donde constantemente se renueva el medio circundante, encontrándose con cambios de pHs, y zonas con mayor densidad microbiana y el respectivo alginato microbiano.

La actividad del AL-CLEAs se redujo a un 40\% después del primer ciclo de uso, pero se mantuvo constante a partir de los siguientes (hasta el quinto ciclo) (Figura 3.12). Esta drástica reducción se puede explicar debido a que los agregados no fueron lo suficientemente robustos y/o debido a una proceso de inactivación en la interface liquido-CLEA, y se produjo la filtración de la enzima no unida después del primer ciclo. 
También puede producirse debido a que los productos de reacción no pueden difundir fuera de la matriz e inhiben parcialmente la enzima (Talekar y col., 2012).

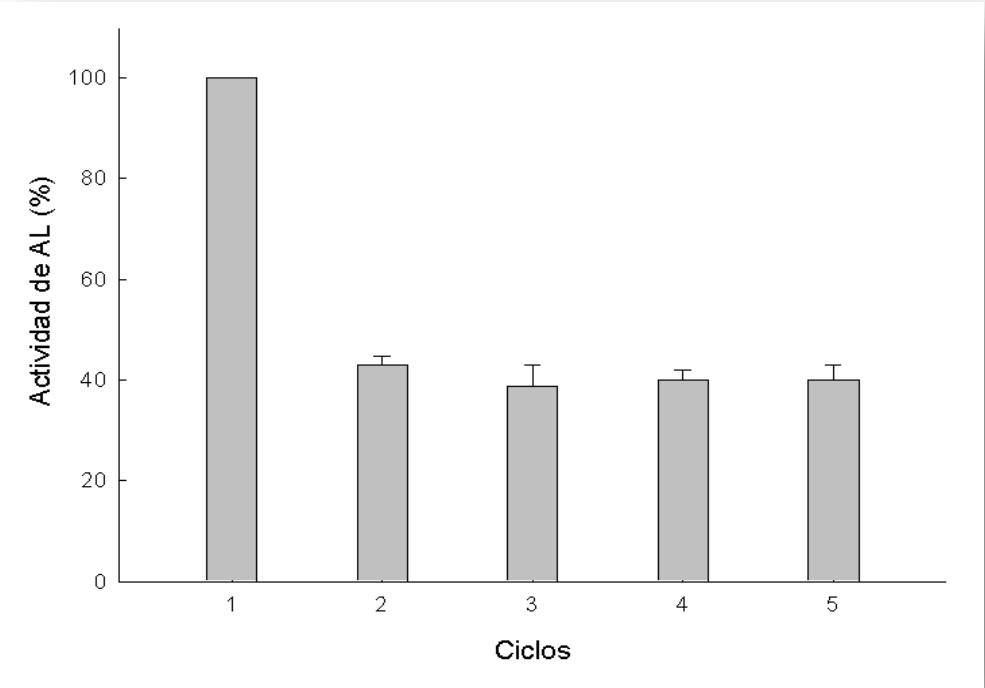

Figura 3.12 Ciclos de reutilización de AL/PBM/BSA CLEAs. En cada ciclo se lavan los agregados y se vuelve a determinar la actividad en alginato $2,0 \%(\mathrm{p} / \mathrm{v})$ a $\mathrm{pH}=7,40$ y $37^{\circ} \mathrm{C}$.

\section{Reducción de la viscosidad de una solución de alginato}

La reducción de la viscosidad de la solución acuosa de alginato es un factor importante en cuanto a la funcionalidad del biocatalizador y vital para el tratamiento de pacientes con fibrosis quística. La reducción de la viscosidad en el lumen del intestino conduce a una mayor difusión de los antibióticos a través de la bio-película bacteriana, con lo cual se facilita la erradicación de la infección (Hatch y col., 1998). Considerando ello, se llevaron a cabo ensayos reológicos incubando el AL/PBM/BSACLEA en $2,0 \%(\mathrm{p} / \mathrm{v})$ de solución de alginato de sodio a $37^{\circ} \mathrm{C}$ durante 3 horas, luego de la cual se observa una reducción de la viscosidad del $25 \%$. Teniendo en cuenta que el alginato mucoide presente en los pacientes es menor al 2,0\% $(p / v)$, esta reducción posee significancia a los fines del tratamiento de la patología (Islan y col., 2013).

Los resultados descritos en el presente capítulo sugieren la ventaja de utilizar agregados enzimáticos entrecruzados de la AL como una alternativa estable y funcional para la administración oral de la enzima a fin de reducir la viscoelasticidad del mucus producido en el intestino de pacientes con FQ por microorganismos. 


\subsection{Conclusiones}

En el presente capítulo se desarrolló una forma estable de administración oral de alginato liasa basado en la técnica de "agregados enzimáticos entrecruzados" (CLEAs) para el tratamiento de la fibrosis quística. Este es el primer reporte en el área de una síntesis de un CLEAs de alginato liasa de acuerdo a las informaciones que obran en conocimiento público a la fecha.

La formulación CLEA compuesta por AL/PBM/BSA fue elegida debido a presentar el mayor rendimiento de inmovilización (15\%) y una mayor estabilidad bajo diferentes condiciones de $\mathrm{pH}$, temperatura, fuerza iónica, presencia de agentes de desnaturalizantes y disolventes orgánicos en comparación con la AL soluble. Un efecto protector sinérgico se encontró entre BSA y PBM como componentes del CLEA, brindando estabilidad al pH y a la temperatura.

En conclusión, se ha planteado una posible alternativa para una de las principales limitaciones asociadas con el uso de enzimas para administración oral mediante la formación de CLEAs. Los resultados indican que AL-CLEA presenta una significativa estabilidad mejorada que podría mejorar la bio-disponibilidad de la enzima para su tratamiento sobre el alginato acumulado en el intestino de pacientes con FQ. 


\subsection{Bibliografía}

Augst A. D., Kong H. J., Mooney D. J., Alginate hydrogels as biomaterials. Macromol. Biosci., 2006, 6, 623.

Braccini I., Perez S., Molecular basis of $\mathrm{Ca}^{2+}$-induced gelation in alginates and pectins: the eggbox model revisited. Biomacromolecules 2001, 2, 1089.

Brenda http://www.brenda-enzymes.info/php/result flat.php4?ecno=4.2.2.11\&organism.

Dong T., Zhao L., Huang Y., Tan X., Preparation of cross-linked aggregates of aminoacylase from Aspergillus melleus by using bovine serum albumin as an inert additive. Bioresour. Technol., 2010, 101, 6569.

Fan L., Cao M., Gao S., Wang W., Peng K., Tan C., Wen F., Tao S., Xie W., Preparation and characterization of a quaternary ammonium derivative of pectin. Carbohydr. Polym., 2012, 88, 707.

Hatch R. A., Schiller N. L., Alginate Lyase Promotes Diffusion of Aminoglycosides through the Extracellular Polysaccharide of Mucoid Pseudomonas aeruginosa. Antimicrob. Agents Chemother. 1998, 42, 974.

Hodges N. A., Gordon C. A., Protection of Pseudomonas aeruginosa against ciprofloxacin and beta-lactams by homologous alginate. Antimicrob. Agents Chemother. 1991, 35, 2450.

Illanes A., Enzyme Biocatalysis: Principles and Applications, ed. Springer, Netherlands, 2008

Islan G. A., Bosio V. E., Castro G. R., Alginate Lyase and Ciprofloxacin Co-Immobilization on Biopolymeric Microspheres for Cystic Fibrosis Treatment. Macromol. Biosci., 2013, 13, 1238.

Krall S. M., Mc Feeters R. F., Pectin hydrolysis: effect of temperature, degree of methylation, pH, and calcium on hydrolysis rates. J. Agric. Food Chem., 1998, 46, 1311.

Moelbert S., Normand B., De Los Rios P., Kosmotropes and chaotropes: modelling preferential exclusion, binding and aggregate stability. BIOPHYSICAL CHEMISTRY, 2004, 112, 45.

P. Wingfield, in Current Protocols Protein Science ed. John Wiley and Sons Inc., Germany, 2001, APPENDIX 3F.

Schoevaart R., Wolbers M., Golubovic M., Ottens M., Kieboom A., Van Rantwijk F., Van der Wielen L., Sheldon R., Preparation, optimization, and structures of cross-linked enzyme aggregates (CLEAs). Biotechnol. Bioeng., 2004, 87, 754.

Shah S., Sharma A., Gupta M. N., Preparation of cross-linked enzyme aggregates by using bovine serum albumin as a proteic feeder. Anal. Biochem., 2006, 351, 207. 
Talekar S., Ghodake V., Ghotage T., Rathod P., Deshmukh P., Nadar S., Mulla M., Ladole M., Novel magnetic cross-linked enzyme aggregates (magnetic CLEAs) of alpha amylase. Bioresour. Technol., 2012, 123, 542.

Wilson L., Fernández-Lorente G., Fernández-Lafuente R., Illanes A., Guisán J. M., Palomo J. M., CLEAs of lipases and poly-ionic polymers: A simple way of preparing stable biocatalysts with improved properties. Enzyme Microb. Technol., 2006, 39, 750.

Wong T. Y., Preston L. A., Schiller N. L., Alginate lyase: review of major sources and enzyme characteristics, structure-function analysis, biological roles, and applications. Annu. Rev. Microbiol., 2000, 54, 289. 


\section{CAPITULO 4 \\ Desarrollo de una matriz inhalable con propiedades bactericidas}

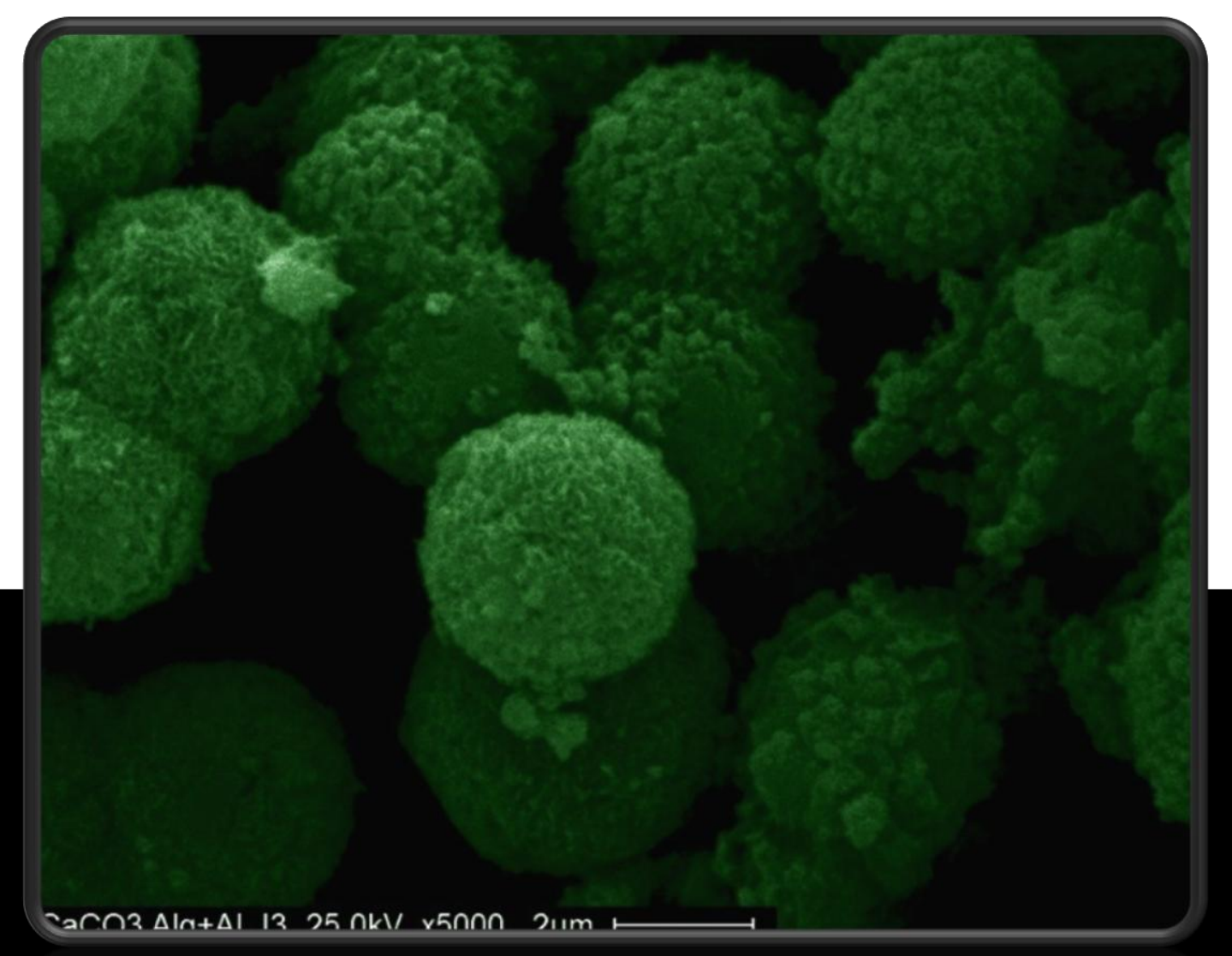

Imagen de micropartículas hibridas de biopolímero y carbonato de calcio luego de un tratamiento enzimático, obtenida mediante microscopia electrónica de barrido a 5.000x. 


\section{Objetivos específicos}

* Establecer las condiciones de síntesis de partículas de 5 micrones de diámetro compuestas por biopolímeros.

* Evaluar la capacidad de almacenamiento y liberación de un antibiótico utilizado para terapia inhalatoria: Levofloxacina.

* Estudiar la estabilidad mecánica de las micropartículas.

* Caracterizar las propiedades de la matriz y sus componentes por microscopia SEM, epifluorescencia, FTIR, DSC y rayos $X$.

Evaluar la capacidad antimicrobiana del sistema contra Pseudomonas aeruginosa.

Ensayar la capacidad del sistema para incorporar una enzima hidrolítica (ADNasa) y liberarla de forma activa.

4.1. Introducción

4.2. Materiales y métodos

* Materiales ... 149

* Síntesis de micropartículas ... 149

- Método de emulsión ... 149

- Co-precipitación de carbonato de calcio/biopolímeros (vía síntesis química) ... 150

* Modificación de micropartículas hibridas por tratamiento con alginato liasa ... 150

* Caracterización de las micropartículas ... 150

* Microscopia electrónica de barrido (SEM) ... 150

* Análisis de rugosidad ... 151

* Microscopía óptica y fluorescente ... 151

* Determinación del contenido total de biopolímero por el método de Antrona ... 151

* Espectroscopia Infrarroja con transformada de Fourier (FTIR) ... 152

* Difracción de rayos X (DRX) ... 152

* Calorimetría diferencial de barrido (DSC) ... 152

* Isotermas de adsorción de nitrógeno ... 152

* La distribución de tamaño ... 152

* Carga de Levofloxacina en las micropartículas ... 153

* Adsorción de Levo y ADNasa en micropartículas ... 153

* Liberación de Levofloxacina y ADNasa ... 153

* Determinación de la actividad ADNasa ... 154

* Ensayo microbiológico ... 154

4.3. Resultados y discusión

* Síntesis y caracterización de micropartículas biopoliméricas por método de emulsión ... 156

* Síntesis y caracterización de micropartículas híbridas de $\mathrm{CaCO}_{3} /$ biopolímeros ... 159

* Carga de Levofloxacina ... 172

* Ensayo microbiológico ... 176

* Incorporación de una ADNasa a la matriz ... 179

4.4. Conclusiones 


\subsection{Introducción}

Los pacientes con fibrosis quística (FQ) padecen infecciones recurrentes y crónicas a nivel del tracto respiratorio inferior. Entre los patógenos, Pseudomonas aeruginosa está particularmente asociado con la morbilidad y la mortalidad de los pacientes, y ha sido catalogado como el responsable de la disminución de la función pulmonar a través de la formación de bio-películas (Høiby y col., 2010). A su vez, esta infección pulmonar actúa como reservorio para esparcir el patógeno hacia otras regiones del organismo (Sarles, 2012).

En los capítulos anteriores el objetivo fue desarrollar formulaciones que actuaran en infecciones intestinales causantes de una desnutrición progresiva de los pacientes, sin embargo en el presente capitulo se desea que la formulación pueda actuar sobre la infección en el foco principal de la patología: el pulmón. Para ello, se desarrollaron matrices a base de biopolímeros con propiedades bactericidas para su administración por vía pulmonar.

Actualmente, el tratamiento de las infecciones respiratorias bacterianas se realiza con la nueva generación de antibióticos como las fluoroquinolonas (levofloxacina, gatifloxacina, moxifloxacina), y/o macrólidos (claritromicina y azitromicina), o amoxicilina o amoxicilina/clavulánico (para aislados sensibles a la penicilina). Una terapia antibiótica agresiva temprana es esencial para prevenir el establecimiento de bacterias y la formación de biopelículas consecuente.

En particular, la Levofloxacina (Levo) es un antibiótico de amplio espectro utilizado para el tratamiento de infecciones bacterianas, incluyendo respiratorias, tracto urinario, gastrointestinales o infecciones abdominales. La Levofloxacina es una de las fluoroquinolonas de última generación y es considerada la más segura entre las fluoroquinolonas al producir una baja tasa de anormalidades hepáticas (Carbon y col., 2001). Sin embargo, los efectos secundarios comunes de la droga afectan el normal funcionamiento del tracto gastrointestinal, causando náuseas o vómitos, diarrea, dolor de cabeza, y estreñimiento. La alteración de la flora normal del colon por lo general produce colitis pseudomembranosa (Rubinstein, 2001). 
El suministro de partículas en forma de aerosol posee ciertas ventajas en comparación con otras formas de administración. Por un lado, el antibiótico se administra directamente en el pulmón infectado y se logra incrementar la concentración local del fármaco. En este sentido, no sólo la destrucción de la bacteriana patógena es potenciada, sino que también se evita la proliferación de microorganismos resistentes (Geller y col., 2011). Por otro lado, la inhalación de micropartículas es una alternativa de administración sistémica no invasiva de fármacos, ofreciendo un perfil de liberación controlada del mismo, prolongando el tiempo de residencia en las vías respiratorias, disminuyendo los efectos secundarios y reduciendo el número de dosis de los medicamentos en los pacientes.

Para el diseño de las matrices, se debe considerar que las partículas de gran tamaño (mayores a $10 \mu \mathrm{m}$ ) se acumulan principalmente en la periferia del pulmón, mientras que las que poseen un tamaño menor a 1 micrón suelen ser fagocitadas por los macrófagos y eliminadas en un proceso comúnmente denominado de "limpieza pulmonar" (Cai y col., 2013). Por ello, el tamaño cercano a las 5 micrones resulta el ideal para la administración pulmonar (Edwards y col., 1997). Además de este parámetro de tamaño, la porosidad de la partícula debe tenerse en cuenta, debido a que proporciona propiedades únicas como una mayor capacidad de absorción del fármaco dada por un aumento en la superficie específica, y una baja densidad para facilitar su aerosolización (Peng y col., 2010).

En el transcurso del presente capítulo se desarrollaron dos métodos de síntesis de micropartículas biopoliméricas.

Por un lado, se produjeron microesferas por medio del método de emulsión (Guo y col., 2004). Este método tiene la ventaja de ser escalable, permite obtener partículas de tamaños menores a las 10 micrones dependiendo de la viscosidad de la solución biopolimérica y de la velocidad de agitación. No obstante, debe considerarse que las condiciones de síntesis deben ajustarse para obtener micropartículas estables, con la mayor esfericidad posible y evitar fenómenos de agregación de las mismas (Fundueanu y col., 1998).

Como método alternativo, y a fin de obtener una matriz de mayor estabilidad mecánica, se sinterizaron micropartículas hibridas de biopolímeros con carbonato de calcio como matriz base (Bosio y col., 2014). El carbonato de calcio $\left(\mathrm{CaCO}_{3}\right)$ es uno de 
los minerales más abundantes que existen en la naturaleza y un material importante en el campo de la industria farmacéutica. Se han reportado seis polimorfismos diferentes de $\mathrm{CaCO}_{3}$, pero la vaterita es la forma más interesante para la producción de micropartículas. Las partículas de vaterita pueden ser sintetizados a escala de laboratorio por dos métodos de síntesis: por fluidos supercríticos o por síntesis química (Bosio y col., 2014). Mediante ambas, se obtienen geometrías esféricas con un tamaño de cristal pequeño y estrecha distribución de diámetro de partícula (Beuvier y col., 2011). Mezclas acuosas de biopolímeros y $\mathrm{CaCO}_{3}$ en condiciones controladas de precipitación producen "partículas híbridas" que presentan propiedades de liberación sostenida de moléculas y un diseño de mayor biocompatibilidad y versatilidad (Islan y col., 2012: Bosio y col., 2012). En base a los resultados obtenidos en los capítulos anteriores, se procedió a sintetizar micropartículas híbridas con alginato y un coacervado de alginato/pectina de alto metoxilo, debido las propiedades de dichos polímeros para interaccionar con las quinolonas y mejorar sus perfiles de liberación.

Por otra parte, debido a que las partículas hibridas poseen estructuras demasiado rígidas y condensadas, se propone un tratamiento parcial de las micropartículas con Alginato Liasa. De esta forma, el biocatalizador será capaz de hidrolizar regiones selectivas de las micropartículas, desempeñando un papel importante al proporcionar nuevas arquitecturas con nuevas propiedades como cambios en la porosidad, patrones de superficie y reticulado de la red del biogel, los cuales impactan directamente en la eficiencia de carga y en los procesos de liberación de moléculas (Klak y col., 2013; Islan y col., 2013).

Finalmente, una vez optimizado el transportador con propiedades bactericidas para su administración por vía inhalatoria, se procederá a incorporar una enzima hidrolítica para complementar la función del antibiótico. En el caso de tratamiento pulmonar en FQ, la ADNasa es una enzima clave de uso cotidiano y gran importancia para la mejorar de la calidad de vida de los pacientes (Ratjen y col., 2005). Formas comerciales de la enzima facilitan la reducción de la viscosidad de los fluidos pulmonares, favoreciendo la expectoración del mucus que dificulta la mecánica respiratoria de los pacientes y favorece el establecimiento de patógenos oportunistas (Robinson, 2002). 


\subsection{Materiales y métodos}

\section{Materiales}

Levofloxacina (Levo), (S)-9-fluoro-2,3-dihydro-3-methyl-10-(4-methylpiperazin1-yl)-7-oxo-7H-pyrido[1,2,3-de]-1,4-benzoxazine-6-carboxylic acid), pectina de manzana (GE: 70-75\%), glicina (Gly), alginato liasa ( $\mathrm{AL}$ ) de Flavobacterium sp., ADNasa de páncreas bovino, el agar ADNasa (con azul de toluidina) y el Tritón X-100 fueron proporcionados por Sigma-Aldrich (Buenos Aires, Argentina). El alginato de sodio (PM= 120 kDa) fue donado por Monsanto (Buenos Aires, Argentina). Se utilizó una Pseudomonas aeruginosa ATCC 15442 en los experimentos. Otros reactivos fueron de calidad analítica a partir de fuentes disponibles comercialmente y se utilizaron tal como se recibió de Merck (Darmstad, Alemania) o marca similar.

\section{Síntesis de micropartículas}

\section{- Método de emulsión}

Las

micropartículas

biopoliméricas se prepararon por el método de emulsificación, seguido de entrecruzado por gelificación iónica con cloruro de calcio

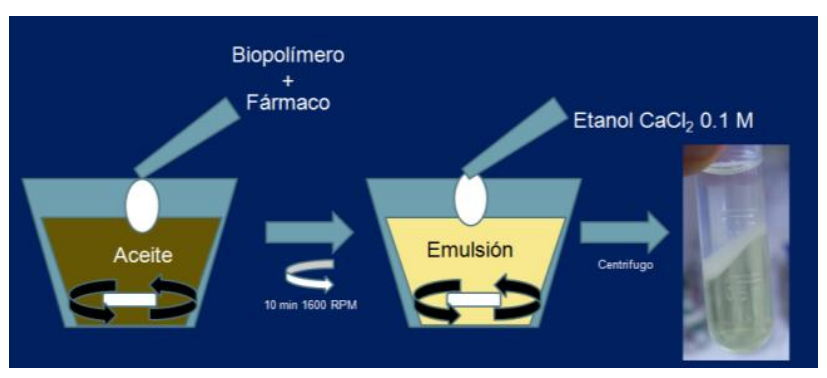
(Fundueanu y col., 1998). Un volumen de $2,0 \mathrm{ml}$ de una mezcla de solución de alginato $2,0 \%(p / v)$-pectina alto metoxilo $1,0 \%(p / v)$, fue dispersada en $10 \mathrm{ml}$ de medio orgánico (aceite de siliconas) conteniendo 0,1\% (v/v) de agente tensioactivo (Tween 80 o Tritón X-100) bajo agitación magnética a 10.000 rpm. Después de 15 minutos, se añadieron 10,0 $\mathrm{ml}$ de solución de cloruro de calcio $500 \mathrm{mM}$ en etanol. Las micropartículas obtenidas se centrifugaron a $10.000 \mathrm{rpm}$ y se lavaron con soluciones acuosas de acetona $(25 \%, 50 \%$ y $75 \%(\mathrm{v} / \mathrm{v})$, respectivamente) para eliminar los residuos de aceite. 


\section{- Co-precipitación de carbonato de calcio/biopolímeros (vía síntesis química)}

Se sintetizaron micropartículas híbridas por cristalización coloidal de $\mathrm{CaCO}_{3}$, en presencia de biopolímeros: alginato o coacervado de alginato/pectina de alto metoxilo (PAM). Brevemente, 9,0 ml de una solución acuosa de $\mathrm{Na}_{2} \mathrm{CO}_{3}(3,20 \%, \mathrm{p} / \mathrm{v})$ preparada en agua miliQ se mezclaron con 2,0 ml de la solución biopolimérica al 1,0 \%(p/v). Luego, se adicionaron 9,0 $\mathrm{ml}$ de una solución de $\mathrm{CaCl}_{2}$ al 3,20\% (p/v) en solución reguladora Gly $(\mathrm{pH}=10,0)$ y se agitó a $1.000 \mathrm{rpm}$ a $0^{\circ} \mathrm{C}$ (un baño de hielo) durante 5 min. La mezcla de reacción fue centrifugada a 10.000 xg durante 10 minutos y el precipitado resultante fue lavado con agua miliQ. Más tarde, las muestras se resuspendieron en agua, se congelaron con $\mathrm{N}_{2}$ líquido y se liofilizaron. Por último, el polvo obtenido fue almacenado en desecadores al vacío a temperatura ambiente hasta su uso posterior.

\section{Modificación de micropartículas hibridas por tratamiento con alginato liasa}

Una masa de 25,0 mg de micropartículas híbridas fueron incubadas con 1,5 ml de solución de alginato liasa $(1,0 \mathrm{mg} / \mathrm{ml} ; 40 \mathrm{UE} / \mathrm{ml}$, solución reguladora fosfato $25 \mathrm{mM}$, $\mathrm{pH}=7,4)$ a $37{ }^{\circ} \mathrm{C}$ durante 48 horas. Luego, las micropartículas se lavaron dos veces con agua miliQ y se liofilizaron. Se realizaron controles con micropartículas híbridas incubadas bajo las mismas condiciones experimentales pero sin la enzima.

\section{Caracterización de las micropartículas}

\section{Microscopia electrónica de barrido (SEM)}

Las microesferas fueron liofilizadas durante 24 horas antes de realizar la microscopía electrónica de barrido (SEM). Luego, las muestras fueron recubiertas en su superficie con oro pulverizado mediante un metalizador Balzers SCD 030 hasta obtener un espesor de capa entre 15 a $20 \mathrm{~nm}$. La superficie y morfología de las microesferas fueron observadas con el equipo Philips SEM 505 (Rochester, EE.UU.), y las imágenes procesadas por un programa digitalizador de imágenes (Soft Imaging System ADDA II $(\mathrm{SIS})$ ).

En base a las imágenes obtenidas, se procedió a seleccionar las condiciones óptimas de síntesis de micropartículas basándose en su tamaño, distribución y morfología. 


\section{Análisis de rugosidad}

Imágenes de SEM fueron analizados con el programa ImageJ (NIH, EE.UU.). La rugosidad de la superficie se refleja por la variación en los valores de grises de todos los píxeles de la imagen. En primer lugar, los archivos de imagen de SEM fueron abiertos con el programa y convertidos a una imagen de 8 bits. Luego, se seleccionaron todos los píxeles de una micropartícula de la imagen y los parámetros de superficie fueron medidos (histograma, desviación estándar de los valores de grises). Cuanto menor sea el valor de la desviación estándar, menos rugosa será la superficie. Los histogramas obtenidos se realizaron por duplicado de las imágenes de SEM con una magnificación de 710X.

\section{Microscopía óptica y fluorescente}

Se utilizó un microscopio óptico de epi-fluorescencia Leica DM 2500 (Leica Microsystems, Buffalo Grove, IL). Se realizaron observaciones en el modo visible a fin de determinar el tamaño y distribución de las micropartículas recién sintetizadas. A su vez, se utilizó el modo de fluorescencia (con un filtro de excitación en la región espectral del azul: 450-490 nm) para evidenciar la presencia del antibiótico en el interior de las micropartículas.

\section{Determinación del contenido total de biopolímero por el método de Antrona}

Con el fin de determinar la cantidad de biopolímero en las micropartículas híbridas después de la síntesis y luego del tratamiento con la AL, el contenido total de carbohidratos se cuantificó por el método de Antrona (Yemm y col., 1954). Brevemente, 10,0 mg de cada formulación se disolvieron completamente en $2 \mathrm{ml}$ de solución de $\mathrm{HCl} 3,0 \mathrm{M}$. Las muestras se diluyeron y se incubaron con el reactivo de antrona (en $75 \%(\mathrm{v} / \mathrm{v}) \mathrm{H}_{2} \mathrm{SO}_{4}$ ) a $100^{\circ} \mathrm{C}$ durante diez minutos. A continuación, la mezcla de reacción fue enfriada en baño de hielo y se midió la absorbancia a $625 \mathrm{~nm}$. Finalmente, los datos se correlacionaron con una curva de calibración de un biopolímero conocido (alginato). 


\section{Espectroscopia Infrarroja con transformada de Fourier (FTIR)}

Los espectros FTIR de las muestras liofilizadas se registraron en un espectrómetro IR (Thermo Scientific, Nicolet 6700), con una resolución de $4 \mathrm{~cm}^{-1}$. Se realizaron un número de 32 barridos para cada muestra en el intervalo de 600 a 4000 $\mathrm{cm}^{-1}$. El accesorio de ATR (reflectancia total atenuada) se utilizó para llevar a cabo todas las mediciones.

\section{Difracción de rayos $X$ (DRX)}

Se utilizó el equipo de Rayos $X$ (Analytical Expert Instrument) con $\lambda=0,154 \mathrm{~nm}$ para caracterizar la estructura cristalina de las micropartículas. Las muestras fueron escaneadas en rangos de $2 \theta$ variando de 2 a $50^{\circ}\left(2^{\circ} / \mathrm{min}\right)$.

\section{Calorimetría diferencial de barrido (DSC)}

Se obtuvo el perfil de DSC de las muestras utilizando el equipo DSC Q2000-TA Instrument. Brevemente, se colocaron 5,0 mg de microesferas liofilizadas en una cápsula estándar de aluminio, se cerró herméticamente y posteriormente fue calentado a una velocidad constante de $10^{\circ} \mathrm{C} / \mathrm{min}$ desde temperatura ambiente hasta $225^{\circ} \mathrm{C}$, bajo purga de nitrógeno a $20 \mathrm{ml} / \mathrm{min}$. Todas las muestras se ensayaron por triplicado.

\section{Isotermas de adsorción de nitrógeno}

Se llevó a cabo la medición de la adsorción-desorción de nitrógeno por parte de las micropartículas secas a $77 \mathrm{~K}$ empleando un baño a $-195,8^{\circ} \mathrm{C}$. La superficie específica, el volumen de poro y el tamaño de los poros de las distintas formulaciones se calcularon con el programa Micromeritics (ASAP Software 2020V3.00 (considerando la ecuación de Brunauer Emmett Teller (BET) o el método Barrett Joyener Halenda (BJH).

\section{La distribución de tamaño}

El tamaño medio de las micropartículas se determinó a partir de las imágenes de SEM a 500x aumentos y se procesaron con el software ImageJ (NIH, EE.UU.). 
Después de ajustar la escala, se midió el diámetro de las micropartículas ( $n=100$ ) y se calculó la media.

\section{Carga de Levofloxacina en las micropartículas}

La Levofloxacina fue incorporada por absorción mediante la siguiente técnica: 25,0 mg de micropartículas secas se incubaron en 1,0 $\mathrm{ml}$ de solución de Levofloxacina $(1,0 \mathrm{mg} / \mathrm{ml})$ a $5^{\circ} \mathrm{C}$ con agitación carrusel a $150 \mathrm{rpm}$ durante 20 horas. Después de la carga, las micropartículas se separaron por centrifugación a 10.000 xg durante 5 minutos y se lavaron dos veces con agua miliQ. El sobrenadante y el agua de lavado se diluyeron cien veces y se determinó la Levofloxacina no incorporada mediante medición espectrofotométrica a $286 \mathrm{~nm}$ como fuera mencionado previamente. Por cálculo de la diferencia de cantidades, se obtuvo el porcentaje de encapsulación y la masa de Levo absorbida por masa de micropartículas.

\section{Adsorción de Levo y ADNasa en micropartículas}

Se pesaron $25,0 \mathrm{mg}$ de micropartículas y se les agregó $1,0 \mathrm{ml}$ de solución de Levofloxacina $(10 \mathrm{mg} / \mathrm{ml})$ a $5^{\circ} \mathrm{C}$ con agitación carrusel a $150 \mathrm{rpm}$ durante 20 horas, de forma similar a lo descripto anteriormente. Pasadas las 20 horas, se les adicionó $100 \mu \mathrm{l}$ de solución de ADNasa $(10 \mathrm{mg} / \mathrm{ml}$ en solución reguladora $10 \mathrm{mM}$ TRIS/HCl pH= 7.0) y se dejó bajo agitación durante 4 horas más. Finalizado dicho tiempo, se procedió a centrifugar las micropartículas a 10.000 xg durante 5 minutos y se lavaron una vez con agua miliQ. Se resuspendieron en $1 \mathrm{ml}$ de agua destilada, se congelaron en nitrógeno líquido y se sometieron a un ciclo de liofilización para obtener un fino polvo.

Tanto el porcentaje de encapsulación de Levo, como de ADNasa se determino como fuese previamente descripto, determinando el fármaco no adsorbido en los sobrenadantes. La Levo fue determinada por absorbancia al UV a $286 \mathrm{~nm}$, mientras que la ADNasa por su máximo de absorción a $277 \mathrm{~nm}$.

\section{Liberación de Levofloxacina y ADNasa}

Micropartículas conteniendo Levofloxacina $(25,0 \mathrm{mg})$ se incubaron en 1,5 $\mathrm{ml}$ de solución fisiológica $(\mathrm{pH}=7,0)$ a $37^{\circ} \mathrm{C}$. Alícuotas de $0,5 \mathrm{ml}$ fueron retiradas a diferentes tiempos durante 24 horas, en tanto que $0,5 \mathrm{ml}$ de medio fresco era repuesto para 
mantener el volumen constante. La liberación acumulada de Levo se determinó por medición de la absorbancia (a la longitud de onda máxima: $286 \mathrm{~nm}$ ) de cada alícuota y considerando el factor de dilución. La ADNasa liberada se determino por absorbancia a $277 \mathrm{~nm}$.

\section{Determinación de la actividad ADNasa}

Para determinar si la enzima es liberada desde las micropartículas en forma activa, se procedió a tomar los sobrenadantes de liberación y ensayar su actividad en un agar ADNasa (Sigma) con azul de toluidina como indicador. Se colocaron $10 \mathrm{ml}$ del agar en una placa de $10 \mathrm{~cm}$ de diámetro y fueron secadas en flujo laminar durante 30 minutos. Posteriormente se procedió a disponer cilindros de vidrio estériles de $8 \mathrm{~mm} \mathrm{x}$ $6 \mathrm{~mm} \times 10 \mathrm{~mm}$ (diámetro externo e interno y longitud) sobre la superficie del agar y colocar en cada uno $50 \mu \mathrm{l}$ del medio de liberación conteniendo la ADNasa. Se realizó un control difusional colocando el mismo volumen de solución fisiológica y un control positivo de actividad de una solución de ADNasa $(10 \mathrm{mg} / \mathrm{ml})$. Se incubaron las placas a $37^{\circ} \mathrm{C}$ por 24 horas. La actividad positiva se evidencia por la aparición de un halo color violeta.

\section{Ensayo microbiológico}

Se cultivó la cepa de Pseudomonas aeruginosa ATCC 15442 en caldo nutritivo y se dejo en incubación a $37^{\circ} \mathrm{C}$ durante 12 horas. Una alícuota $(1,0 \mathrm{ml})$ del medio crecido se añadió a $70 \mathrm{ml}$ de caldo nutritivo fresco para iniciar el cultivo a $37^{\circ} \mathrm{C}$. Después de 5 horas de incubación, cuando las bacterias estaban alcanzando la mitad de la fase exponencial, se añadieron $25,0 \mathrm{mg}$ de micropartículas cargadas con Levo y el punto final de la inhibición se determinó después de 24 horas de incubación. La inhibición del crecimiento bacteriano se midió mediante densidad óptica a $600 \mathrm{~nm}$ y la supervivencia bacteriana se estimó mediante recuento de Unidades Formadoras de Colonia por unidad de volumen (UFC/ml) en placas de ágar. Se tomaron fotos de cada condición con el fin de poner de manifiesto la producción del típico biopolímero mucoide y de pigmentos verdes característicos de la Pseudomonas aeruginosa. Se realizaron controles del crecimiento bacteriano sin aditivos y controles con micropartículas sin el antibiótico. 
Se realizaron ensayos antimicrobianos contra la misma cepa en medio solido, utilizando el método de difusión en agar de acuerdo con CLSI/NCCLS, pero sustituyendo los discos por cilindros de vidrio estériles de $8 \mathrm{~mm}$ x $6 \mathrm{~mm}$ x $10 \mathrm{~mm}$ (diámetro externo e interno y longitud). Brevemente, se tomaron de cuatro a cinco colonias del microorganismo y se resuspendieron en solución fisiológica estéril para ajustar la turbidez del cultivo a menos de $3 \times 10^{8} \mathrm{UFC} / \mathrm{ml}$ (0,5 en la escala McFarland). Vale aclarar que dicha escala se prepara a partir de diluciones de una solución de cloruro de bario al $1 \%$ con ácido sulfúrico al 1\%, cuya densidad óptica se utiliza como referencia de un número determinado de bacterias por mililitro. Placas de agar de 10 $\mathrm{cm}$ de diámetro fueron cargadas con $25 \mathrm{ml}$ de agar Mueller-Hinton y secada en flujo laminar durante 30 minutos. Luego, fueron inoculadas con la suspensión bacteriana, usando un hisopo de algodón estéril. Dentro de los 5 minutos se colocaron los cilindros y se sembraron $50 \mu \mathrm{l}$ de cada sobrenadante de liberación conteniendo Levo, dentro de los cilindros. Las placas se incubaron a $37^{\circ} \mathrm{C}$ durante $24 \mathrm{~h}$. Finalmente, los halos de inhibición fueron medidos. 


\subsection{Resultados y discusión}

Síntesis y caracterización de micropartículas biopoliméricas por método de emulsión

Considerando la compatibilidad hallada entre la formulación de alginato/pectina alto metoxilo y las quinolonas (Islan y col., 2012: Martinez y col., 2012) se sintetizaron micropartículas de dicho coacervado biopolimérico (2:1) en un medio hidrofóbico (aceite de siliconas) en presencia de dos agentes emulsificantes: Tween 80 y Tritón X-100. Las micropartículas obtenidas fueron separadas por centrifugación, y lavadas con concentraciones crecientes de acetona $(25,50$ y $75 \%$, v/v) a fin de eliminar los residuos de aceite. Posteriormente, las micropartículas fueron inmersas en una solución de Levofloxacina $(1,0 \mathrm{mg} / \mathrm{ml})$ durante 20 horas. Posterior a ello, fue determinada la eficiencia de encapsulación del antibiótico mediante espectrofotometría $\left(\lambda_{\text {máx }}=286 \mathrm{~nm}\right)$, resultando en una carga menor del $10 \%$ para dichas micropartículas.

Las partículas se observaron al microscopio óptico (MO) y se corroboró no sólo la dispersión de tamaño, sino también (mediante microscopia de fluorescencia) que el antibiótico se hallaba incorporado en las microesferas (Figura 4.1). Se estableció que la síntesis de las micropartículas en presencia de Tween 80 producía una distribución bimodal de micropartículas, con un grupo de $32,1 \pm 5,1 \mu \mathrm{m}$ y otro de $13,5 \pm 2,3 \mu \mathrm{m}$. A los fines de una terapia inhalatoria, esta distribución heterogénea de micropartículas no resulta conveniente, debido a que las mismas tendran diferente alcance en distintas zonas del pulmón, por lo que no se puede establecer un sitio de acción en particular y, en consecuencia, se tendría una dosis dispersa del antibiótico. Respecto de Levofloxacina, se puede observar por microscopía de fluorescencia que se hallaba incorporada en las partículas.

Por su parte, la síntesis de micropartículas en presencia de Tritón X-100, produjo micropartículas con una mejor dispersión y un tamaño aproximado de 10,2 $\pm 1.1 \mu \mathrm{m}$. La incorporación de Levofloxacina fue puesta de manifiesto al observar las micropartículas por microscopía de fluorescencia, evidenciando una localización del antibiótico en la matriz biopolimérica. 

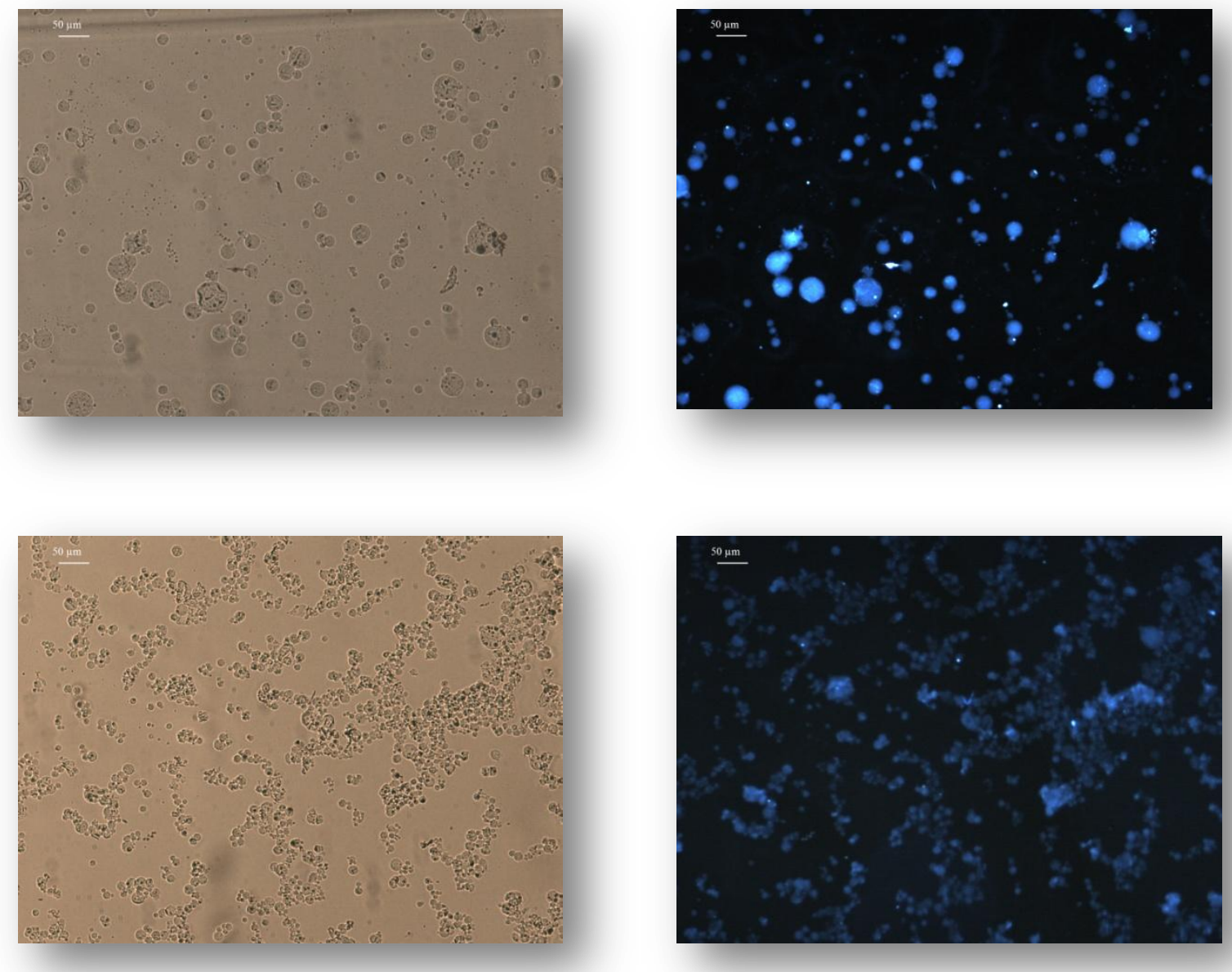

Figura 4.1 Micropartículas de alginato/pectina alto metoxilo sintetizadas por el método de emulsión en presencia de: arriba) TWEEEN 80 (polisorbato); debajo) TRITON X-100. Se observan las microparticulas por microscopía óptica y por fluorescencia para determinar la Levofloxacina incorporada.

A continuación, se procedió a evaluar el perfil de liberación de Levo desde las micropartículas en solución fisiológica a $37^{\circ} \mathrm{C}$, simulando un posible entorno similar al descrito en el pulmón (Figura 4.2). Se pudo observar que para ambas micropartículas sintetizadas con diferentes emulsificantes, el perfil de liberación fue brusco, y cerca del $90 \%$ y un $100 \%$ de la Levo encapsulada fue liberada en 2 horas para las micropartículas cuyo tensioactivo fue TWEEN 80 y TRITON X-100 respectivamente.

Debido a que el fármaco es liberado rápidamente, no habría ventajas con respecto a la administración del fármaco libre, con lo cual se deberán ajustar las 
condiciones de carga y la composición de la formulación para mejorar el perfil de liberación de Levo y brindar uno más sostenido en el tiempo.
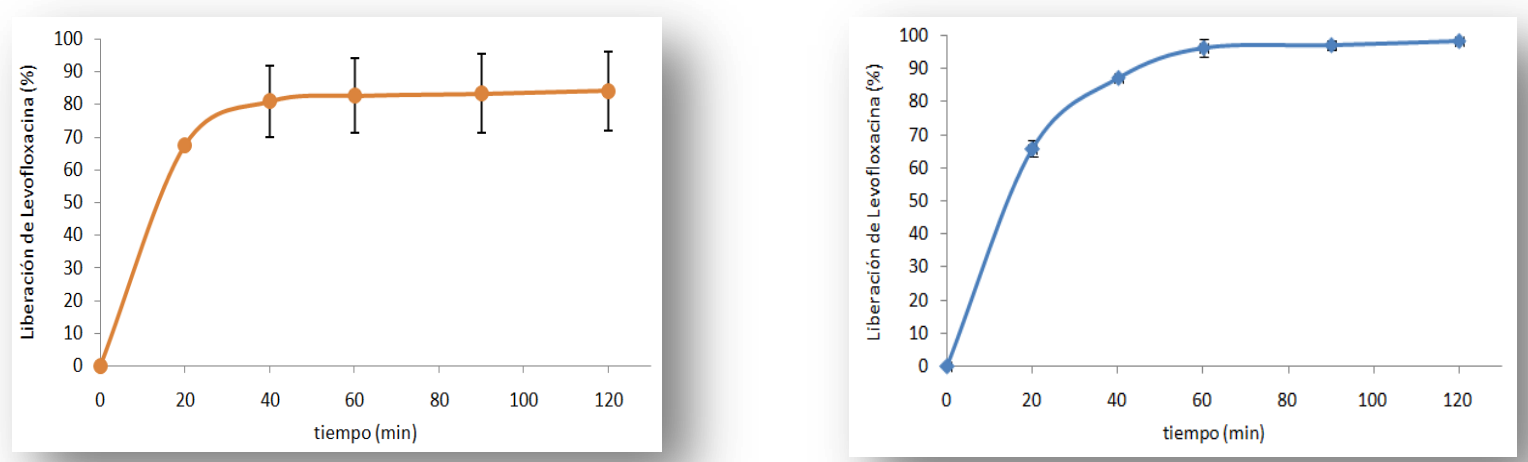

Figura 4.2 Pefil de liberación de Levofloxacina desde micropartciulas de alginato/pectina alto metoxilo sintetizadas por el método de emulsión en presencias de: izq) TWEEN 80; der) TRITON X-100.

Finalmente, la formulación fue sometida a un proceso de secado por liofilización. Se obtuvo un polvo fino que fue preparado para su observación por microscopía electrónica de barrido (SEM). Tal como se observan en las imágenes de la Figura 4.3, luego del proceso de secado se produjo la agregación de las partículas y la pérdida de la morfología (la esfericidad que era observada por MO). Esto genera una dispersión en el tamaño de las mismas y productos amorfos de restos de biopolímero.
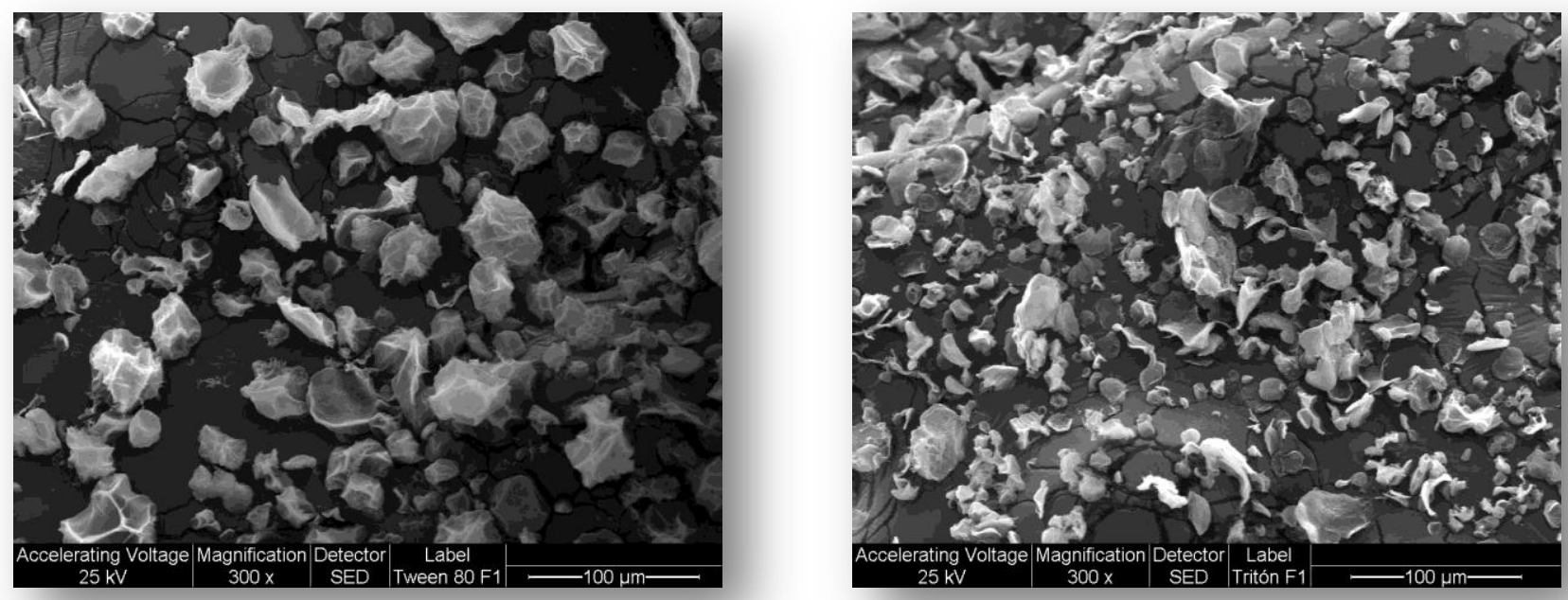

Figura 4.3 Imágenes de SEM de micropartciulas de alginato/pectina alto metoxilo sintetizadas en presencia de: izq) TWEEN 80; der) TRITON X-100. Observaciones con magnificaciones de 300X. 
Basándonos en la complejidad de las etapas de purificación de las partículas, en la baja capacidad de carga de Levo y los elevados perfiles de liberación del antibiótico, así como una baja estabilidad mecánica de la matriz, con procesos de agregación y perdida de morfología luego del secado, se procedió a buscar otra alternativa de síntesis de micropartículas.

\section{Síntesis y caracterización de micropartículas híbridas de $\mathrm{CaCO}_{3} /$ biopolímeros}

A fin de incrementar la estabilidad mecánica de las micropartículas biopoliméricas, se sintetizaron mediante hibridización con una matriz de carbonato de calcio. Se desarrollarán dos tipos de matrices híbridas:

* una matriz de $\mathrm{CaCO}_{3}$ con alginato $\left(\mathrm{CaCO}_{3} / \mathrm{Alg}\right)$.

* una matriz de $\mathrm{CaCO}_{3}$ con un coacervado alginato/pectina alto metoxilo (1:1) $\left(\mathrm{CaCO}_{3} / \mathrm{Alg}-\mathrm{PAM}\right)$.

A su vez, las micropartículas obtenidas fueron modificadas enzimáticamente, mediante un tratamiento con alginato liasa, para obtener estructuras de mayor porosidad. Con lo cual, a los fines comparativos, evaluaremos dos matrices más:

* $\mathrm{CaCO}_{3} / \mathrm{Alg}+\mathrm{AL}$ (que refiere a las micropartículas tratadas con la alginato liasa).

$* \mathrm{CaCO}_{3} / \mathrm{Alg}-\mathrm{PAM}+\mathrm{AL}$.

Luego de la síntesis, las micropartículas fueron secadas por liofilización y observadas por microscopia SEM a fin de determinar si las mismas poseían resistencia mecánica y eran estables al mantener su individualidad y morfología. En la Figura 4.4 se pueden observar las imágenes de las micropartículas hibridas de $\mathrm{CaCO}_{3} / \mathrm{Alg}$ a diferentes aumentos. Se observa una distribución homogénea de tamaño, ausencia de agregados y partículas con forma esférica y superficies lisas (Fig. 4.4, izquierda). Por su parte, las micropartículas tratadas con la alginato liasa, no sólo mantuvieron las características de distribución homogénea y esfericidad, sino que además mostraron interesantes cambios en su superficie (Fig. 4.4, derecha). Se puso de manifiesto una arquitectura más rugosa y poros distribuidos en toda la superficie. Estos cambios topológicos se deben principalmente a la eliminación enzimática del alginato inicialmente incorporado en las micropartículas de $\mathrm{CaCO}_{3} / \mathrm{Alg}$, con lo cual se produce un nuevo patrón superficial con un aumento en la relación superficie/volumen. Estos cambios en la matriz resultan interesantes para la administración al pulmón, debido a 
que se sintetizan micropartículas con menor densidad y mayor porosidad, lo cual es ventajoso para garantizar la aerosolización de la muestra y su llegada a los intersticios más profundos del tejido pulmonar.
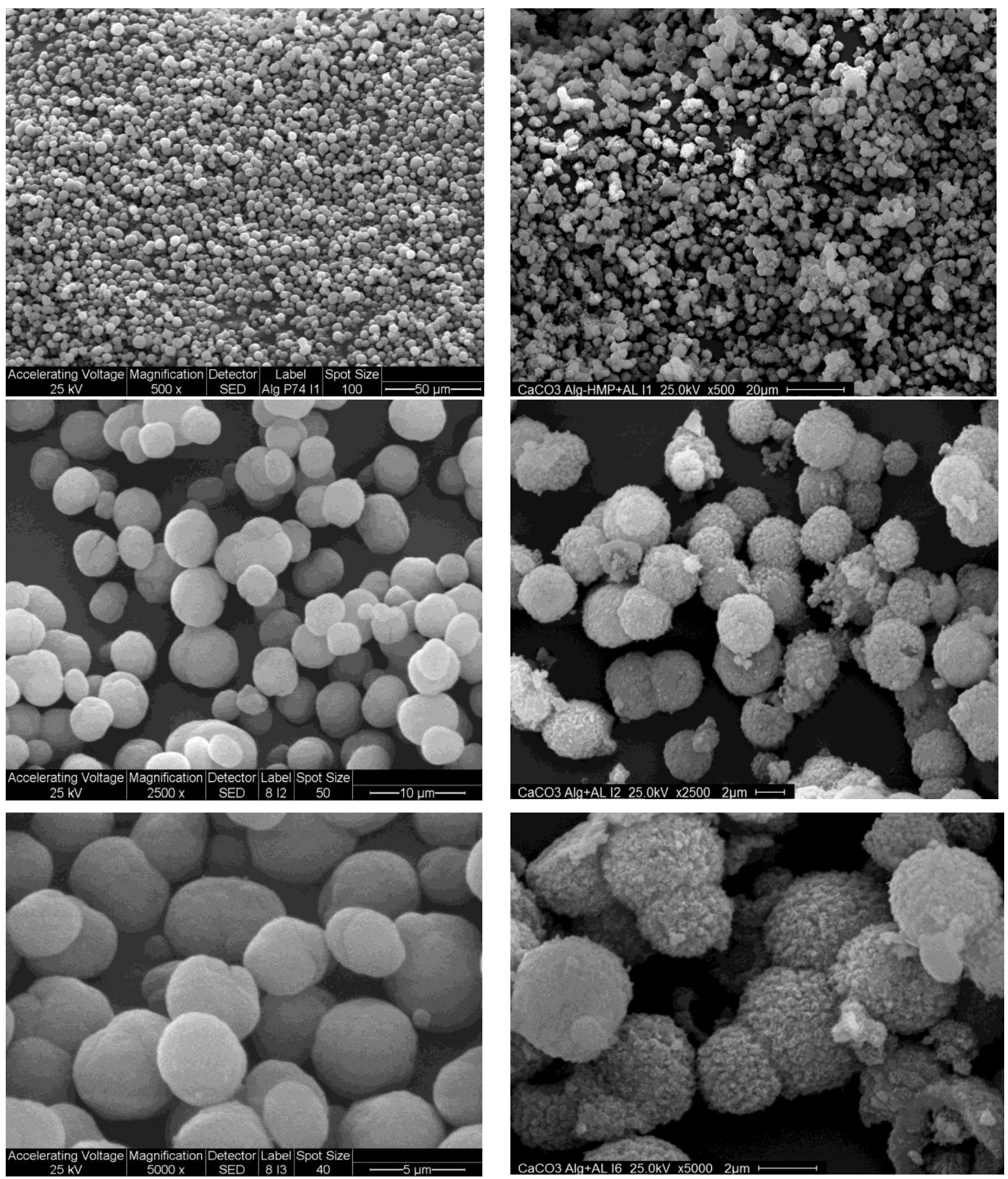

Figura 4.4 Imágenes de SEM de micropartículas de $\mathrm{CaCO}_{3} /$ Alg a 500, 2.500 y 5.000X: izq) no tratadas; derecha) tratadas con alginato liasa. 
De la misma manera, se obtuvieron micropartículas estables y con una buena distribución de tamaño para el caso de la formulación de $\mathrm{CaCO}_{3} / \mathrm{Alg}$-PAM (Figura 4.5, izquierda). A su vez, se observaron cambios significativos en la superficie de las micropartículas después del tratamiento con la AL. Estas últimas, mostraron patrones de superficie diferentes, caracterizándose por la aparición de "nano-globos" en la superficie. Estos "parches" observados en la superficie son probablemente las regiones inicialmente ocupados por cadenas pectina de alto metoxilo. Como la enzima es capaz de hidrolizar las zonas donde se halla el alginato, aquellas en las cuales se hallaba la PAM no se vieron afectadas por la AL y mantuvieron su lugar en la superficie (Figura

\section{5, derecha).}
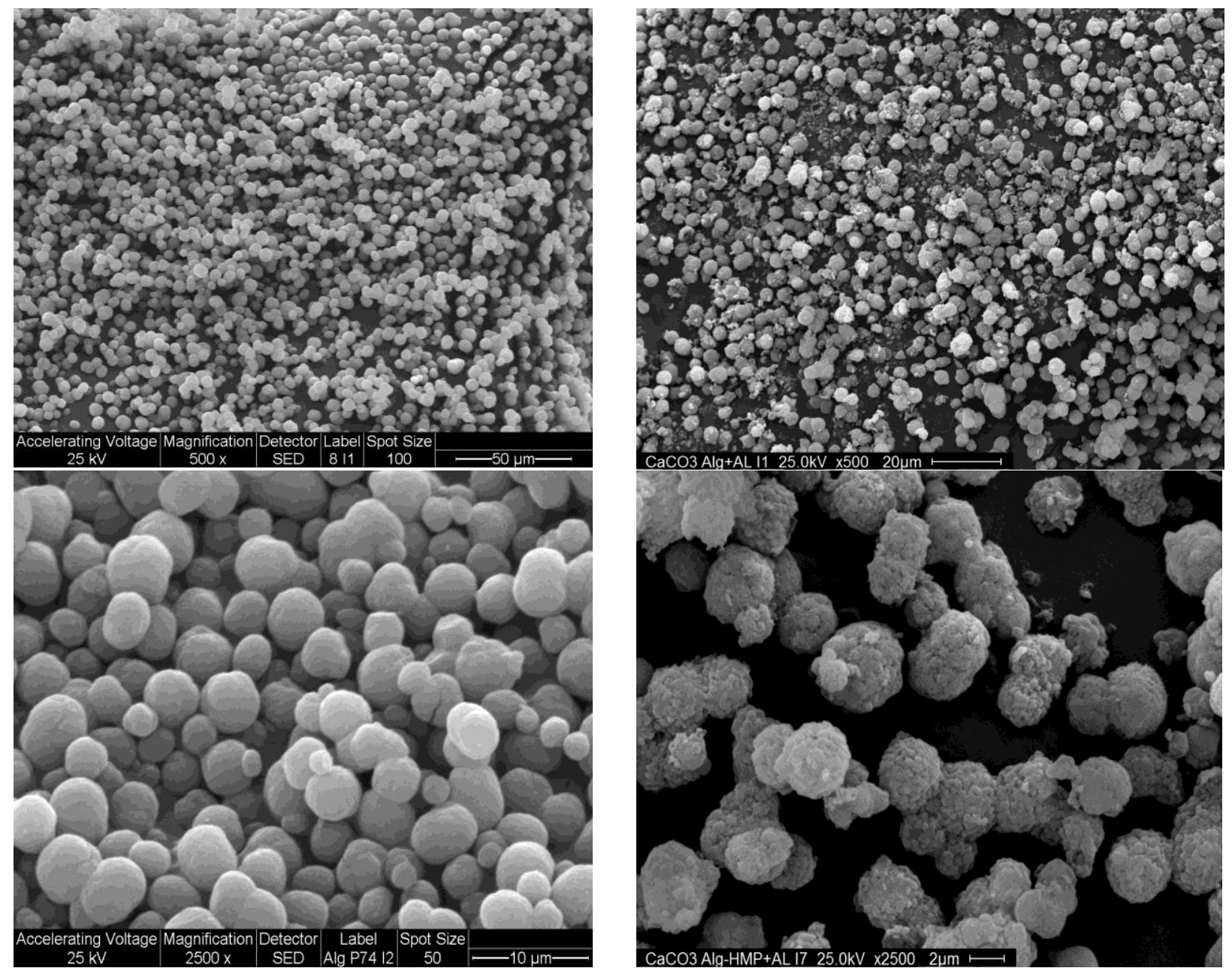

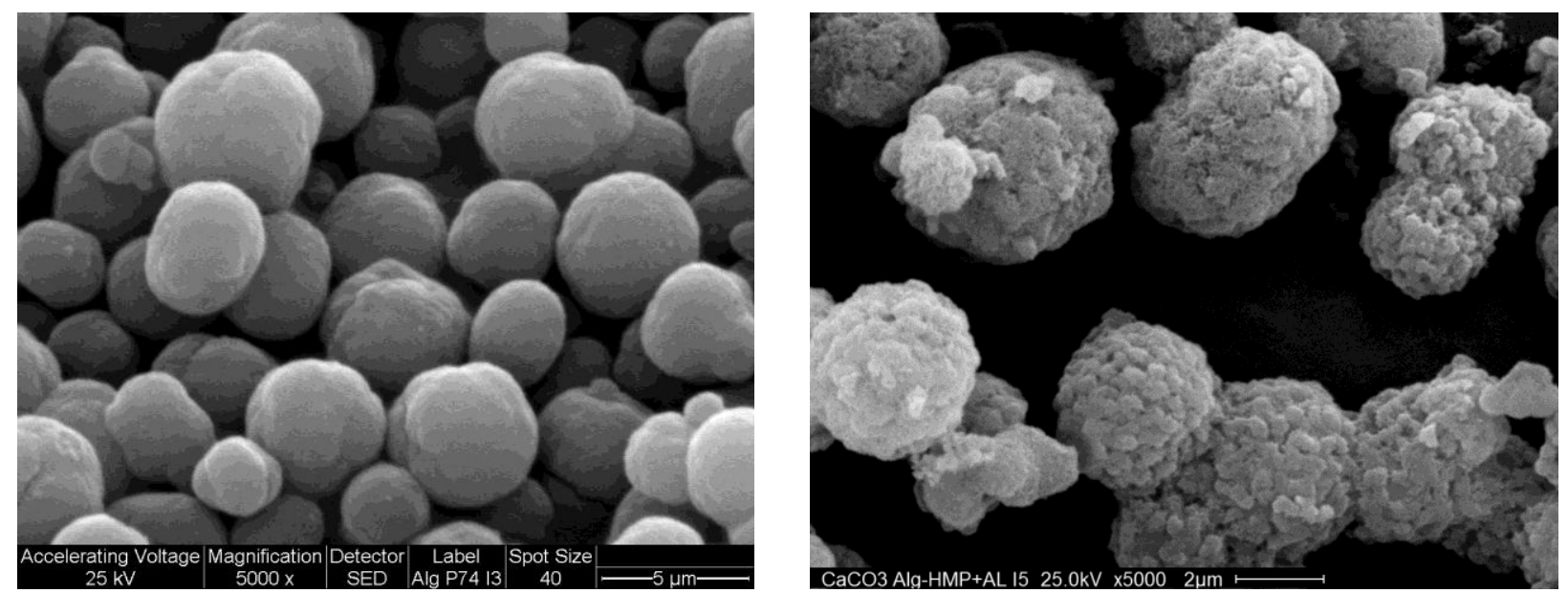

Figura 4.5 Imágenes de SEM de micropartículas de $\mathrm{CaCO}_{3} / \mathrm{Alg}$-PAM a 500, 2500 y 5000 aumentos: izq) no tratadas; derecha) tratadas con alginato liasa.

Estas observaciones resultaron interesantes debido a que se obtuvieron novedosas arquitecturas cuando otro biopolímero (no hidrolizable por AL) era incorporado en la formulación. Se realizaron controles, incubando las micropartículas no tratadas en las mismas condiciones en las que se hallaba la enzima, pero en este caso sin la presencia de la $\mathrm{AL}$ : solución reguladora fosfato $(25 \mathrm{mM})$ a $37^{\circ} \mathrm{C}$ durante 48 horas. Luego de la incubación fueron observadas por microcopia SEM, revelando que las micropartículas mantenían su estructura y no se producían cambios en la superficie, lo que indica que es necesaria la presencia de la AL para desarrollar estas nuevas arquitecturas. Sin embargo, de detectó una pequeña cantidad de deposición de apatita (fosfato de calcio), que no era observable por imágenes de SEM, debido a que un pequeño pico de fósforo se observa en el espectro EDAX (microanálisis por dispersión de energías de rayos-X) de las micropartículas control (Figura 4.6).

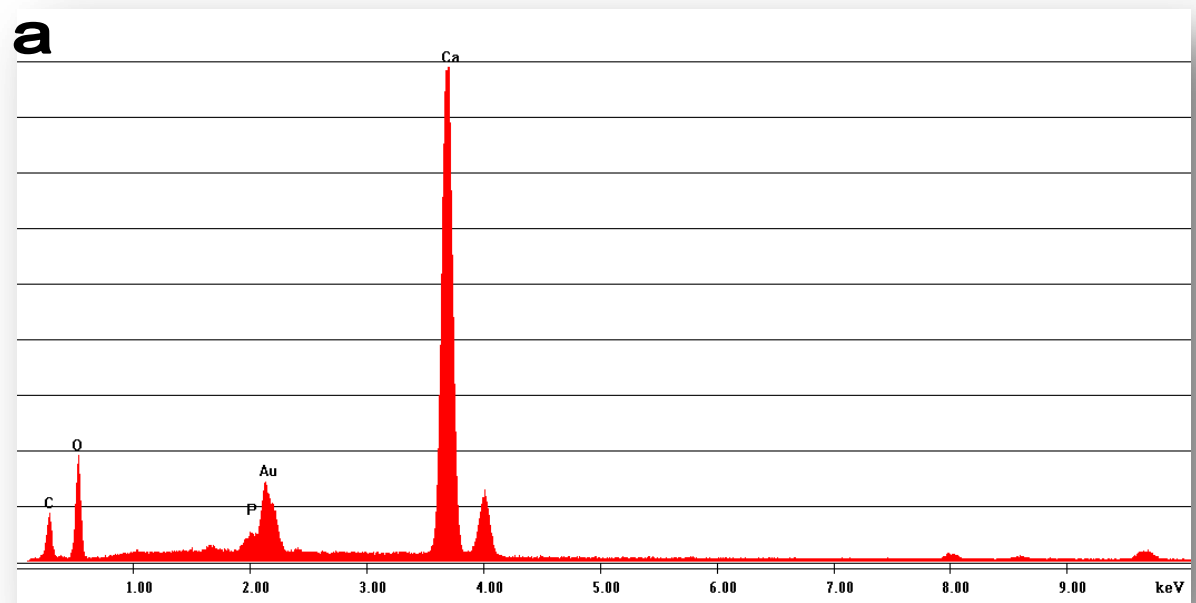




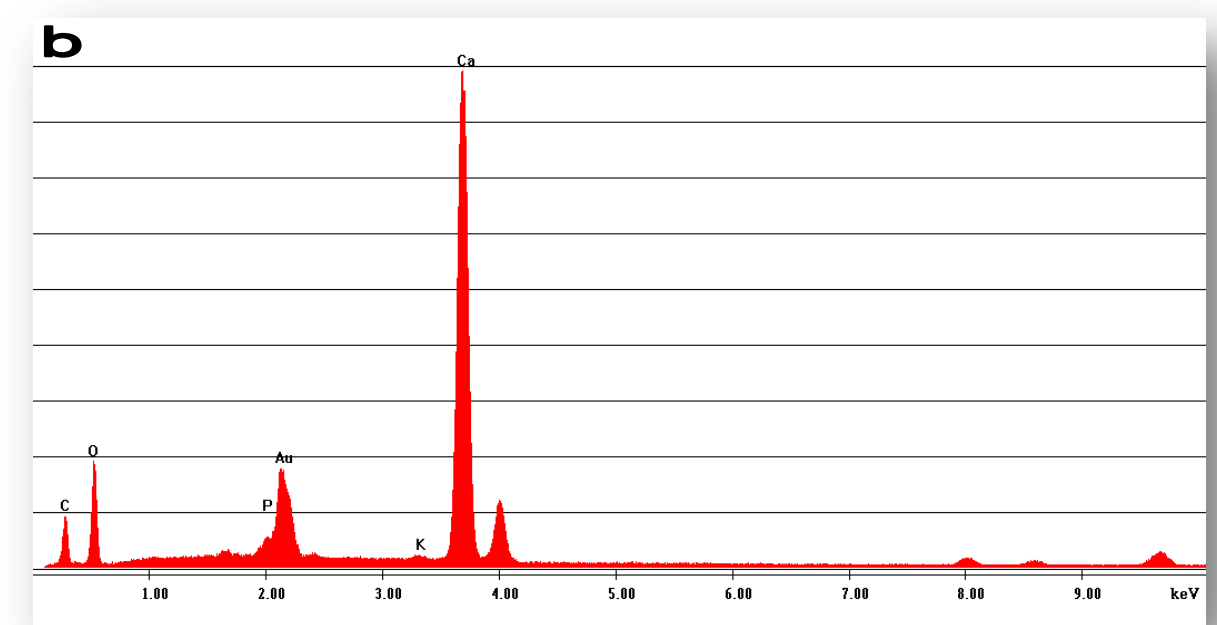

Figura 4.6 Espectro EDAX de micropartículas control: a) $\mathrm{CaCO}_{3} / \mathrm{Alg}$ y b) $\mathrm{CaCO}_{3} / \mathrm{Alg}-\mathrm{PAM}$.

A fin de cuantificar los cambios observados en superficie luego del tratamiento con la enzima, las imágenes SEM fueron analizadas con el programa ImageJ. Como se muestra en la Tabla 18, las micropartículas de $\mathrm{CaCO}_{3} / \mathrm{Alg}$ presentaron un perfil de superficie liso, sin diferencias significativas en los valores de grises de la superficie analizada. Este hecho se ha reflejado en el valor de la desviación estándar, que es uno de los más bajos. En contraste, cuando se analizó la superficie de las micropartículas de $\mathrm{CaCO}_{3} / \mathrm{Alg}+\mathrm{AL}$, el gráfico de perfil mostró un patrón con mayor rugosidad y un aumento de la desviación estándar desde 15 a 23 (aproximadamente 53\%). En trabajos anteriores, se ha demostrado que "a menor valor de la desviación estándar, más lisa es la superficie" (Wang y col., 2005). Como era de esperar, las micropartículas de $\mathrm{CaCO}_{3} /$ Alg-PAM mostraron un perfil sin rugosidades, el cual fue modificado significativamente después del tratamiento con AL. La desviación estándar se incrementó de 22 a 27 (aproximadamente un 23\%), revelando las diferencias en la altura de los patrones de superficie. 


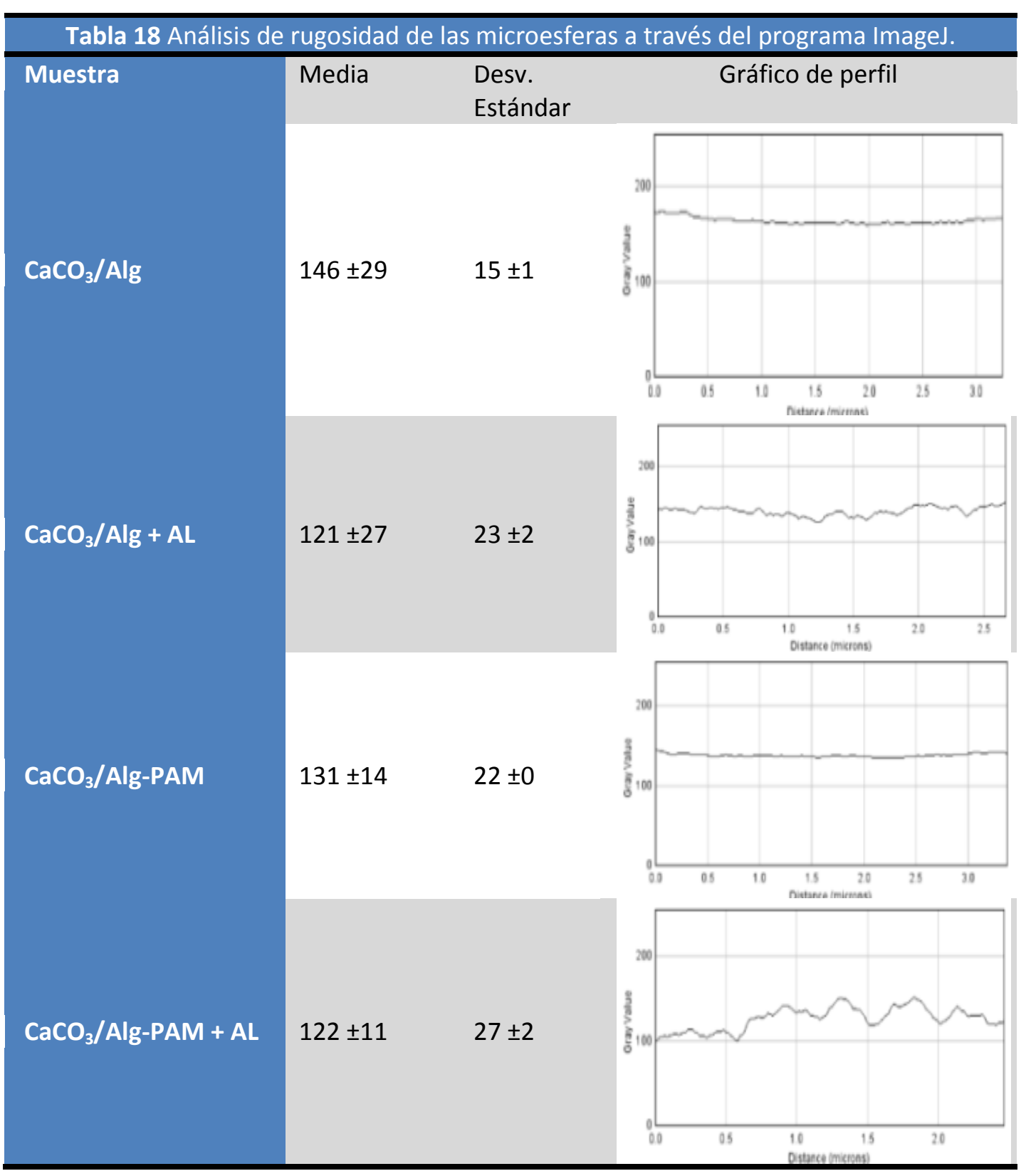

Hubo una clara diferencia en el perfil de superficie de ambas matrices tratadas. Mientras que las partículas de $\mathrm{CaCO}_{3} / \mathrm{Alg}+\mathrm{AL}$ mostraron picos de alrededor de los 50 $\mathrm{nm}$, las de $\mathrm{CaCO}_{3} / \mathrm{Alg}$-PAM $+\mathrm{AL}$ exhibieron los anteriormente denominados "nanoglobos" en la superficie en el rango de los 200 a $500 \mathrm{~nm}$.

En un siguiente análisis, se determino La distribución del tamaño de las micropartículas a fin de establecer si son aceptables para la administración pulmonar (Figura 4.7). 

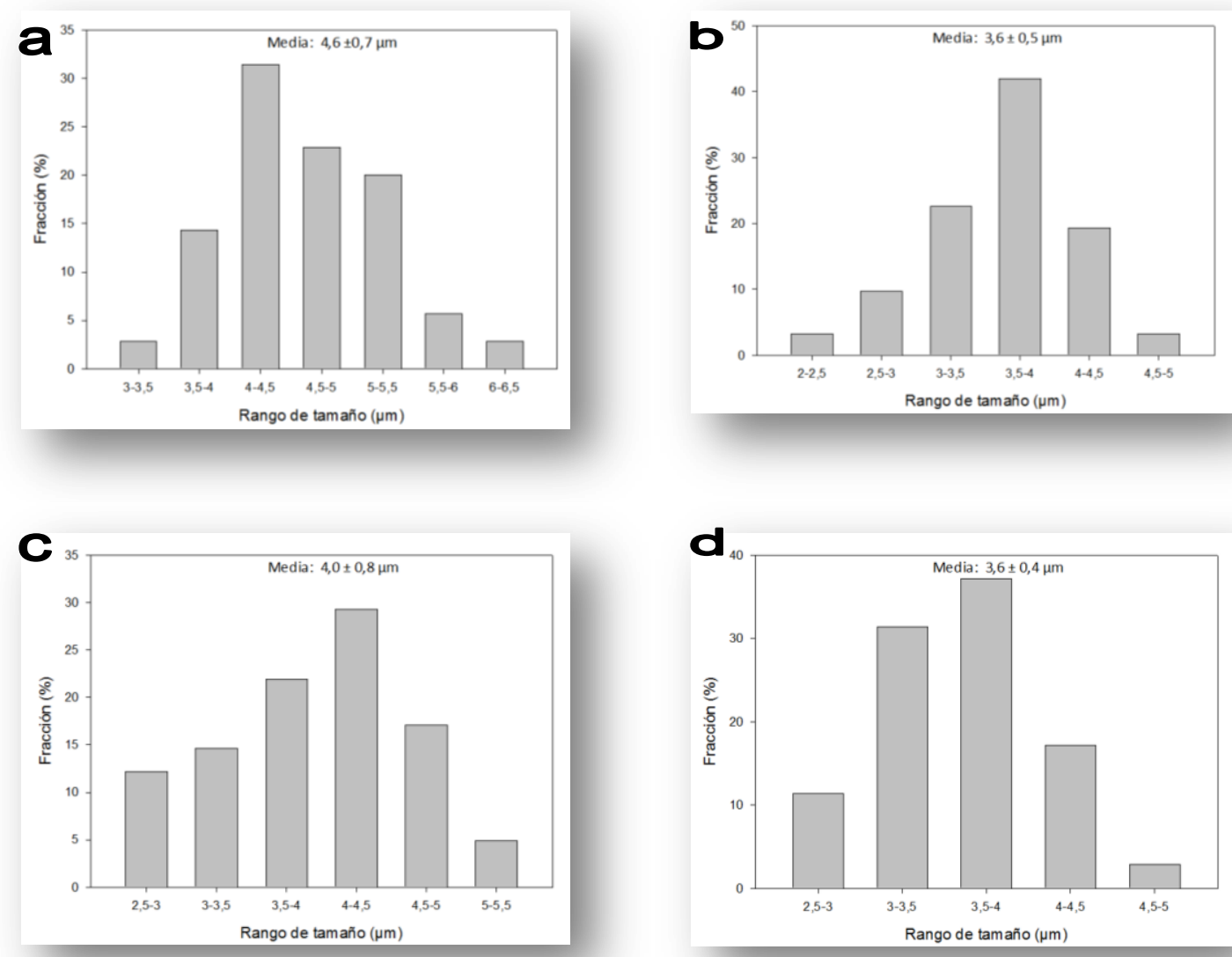

Figura 4.7 Distribución de tamaño de micropartículas a) $\mathrm{CaCO}_{3} / \mathrm{Alg}$; b) $\mathrm{CaCO}_{3} / \mathrm{Alg}+\mathrm{AL}$; c) $\mathrm{CaCO}_{3} /$ Alg-PAM; d) $\mathrm{CaCO}_{3} /$ Alg-PAM + AL. El diámetro medio de cada tipo de particular se indica en la parte superior.

Mientras que las micropartículas de $\mathrm{CaCO}_{3} / \mathrm{Alg}$ presentaron un diámetro medio de 4,6 $\pm 0,7 \mu \mathrm{m}$, las de $\mathrm{CaCO}_{3} / \mathrm{Alg}+\mathrm{AL}$ mostraron una reducción de su tamaño medio a 3,6 $\pm 0,5 \mu \mathrm{m}$, posiblemente debido a la hidrólisis del biopolímero expuesto en la superficie de la micropartícula a la acción enzimática. Por otra parte, las micropartículas de $\mathrm{CaCO}_{3} / \mathrm{Alg}$-PAM mostraron un tamaño medio de 4,0 $\pm 0,8 \mu \mathrm{m}$ y de $3,6 \pm 0,4 \mu \mathrm{m}$, antes y después del tratamiento con AL respectivamente. Todas las micropartículas desarrolladas estuvieron en el orden de las 5 micrones, que es el tamaño ideal para la administración pulmonar (Cai y col., 2013), lo cual valida su potencial uso como transportador para la Levofloxacina.

Por otra parte, se realizó un análisis composicional por el método de Antrona a fin de cuantificar el contenido de biopolímeros en la matriz (Tabla 19). Las micropartículas híbridas sintetizadas en presencia de 0,1\%p/v de biopolímero total (ya sea de alginato o de la mezcla alginato/pectina) presentaron un $24 \%$ de contenido de 
hidratos de carbono en la matriz, independientemente de las fuentes de biopolímeros utilizados en la síntesis. No obstante, si se observaron cambios en la composición de ambos tipos de micropartículas después del tratamiento con la $\mathrm{AL}$. Las de $\mathrm{CaCO}_{3} / \mathrm{Alg}$ mostraron una reducción del contenido biopolimérico de un $72 \%$, mientras las de $\mathrm{CaCO}_{3} / \mathrm{Alg}$-PAM un descenso de sólo el $28 \%$ después del tratamiento enzimático. Esto refleja la acción diferencial de la enzima, al reconocer las cadenas de alginato, que son más abundantes en el primer tipo de macropartícula. Además permite efectuar un diseño de la partícula variando las proporciones de alginato y de pectina.

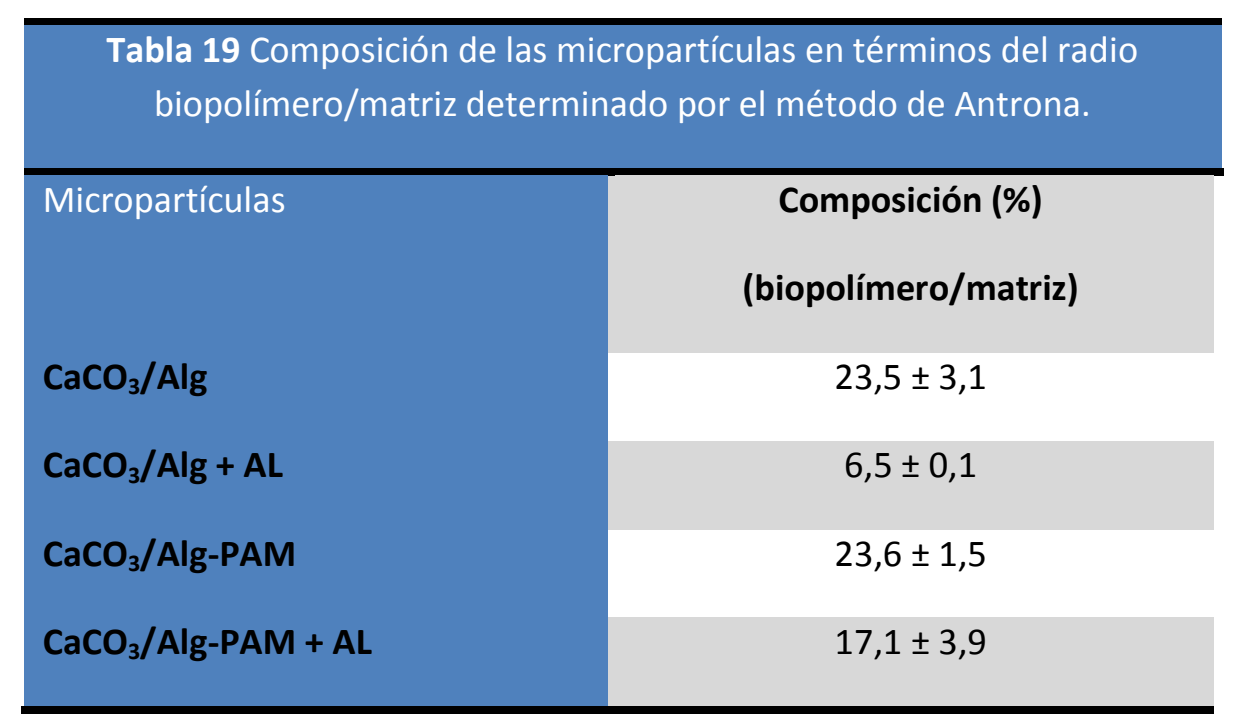

Para continuar con la caracterización de las micropartículas, se realizó un análisis por calorimetría diferencial de barrido (DSC). El espectro de las micropartículas de $\mathrm{CaCO}_{3} / \mathrm{Alg}$ mostró un pico endotérmico a $90,59^{\circ} \mathrm{C}$ durante el calentamiento (Figura 4.8, curva 1). Este pico corresponde a la deshidratación de la estructura de carbonato de calcio, es decir, a las moléculas de agua ligadas intrínsecamente dentro de la matriz. Si se realiza una integración de este pico y se normaliza con la cantidad de agua pérdida, se encuentran valores cercanos a la entalpía de vaporización del agua líquida a $100^{\circ} \mathrm{C}(40,87 \mathrm{~kJ} / \mathrm{mol})$ como se ha reportado en bibliografía (Radha y col., 2010). 


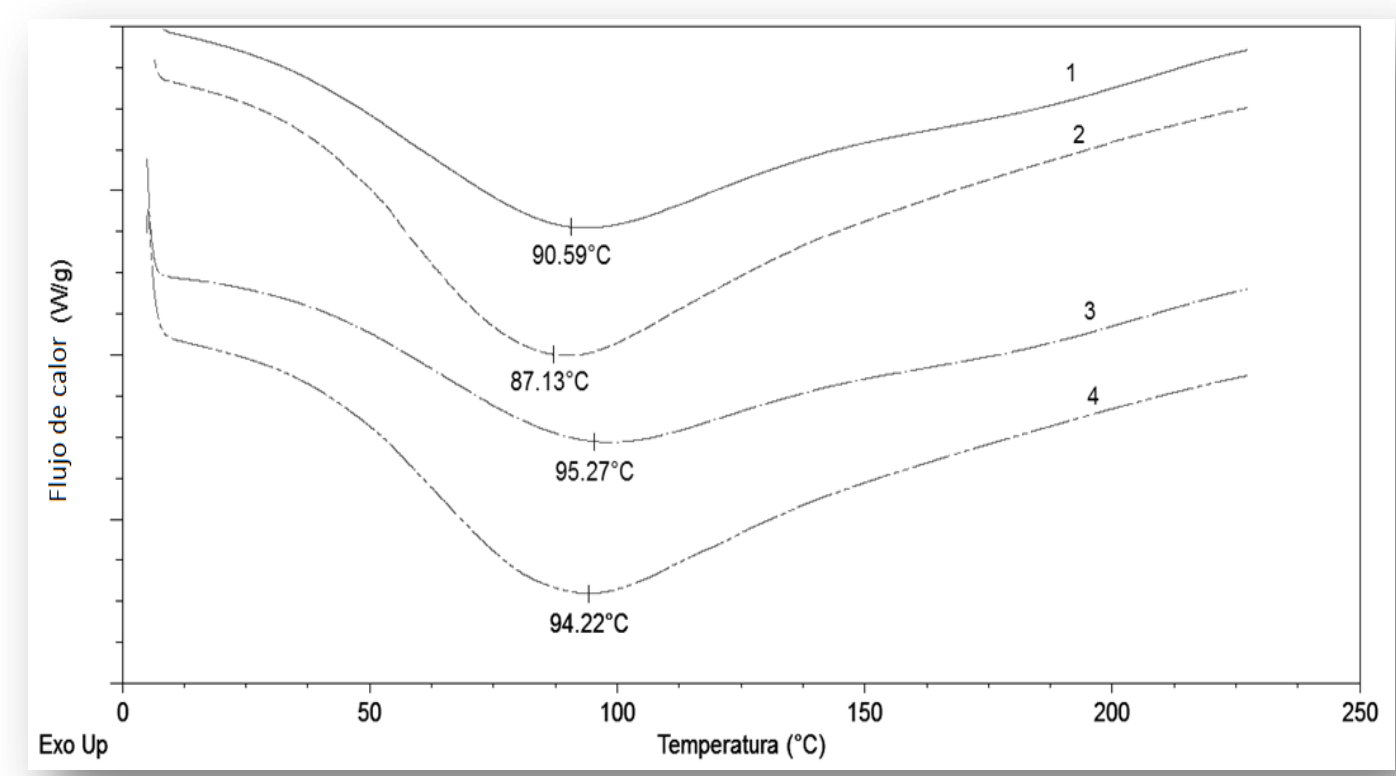

Figura 4.8 Curvas de DSC de micropartículas de: (1) $\mathrm{CaCO}_{3} / \mathrm{Alg}$; (2) $\mathrm{CaCO}_{3} / \mathrm{Alg}+\mathrm{AL}$; (3) $\mathrm{CaCO}_{3} / \mathrm{Alg}-\mathrm{PAM}$; (4) $\mathrm{CaCO}_{3} / \mathrm{Alg}-\mathrm{PAM}+\mathrm{AL}$.

Después del tratamiento con $\mathrm{AL}$, las micropartículas presentaron una disminución de $3,5^{\circ} \mathrm{C}$ en el valor del mínimo (curva 2). Este resultado indica la presencia de una estructura más lábil, y/o una arquitectura más porosa, razón por la cual las moléculas de agua están más expuestas y propensas a migrar hacia el exterior de la matriz. Esta consideración es razonable teniendo en cuenta la capacidad de la AL para hidrolizar las cadenas de alginato reticuladas desde la superficie de las micropartículas híbridas de $\mathrm{CaCO}_{3} / \mathrm{Alg}$, modificando así su estructura. En un perfil similar, se observó un pico endotérmico a $95,27^{\circ} \mathrm{C}$ para las micropartículas de $\mathrm{CaCO}_{3} /$ Alg-PAM (curva 3). No obstante, se produjo una leve disminución de la temperatura del pico (alrededor de $1^{\circ} \mathrm{C}$ ) después del tratamiento con la AL (curva 4). Aunque se sugiere una posible modificación de la matriz, los cambios son menos pronunciados con respecto a las micropartículas $\mathrm{CaCO}_{3} / \mathrm{Alg}$ y por lo tanto menos detectables por esta técnica. Este hecho podría explicarse en términos de la composición de las micropartículas, debido a que las de $\mathrm{CaCO}_{3} / \mathrm{Alg}$ se sintetizaron en presencia de alginato (1,0\%), mientras que las de $\mathrm{CaCO}_{3} / \mathrm{Alg}$-PAM en presencia de la mitad de concentración $(0,5 \%)$, con lo cual el proceso de hidrólisis por parte de la AL es menos marcado. 
Otra técnica que permite poner de manifiesto la modificación de las partículas con el tratamiento enzimático es la difracción de rayos X (Figura 4.9). Se estudió el espectro de las diferentes microesferas híbridas, tratadas y no tratadas con la AL.

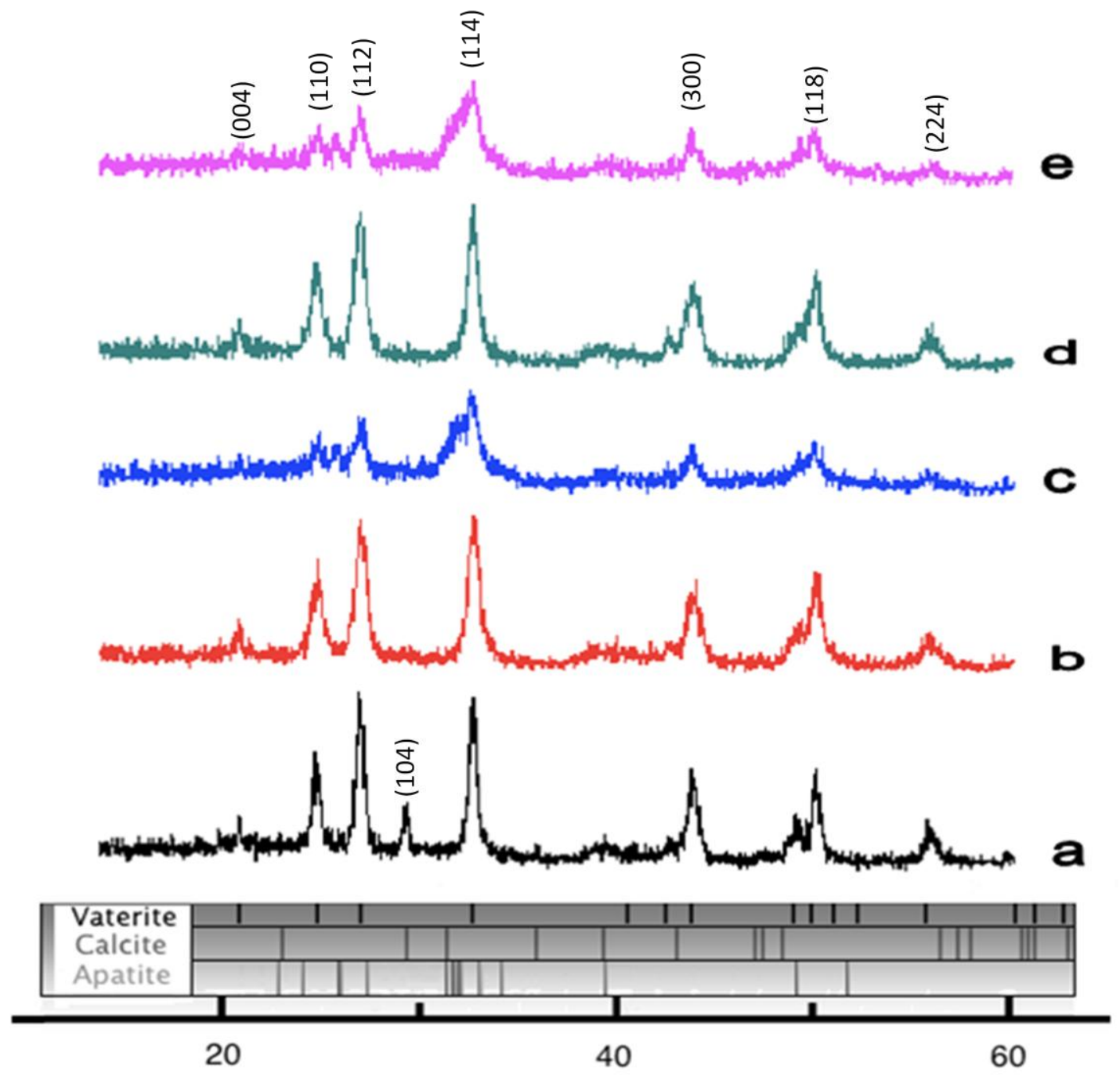

Figura 4.9 Perfiles de difracción de rayos $\mathrm{X}$ de microesferas de: a) $\mathrm{CaCO}_{3}$; b) $\mathrm{CaCO}_{3} / \mathrm{Alg}$; c) $\mathrm{CaCO}_{3} / \mathrm{Alg}+\mathrm{AL} ;$ d) $\mathrm{CaCO}_{3} / \mathrm{Alg}-\mathrm{HMP} ; \mathrm{CaCO}_{3} / \mathrm{Alg}-\mathrm{HMP}+\mathrm{AL}$. Las reflexiones de Bragg representativas de los difractogramas de rayos $X$ de vaterita, calcita y apatita (ICSD 15879) se indican con marcadores verticales por debajo de los perfiles.

Se observa la presencia en todos los espectros de los picos característicos de la vaterita polimorfa de $\mathrm{CaCO}_{3}$. La presencia del pico a $29,3^{\circ}$ en el difractograma de rayos $X$ de las micropartículas de $\mathrm{CaCO}_{3}$ se atribuye al pico más intenso de la calcita. Este pico, sin embargo, no aparece en el resto de los sistemas híbridos y es debido a que la presencia de los biopolímeros sirve de templado para la formación de estructura cristalina y mejora la estabilidad de los cristales de vaterita, tal como se ha descrito en 
trabajos previos de nuestro laboratorio (Bosio y col., 2014). Una observación interesante es que el tratamiento con la AL genera una modificación del perfil de rayos $\mathrm{X}$ de las micropartículas. En los sistemas tratados, el máximo característico en de la vaterita a 25 grados está ahora acompañado por otro pico a $26^{\circ}$ en ambos casos $\left(\mathrm{CaCO}_{3} / \mathrm{Alg}+\mathrm{AL}\right.$ y $\left.\mathrm{CaCO}_{3} / \mathrm{Alg}-\mathrm{PAM}+\mathrm{AL}\right)$. Además, cerca del máximo característico de vaterita a $33^{\circ}$ se encuentra otro pico a $32^{\circ}$. Se realizo a modo de control, una comparación con el difractograma de apatita a fin de evaluar la posible presencia de estructuras cristalográficas de (Tas, 2009), teniendo en cuenta que el tratamiento con AL se realizó en una solución reguladora fosfato que puede dar lugar a la formación cristales de fosfato de calcio. La aparición de máximos característicos a 25 y 32 grados de la apatita en los espectros de las micropartículas tratados, podrían ser elementos claves para poder especular con posible la formación y depósito de cristales de apatita en la superficie de las micropartículas. Además, se observó una disminución de la intensidad de los máximos de vaterita cuando se llevó a cabo el tratamiento con AL y la aparición de nuevos picos posiblemente se deban a la formación de apatita superficial.

Tal como se había observado en la figuras de imágenes de SEM de las micropartículas, la reestructuración cristalográfica después del tratamiento AL podría producirse por dos eventos: en primer lugar, el aumento de la porosidad por la remoción de cadenas de alginato mas expuesta a la acción enzimática; y la segunda, una superficie más disponible para que se produzca la deposición de grupos fosfato considerando que la solución reguladora está compuesta por iones fosfato en el que se hallaban las micropartículas. Este hecho explicaría la aparición de máximos característicos de apatita en microesferas tratadas, así como la aparición de un pequeño pico de fosforo en el espectro EDAX de las micropartículas.

Siguiendo con la caracterización de las micropartículas, en la Figura 4.10 se muestran los espectros de FTIR de las distintas formulaciones. 


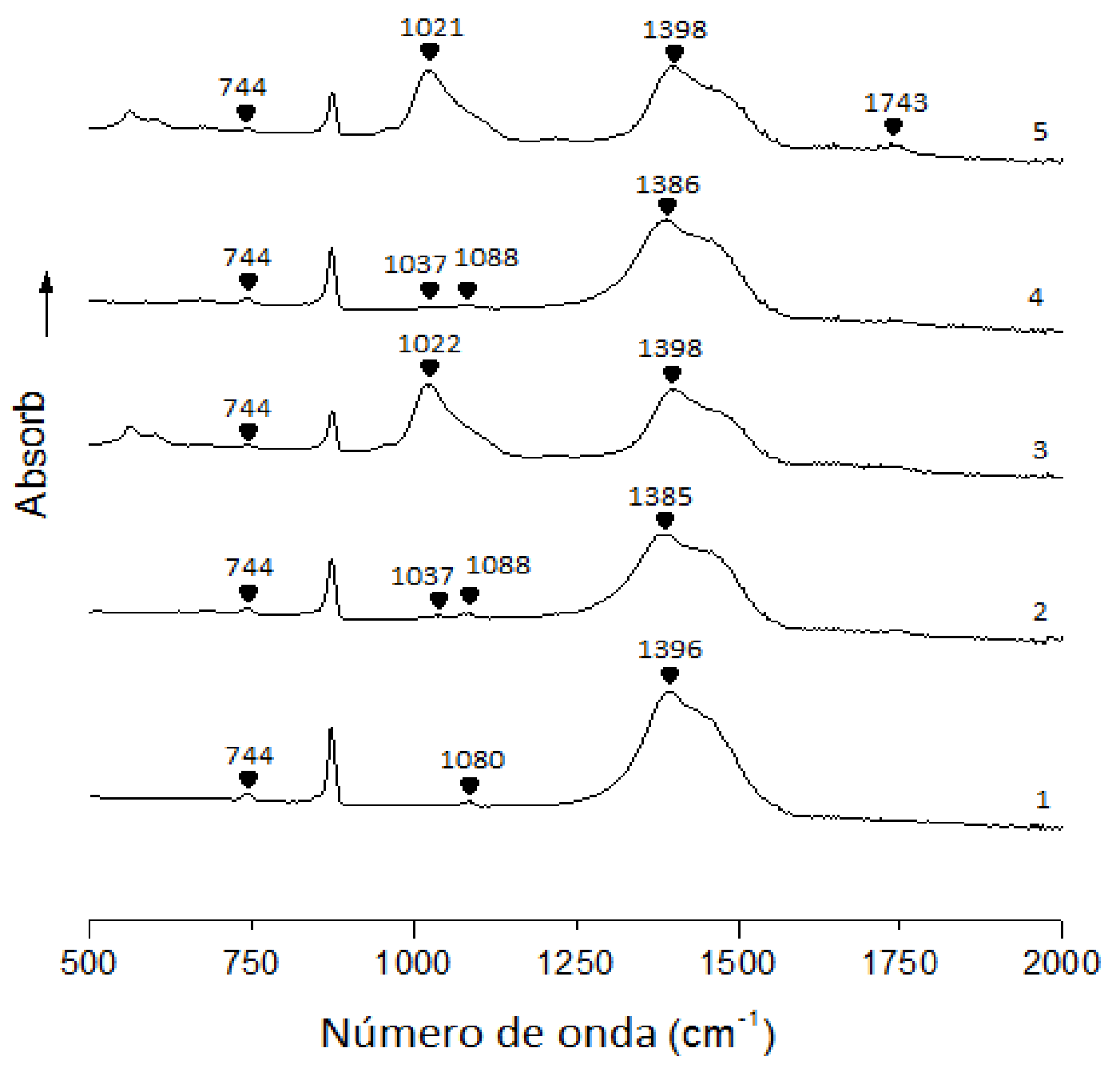

Figura 4.10 Espectros de FTIR de micropartículas de: (1) $\mathrm{CaCO}_{3}$; (2) $\mathrm{CaCO}_{3} / \mathrm{Alg}$; (3) $\mathrm{CaCO}_{3} / \mathrm{Alg}+\mathrm{AL}$; (4) $\mathrm{CaCO}_{3} /$ Alg-PAM; (5) $\mathrm{CaCO}_{3} /$ Alg-PAM + AL.

En los espectros se pueden observar las bandas típicas asociadas a la estructura de microesferas de carbonato de calcio. En todas las formulaciones, se observó el pico asociado a vaterita a $744 \mathrm{~cm}^{-1}$, lo que indica que ésta es la estructura polimorfa predominante del carbonato de calcio en las condiciones experimentales de síntesis y que no hubo una conversión a otras fases más estables (Tas, 2009). En las microesferas de $\mathrm{CaCO}_{3} / \mathrm{Alg}$, se puso de manifiesto una banda a $1037 \mathrm{~cm}^{-1}$, que corresponde la flexión de los -OH del alginato (Sakugawa y col., 2004). Este resultado está indicando que el alginato es incorporado en la estructura cristalina del $\mathrm{CaCO}_{3}$, generando el material híbrido. El máximo que se observa aproximadamente $1396 \mathrm{~cm}^{-1}$ del carbonato de calcio mostró un desplazamiento hipsocrómico hacia $1385 \mathrm{~cm}^{-1}$, lo 
que indicaría la presencia de posibles interacciones entre el biopolímero y la matriz de $\mathrm{CaCO}_{3}$. Después del tratamiento de las micropartículas de $\mathrm{CaCO}_{3} / \mathrm{Alg}$ con $\mathrm{AL}$ se produjo otro desplazamiento de dicho pico característico, en este caso apareció a un valor de $1398 \mathrm{~cm}^{-1}$, el cual se acerca nuevamente al valor inicial encontrado en la matriz sola de carbonato de calcio. Un pico nuevo e intenso apareció a $1022 \mathrm{~cm}^{-1}$ y podría estar asociado con los productos de degradación de la alginato liasa. La mencionada banda podría ser asignada a la flexión-OH de las cadenas de poli-gulurónico del alginato, la cual se intensifica por la eliminación enzimática de los residuos de ácido manurónico (Sakugawa y col., 2004). Este resultado sugiere la eliminación parcial de las cadenas de alginato incorporado en el material híbrido y una modificación de su interacción en el interior de la matriz. En los micropartículas híbridos de Alg-PAM, se observó un comportamiento similar. Una vez más, se observó un corrimiento d la banda típica del carbonato de calcio tras la formación del material híbrido, y a su vez, un retorno cerca de la banda inicial de $\mathrm{CaCO}_{3}$ después del tratamiento con AL. Además, se produce la aparición de un pico a $1021 \mathrm{~cm}^{-1}$, producto de la hidrólisis del alginato. En este caso, teniendo en cuenta que se eliminaron sólo cadenas de alginato, se esperaba que la concentración de PAM en la matriz se incrementara, y eso mismo fue lo que se observó al evidenciar un aumento de la intensidad de una banda a $1743 \mathrm{~cm}^{-1}$, la cual puede ser asignada al modo de vibración de estiramiento de los grupos éster de metilo de la PAM.

Finalmente, las micropartículas fueron caracterizadas por isotermas de adsorción de nitrógeno (BET), técnica que permite determinar cambios en la porosidad y superficie específica de una muestra. En este sentido, esta técnica permitiría establecer si el tratamiento con AL estaría modificando la porosidad de las partículas (Sing, 2001). En la Tabla 20 se muestran los resultados. Las micropartículas de carbonato de calcio mostraron un área de superficie de $16,4 \mathrm{~m}^{2}$ por gramo de muestra. Cuando en ambos casos, alginato y alginato-PAM se añadieron a la formulación, se produjo un aumento en el área superficial de 3 y 2 veces, respectivamente. Ello se puede explicarse teniendo en cuenta que los geles de biopolímeros pueden proporcionar una nueva red interna dentro de la estructura de $\mathrm{CaCO}_{3}$, generando una mayor relación entre superficie/volumen. Además, es interesante analizar la reducción en el tamaño de poro de las micropartículas de $\mathrm{CaCO}_{3}$ (calculado por las ecuaciones de 
BJH y de BET) de $32 \mathrm{~nm}$ a 6 y $11 \mathrm{~nm}$ para $\mathrm{CaCO}_{3} / \mathrm{Alg}$ y $\mathrm{CaCO}_{3} /$ Alg-PAM respectivamente. De la misma forma, se observó una reducción en el volumen de poro. Los resultados sugieren que los biopolímeros adicionados a la formulación se incorporan rellenando los poros originales de la matriz de $\mathrm{CaCO}_{3}$. Por otra parte, los cambios en el tamaño de poro de las partícula híbrida al ser tratadas con la AL, corroboran los resultados observados anteriormente.

\section{Tabla 20 Caracterización de micropartículas por isotermas de adsorción de nitrógeno.}

\begin{tabular}{|c|c|c|c|c|}
\hline \multirow{2}{*}{ Muestra } & \multirow{2}{*}{$\begin{array}{c}\text { Área } \\
\text { superficial } \\
\left(\mathrm{m}^{2} / \mathrm{g}\right)\end{array}$} & \multirow{2}{*}{$\begin{array}{l}\text { Volúmen } \\
\text { de poro } \\
\left(\mathrm{cm}^{3} / \mathrm{g}\right)^{*}\end{array}$} & \multicolumn{2}{|c|}{ Tamaño de poro $(\mathrm{nm})$} \\
\hline & & & Adsorción BJH & Método BET \\
\hline $\mathrm{CaCO}_{3}$ & 16,4 & 0,13 & 32,54 & 31,12 \\
\hline $\mathrm{CaCO}_{3} / \mathrm{Alg}$ & 51,4 & 0,08 & 6,07 & 6,48 \\
\hline $\mathrm{CaCO}_{3} / \mathrm{Alg}+\mathrm{AL}$ & 75,0 & 0,25 & 13,04 & 13,16 \\
\hline $\mathrm{CaCO}_{3} / \mathrm{Alg}-\mathrm{PAM}$ & 34,9 & 0,09 & 11,01 & 10,79 \\
\hline $\mathrm{CaCO}_{3} / \mathrm{Alg}-\mathrm{PAM}+\mathrm{AL}$ & 71,6 & 0,24 & 13,46 & 13,26 \\
\hline
\end{tabular}

Se puede observar que las micropartículas de $\mathrm{CaCO}_{3} / \mathrm{Alg}+\mathrm{AL}$ mostraron un aumento del $50 \%$ en el área de superficie en comparación con las micropartículas no tratadas. El volumen de poro se incremento 3 veces, mientras que el tamaño de los poros después de la hidrólisis con AL se expandió en al menos al doble. La misma tendencia se observó para las micropartículas de $\mathrm{CaCO}_{3} / \mathrm{Alg}-\mathrm{PAM}$. Después del tratamiento, el área de superficie aumentó en un 100\%, el volumen de poro se incremento 2,5 veces y se produjo un aumento de $3 \mathrm{~nm}$ en el tamaño de poro. Estos cambios reflejan que la actividad enzimática está produciendo una nueva arquitectura en las matrices, haciéndolas más porosa, debido a la eliminación parcial (no total) de las cadenas de alginato de la estructura de carbonato de calcio híbrido.

\section{Carga de Levofloxacina}

La Levofloxacina (Levo) fue incorporado en las micropartículas por el mecanismo de absorción. La eficiencia de carga de las distintas formulaciones y la relación entre la cantidad de antibiótico respecto del peso de matriz se muestran en la 
Tabla 21. Las micropartículas híbridas de $\mathrm{CaCO}_{3}$ incorporaron una baja cantidad de Levo. Mientras que las de $\mathrm{CaCO}_{3} / \mathrm{Alg}$ cargaron un $13,5 \%$ de Levo inicial, las de $\mathrm{CaCO}_{3} / \mathrm{Alg}-\mathrm{PAM}$ sólo cargaron un 5,8\%. Este último resultado fue en desmedro de las expectativas, debido a que en trabajos anteriores de nuestro laboratorio se encontraron interacciones especificas entre antibióticos de la familia de las fluoroquinolonas (como por ejemplo, Enrofloxacina y Ciprofloxacina) con la pectina de alto metoxilo (Islan y col., 2012: Martínez y col., 2012). La baja incorporación de Levo en la matriz híbrida de Alg-PAM puede explicarse teniendo en cuenta la interacción sinérgica entre las cadenas de pectina y alginato (Walkenström y col., 2003), restringiendo los sitios para interaccionar con la Levo. Sin embargo, después del tratamiento con $\mathrm{AL}$, la absorción del antibiótico se incrementó en 3 y 9 veces para $\mathrm{CaCO}_{3} / \mathrm{Alg}$ y $\mathrm{CaCO}_{3} / \mathrm{Alg}$-PAM respectivamente.

\begin{tabular}{lcc}
\hline \multicolumn{3}{c}{ Tabla 21 Carga de Levofloxacina en micropartículas por absorción } \\
\hline \multicolumn{1}{c}{ Muestra } & $\begin{array}{c}\text { Eficiencia de carga } \\
(\%)\end{array}$ & $\begin{array}{c}\text { Levo/matriz } \\
(\mu \mathrm{g} / \mathrm{mg})\end{array}$ \\
$\mathrm{CaCO}_{3} / \mathrm{Alg}$ & $13,5 \pm 2,1$ & $4,3 \pm 0,7$ \\
$\mathrm{CaCO}_{3} / \mathrm{Alg}-\mathrm{PAM}$ & $5,8 \pm 1,4$ & $1,8 \pm 0,4$ \\
$\mathrm{CaCO}_{3} / \mathrm{Alg}+\mathrm{AL}$ & $38,1 \pm 0,3$ & $12,1 \pm 0,1$ \\
$\mathrm{CaCO}_{3} / \mathrm{Alg}-\mathrm{PAM}+\mathrm{AL}$ & $43,4 \pm 1,4$ & $14,0 \pm 0,6$ \\
\hline
\end{tabular}

Este incremento en la eficiencia de carga se ha producido principalmente debido a un aumento en el área específica de las micropartículas después de la incubación con la $\mathrm{AL}$, exponiendo de esta forma más sitios de unión para Levofloxacina. La AL es capaz de hidrolizar las cadenas de alginato, de forma tal que los grupos funcionales de la pectina están más disponibles para interaccionar con la fluoroquinolona, tal como se ha determinado experimentalmente en nuestro laboratorio.

Con el fin de corroborar el aumento en la absorción de Levofloxacina y aprovechando las propiedades de fluorescencia de la molécula, se estudió la localización de la droga en el interior de las micropartículas mediante microscopía óptica de epi-fluorescencia (Figura 4.11). 

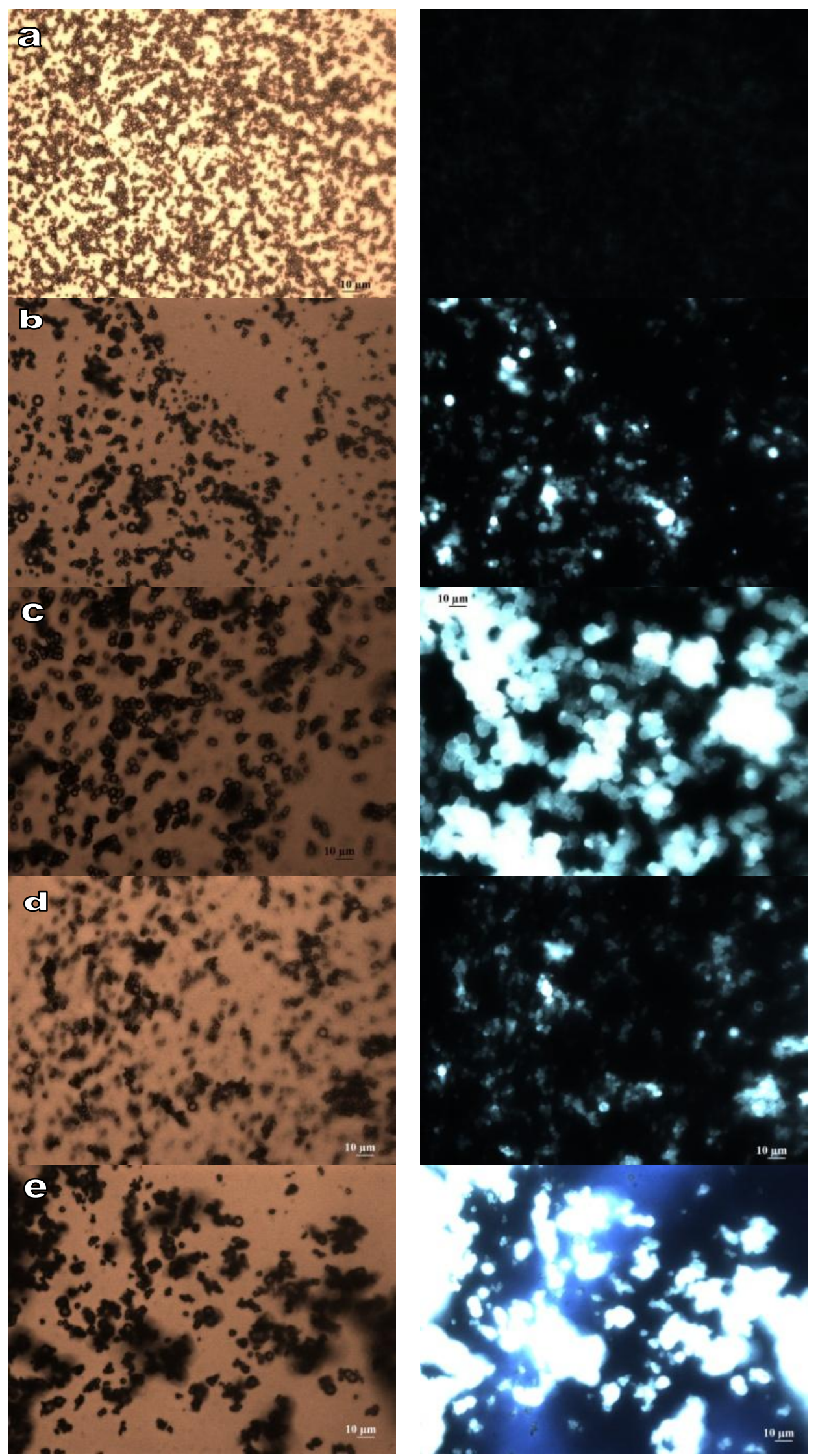

Figura 4.11 Microscopia óptica al visible (izq) y bajo fluorescencia (derecha) de micropartículas de: a) $\mathrm{CaCO}_{3}$ (vacías); b) $\mathrm{CaCO}_{3} / \mathrm{Alg}$ (Levo); c) $\mathrm{CaCO}_{3} / \mathrm{Alg}+\mathrm{AL}$ (Levo); d) $\mathrm{CaCO}_{3} /$ Alg-PAM (Levo); e) $\mathrm{CaCO}_{3} /$ Alg-PAM + AL (levo). 
Se pudo observar que las micropartículas de $\mathrm{CaCO}_{3} / \mathrm{Alg}$ (levo) mostraron la fluorescencia típica asociada al antibiótico con particular localización en la región interior de las mismas. A su vez, cuando se observaron las micropartículas tratadas con la $A L$ en las mismas condiciones ópticas, se detectó un aumento significativo de la fluorescencia de las micropartículas debido a un mayor contenido de Levo incorporada. La misma tendencia se observó para las micropartículas de $\mathrm{CaCO}_{3} / \mathrm{Alg}$ PAM, donde se corrobora no solo la localización del antibiótico en las micropartículas, sino también una notable exaltación de la señal de fluorescencia en las micropartículas tratadas con la AL (incluso hasta saturación de la señal). Estos resultados están en concordancia con los resultados anteriores de carga de Levo expuestos en la Tabla 21.

Cuando las micropartículas híbridas se incubaron en el medio de liberación (simulando el fluido pulmonar) se obtuvieron diferentes perfiles de liberación (Figura 4.12). Se pudo observar que las micropartículas de $\mathrm{CaCO}_{3} / \mathrm{Alg}$ liberaban el contenido total de Levofloxacina en 24 horas. Las mismas presentan un perfil que se caracterizaba por una liberación abrupta en las primeras 6 horas, seguido de una etapa de liberación lenta. Después del tratamiento con $A L$, el perfil de liberación se redujo y las micropartículas liberaron el 60\% del fármaco inicial en 24 horas (Figura 4.12.a). Este cambio puede ser atribuido al aumento de la carga de Levo después del tratamiento enzimático, lo que conduce a un incremento de las interacciones $\pi$ entre los anillos aromáticos de las moléculas de Levo, generando una estructura apilada dentro de la matriz y una difusión más lenta hacia afuera de la micropartícula (Maurer y col., 1998).

Por otro lado, la fuerte interacción de la PAM con fluoroquinolonas se refleja en el perfil de liberación de las micropartículas de $\mathrm{CaCO}_{3} / \mathrm{Alg}-\mathrm{PAM}$ (Figura 4.12.b). La Levofloxacina fue liberada en un $20 \%$ en las primeras 6 horas, mientras que una pequeña proporción del fármaco fue liberado en las próximas 18 horas, posiblemente debido a su unión con la PAM. Sin embargo, después del tratamiento con la AL, las micropartículas mostraron un aumento en el área superficial y el fármaco fue más susceptible a ser liberado de la PAM y, en consecuencia, continuó siendo liberado después de las primeras 6 horas. Esto se convierte en una herramienta interesante para modificar y controlar los patrones de liberación del dispositivo y la regulación de las dosis de los fármacos necesarias para alcanzar concentraciones terapéuticas. 

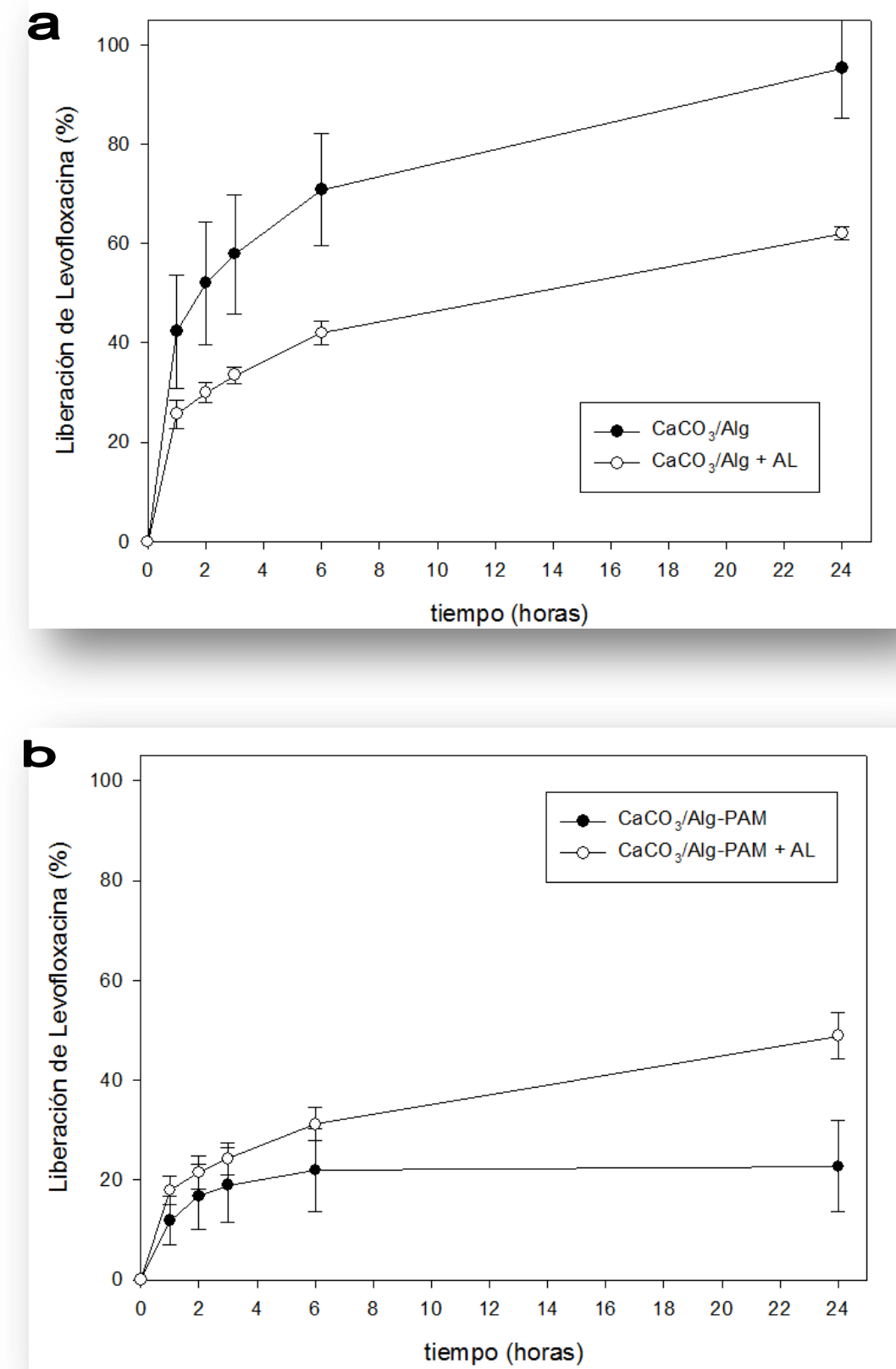

Figura 4.12 Liberación de Levofloxacina desde a) micropartículas de $\mathrm{CaCO}_{3} / \mathrm{Alg}$ y b) $\mathrm{CaCO}_{3} /$ Alg-PAM. Se evaluó el efecto sobre la liberación después del tratamiento con alginato liasa $(\mathrm{AL})$

\section{Ensayo microbiológico}

La capacidad antimicrobiana de las micropartículas fue ensayada en Pseudomonas aeruginosa (ATCC 15442), un patógeno oportunista recurrente y comúnmente hallado en infecciones pulmonares (May y col., 1991) (Figura 4.13). Se realizaron controles, en los que se inoculó por un lado la bacteria en medio de cultivo y por otro en un medio de cultivo en presencia de micropartículas vacías. En ambos 
casos se observó un intenso crecimiento después de 24 horas de incubación, con un aumento de la viscosidad del medio, asociado a la producción de biopolímeros, y un color verde oscuro que puede ser correlacionado con la producción de pigmentos fluorescentes. También se ensayó la supervivencia bacteriana en presencia de diferentes concentraciones de Levo libre (de 0,5 a 3,0 $\mathrm{\mu g} / \mathrm{ml}$ ), mostrando una inhibición progresiva con el aumento del antibiótico, hasta alcanzar una concentración de $3,0 \mu \mathrm{g} / \mathrm{ml}$ donde la supervivencia es cercana a cero (recuadro interno de la Figura 4.13). Cuando las micropartículas cargadas con Levo (tanto las de $\mathrm{CaCO}_{3} / \mathrm{Alg}$ y $\mathrm{CaCO}_{3} / \mathrm{Alg}$-PAM) se incorporaron al medio que contenía las bacterias creciendo en fase exponencial, se observó una inhibición parcial a las 24 horas de tratamiento. Si bien se observó cierto crecimiento ( $20 \%$ y $40 \%$ respectivamente), las bacterias no fueron capaces de alcanzar la fase estacionaria, lo cual resulta evidente al no observarse la viscosidad típica producida por la producción de biopolímero, y la pigmentación verdosa característica (fotos de la Figura 4.13). Comparativamente, las micropartículas de $\mathrm{CaCO}_{3} / \mathrm{Alg}$ produjeron una inhibición mayor que las micropartículas de $\mathrm{CaCO}_{3} / \mathrm{Alg}$ PAM, debido a su mayor carga y elevado porcentaje de liberación de Levo. Más interesante aún, resulta observar que cuando la misma proporción de micropartículas tratadas con AL (conteniendo Levo) se incubaron con las bacterias, una alta tasa de inhibición fue encontrada después de 24 horas: mayor al $90 \%$ para el caso $\mathrm{CaCO}_{3} / \mathrm{Alg}$ +AL y casi del $100 \%$ para el de $\mathrm{CaCO}_{3} / \mathrm{Alg}$-PAM. En este sentido, no se observaron cambios de viscosidad en el cultivo microbiano ni producción de pigmentos lo que sugiere una fuerte disminución de la producción de biopolímero bacteriano a raíz de la rápida inhibición de la Pseudomonas aeruginosa. Dicha inhibición se produce principalmente debido a la mayor eficacia de carga de las micropartículas tratadas, y la capacidad de liberar más cantidad de antibiótico y alcanzar la concentración inhibitoria mínima de la cepa.

Estos resultados confirman la importancia terapéutica de la modificación de las micropartículas híbridas con la alginato liasa y validan su aplicación como agente antimicrobiano. 

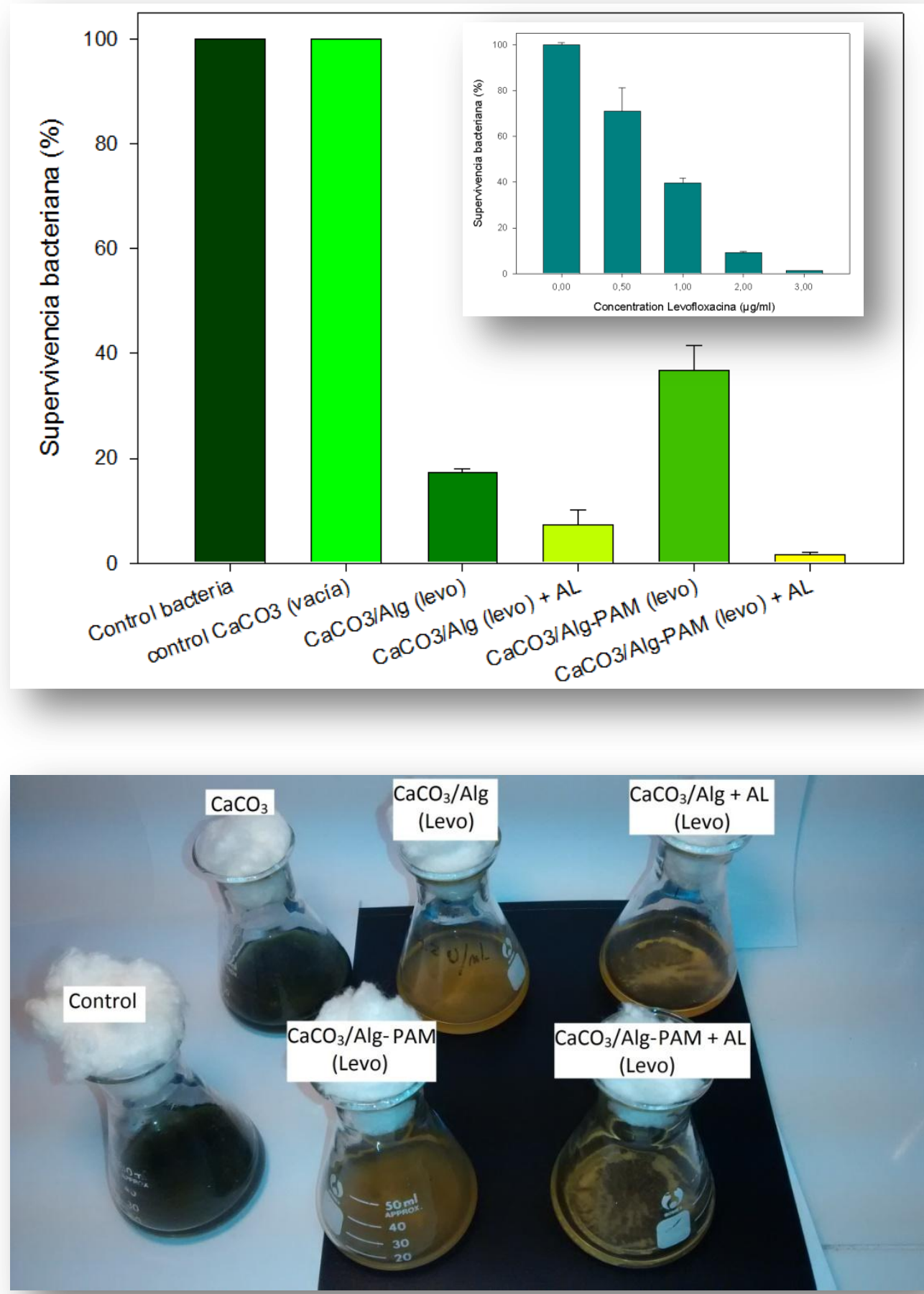

Figura 4.13 Ensayo antimicrobiano de las micropartículas contra Pseudomonas aeruginosa después de 24 horas de incubación. 


\section{Incorporación de una ADNasa a la matriz}

En una etapa final, considerando que hasta el momento se desarrolló una matriz micro-particulada con la capacidad de absorber Levofloxacina y liberarla de forma controlada, con potencial antimicrobiano contra Pseudomonas aeruginosa así como un tamaño y porosidad óptimos para la administración pulmonar, se procedió a incorporar una enzima hidrolítica de ADN en la superficie de las micropartículas. Se desea que dicha enzima permita mejorar la efectividad de las micropartículas en el tratamiento de la infección causada en los pulmones de pacientes con FQ, ya que proporcionara una herramienta adicional para disminuir la viscoelasticidad del mucus que dificulta la difusión de los antibióticos (Ratjen y col., 2005).

Para ello se realizaron los ensayos de absorción, bajo dos consideraciones:

- Se seleccionó la matriz de $\mathrm{CaCO}_{3} / \mathrm{Alg}$ (y la tratada con la $\mathrm{AL}$ ) para evaluar la carga de ADNasa, por ser una matriz simple y presentar un área superficial mayor que la de las micropartículas de $\mathrm{CaCO}_{3} / \mathrm{Alg}-\mathrm{HMP}$, así como una capacidad de de carga de Levo no muy distinta de las mismas (Tabla 20 y 21 respectivamente).

- Se procedió a absorber una cantidad de Levofloxacina 10 veces mayor (incubación inicial con $10 \mathrm{mg} / \mathrm{ml}$ ) que la ensayada anteriormente, a fin de incrementar la proporción de antibiótico/matriz.

Los resultados de la absorción simultánea de Levo con ADNasa se muestran en la Tabla 22. Se observó que las micropartículas híbridas de alginato eran capaces de cargar cerca de un $30 \%$ del antibiótico, la cual representa un porcentaje de más del doble del observado en la Tabla 21 (que era del 14\%), donde las micropartículas eran incubadas con una concentración de antibiótico 10 veces menor. En este caso en particular, dicho aumento se deba posiblemente no sólo al incremento del gradiente de concentración que favorece la absorción de la Levo en los intersticios de la matriz, sino también al fenómeno de apilamiento entre las mismas moléculas de Levo, que permite incorporar mas moléculas independientemente de la saturación de los sitios de interacción con la matriz (Maurer y col., 1998). Por otra parte, se observó la capacidad de las micropartículas para absorber la ADNasa con una eficiencia de carga del 29 \%. Considerando su peso molecular promedio de 31 KDa y una estructura globular (Salnikow y col., 1970), y mediante el uso de una ecuación que permite 
vincular el peso molecular con las dimensiones de la proteína (Erikson, 2009) fue posible estimar un tamaño de $37,5 \mathrm{~nm}^{3}$, con un diámetro aproximado de 4,2 $\mathrm{nm}$. Considerando dicho valor y que el tamaño de poro de las micropartículas de $\mathrm{CaCO}_{3} / \mathrm{Alg}$ se encuentra en el mismo orden ( $6 \mathrm{~nm}$ según Tabla 20, determinado por el método de BET) se podría deducir que la enzima dificultosamente sería capaz de penetrar la malla entrecruzada de la matriz y el posible mecanismo por el cual la ADNasa es incorporada sería por un proceso de adsorción mayormente en la superficie de las microesferas.

\begin{tabular}{|c|c|c|c|c|}
\hline \multirow[t]{2}{*}{ Micropartículas } & \multicolumn{2}{|c|}{ Eficiencia de carga (\%) } & \multicolumn{2}{|c|}{$\begin{array}{c}\text { Masa fármaco/masa matriz } \\
(\mu \mathrm{g} / \mathrm{mg})\end{array}$} \\
\hline & Levo & ADNasa & Levo & ADNasa \\
\hline $\mathrm{CaCO}_{3} / \mathrm{Alg}$ & $29,5 \pm 1,9$ & $28,7 \pm 3,4$ & $118,1 \pm 7,5$ & $11,5 \pm 1,3$ \\
\hline $\mathrm{CaCO}_{3} / \mathrm{Alg}+\mathrm{AL}$ & $40,0 \pm 4,7$ & $67,8 \pm 2,2$ & $159,9 \pm 18,8$ & $27,1 \pm 0,9$ \\
\hline
\end{tabular}

Por su parte, las micropartículas de $\mathrm{CaCO}_{3} / \mathrm{Alg}+\mathrm{AL}$ mostraron una mayor eficiencia de incorporación de ambos agentes. La carga de Levo fue del $40 \%$, representado unos $160 \mu \mathrm{g}$ de Levo por miligramo de matriz (una cantidad 13 veces mayor que la expuesta en la Tabla 21), mientras que la de ADNasa fue cercana al $70 \%$. Ello pone en evidencia nuevamente que el tratamiento de la matriz híbrida con la enzima genera un aumento de la superficie específica que permite incrementar la incorporación de moléculas por absorción. A diferencia de lo que ocurría con las micropartículas de $\mathrm{CaCO}_{3} / \mathrm{Alg}$ y considerando que el tamaño de poro de estas micropartículas tratadas es de aproximadamente $13 \mathrm{~nm}$, se espera que la enzima sea adsorbida no solo en la superficie, sino también en los intersticios de la red matricial, lo cual explica su elevada eficiencia de absorción.

A continuación se realizó una microscopia SEM de las micropartículas, antes y después de co-absorber la Levo y la ADNasa. Se puede observar en la Figura 4.14 que no hubo grandes cambios en la distribución y tamaño de las micropartículas de $\mathrm{CaCO}_{3} / \mathrm{Alg}$ luego de la co-absorción. Tampoco se observaron grandes cambios a nivel superficial. 

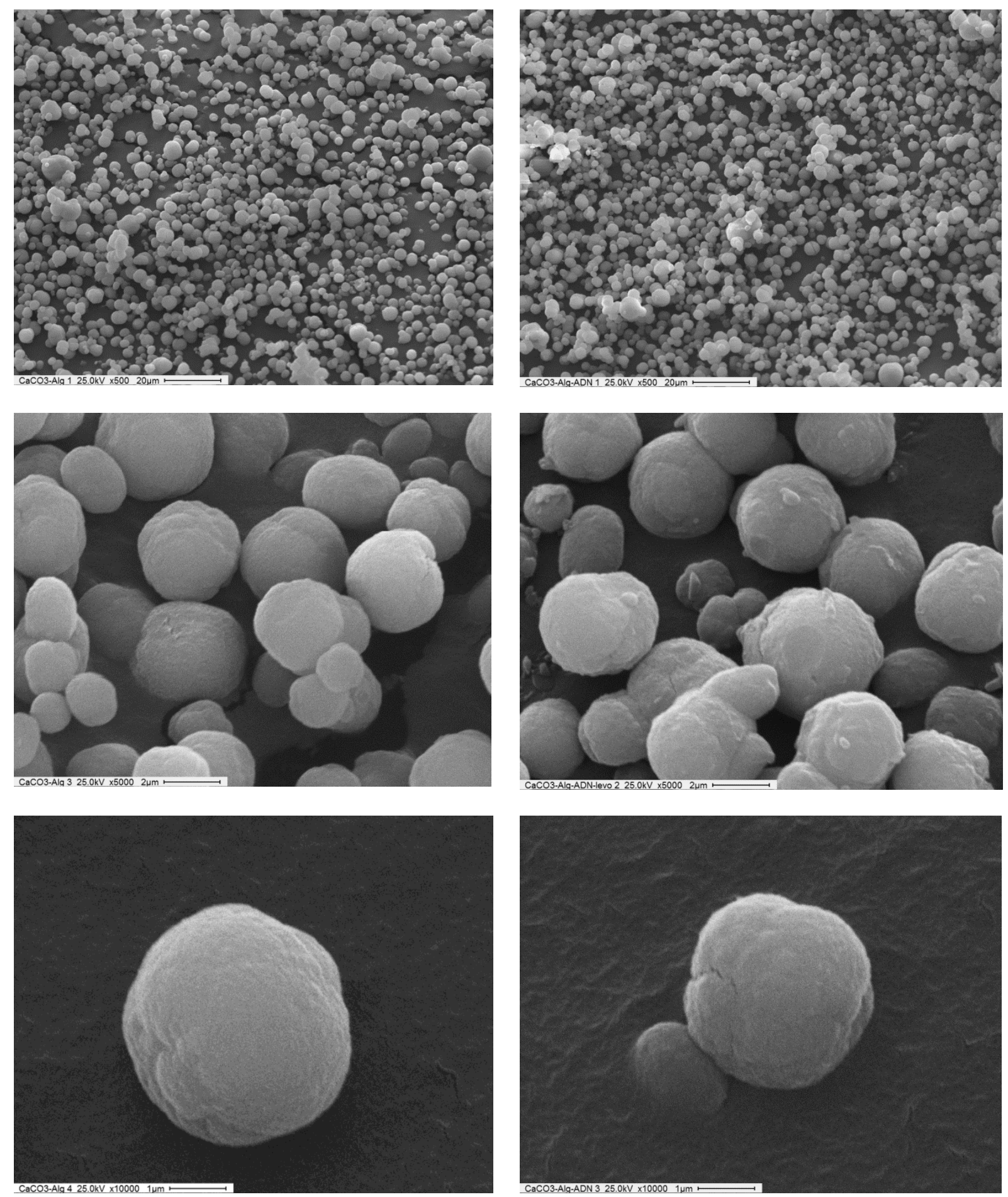

Figura 4.14 Imágenes de SEM de micropartículas de $\mathrm{CaCO}_{3} / \mathrm{Alg}$ a 500, 5.000 y 10.000 aumentos: izq) vacias; derecha) luego de cargar Levo y ADNasa.

Por el contrario, fueron observadas diferencias considerables en la topología de las partículas de $\mathrm{CaCO}_{3} / \mathrm{Alg}+\mathrm{AL}$ luego de la incorporación de Levo y ADNasa (Figura Figura 4.15). Las partículas tratadas con la enzima, tal como se ha discutido previamente, presentan una superficie rugosa, con cadenas de alginato parcialmente hidrolizadas expuestas hacia el exterior. Luego de la absorción conjunta de ambas 
moléculas se produjo un alisamiento de la superficie y se observaron agregados que podrían estar constituidos por la ADNasa, lo cual refleja claramente la capacidad de las micropartículas para incorporar eficientemente moléculas por absorción.
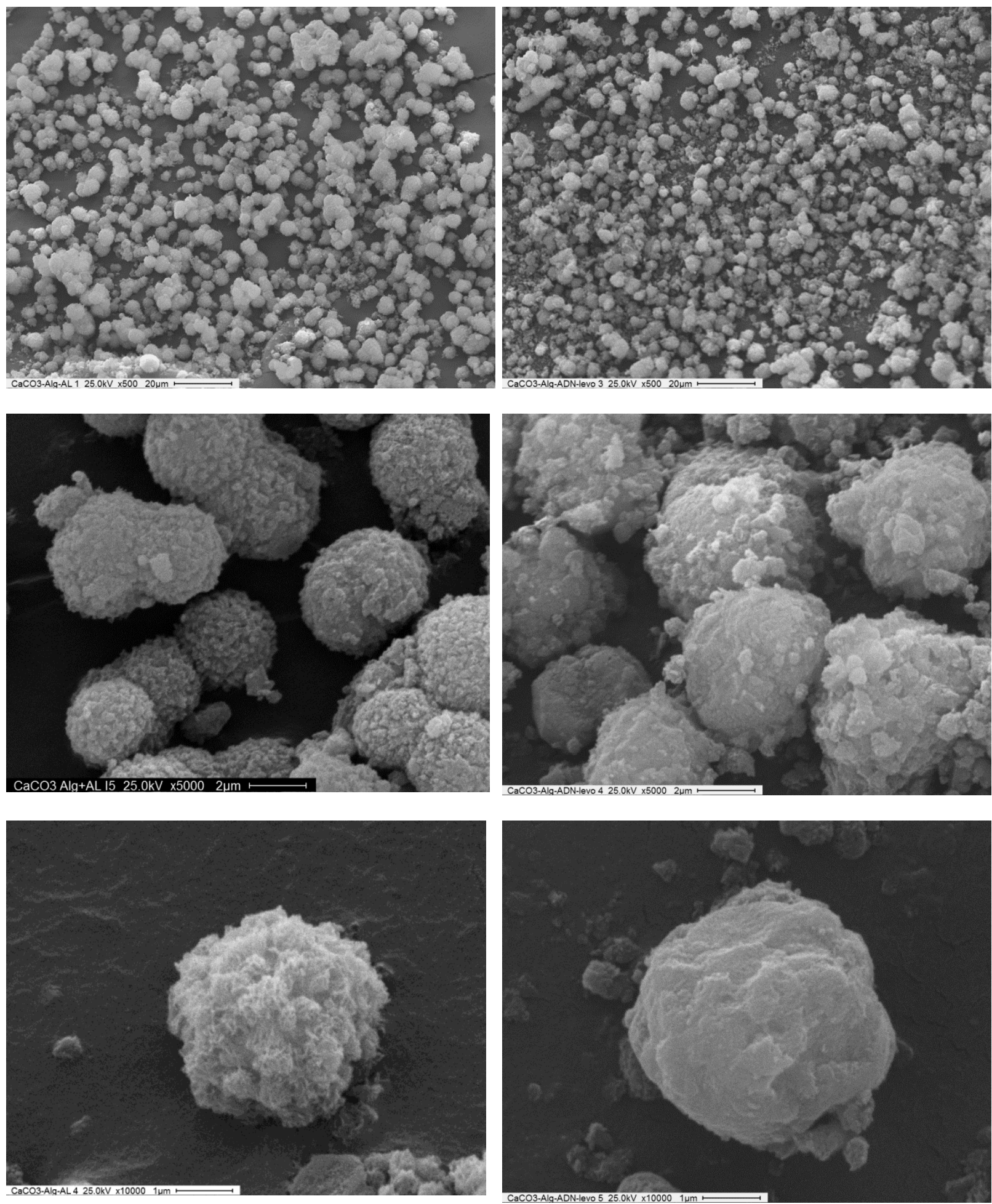

Figura 4.15 Imágenes de SEM de micropartículas de $\mathrm{CaCO}_{3} / \mathrm{Alg}+\mathrm{AL}$ a 500, 5.000 y $10.000 \mathrm{X}$ : izq) vacías; derecha) luego de cargar Levo y ADNasa. 
Posteriormente, se procedió a estudiar el comportamiento de las micropartículas en un medio de liberación, simulando el posible perfil que presentarían en las condiciones pulmonares. La liberación de Levo fue de forma controlada desde ambas matrices (Figura 4.16). Mientras que la de $\mathrm{CaCO}_{3} / \mathrm{Alg}$ liberó casi un $50 \%$ del contenido total de Levo, la de $\mathrm{CaCO}_{3} / \mathrm{Alg}+\mathrm{AL}$ cerca de un $35 \%$ en un período de 72 horas. Esta reducción en la liberación se puede deber a la gruesa capa de ADNasa adsorbida en la superficie, que actúa como barrera difusional para retardar la salida de la Levo desde el interior de la microesfera.

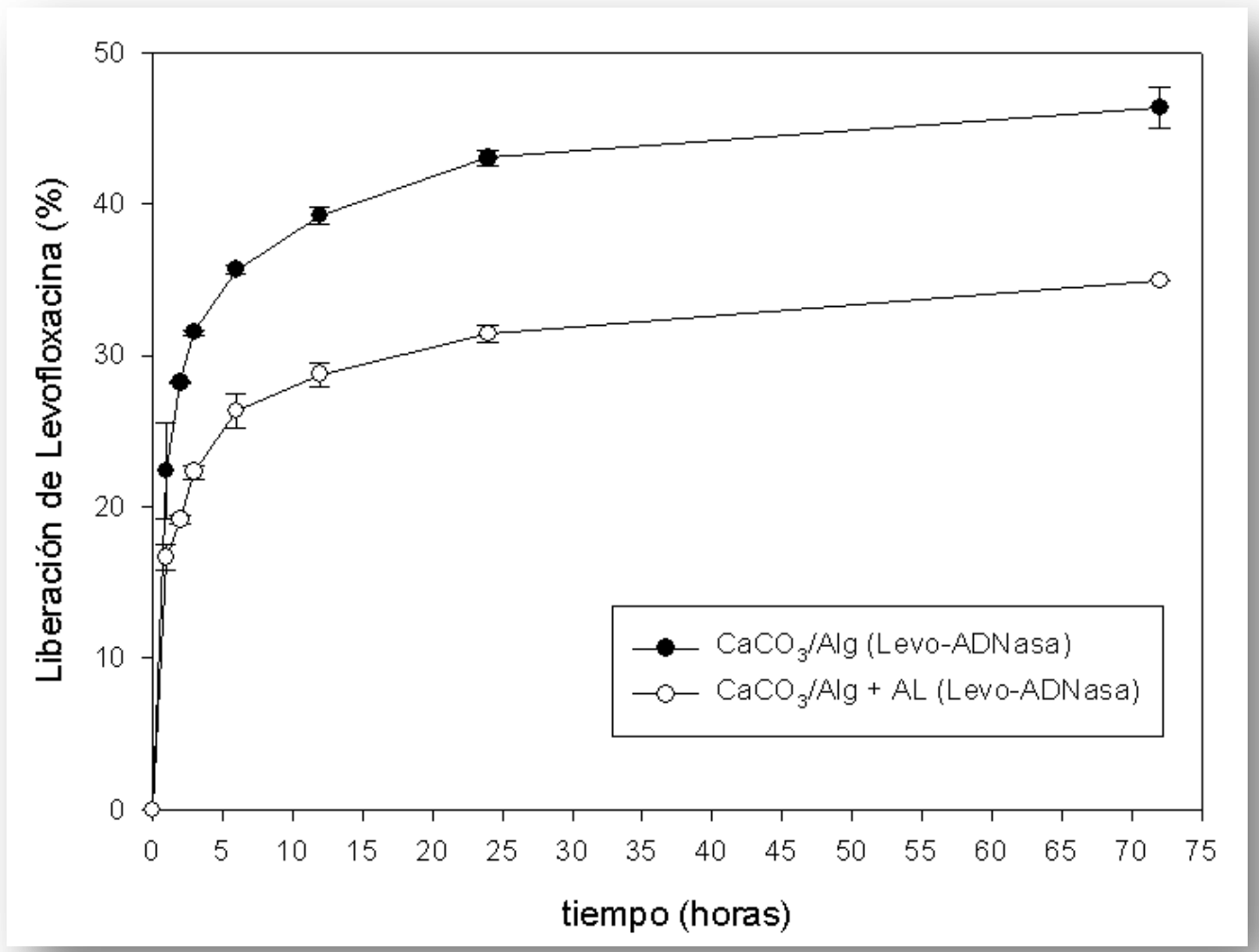

Figura 4.16 Liberación de Levofloxacina desde micropartículas de $\mathrm{CaCO}_{3} / \mathrm{Alg}$ y $\mathrm{CaCO}_{3} / \mathrm{Alg}+\mathrm{AL}$ conteniendo Levo y ADNasa.

Por su parte la liberación de ADNasa desde las micropartículas reveló un interesante perfil. Tanto las micropartículas de $\mathrm{CaCO}_{3} / \mathrm{Alg}$ como las de $\mathrm{CaCO}_{3} / \mathrm{Alg}+\mathrm{AL}$ mostraron una similar capacidad de liberar la ADNasa en cuanto a porcentaje de liberación (Figura 4.17, a). Ello claramente está indicando que la desorción de la enzima desde la superficie de las microesferas se estaría produciendo por la disolución de las capas más expuestas, evidenciando que las interacciones con la matriz son débiles y no se han producido uniones químicas (covalentes). Esto resulta de interés, 
debido a que no habría modificaciones del sitio activo de la ADNasa ni rigidificación de su estructura que impida su plegamiento en una forma conformacional activa, con la cual se estaría liberando de forma activa. En un período de aproximadamente 24 horas el total de la ADNasa fue liberado de ambos tipos de micropartículas.
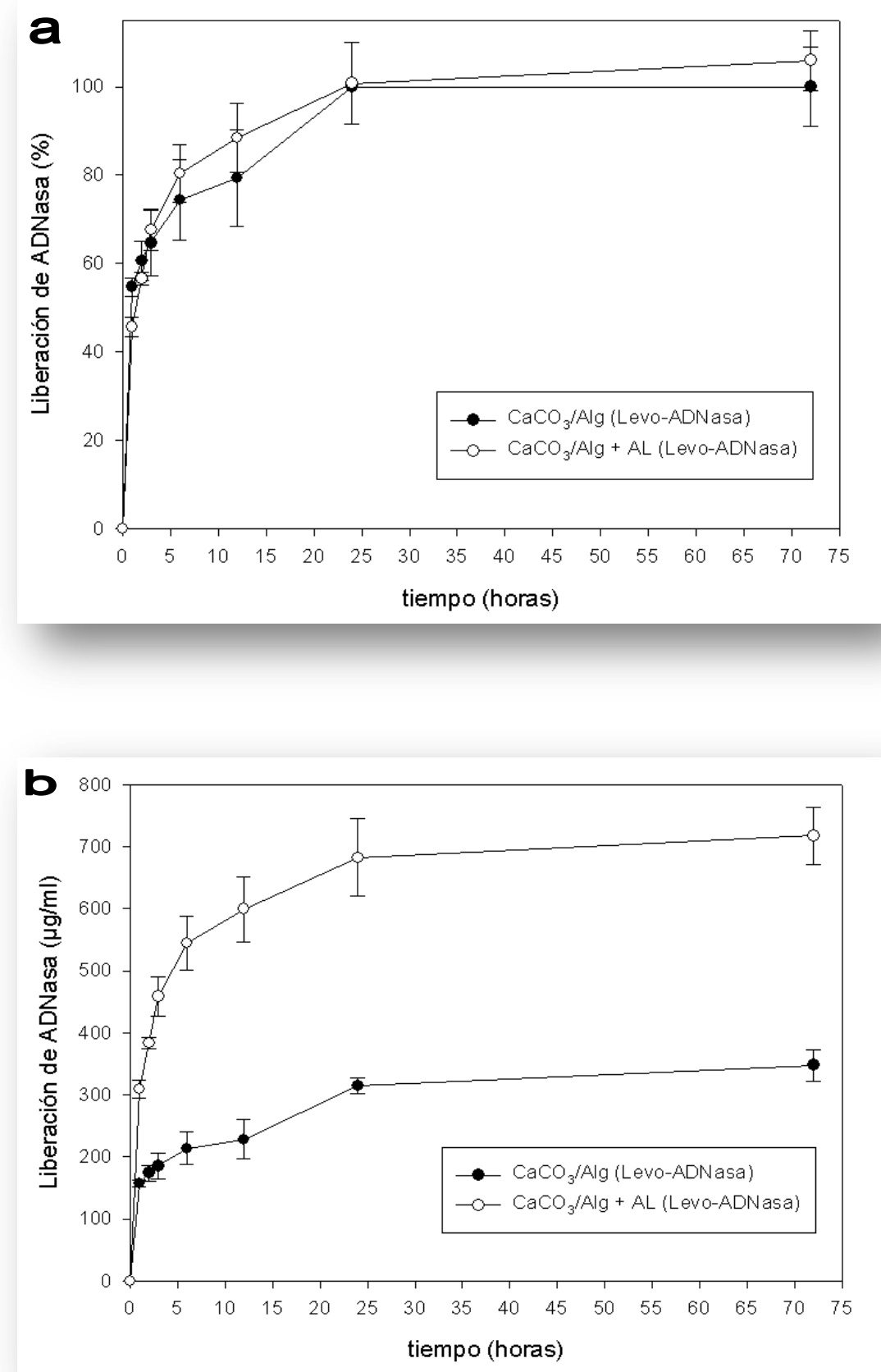

Figura 4.17 Liberación de ADNasa desde micropartículas de $\mathrm{CaCO}_{3} / \mathrm{Alg}$ y $\mathrm{CaCO}_{3} / \mathrm{Alg}+\mathrm{AL}$ conteniendo Levo y ADNasa: a) liberación porcentual; b) liberación en masa de enzima por masa de matriz. 
Al comparar con los valores de absorción de ADNasa en ambos tipos de microesferas (Tabla 22), se puede observar que el sistema de $\mathrm{CaCO}_{3} / \mathrm{Alg}+\mathrm{AL}$ es capaz de suministrar una mayor cantidad de enzima (microgramos de ADNasa liberada por miligramos de matriz) en el mismo periodo de incubación (Figura 4.17, b).

El hecho que la enzima sea totalmente liberada en 24 horas, incluso antes que se libere la totalidad de la Levofloxacina, resulta de gran importancia terapéutica porque a medida que el antibiótico se va liberando desde las micropartículas, la ADNasa ya produciría una reducción de la viscosidad del mucus hallado en los pulmones de los pacientes, con lo que, la difusión del antibiótico hacia la zona de la infección se vería favorecida.

Como última etapa de validación del sistema, se tomaron los sobrenadantes de la liberación y se testeó por un lado, que el antibiótico sea liberado sin perder su capacidad bactericida, mientras que por otro, que la ADNasa sea liberada en forma activa. Se pudo observar que la actividad enzimática evaluada en una placa de agar ADNasa era mayor para el caso de las partículas de $\mathrm{CaCO}_{3} / \mathrm{Alg}+\mathrm{AL}$, mostrando un halo de color violáceo de mayor tamaño (Figura 4.18, izq). Ello está en concordancia con los datos anteriores que indicaban que dichas micropartículas eran capaces de liberar una mayor cantidad de enzima.
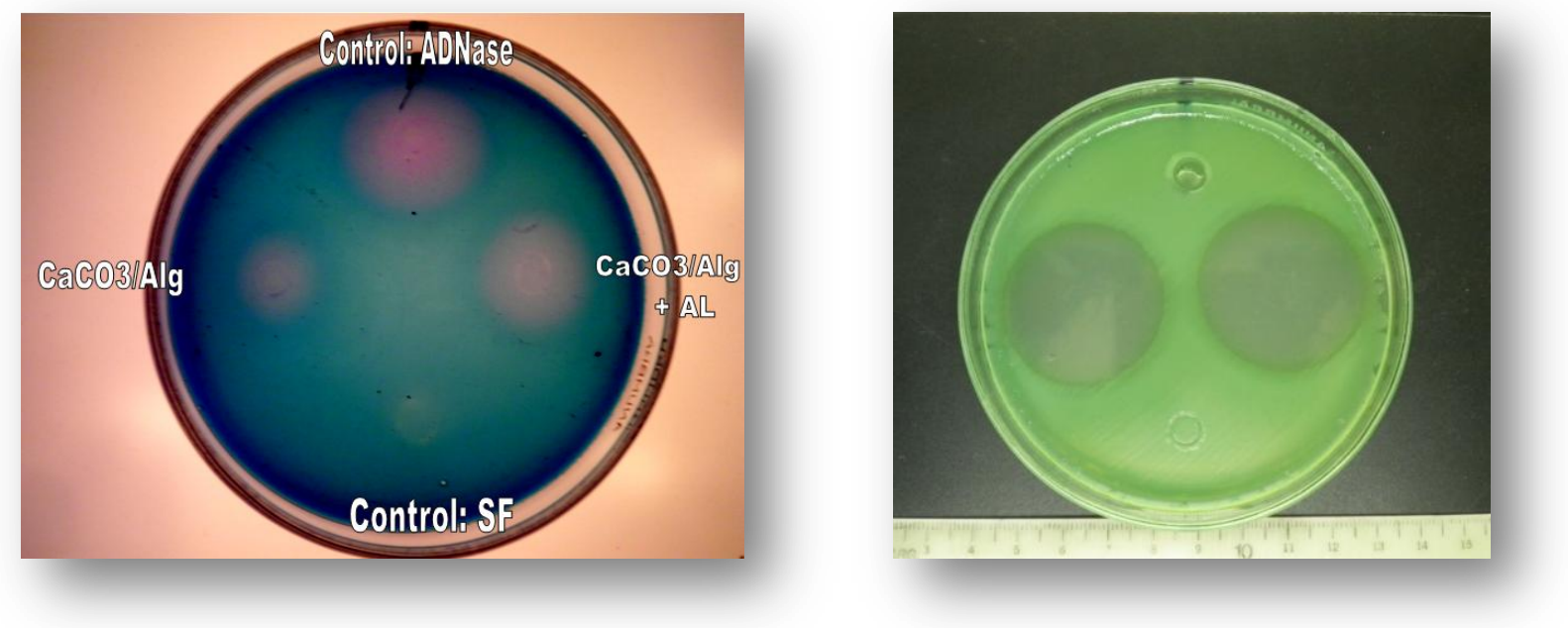

Figura 4.18 Evaluación de los sobrenadantes de liberación de las micropartículas de $\mathrm{CaCO}_{3} / \mathrm{Alg}$ y $\mathrm{CaCO}_{3} / \mathrm{Alg}+\mathrm{AL}$. izq) agar ADNasa con azul de toluidina; der) placa con Pseudomonas aeruginosa. Ambas placas fueron inoculadas con los mismos volúmenes $(25 \mu \mathrm{l})$ de cada una de las soluciones indicadas en cada posición. 
Finalmente, los mismos sobrenadantes de liberación fueron testeados en una placa de agar con Pseudomonas aeruginosa sembrada superficialmente (Figura 4.18, der). Como era de esperar, tanto la ADNasa libre, como el control de solución fisiológica (SF) no mostraron actividad antimicrobiana. En cambio ambos sobrenadantes de las micropartículas de $\mathrm{CaCO}_{3} / \mathrm{Alg}$ y $\mathrm{CaCO}_{3} / \mathrm{Alg}+\mathrm{AL}$ mostraron sus respectivos halos de inhibición, siendo el de estas últimas levemente mayor dada su considerable carga de antibiótico. Ello indicaría que la Levo estaría siendo liberada desde las micropartículas y sería activa incluso en presencia de la ADNasa. 


\subsection{Conclusiones}

En el presente capítulo se ha propuesto el desarrollo de micropartículas híbridas de $\mathrm{CaCO}_{3}$ mediante un tratamiento enzimático que permite el diseño de una matriz con características óptimas para la administración de una fluoroquinolona a pulmón, en particular, Levofloxacina. Se obtuvieron micropartículas con un diámetro de alrededor de los 4 micrones, una estructura porosa y capacidad de carga de un antibiótico. Se realizaron estructuras hibridas con otro biopolímero (pectina de alto metoxilo) no hidrolizable por la alginato liasa, las cuales mostraron patrones de superficie diferentes a las híbridas de alginato. El aumento del área superficial después del tratamiento con la alginato liasa permitió la eficiente absorción del fármaco modelo, Levofloxacina. A su vez, la matriz presentó propiedades de liberación controlada proporcionando una administración sostenible del fármaco en el tiempo. La modificación de las matrices se caracterizó por DSC, FTIR, XRD, isotermas de adsorción de nitrógeno, microscopias SEM, óptica y de epi-fluorescencia, así como un análisis composicional por el método de Antrona. Las micropartículas tratadas mostraron un efecto antimicrobiano mejorado frente a un patógeno oportunista como Pseudomonas aeruginosa. A su vez, mostraron la capacidad de adsorber una enzima terapéutica (ADNasa) con una alta eficiencia de carga, con el potencial de liberarla de forma activa.

Los resultados indican el desarrollo de micropartículas con una nueva arquitectura de superficie que permite la co-adsorción de Levofloxacina y una ADNasa. Su tamaño y porosidad también le brindan un atractivo para su aplicación en el tratamiento de infecciones pulmonares, y en particular, las generadas en pacientes con FQ. 


\subsection{Bibliografía}

Bajpai S. K., Sharma S., Investigation of swelling/degradation behaviour of alginate beads crosslinked with $\mathrm{Ca}^{2+}$ and $\mathrm{Ba}^{2+}$ ions. React. Funct. Polym. 2004, 59, 129.

Beuvier T., Calvignac B., Delcroix G. J. R., Tran M. K., Kodjikian S., Delorme N., Bardeau J. F., Gibaud A., Boury F., Synthesis of hollow vaterite $\mathrm{CaCO}_{3}$ microspheres in supercritical carbon dioxide medium. J. Mater. Chem. 2011, 21, 9757.

Bosio V. E., Cacicedo M. L., Calvignac B., León I., Beuvier T., Boury F., Castro G. R., Synthesis and characterization of $\mathrm{CaCO}_{3}$-biopolymers hybrid nanoporous microparticles for cancer damaged bone therapy. Colloids and surfaces B: Biointerfaces 2014. DOI: 10.1016/j.colsurfb.2014.09.011.

Bosio V. E., Machain V., Pérez De Berti I., Gómez López A., Marchetti S. G., Mechetti M., Castro G. R., Binding and encapsulation of doxorubicin on smart pectin hydrogels for oral delivery. Appl. Biochem. Biotechnol. 2012, 167, 1365.

Braccini I., Perez S., Molecular basis of $\mathrm{Ca}^{2+}$-induced gelation in alginates and pectins: the eggbox model revisited. Biomacromolecules 2001, 2, 1089.

Cai Y., Chen Y., Hong X., Liu Z., Yuan W., Porous microsphere and its applications. Int J Nanomedicine 2013, 8, 1111.

Carbon C., Comparison of Side Effects of Levofloxacin versus Other Fluoroquinolones. Chemotherapy 2001, 47, 9.

Dockrell D. H., Breen R., Lipman M., Miller R. F., 3 Pulmonary opportunistic infections, HIV Medicine 2011, 12, 25.

Edwards D. A., Hanes J., Caponetti G., Hrkach J., Ben-Jebria A., Eskew M. L. y col., Large porous particles for pulmonary drug delivery. Science 1997, 276, 1868.

Erickson H. P., Size and shape of protein molecules at the nanometer level determined by sedimentation, gel filtration, and electron microscopy. Biological procedures online 2009, $11,32$.

Fundueanu G., Esposito E., Mihai D., Carpov A., Desbrieres J., Rinaudo M., Nastruzzi C., Preparation and characterization of Ca-alginate microspheres by a new emulsification method. International Journal of Pharmaceutics 1998, 170, 11.

Geller D. E., Flume P. A., Griffith D. C., Morgan E., White D., Loutit J. S., Dudley M. N., Pharmacokinetics and Safety of MP-376 (Levofloxacin Inhalation Solution) in Cystic Fibrosis Subjects. Antimicrob. Agents and Chemother. 2011, 55, 2636. 
Guo W., Luo G. S., Wang Y. J., A new emulsion method to synthesize well-defined mesoporous articles. Journal of Colloid and Interface Science 2004, 271, 400.

Høiby N., Ciofu O., Bjarnsholt T., Pseudomonas aeruginosa biofilms in cystic fibrosis. Future Microbiol., 2010, 5, 1663.

Islan G. A., Bosio V. E., Castro G. R., Alginate Lyase and Ciprofloxacin Co-Immobilization on Biopolymeric Microspheres for Cystic Fibrosis Treatment. Macromol. Biosci. 2013, 13, 1238.

Islan G. A., Perez de Verti I., Marchetti S. G., Castro G. R., Studies of ciprofloxacin encapsulation on alginate/pectin matrixes and its relationship with biodisponibility. Appl. Biochem. Biotechnol. 2012, 167, 1408.

Klak M. C., Lefebvre E., Rémy L., Agniel R., Picard J., Giraudier S., Larreta-Garde V., Gelatin-Alginate Gels and Their Enzymatic Modifications: Controlling the Delivery of Small Molecules. Macromol. Biosci. 2013, 13, 687.

Martinez Y. N., Piñuel L., Castro G. R., Breccia J. D., Polyvinyl alcohol-pectin cryogel films for controlled release of enrofloxacin. Appl. Biochem. Biotechnol, 2012, 167, 1421.

Maurer N., Wong K. F., Hope M. J., Cullis P. R., Anomalous solubility behavior of the antibiotic ciprofloxacin encapsulated in liposomes: $a^{1}$ H-NMR study. Biochimica et Biophysica Acta (BBA)-Biomembranes, 1998, 1374, 9.

May T. B., Shinabarger D., Maharaj R., Kato J., Chu L., Devault J. D., Roychoudhury S., Zielinski N. A., Berry A., Rothmel R. K., Misra T. K., Chakrabarty A. M., Alginate synthesis by Pseudomonas aeruginosa: a key pathogenic factor in chronic pulmonary infections of cystic fibrosis patients. Clin. Microbiol. Rev. 1991, 4, 191.

Peng C. Y., Zhao Q. H., Gao C. Y., Sustained delivery of doxorubicin by porous $\mathrm{CaCO}$ and chitosan/alginate multilayers-coated $\mathrm{CaCO} 3$ microparticles. Colloids Surf A Physicochem Eng Asp. 2010, 353,132.

Radha A. V., Forbes T. Z., Killian C. E., Gilbert P. U. P. A., Navrotsky A., Transformation and crystallization energetics of synthetic and biogenic amorphous calcium carbonate. Proceedings of the National Academy of Sciences 2010, 107, 16438.

Ratjen F., Paul K., van Koningsbruggen S., Breitenstein S., Rietschel E., Nikolaizik W., DNA concentrations in BAL fluid of cystic fibrosis patients with early lung disease: influence of treatment with dornase alpha. Pediatr Pulmonol. 2005, 39, 1.

Robinson P. J., Dornase alfa in early cystic fibrosis lung disease. Pediatr Pulmonol. 2002, 34, 237.

Rubinstein E., History of Quinolones and Their Side Effects. Chemotherapy 2001, 47, 3. 
Ruckdeschel J. C., Greene J., Sommers K. E., Fields K. K., Respiratory infections in patients with cancer in Holland-Frei Cancer Medicine, ed. D. W. Kufe, R. E. Pollock, R. R. Weichselbaum, et al., BC Decker, Canada, 6th edn., 2003.

Sakugawa K., Ikeda A., Takemura A., Ono H., Simplified Method for Estimation of Composition of Alginates by FTIR. Journal of applied polymer science 2004, 93, 1372.

Salnikow J., Moore S., Stein W. H., Comparison of forms of bovine pancreatic deoxyribonuclease. J. Biol. Chem. 1970, 245, 5685.

Sing K., The use of nitrogen adsorption for the characterisation of porous materials. Colloids Surf. A Physicochem. Eng. Asp. 2001, 187, 3.

Tas A. C., Use of Vaterite and Calcite in Forming Calcium Phosphate Cement Scaffolds. Developments in Porous, Biological and Geopolymer Ceramics: Ceramic Engineering and Science Proceedings 2009, 28, 135.

Walkenström P., Kidman S., Hermansson A. M., Rasmussen P. B., Hoegh L., Microstructure and rheological behaviour of alginate/pectin mixed gels. Food Hydrocolloids 2003, 17, 593.

Wang Y. W., Wu Q., Chen G. Q., Gelatin blending improves the performance of poly (3hydroxybutyrate-co-3-hydroxyhexanoate) films for biomedical application. Biomacromolecules 2005, 6, 566.

Yemm E.W., Willis A. J., The estimation of carbohydrates in plant extracts by anthrone. Biochemical Journal 1954, 57, 508. 


\section{CONCLUSIONES}

Conclusión final, logros y

perspectivas

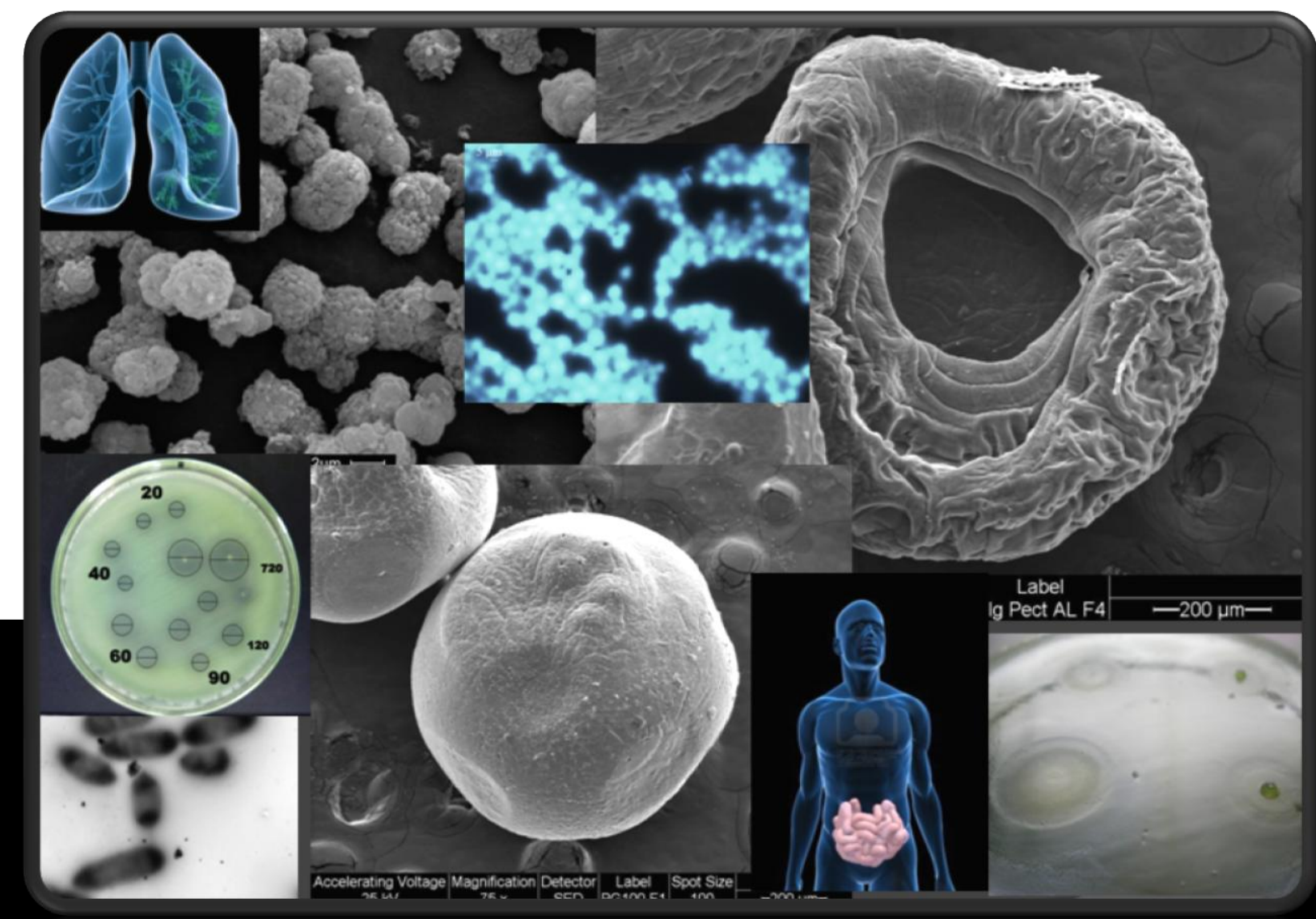


En el presente trabajo de Tesis se lograron desarrollar dos tipos de matrices:

una matriz de base biopolimérica conteniendo un antibiótico (Ciprofloxacina) y una enzima hidrolítica (alginato liasa) para la administración oral. Se probó in vitro que la misma era un vehículo adecuado para la liberación controlada del antibiótico y prevenir la inactivación de la enzima durante el pasaje por el pH ácido del estómago. La misma posee propiedades bactericidas potenciadas contra Pseudomonas aeruginosa y demostró no ser citotóxica para células de mamífero, utilizando células $\mathrm{CHO}$ como modelo (capítulos 1 y 2). Vale aclarar que se desarrollo una forma estable de la alginato liasa en forma de agregados enzimáticos entrecruzados (CLEAs) para la administración oral, como otra alternativa para prevenir su rápida inactivación por el $\mathrm{pH}$ gástrico y las temperaturas superiores a $37^{\circ} \mathrm{C}$ por condiciones febriles de los pacientes (capítulo $3)$.

una matriz para terapia inhalatoria, a base de micropartículas hibridas de $\mathrm{CaCO}_{3}$ y biopolímeros (alginato y pectinas) conteniendo Levofloxacina y una ADNasa, mostrando propiedades aptas para su inhalación (tamaño alrededor de los 4 micrones y estructura porosa), así como capacidad antimicrobiana contra Pseudomonas aeruginosa y actividad hidrolítica de ADN (capítulo 4).

Potencialmente, el primer sistema está diseñado para su administración oral, a fin de tratar la infección intestinal que se encuentra potenciada por una bio-película de alginato, que impide el tratamiento normal con antibióticos, así como la difusión de enzimas pancreáticas necesarias para la absorción de nutrientes.

El segundo sistema intentaría atacar el principal foco de infección y primer causante de la mortalidad de los pacientes con FQ que es la pérdida progresiva de la función pulmonar por infecciones recurrentes con Pseudomonas aeruginosa. Se espera que las micropartículas lleguen a los intersticios más profundos del pulmón para ejercer la acción antimicrobiana de la Levofloxacina junto con la acción conjunta de la ADNasa para recudir la viscoelasticidad de la mucosidad hallada en dichos tejidos.

Vale aclarar que los prototipos desarrollados pretenden brindar un tratamiento paliativo a pacientes que padecen $\mathrm{FQ}$, una patología de origen genético, con el objeto 
de mejorar la calidad de vida de los mismos a través de sistemas de administración más eficientes, en menores dosis y reduciendo los posibles efectos secundarios.

Es necesario aclarar que para alcanzar la fase clínica, se deben realizar una serie de estudios adicionales, algunos de los cuales se mencionan como perspectivas al trabajo realizado:

- Evaluar la capacidad de los prototipos desarrollados de modificar las propiedades visco-elásticas del esputo (mucosidad pulmonar) aislado de pacientes con Fibrosis Quística.

Evaluación en modelos animales de fibrosis quística, a fin de establecer el comportamiento de los sistemas in vivo y determinar su toxicidad.

- Optimización de las condiciones de liberación de los fármacos in vivo para ajustar las dosis de acuerdo a los niveles plasmáticos detectadas en sangre y de acuerdo al tipo de patología. 
Finalmente, cabe mencionar que parte de los resultados de la presente tesis han sido publicados en artículos de revistas internacionales con referato, se han protegido mediante una patente de alcance nacional y han sido parte de capítulos de libro, los cuales se mencionan a continuación:

Artículos:

- Cecilia Dini, Germán A. Islan, Patricio J. de Urraza, Guillermo R. Castro (2012). "Novel biopolymer matrices for microencapsulation of phage: enhanced protection against acidity and protease activity". Macromolecular Bioscience 12, 1200-1208.

- Germán A. Islan, Ignacio Pérez de Verti, Sergio G. Marchetti, Guillermo R. Castro (2012). "Studies of Ciprofloxacin encapsulation on Alginate/Pectin matrixes and its relationship with biodisponibility". Applied Biochemistry and Biotechnology 167, 1408-1420.

- Germán A. Islan, Valeria E. Bosio, Guillermo R. Castro (2013). “Alginate Lyase and Ciprofloxacin co-immobilization on biopolymeric microspheres for Cystic Fibrosis treatment". Macromolecular Bioscience 13, 1238-1248.

- Germán A. Islan, Yanina N. Martínez, Andrés Illanes, Guillermo R. Castro (2014). "Development of novel alginate lyase cross-linked aggregates for the oral treatment of cystic fibrosis". RSC Advances 4, 11758-11765.

- Germán A. Islan, Guillermo R. Castro (2014). "Tailoring of alginate-gelatin microspheres properties for oral Ciprofloxacin controlled release against Pseudomonas aeruginosa". Drug Delivery 1-12. En prensa. DOI: $10.3109 / 10717544.2013 .870257$

- Cecilia Dini, Germán A. Islan, Guillermo R. Castro (2014). “Characterization and stability analysis of biopolymeric matrices designed for phage controlled release". Applied Biochemistry and Biotechnology 174, 2031-2047. 
- Germán A. Islan, Maximiliano L. Cacicedo, Valeria E. Bosio, Guillermo R. Castro (2015). "Development and characterization of new enzymatic modified hybrid $\mathrm{CaCO}_{3}$ microparticles to obtain nano-architectured surfaces for enhanced drug loading". Journal of Colloid and Interface Science 439, 76-87.

- Germán A. Islan, Arup Mukherjee, Guillermo R. Castro (2015). “Development of biopolymer nanocomposite for silver nanoparticles and Ciprofloxacin controlled release". International Journal of Biological Macromolecules 72, 740-750.

\section{Patente:}

Parte de los resultados expuestos en la presente tesis doctoral han sido protegidos a través de una patente nacional tramitada por el CONICET ante el INPI bajo el título: "Forma de liberación controlada para la administración de fluoroquinolonas para el tratamiento de Fibrosis Quística". Autores: Germán A. Islan; Guillermo R. Castro. Año: 2014. INPI Expediente \# 20140101245 - 17/03/2014 en trámite.

\section{Capítulos de libro:}

Valeria E. Bosio, Germán A. Islan, Yanina N. Martínez, Guillermo R. Castro (2011). Capítulo de libro titulado "Control release applications in food technology", del libro: Advances in Bioprocesses in Food Industries. Volumen 4, páginas 1-13. ISBN 81-87680-28-8.

Ana Cauerhff, Yanina N. Martínez, Germán A. Islan., Guillermo R. Castro (2013). Capítulo de libro titulado "Nanostability", del libro: Nanotoxicology: Materials, methodologies, and assessments. Cap. 3, páginas 1-32. Springer Verlag, Germany.

Germán A. Islan, Maximiliano L. Cacicedo, Valeria E. Bosio, Guillermo R. Castro (2014). Capítulo de libro "Advances in smart nanopreparations for ORAL DRUG DELIVERY", del libro: Smart Pharmaceutical Nanocarriers. Vladimir Torchilin (Ed.) Editorial: Imperial College Press, Inglaterra. En prensa. 